JAIR FELICIO

\title{
AVALIAÇÃO DA EXPOSIÇÃO OCUPACIONAL AO RUÍDO EM ATIVIDADES QUE UTILIZAM FONES DE OUVIDO \\ (HEADSETS E HEADPHONES)
}


JAIR FELICIO

\section{AVALIAÇÃO DA EXPOSIÇÃO OCUPACIONAL AO RUÍDO EM ATIVIDADES QUE UTILIZAM FONES DE OUVIDO (HEADSETS E HEADPHONES)}

Dissertação apresentada à Escola Politécnica da Universidade de São Paulo para obtenção do título de Mestre em Engenharia 
JAIR FELICIO

\section{AVALIAÇÃO DA EXPOSIÇÃO OCUPACIONAL AO RUÍDO EM ATIVIDADES QUE UTILIZAM FONES DE OUVIDO (HEADSETS E HEADPHONES)}

Dissertação apresentada à Escola Politécnica da Universidade de São Paulo para obtenção do título de Mestre em Engenharia

Área de Concentração:

Engenharia Mineral

Orientador:

Prof. Dr. Wilson Siguemasa Iramina 


\section{DEDICATÓRIA}

Aos meus queridos e saudosos pais Jorge e Rosária

A minha família

Elena

Vanessa e Carlos Henrique

Vanessa ... Obrigado

Ao estimado amigo Marcos Domingos da Silva Incentivador permanente dos meus objetivos 


\section{AGRADECIMENTOS}

A DEUS, Grande Arquiteto do Universo, acima de tudo!

Ao Prof. Dr. Sérgio Médici de Eston, Professor Titular e Chefe do Departamento de Engenharia de Minas da EPUSP, que incentivou meu ingresso no Programa de Pós - Graduação.

Ao Prof. Dr. Wilson Siguemasa Iramina, Professor Associado do Departamento de Engenharia de Minas da EPUSP, meu estimado Orientador.

Ao Prof. Dr. Sylvio Reynaldo Bistafa, PhD do Departamento de Engenharia Mecânica da EPUSP, pela sua atenção e compreensão.

Ao Prof. Dr. Samir Nagi Yoursri Gerges, PhD do Departamento de Engenharia Mecânica, da Universidade Federal de Santa Catarina, exemplo de generosidade.

Meu reconhecimento ao Dr. Antônio Cândido de Lara Duca, Médico do Trabalho, com quem tive a satisfação de trabalhar por mais de 15 anos, que muito me estimulou para o desenvolvimento profissional, a quem tenho profunda gratidão.

Aos colegas e amigos da Associação Brasileira de Higienistas Ocupacionais - ABHO e da FUNDACENTRO.

Aos colegas que compartilharam das aulas/créditos do Programa de Pós Graduação, que permitiram alcançar este momento. Sem essa sinergia e coleguismo, não teria chegado até aqui.

Ao Prof. Dr. João Vicente de Assunção, Prof. Titular e Chefe do Departamento de Saúde Ambiental da Faculdade de Saúde Pública da USP e ao Dr. Irlon de Ângelo da Cunha, Pesquisador Sênior da Fundacentro, pelas sugestões e orientações importantes e pelas suas participações na banca julgadora deste trabalho.

A todos os amigos e verdadeiros irmãos, muito obrigado e meu forte abraço. 


\section{RESUMO}

Com o avanço técnico-científico e a necessidade de rapidez nas comunicações dos diversos segmentos da economia e da vida moderna, a utilização de fones de ouvido não se restringe mais somente aos serviços de Telefonia (telefonistas, atendentes, técnicos e cabistas), operadores de telemarketing ou teleatendimento, mas também a outras profissões como pilotos de aeronaves e de helicópteros, músicos, operadores de áudio e vídeo, além de profissionais de inúmeras outras atividades que necessitam utilizar fones para comunicações, como na indústria naval, do petróleo, da mineração (telemineração, mineração remota), etc. Com isso, a avaliação de risco de surdez ocupacional deve ser adequada à realidade de milhares de pessoas hoje envolvidas com a utilização de fones de ouvido. Essa questão se amplia quando se considera uma legião de pessoas que diariamente passa horas ouvindo música em seus tocadores digitais de música com o volume tão alto que qualquer um ao lado delas pode também ouvir os mesmos sons. Principalmente devido aos outros tipos de exposição, mais difundidos, a exposição ocupacional ao ruído é um assunto bastante discutido, e há, inclusive, critérios adequados de avaliação dos níveis sonoros, que estão, no entanto, voltados para os sons que podem ser medidos na zona auditiva em campo aberto, mas não no interior do pavilhão auricular, que é o caso do presente trabalho. Considerando tal lacuna relacionada aos critérios adotados na avaliação dos níveis sonoros, este trabalho objetiva: estudar os trabalhos sobre as medições sonoras que são atualmente realizadas no interior do pavilhão auricular; demonstrar que o estudo da avaliação do nível sonoro em atividades que utilizam fones de ouvido ainda é incipiente, complexo e oneroso; identificar qual(is) norma(s) é(são) mais adequada(s) para avaliar os níveis de ruído em fones. Para tanto, fez-se uma revisão da literatura, utilizando como materiais e métodos, de forma comparativa, os resultados das experiências e dos estudos do autor e de outros especialistas frente às normas disponíveis pertinentes relativas aos critérios metodológicos de medição dos níveis de ruído em fones de ouvido. Concluindo, esta pesquisa traz importantes parâmetros necessários para uma avaliação confiável e subsídios para o desenvolvimento de uma Instrução Técnica ou elaboração de uma Norma de Higiene Ocupacional NHO específica para este tipo de avaliação.

Palavras-chave: Headsets. Fones de telefonista. Headphones. Fones de ouvido. Exposição ao ruído. Metodologia de avaliação. Medições de Ruído. Critérios. 
ABSTRACT

New electronic technologies have improved the communication systems in general ways, and consequently sound devices have become better, cheaper and widely used. In the professional field, millions of workers use every day headsets and headphones talking to clients, transmitting information and news to control centers, and also listening music. It is a common practice among telephone operators, telemarketing attendees, pilots, musicians, police officers, etc; also, young people using modern sound and video players with individual speakers. If on one side the communication systems are much better, on other way the sound pressure levels inside of headsets or headphones are a big concern, especially when people are listening their favorite songs. Sometimes the sound levels are so high that anyone around is able to listen its music. It is a fact very known that the acoustic energy may destroy the cochlea cells after long noise exposures at high levels. Therefore, million of users of those electronic apparatus are exposure to a potential hearing loss risk in spite of experimenting pleasure moments or just doing their job. The problem of hearing losses is more complicate to headset or headphone users because there is not criterion very well established as it is common to general workers. The standards for prevention of hearing losses are addressed to environment noise that is measured outside of the auricular pavilion. The technology applied to measure sound levels inside of auricular pavilion is complex and there are a few instruments available in the market. However, the most important limitation is absence of technical criteria that define which acoustic situations could be considered a hearing loss risk. Considering all these limitations, this paper has the following objectives: review technical articles that present evaluations of noise inside of auricular pavilion; demonstrate that published studies in this matter are embryonic face to complexity and costs involved with; identify the most appropriate standard to evaluate noise levels inside of auricular pavilion. Thus, the Material and Methods adopted in this paper are based on a comparative review of the literature available, including results from experiences developed by the own author, and other data published by several experts. The numbers, records and levels, etc presented here are related to the respective methods or criteria. Therefore, the information, data, discussion, analyses, and conclusions presented in this paper are addressed to motivate new studies and debates that may result in a new national or international standard easier and less expensive than those are complied today. New proceedings should be developed with clear instructions that avoid misunderstanding and guide different practitioners to reproduce studies with similar methodologies. Concluding, this paper introduces important parameters that are necessary to evaluate noise generated by headphones in workplaces, and, also, gives some guidelines and subsidies to develop a measuring procedure or a technical standard related to occupational hygiene in this matter.

Keywords: Headsets. Headphones. Noise exposure. Evaluation methods. Noise measurements. Noise criteria. 


\section{LISTA DE ILUSTRAÇÕES}

Gráfico 1 - Dados/Emissão de Comunicação de Acidente do Trabalho ....................38

Figura 1 - Vista geral do conjunto gerador do sinal padrão da TELESP ..................62

Figura 2 - Detalhe da cápsula transmissora na cabeça artificial...............................63

Figura 3 - Detalhe da cápsula receptora na cabeça artificial ...................................64

Figura 4 - Acopladores e discos de encosto normalizados ....................................64

Figura 5 - Detalhe do conjunto montado na recepção - CESP ................................65

Figura 6 - Vista principal do conjunto de equipamentos na CESP .........................66

Figura 7 - Vista geral da montagem dos instrumentos em campo..........................67

Figura 8 - Vista geral de uma das salas de PABX na CESP .................................67

Figura 9 - Posição dos equipamentos na sala das telefonistas .............................. 72

Figura 10 - Posição das telefonistas e os headsets utilizados.................................73

Figura 11 - Cabeça/Torso Artificial- Head And Torso Simulator (HATS) .................. 82

Figura 12 - Analisador de Espectro de Freqüência de Duplo Canal ..........................83

Figura 13 - Esquema do sistema de medição com Cabeça Artificial .......................87

Figura 14 - Posição do microfone no tripulante de helicóptero ................................. 89

Figura 15 - Posição do microfone no piloto de helicóptero ....................................... 89

Figura 16 - Posição do microfone do dosímetro no capacete do piloto ......................90

Figura 17 - Esquema de medição - em ouvido real e manequim............................92

Figura 18 - Dosímetro de ruído do sistema da Etymotic Research ........................97

Figura 19 - Sistema Microfone e Sonda da Etymotic Research .............................97

Figura 20 - Diagrama para dosimetria em fones da Etymotic Research ..................98

Figura 21 - ISO 11904-1 - Posições do microfone no canal auditivo.......................110

Figura 22 - Esquemático da anatomia da orelha / pontos de referência ................. 144

Figura 23 - Simulador de orelha moldado anatomicamente ................................ 146

Figura 24 - Fones de ouvido circum-auriculares.............................................. 146

Figura 25 - Fones de ouvido supra-auriculares ................................................ 147

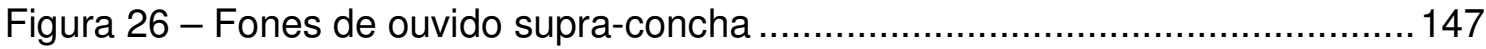

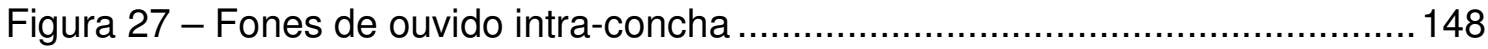

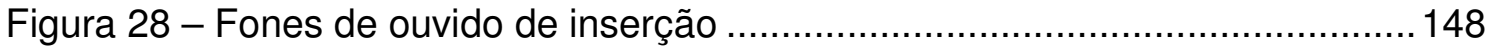




\section{LISTA DE TABELAS}

Tabela 1 - Dados Estatísticos e Casuística - TELEBRASILIA …...............................34

Tabela 2 - Casos de doenças ocupacionais por ruído - TELEBRÁS..........................37

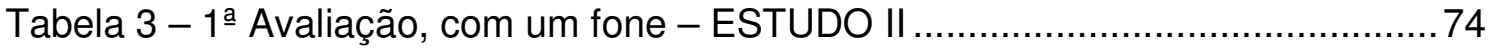

Tabela 4 - $1^{\text {a }}$ Avaliação, com dois fones - ESTUDO II.......................................... 74

Tabela 5 - 1를 Avaliação - Resultado dos Níveis Sonoros - ESTUDO II......................74

Tabela 6 -1 ${ }^{a}$ Avaliação - №. de chamadas no período - ESTUDO II ………….........75

Tabela 7 - 2 ${ }^{\mathrm{a}}$ Aval. - Um fone c/ ajuste de nível sonoro - ESTUDO II ......................76

Tabela 8 - 2 $2^{\mathrm{a}}$ Aval. - Dois fones c/ ajuste de nível sonoro - ESTUDO II....................76

Tabela 9 - $2^{\text {a }}$ Avaliação - Resultado dos Níveis Sonoros - ESTUDO II....................76

Tabela 10 - 2 $2^{\text {a }}$ Avaliação - №. de chamadas no período - ESTUDO II ………........77

Tabela 11 - 3를 Avaliação - fones c/ ajuste na pos. mínima - ref. $0 \mathrm{~km}$.......................78

Tabela $12-3^{\text {a }}$ Avaliação - fones c/ ajuste na pos. máxima - ref. $0 \mathrm{~km}$....................78

Tabela $13-3^{\text {a }}$ Avaliação - fones c/ ajuste na pos. mínima - ref. $7 \mathrm{~km} \mathrm{.....................78}$

Tabela 14 - $3^{\mathrm{a}}$ Avaliação - fones c/ ajuste na pos. máxima - ref. $7 \mathrm{~km}$................... 79

Tabela 15 - №. de trabalhadores que usam fones - ESTUDO III ...........................80

Tabela 16 - Estimativa das perdas auditivas - ESTUDO III .................................80

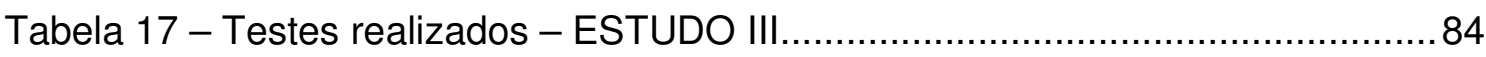

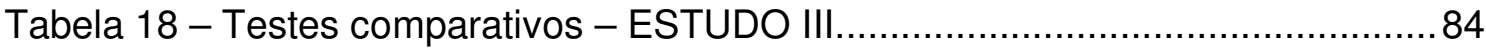

Tabela 19 - Usuários de fones - Testes de Campo - ESTUDO III............................85

Tabela 20 - Resultados das Medições de Campo - ESTUDO III ...............................86

Tabela 21 - Valores médios e os desvios padrão - ESTUDO VI.............................95

Tabela 22 - Correção dos níveis de pressão sonora - ISO 11904-1 …..................111

Tabela 23 - Ponderações em freqüência e tolerância - ISO 11904-1 .................... 113

Tabela 24 - Resposta em freqüência com Manequim - ISO 11904-2 …............... 122

Tabela 25 - Correção dos níveis de pressão sonora - ITU -T P.58........................ 123

Tabela 26 - Informações para Relatório de Teste - Série ISO 11904 ................... 127

Tabela 27 - Análise das Incertezas - ISO 11904-1 .......................................... 128

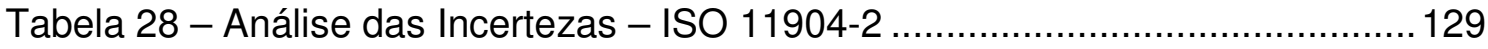

Tabela 29 - Visão geral das fontes de incerteza - Série ISO $11904 \ldots \ldots \ldots \ldots \ldots \ldots \ldots . . . . .133$

Tabela 30 - Balanço das Incertezas para Sistema MIRE de Medição ...................... 135 
Tabela 31 - Visão geral das diferenças - Técnicas MIRE e Manequim .................. 136

Tabela 32 - Visão geral dos tipos de simuladores de ouvido................................. 149

Tabela 33 - Função de Transferência SDE de DRP para ERP ................................151 


\section{LISTA DE ABREVIATURAS E SIGLAS}

$\mathrm{ABHO}$

ABNT

ABT

ACGIH

ACP

ANATEL

ANSI

CAT

CCITT

CESP

CID

CLT

CODEMAT

$\mathrm{CR}$

$\mathrm{dB}$

DORT

DOU

DRP

EEP

ERP

FAP

FAT

FUNDACENTRO
Associação Brasileira de Higienistas Ocupacionais

Associação Brasileira de Normas Técnicas

Associação Brasileira de Telesserviços

American Conference of Governmental Industrial Hygienists

Ação Civil Pública

Agência Nacional de Telecomunicações

National Standards Institute

Comunicação de Acidente do Trabalho

International Telephone and Telegraph Consultative Committee

Companhia Energética de São Paulo

Classificação Internacional de Doenças

Consolidação das Leis do Trabalho

Coordenadoria Nacional de Defesa do Meio Ambiente do

Trabalho

Critério de Referência - nível médio para o qual a exposição, por um período de 8 horas, corresponderá a uma dose de $100 \%$.

(Criterion Level - CL)

Decibel - é o coeficiente (divisão de uma escala logarítmica) de um nível qualquer em relação a um nível de referência (no caso do ruído: $20 \mu \mathrm{Pa}=20$ micro Pascal). dB é adimensional.

Distúrbio Osteomuscular Relacionado ao Trabalho

Diário Oficial da União

Ear Drum Reference Point - Ponto de Referência do Tímpano

Ear Canal Entrance Point - Ponto de Entrada do Canal Auditivo

Ear Reference Point - Ponto de Referência da Orelha

Fator Acidentário Previdenciário

Fundo de Amparo ao Trabalhador

Fundação Jorge Duprat Figueiredo de Segurança e Medicina do Trabalho, do Ministério do Trabalho e Emprego 
GHE

GEIM

GUM

HATS

HCS

HSE

HSL

IEC

IEEE

INMETRO

INRS

INSS

ISO

ITU

LE

LE-VT

LTCAT

MAX

MIN

MIRE

MPS

MPT

MS

MTE

$\mathrm{N}$

NE

NEN
Grupo Homogêneo de Exposição - corresponde a um grupo de trabalhadores que experimentam exposição semelhante, e que seja representativo da exposição de todos os trabalhadores que compõem o mesmo grupo

Guia de expressão de incertezas nas medições

Guide to the expression of uncertainty in measurement

Head and Torso Simulator

Health \& Safety Commission - Comissão do HSE

Health \& Safety Executive - Organismo de Saúde e Segurança

do Trabalho do Reino Unido

Health \& Safety Laboratory - Órgão de Pesquisa do HSE

International Electrotechnical Commission

Institute of Electrical and Eletronics Engineers

Instituto Brasileiro de Metrologia, Normalização e Qualidade

Industrial

Instituto Nacional de Pesquisas e Segurança da França

Instituto Nacional do Seguro Social

International Organization for Standardization

International Telegraph Union

Limite de Exposição (Threshold Limit Value - TLV)

Limite de Exposição Valor Teto (TLV - Ceiling - TLV-C)

Laudo Técnico das Condições Ambientais do Trabalho

Máximo valor que ocorreu durante a medição

Mínimo valor que ocorreu durante a medição

Microphone in a Real Ear

Ministério da Previdência Social

Ministério Público do Trabalho

Ministério da Saúde

Ministério do Trabalho e Emprego

Força em Newton

Nível médio representativo da exposição ocupacional diária

Nível de Exposição Normalizado - nível de exposição, convertido para jornada padrão de 8 horas diárias, para fins de comparação com o limite de exposição 
Neq

$\mathrm{NIOSH}$

NLI

NM

NTEP

NR

OMS

OSHA

PAIR

PCA

PCMSO

PGR

PNSST

PPRA

PPP

q ou ER

RGPS

RPS

SAT

SDE

SPL

SUS

TELEBRÁS

TELEBRASILIA

TELERJ

TELEPAR

TELESP
Nível Equivalente de Ruído, baseado na equivalência de energia, conhecido como Leq

Norma de Higiene Ocupacional

National Institute for Occupational Safety and Health

Nível Limiar de Integração (Threshold Level) a partir do qual os

valores devem ser computados na integração para fins de

determinação do nível médio ou da dose de exposição.

Nível Médio de ruído representativo da exposição ocupacional

relativo ao período de medição - Lavg (Average Level)

Nexo Técnico Epidemiológico Previdenciário

Norma Regulamentadora

Organização Mundial de Saúde

Occupational Safety and Health Act

Perda Auditiva Induzida por Ruído

Programa de Conservação Auditiva

Programa de Controle Médico de Saúde Ocupacional

Programa de Gerenciamento de Riscos

Política Nacional de Segurança e Saúde do Trabalhador

Programa de Prevenção de Riscos Ambientais

Perfil Profissiográfico Previdenciário

Incremento de Duplicação de Dose - q ou (Exchange Rate - ER)

Regime Geral da Previdência Social

Regime da Previdência Social

Seguro Acidente do Trabalho

Função de Transferência, de DRP para ERP

Nível de Pressão Sonora - valor instantâneo

Sistema Único de Saúde

Telecomunicações Brasileiras S.A.

Telecomunicações de Brasília S.A.

Telecomunicações do Rio de Janeiro S.A.

Telecomunicações do Paraná S.A.

Telecomunicações de São Paulo S.A. 


\section{SUMÁRIO}

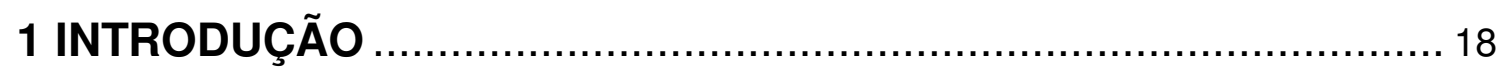

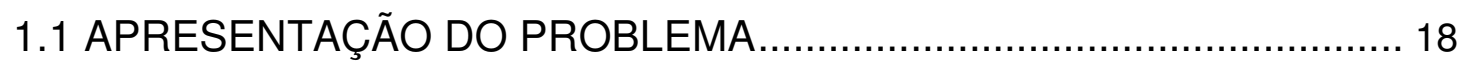

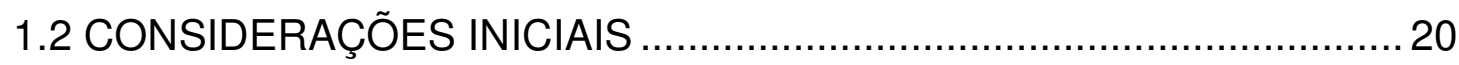

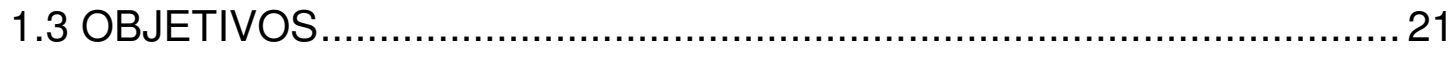

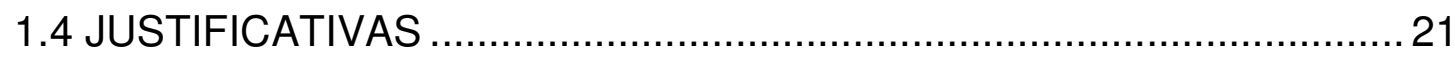

2 REVISÃO DOCUMENTAL E DA LITERATURA .......................... 26

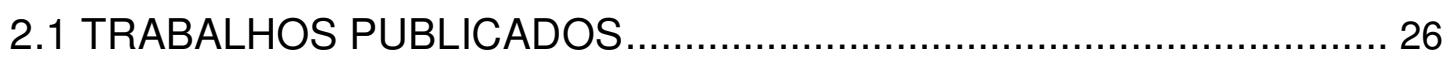

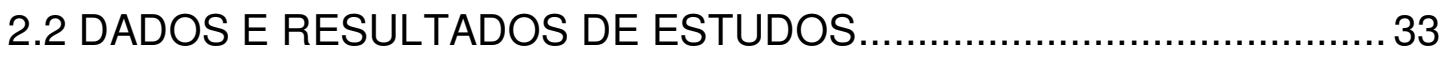

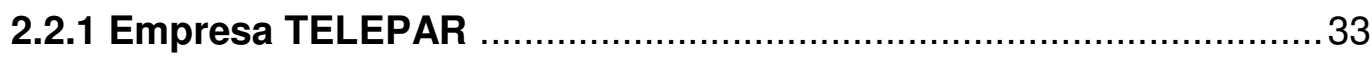

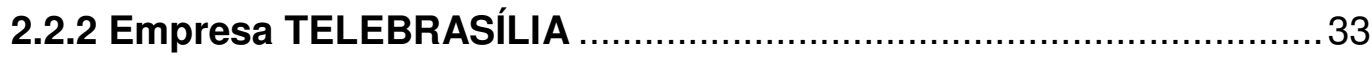

2.2.3 Relatório sobre alteração na audição nos empregados

que ocupam cargos de risco auditivo na

Telecomunicações do Rio de Janeiro S.A. - TELERJ ………............35

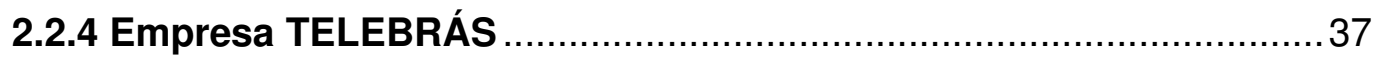

2.2.5 Empresa TELESP - Telecomunicações de São Paulo

S.A.

2.2.6 Estimativa do número de operadores de

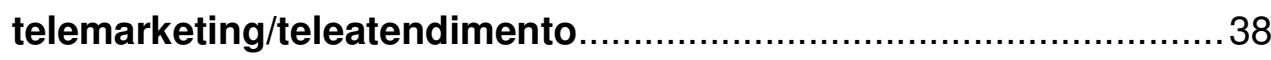

2.3 PERDA AUDITIVA INDUZIDA POR RUÍDO (PAIR) …......................... 39

2.4 LEGISLAÇÃO BRASILEIRA SOBRE RUÍDO

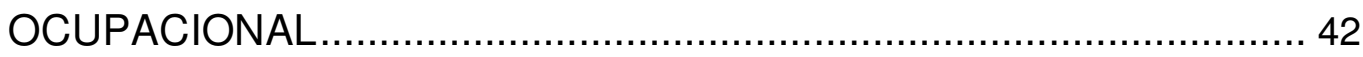

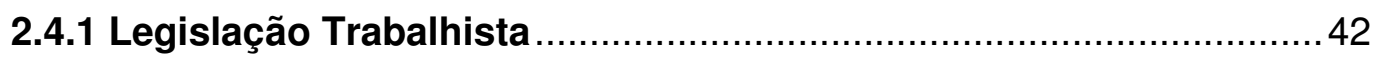

2.4.1.1 Portaria no. 3.214 de 08 de junho de 1978 do

Ministério do Trabalho 42

2.4.1.2 NHO 01 - Norma de Higiene Ocupacional da

Fundacentro: Procedimento Técnico - Avaliação

da Exposição Ocupacional ao Ruído .43 
2.4.1.3 NR 9 - Programa de Prevenção de Riscos

Ambientais (PPRA) 43

2.4.1.4 Sobre a NR 7 - Programa de Controle Médico de

Saúde Ocupacional (PCMSO)............................................. 44

2.4.1.5 NR 17 - Ergonomia ........................................................ 45

2.4.1.6 Sobre a Portaria no. 08, de 30/03/2007, que

aprova o Anexo I da NR 17: Trabalho dos

Operadores de Checkout 46

2.4.1.7 Portaria no. 09, de 30/03/2007, que aprova o

Anexo II da NR 17: Trabalho em

Teleatendimento/Telemarketing 47

2.4.2 Legislação Previdenciária 49

2.4.2.1 Instrução Normativa INSS/PRES nํ. 11,

20/09/2006, DOU de 21/09/2006 49

2.4.2.2 Portaria Interministerial MPS/MS/MTE n․ 800, de

03/05/2005, DOU de 05/05/2005 50

2.4.2.3 Lei nº 11.430 de 26 de dezembro de 2006, DOU

de $24 / 12 / 2006$ 50

2.4.2.4 Decreto n‥ 6.042 de 12/02/2007, DOU de $12 / 02 / 2007$ 51

2.4.2.5 Instrução Normativa INSS/PRES nํ. 16 de 27/03/2007, DOU de 30/03/2007. 51

2.5 DISCUSSÃO REFERENTE À LEGISLAÇÃO 52

3 METODOLOGIA 54

3.1 CONSIDERAÇÕES GERAIS SOBRE

NORMAS TÉCNICAS. .55

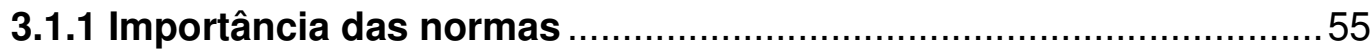

3.1.2 Características das normas técnicas ...........................................5

4 ESTUDOS E EXPERIÊNCIAS ……………………….................. 58

4.1 ESTUDO I - LAUDO TÉCNICO ………………...................................

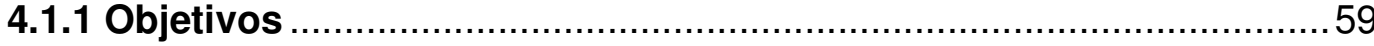




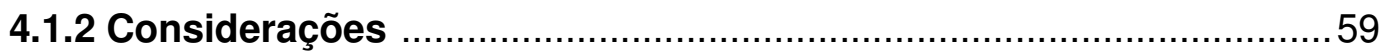

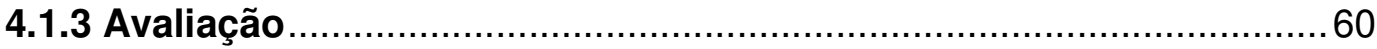

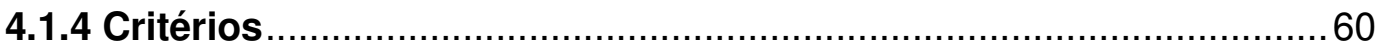

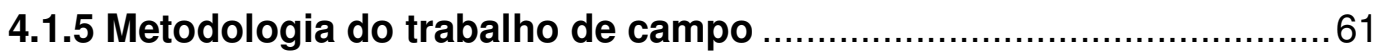

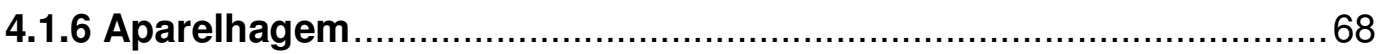

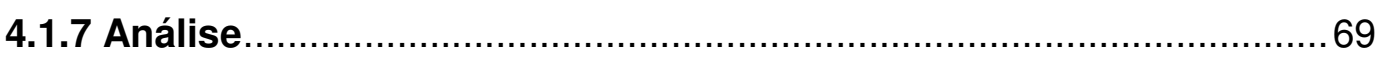

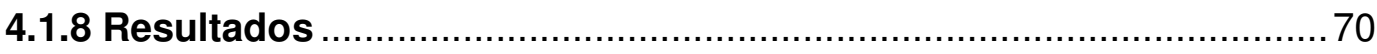

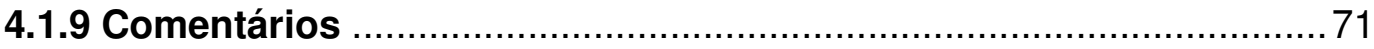

4.2 ESTUDO II - MEDIÇÕES EM FONES TIPO TELEFONISTA

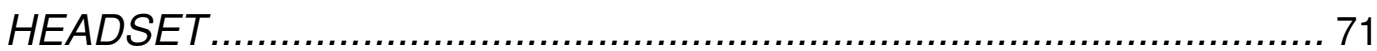

4.2.1 Alguns testes, avaliações e resultados .......................................... 74

4.3 ESTUDO III - ESTUDO PILOTO DA AVALIAÇÃO DE

RUÍDO (IN SITU) EM FONES DE OUVIDO DOS

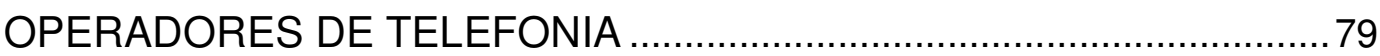

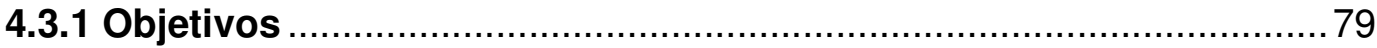

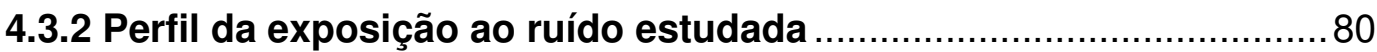

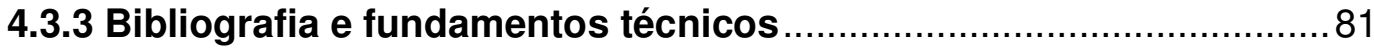

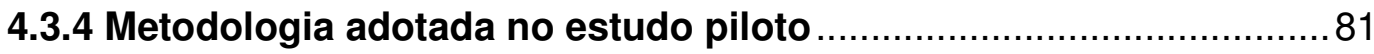

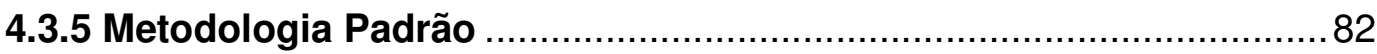

4.3.6 Testes comparativos com o Padrão Primário

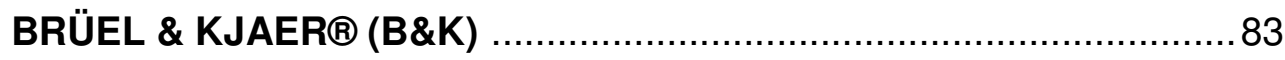

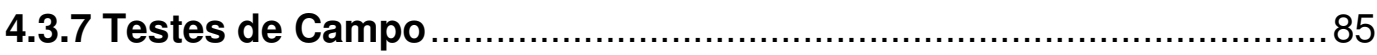

4.4 ESTUDO IV - PERÍCIA E AVALIAÇÃO DE RUÍDO EM

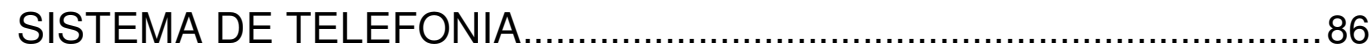

4.5 ESTUDO V - AVALIAÇÃO DOS NÍVEIS DE RUÍDO DA

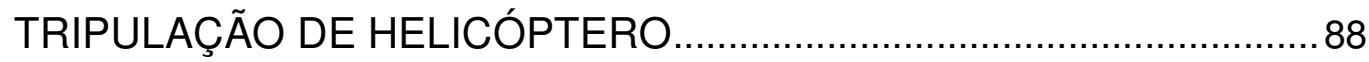

4.6 ESTUDO VI - AVALIAÇÃO DA EXPOSIÇÃO AO RUÍDO

DE OPERADORES DE TELEATENDIMENTO ….................................91

4.7 ESTUDO VII - SISTEMA PROPOSTO PELA EMPRESA

ETYMOTIC RESEARCH PARA AVALIAÇÃO DE

DOSIMETRIA EM FONES DE CALL CENTER -

PROPOSTA TÉCNICO-COMERCIAL 
4.8 DISCUSSÃO REFERENTE AOS ESTUDOS E

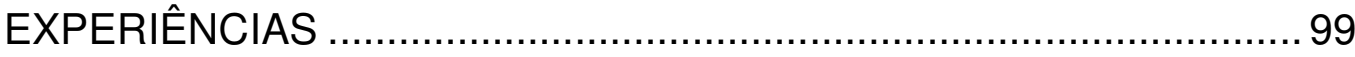

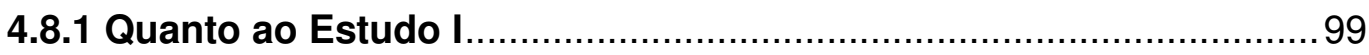

4.8.2 Quanto ao Estudo II.................................................................. 100

4.8.3 Quanto ao Estudo III.................................................................... 100

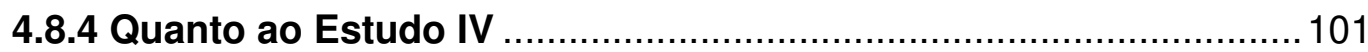

4.8.5 Quanto ao Estudo V ................................................................ 101

4.8.6 Quanto ao Estudo VI ................................................................ 101

4.8.7 Quanto ao Estudo VII ................................................................... 102

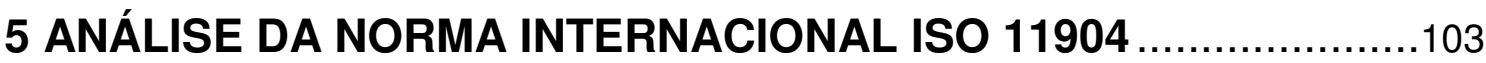

5.1 ISO 11904-1 PARTE 1: TÉCNICA DO MINIMICROFONE

EM OUVIDO REAL, CONHECIDA POR TÉCNICA MIRE -

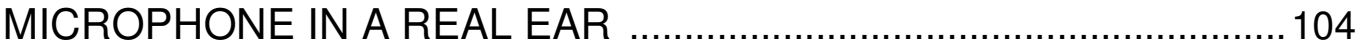

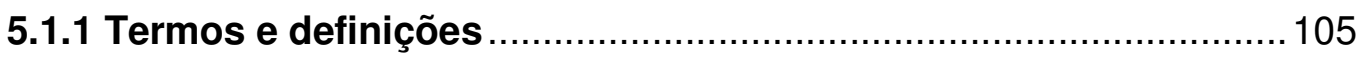

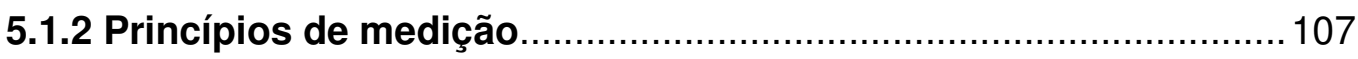

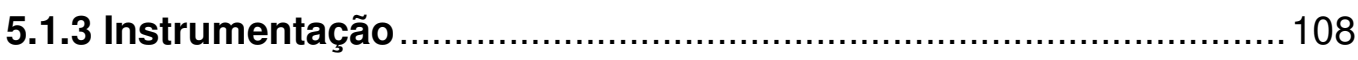

5.1.4 Determinação das respostas em freqüência de campo livre ou campo difuso - Correções ....................................111

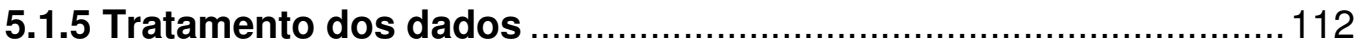

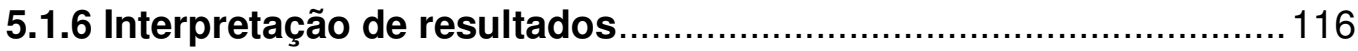

5.2 ISO 11904-2 PARTE 2 - TÉCNICA DA CABEÇA

ARTIFICIAL DE MANEQUIM, CONHECIDA COMO

TÉCNICA USANDO MANEQUIM............................................................. 117

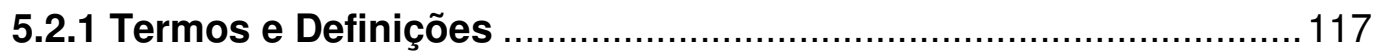

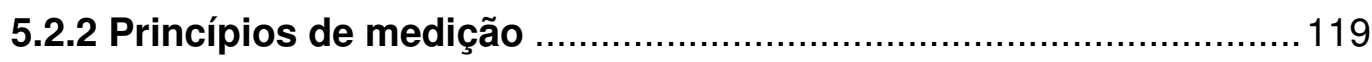

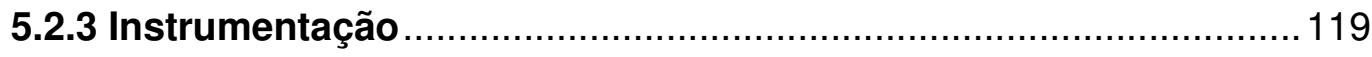

5.2.4 Determinação das respostas em freqüência de campo

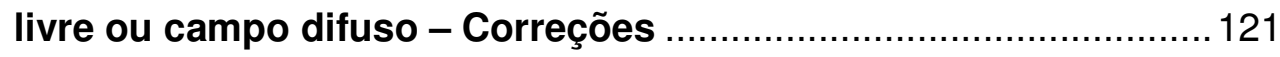

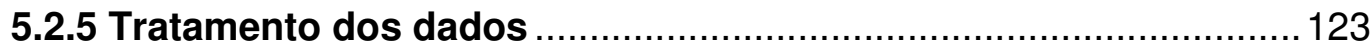

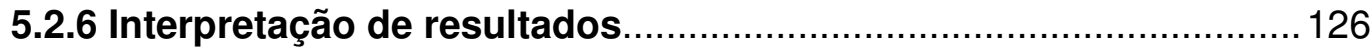

5.3 AVALIAÇÕES (RELATÓRIO E INCERTEZA DAS

MEDIÇÕES)... 
5.3.1 Relatório dos testes

5.3.2 Análise de incertezas 128

5.3.3 Considerações sobre os relatórios dos testes e a incerteza das medições

5.3.4 Quanto ao balanço de incertezas 134

5.4 VISÃO GERAL DAS DIFERENÇAS DAS DUAS PARTES

DA ISO 11904 136

5.5 DISCUSSÃO REFERENTE À NORMA INTERNACIONAL

ISO 11904 137

5.6 IEC 60711(1981) - SIMULADOR DE OUVIDO

OCLUSO/FECHADO PARA MEDIÇÕES DE FONES DE OUVIDO TIPO PLUGUE ACOPLADOS À ORELHA POR INSERÇÃO 141

5.7 RECOMENDAÇÃO UIT - T P.57 (2005) .............................................. 142

5.8 DEMAIS NORMAS E RECOMENDAÇÕES RELEVANTES .................154

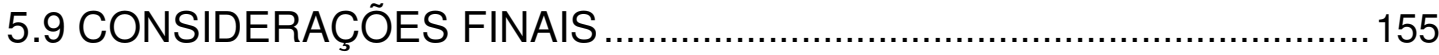

6 CONCLUSÕES 156

6.1 PROPOSTAS PARA FUTUROS TRABALHOS 158

REFERÊNCIAS 159

REFERÊNCIAS CONSULTADAS 170

GLOSSÁRIO 


\section{INTRODUÇÃO}

\subsection{APRESENTAÇÃO DO PROBLEMA}

A despeito do rápido crescimento da indústria da comunicação no último século, relativamente poucas pesquisas têm sido publicadas quanto à exposição ocupacional e não ocupacional ao ruído nas comunicações pessoais.

Essa falta de informação provavelmente se deva às dificuldades no sistema e no conjunto de medições e na avaliação da própria exposição. Além disso, as comunicações telefônicas são tipicamente verbais, e, mesmo se amplificadas, são consideradas tarefas naturais e não são geralmente associadas a riscos de perda auditiva.

Todavia, há um enorme número de pessoas expostas aos níveis sonoros, "ruídos", emitidos pelos mais diversos tipos e modelos de fones de ouvido.

Portanto, a quantificação do nível de exposição ao ruído dos usuários de fones é um assunto complicado, e estende-se ao importante segmento da Indústria da Mineração. Nesse sentido, preocupado com os Sistemas de Comunicação em Trabalhos de Minas Subterrâneas, o Departamento do Interior dos Estados Unidos preparou a Circular 8745 - Underground Mine Communications (UNITED STATES, 1977), sobre métodos e equipamentos de rádio e headsets requeridos para comunicação de várias categorias de profissionais que trabalham em minas subterrâneas.

$\mathrm{Na}$ maioria dos critérios e normas técnicas, as medições dos níveis de som são feitas em campo livre e à altura da zona da audição, o que não se aplica às atividades em que as pessoas usam os fones de ouvido. Nesses casos, portanto, para a caracterização do risco de surdez ocupacional, faz-se necessário utilizar procedimentos específicos, com a utilização de instrumental muito caro e complexo. 
Pesquisas nesse campo exploradas ao longo da revisão mostram resultados não uniformes, pois o problema é a correlação com os dados medidos de nível de pressão sonora na zona do canal auditivo. A caracterização da exposição ocupacional dos usuários de fones difere dos padrões convencionais de Higiene Ocupacional.

Nota-se pela experiência do autor em mais de vinte anos de atuação na área da indústria das telecomunicações, incluindo inúmeras perícias, que, na avaliação dos riscos relativos à exposição sonora acima mencionada, erros são cometidos quando se utilizam instrumentos de medição de ruído com características de campo livre, pois se trata de uma situação diferente, na qual o ruído está circunscrito entre o telefone ou fone de ouvido e a orelha. Nesse caso, configura-se um campo acústico fechado que difere do padrão de campo livre.

Além das características diferentes apontadas, deve-se tomar o cuidado de se realizar uma diferente forma de medição, uma vez que não se pode simplesmente colocar o microfone entre a orelha e o fone, para não se alterar as características do meio.

O incremento da exposição ao ruído na indústria da comunicação é devido à evolução dos aparelhos telefônicos. As empresas favorecem a substituição dos aparelhos tradicionais do tipo telefonista headset por fones de ouvido mais leves e ergonômicos, mas que, por outro lado, são às vezes mais suscetíveis a níveis de ruído amplificados mais importantes do que aqueles que ocorrem em telefones headsets, pois permitem ajuste individual da intensidade do nível sonoro. Há também muitas questões conceituais incompletas e que exigirão ainda um bom tempo de pesquisa.

Obs.: No presente trabalho de pesquisa, por uma questão de simplificação, todos os tipos de aparelhos de audição colocados na orelha serão denominados genericamente de "fones de ouvido". 


\subsection{CONSIDERAÇÕES INICIAIS}

O interesse do pesquisador sobre este assunto nasceu da necessidade diária, como profissional de Engenharia de Segurança do Trabalho, notadamente na Área de Higiene Ocupacional e Ergonomia, dentro de uma empresa de telecomunicações por mais de 20 anos.

Especificamente nessa área de avaliação de ruído em fones, a demanda surgiu no ano de 1990, em virtude de uma solicitação da Companhia Energética de São Paulo - CESP para o levantamento das condições ambientais e a realização de estudos sobre o perfil acústico relacionados às atividades de telefonistas e demais categorias que utilizavam telefones nos diversos locais das instalações da CESP em todo o Estado de São Paulo. Este trabalho de dedicação integral teve início em março de 1990 e término em abril de 1991. Ressalte-se por oportuno que o trabalho serviu para subsidiar conversações sindicais sobre o pedido de adicional de insalubridade oficializado pelo Sindicato dos Trabalhadores nas Indústrias da Energia Elétrica de São Paulo e reivindicado pelos empregados da CESP. A partir daí, muitos outros trabalhos dessa natureza foram realizados.

Desde o primeiro trabalho realizado, foram encontradas dificuldades para se medir os níveis de ruído em fones. Dentre elas, o posicionamento do microfone dentro da orelha da pessoa e a compreensão do complexo comportamento das ondas sonoras no interior do canal auditivo.

Os seguintes pontos devem ser considerados:

i) A forma das ondas sonoras nas proximidades do pavilhão auricular não é bem definida, podendo as ondas ser esféricas ou planas, dependendo da distância da fonte e da freqüência;

ii) O campo sonoro provocado pelo fone de ouvido, junto à orelha, pode ser próximo, livre ou reverberante. Um microfone, então, colocado no pavilhão 
auricular, poderá alterar esse campo e apresentar resultados diferentes, dependendo da situação existente nesse espaço acústico;

iii) Há também a impedância acústica do canal auditivo, que, dependendo da freqüência e das características do fone de ouvido, poderá ampliar ou reduzir os níveis sonoros.

\subsection{OBJETIVOS}

Identificar qual (is) a(s) norma(s) e recomendações que são mais adequadas para avaliação do nível sonoro em atividades que utilizam fones de ouvido. Discutir e comparar estudos, metodologias e critérios de avaliação, para quantificar e avaliar adequadamente o ruído como agente físico relevante aos usuários de fones, de forma a terem-se laudos técnicos consistentes em relação à exposição ao agente ruído que possa causar perdas auditivas, efeitos e danos à saúde, reações fisiológicas como fadiga, queda de rendimento, dentre outros.

\subsection{JUSTIFICATIVAS}

Reconhecer e quantificar adequadamente o ruído como agente físico relevante aos usuários de fones de ouvido é indispensável para que seus efeitos possam ser minimizados, uma vez que os problemas podem estar sendo mascarados ou mesmo subnotificados com a ocultação das doenças ocupacionais, devido ao não acompanhamento da exposição ao ruído em razão da falta de procedimentos e metodologias legalmente válidos.

Prova disso é que, recentemente, um ofício (SÃO PAULO, 2008) do procurador José Fernando Ruiz Maturana, reuniu, após audiências e levantamento de informações técnicas, elementos suficientes para ajuizar uma Ação Civil Pública (ACP), com pedido de liminar, para que a Justiça do Trabalho determine a proteção da saúde 
dos operadores que estão sujeitos aos procedimentos da empresa. Segundo Maturana, existem sérios problemas nas condições de trabalho, como DORT (Distúrbios Osteomusculares Relacionados ao Trabalho) e PAIR (Perdas Auditivas Induzidas por Ruído), e o caso foi encaminhado para avaliação da Codemat (Coordenadoria Nacional de Defesa do Meio Ambiente do Trabalho) para dar tratamento uniforme à questão, em âmbito nacional, podendo atingir a proteção de aproximadamente 700 mil operadores em condições similares. Neste ponto, ele segue, com base em dados da Fundacentro - Fundação Jorge Duprat Figueiredo de Segurança e Medicina do Trabalho, do Ministério do Trabalho e Emprego:

[...] as atividades dos operadores de telefonia que exigem o uso de head-phone expõem os trabalhadores ao ruído, considerando-se basicamente os sons de conversação e eventuais zumbidos por descargas elétricas. Embora seja cada vez maior o uso dessa aparelhagem, tanto no campo profissional como no de lazer, não há ainda normas específicas para avaliar o risco potencial de surdez ocupacional. O risco de surdez é grave para o trabalhador e não pode ser estimado com base em metodologia rudimentar. ${ }^{1}$

Com base nos elementos colhidos, o Ministério Público do Trabalho (MPT) imputa à empresa Telefônica a prática da negativa de emissão de Comunicação de Acidente de Trabalho (CAT) e de avaliação inadequada da exposição ao ruído ocupacional gerado por headphones e outros tipos de transmissores e receptores de sons acoplados ao ouvido e à boca, requerendo a concessão de liminar para determinar, de imediato, que a empresa dê regular encaminhamento aos pedidos de abertura de CAT encaminhados por seus empregados, instruindo-os devidamente, sem questionamentos sobre a existência de nexo causal da doença com o trabalho; a emissão da CAT nas hipóteses de suspeita de doença profissional ou doença profissional em fase inicial até o primeiro dia útil seguinte ao da sua ocorrência ou detecção preliminar, sem condicioná-la à realização de exames complementares ou por insistência do trabalhador interessado; e promova a avaliação da exposição ao ruído ocupacional gerado por headphones e outros tipos de transmissores e receptores de sons. Pede ainda, na hipótese de descumprimento das obrigações, a cominação de multa diária de $\mathrm{R} \$ 5.000,00$ (cinco mil reais) por dia de atraso e a condenação da Telefônica a pagar indenização pelos danos coletivos causados, no

\footnotetext{
${ }^{1}$ Peça de Informação ㄲo 014567/2002. Ofício de Bauru da Procuradoria Regional do Trabalho da 15 Região do Estado de São Paulo, procurador José Fernando Ruiz Maturana, Bauru, 18/02/2008. Disponível em: <http://www.prt15.gov.br/site/institucional/oficio_bauru.php>. Acesso em: 18 fev. 2008.
} 
importe de $R \$ 800.000,00$ (oitocentos mil reais), a ser revertido para o FAT - Fundo de Amparo ao Trabalhador.

Assim, a necessidade deste tipo de avaliação é importante para a realização do Programa de Prevenção de Riscos Ambientais (PPRA), que fornece preciosos dados para o Programa de Controle Médico de Saúde Ocupacional (PCMSO) e para o Programa de Conservação Auditiva (PCA) das empresas comprometidas com o Sistema de Gestão Integrada de Segurança, Saúde, Higiene Ocupacional e Ergonomia.

Especificamente no Brasil, pela sua legislação previdenciária, as atividades que expõem os trabalhadores a níveis de ruído acima dos limites estabelecidos pelo Instituto Nacional do Seguro Social (INSS) são consideradas atividades especiais, podendo assim os segurados terem suas aposentadorias obtidas mais precocemente, em menor tempo de atividade. Entretanto, isso depende da comprovação de exposição ao agente ruído acima dos limites de tolerância.

Além disso, houve o estabelecimento, pelo Instituto Nacional do Seguro Social (INSS), do Perfil Profissiográfico Previdenciário (PPP), do Nexo Técnico Epidemiológico Previdenciário (NTEP), da Flexibilização da Alíquota Seguro Acidente do Trabalho e do Fator Acidentário Previdenciário (FAP), que fazem parte da Política Nacional de Segurança e Saúde dos Trabalhadores (PNSST), aprovada em 27/11/2005. O Nexo Técnico Epidemiológico Previdenciário (NTEP) é um dos critérios de concessão de aposentadoria especial e de benefício acidentário para os segurados incapacitados para o trabalho por doença. A perícia médica do INSS considerará caracterizada a natureza acidentária da incapacidade quando constatar ocorrência de nexo técnico epidemiológico entre o trabalho e o agravo. $\mathrm{O}$ acidente de trabalho também será caracterizado tecnicamente pela perícia médica do INSS mediante a identificação do nexo entre o trabalho e o agravo.

A obrigação de se estabelecer nexo técnico pelo INSS impõe a realização de minuciosa vistoria nos ambientes de trabalho por meio do Programa de Prevenção dos Riscos Ambientais (PPRA) e do Laudo Técnico das Condições Ambientais do Trabalho (LTCAT), condição esta necessária para que se inventariem os riscos da 
atividade e do ambiente de trabalho e se forneça dados para emissão do Perfil Profissiográfico Previdenciário (PPP).

Embora o Nexo Técnico Epidemiológico seja dirigido à Previdência Social, a caracterização do acidente de trabalho pelo critério da presunção repercutirá na prova do acidente de trabalho para fins de reparação de dano pelo regime da reparação civil.

Uma vez admitido pela Previdência Social que a doença caracterizadora do acidente foi desencadeada pelas condições ambientais de trabalho de risco, certamente os elementos de convicção da Previdência Social servirão como prova da efetiva ocorrência do acidente de trabalho (nexo causal) e, em algumas situações, da culpa do empregador, além dos desdobramentos tributários na alíquota do Seguro Acidente do Trabalho (SAT), correspondentes à alteração do Fator Acidentário Previdenciário (FAP).

A proposta do Fator Acidentário Previdenciário (FAP) é incentivar mecanismos de proteção no ambiente de trabalho. Para isso, privilegiam-se as empresas que investem na segurança e saúde de seus trabalhadores, reduzindo em até $50 \%$ a alíquota do Seguro Acidente do Trabalho (SAT), e penalizam-se aquelas cujas atividades geram aposentadoria especial, incapacidade, doenças ou mortes, aumentando em $100 \%$ a alíquota do SAT. A instituição do Nexo Técnico Epidemiológico Previdenciário (NTEP) não desobriga a empresa da emissão da Comunicação de Acidente do Trabalho (CAT).

Ressalte-se, por oportuno, que a equiparação legal das doenças ocupacionais aos acidentes de trabalho foi introduzida no Brasil pela Lei $n$ 으 6.367/1976 (art.2ํㅜ item I $\S 1^{\circ}$ ).

De fato, a ausência legal de critérios e metodologias para avaliação e caracterização da exposição ao ruído em trabalhadores que utilizam fones de ouvido em suas atividades configura-se ausência de tratamento eqüitativo, o que tem levado à dramática situação de uma legião de vitimados pelo trabalho, que não tem obtido os benefícios previdenciários, justamente por dificuldades de prova. 
Ademais, além dos aspectos previdenciários, os problemas advindos do ruído ocupacional geram passivos trabalhistas, indenizatórios, repercussões sindicais e desgaste da imagem da empresa perante a coletividade e os órgãos de fiscalização. 


\section{REVISÃO DOCUMENTAL E DA LITERATURA}

Desafortunadamente, há pouca literatura a respeito. O levantamento bibliográfico feito nos sites das instituições normativas e nos artigos publicados reúne vários trabalhos sobre a atividade com fones, mas somente poucos deles tratam especificamente dos critérios e da metodologia de avaliação do ruído em questão. Nesta pesquisa, são apresentados os resultados desses estudos.

\subsection{TRABALHOS PUBLICADOS}

Segundo Planeau (2005), estudos acústicos realizados nos anos de 1965 a 1975 tendem a mostrar a presença do risco de perda auditiva para esses tipos de profissionais que utilizam fundamentalmente telefones do tipo telefonista headset. De outra forma, estudos mais recentes empreendidos no ano de 1995 em operadores utilizando continuamente fones de ouvido mostram também que o risco de perda auditiva estava presente. Um estudo feito na Inglaterra em 1999 por Jacqueline A. Patel e Keith Broughton (2002) em vários centros de teleatendimento revelou que a exposição diária era em torno de $78 \mathrm{~dB}(\mathrm{~A})$ e que aproximadamente $15 \%$ dos operadores estavam expostos a níveis excedendo $85 \mathrm{~dB}(\mathrm{~A})$. Estudos similares foram feitos na Alemanha, na Holanda e na Itália em 2000 e 2001 e revelaram praticamente os mesmos níveis de exposição (A. PERETTI et al, 2003).

Devido a muitos pedidos concernentes à avaliação dos níveis de exposição ao ruído em operadores de telefonia que utilizam fones de cabeça tipo telefonista headset, um estudo, conduzido por Vincent Planeau, foi feito pelo Instituto Nacional de Pesquisas e Segurança da França - INRS em 24 call centers distribuídos em toda a França e mostrou que a exposição diária dos operadores pode exceder os $85 \mathrm{~dB}(\mathrm{~A})$. Em seu artigo, Planeau (2005) explicou que não foi possível utilizar nenhum dos dois métodos da norma ISO 11904, pois a técnica do microfone em ouvido real - MIRE da ISO 11904-1(2002) especifica que o microfone seja introduzido na orelha real da 
pessoa sob teste, o que dificultou a aplicação do método fora do laboratório, uma vez que é necessário fazer uma correção em freqüência da medição feita para cada pessoa, em condições e ambientes acusticamente bem conhecidos, o que não se conseguiu no ambiente de trabalho.

O outro método, a técnica do manequim da ISO 11904-2 (2004), também não pôde ser utilizado no estudo, devido ao peso e ao tamanho do manequim. Assim, no presente caso, para a avaliação diária da exposição, foi necessário utilizar um ouvido artificial, bem como um particular protocolo de medição dos níveis de ruído presentes nos fones de ouvido dos operadores, utilizando em paralelo um ouvido artificial da marca Brüel \& Kjaer $^{\circledR}$, modelo 4152, e foram feitas as correções tanto dos níveis de pressão sonora para campo difuso, como também, na ponderação A.

A despeito das diferenças das técnicas descritas, segundo o autor do artigo, todas elas são equivalentes, com graus de incerteza estimados globalmente ao redor de 5 dB. Neste estudo, apresentou-se um sumário dos resultados: $73 \%$ das instalações de call center em que utilizam fones geraram níveis de ruído acima de $85 \mathrm{~dB}(\mathrm{~A})$; $27 \%$ dos operadores estão expostos a mais de $85 \mathrm{~dB}(\mathrm{~A})$ e $25 \%$ estão entre 80 e 85 $\mathrm{dB}(\mathrm{A}) ; 66 \%$ das instalações de call center têm um ruído de fundo maior que os recomendados na França. Apesar desses dados, 36\% dos operadores não conhecem ou não têm consciência do potencial de risco de perda auditiva. O nível de ação fixado por lei na França é de 85 dB (A) (PLANEAU, 2005).

Conforme já citado, estudos na Inglaterra foram realizados, em 1999, a respeito de operadores utilizando fones, a pedido do Health \& Safety Executive (HSE), organismo de saúde e segurança do trabalho do Reino Unido, para o Health and Safety Laboratory (HSL), órgão de pesquisa da HSE, e conduzidos por Patel e Broughton (2002). O teste consistiu de 15 visitas em várias centrais de teleatendimento (call centers) com 150 operadores de ambos os sexos utilizando fones de ouvido. Foi utilizado para a medição dos níveis sonoros um manequim - do fabricante Knowles Eletronics Manikin for Acoustic Reseach (KEMAR) - equipado com um molde de orelha e com um simulador de ouvido com microfone de 1/2" tipo pressão modelo 4134 da Brüel \& Kjaer $^{\circledR}$, conectado a um analisador de espectro de freqüência de duplo canal modelo 2144 da Brüel \& Kjaer ${ }^{\circledR}$, com o qual se obteve 
níveis de ruído entre $65 \mathrm{~dB}(\mathrm{~A})$ e $88 \mathrm{~dB}(\mathrm{~A})$ de exposição pessoal ao ruído para esses operadores, com exposição diária média e desvio-padrão de $77 \pm 5 \mathrm{~dB}(\mathrm{~A})$. Os níveis de pressão sonora medidos variaram numa faixa de $\pm 10 \mathrm{~dB}(\mathrm{~A})$ em todas as faixas de freqüência. A principal fonte de exposição pelos headsets é a conversação. Concluíram que existe a possibilidade de exposição a altos níveis de ruído, mas que a duração desses eventos é bastante curta e não tem um significativo efeito nos operadores, sendo o risco de perda auditiva considerado mínimo, dentro da legislação própria pertinente (PATEL; BROUGHTON, 2002).

Apesar do resultado produzido pelos pesquisadores ingleses, as autoridades relacionadas ao trabalho, sindicatos, etc., têm se preocupado quanto aos riscos à saúde e segurança provenientes das atividades na indústria das centrais de atendimento. Nesse sentido, a Health \& Safety Commission (HCS), outra Comissão da Health and Safety Executive (HSE), preparou, em substituição aos Regulamentos para Trabalho com Ruído de 1989, a proposta de uma nova Diretiva Européia (2003/10/EC, 2004) com respeito aos agentes físicos (ruído). Ela introduziu novos limites de exposição e níveis de ação, com novos requisitos para medição, exposição ocupacional, práticas e métodos de controle, e sugeriu a adoção de normas da International Organization for Standardization - ISO, da International Electrotechinical Commission - IEC e da National Standards Institute - ANSI sobre procedimentos de medição de ruído em orelha "fechada" pelo uso de fones de ouvido. Incluiu também a adoção da técnica do microfone na orelha real - MIRE e da técnica do manequim e demais especificações correlatas para testes da performance dos instrumentos de medição.

Em 2005, a Health \& Safety Commission (HCS) preparou uma outra proposta voltada ao controle de ruído em trabalhadores dos setores de música e entretenimento, cujas pesquisas, no Reino Unido, estimaram em mais de um milhão o número de trabalhadores expostos a níveis de ruído que põem em risco a sua saúde, além do número de doentes sofrendo com surdez, zumbidos, etc., estimado em 170.000 pessoas. Essas condições podem causar incapacidade permanente ao trabalho, ainda que elas sejam evitáveis na sua totalidade, se devidamente monitoradas. 
Ainda preocupada com as atividades de call center, a HSE, em outubro de 2006, preparou a Circular LAC no 94/12 (UNITED KINGDOM, 2006), que contem conselhos de boas práticas de trabalho em call center e contemplando, dentre outras, a questão da audição dos que trabalham com headsets por todo o período de trabalho diariamente, cujo uso prolongado pode causar danos à audição. Ressalte-se que a referida Circular dá força legal aos agentes de fiscalização local quanto à exigência do seu cumprimento.

Em Londres, em 2006, Deni Butterfield, da Capita Symonds, com fundos da HSE, preparou o Relatório RR 517 (UNITED KINGDOM, 2006) sobre uma pesquisa contendo um estudo para avaliação da exposição ao ruído de grupos de trabalhadores da indústria da música, em concertos musicais ao vivo, realizado em doze eventos durante o ano. O autor explora a adequação de qualquer medida de controle no local e faz recomendações para melhorias, e pretende, com o relatório que contém detalhes da exposição das pessoas aos níveis de ruído, criar impacto na proposição de uma legislação para concertos musicais ao vivo.

Hughes et al. (1986) apontaram a necessidade de se obter maiores informações dos riscos relacionados ao uso freqüente e por longo tempo de fones de ouvido por usuários de toca-fitas portátil com níveis sonoros altos.

Andrade, Lima e Oliveira (2002) apresentam o resultado de uma avaliação auditiva em músicos de frevo e maracatu, na cidade de Olinda - PE, em que mediu os níveis de pressão sonora gerados por eles, encontrando níveis que variaram de $107 \mathrm{~dB}(\mathrm{~A})$ a $117 \mathrm{~dB}(\mathrm{~A})$ para os músicos do frevo (dança ao som de música nas festas carnavalescas) e de $107 \mathrm{~dB}(\mathrm{~A})$ a $119 \mathrm{~dB}(\mathrm{~A})$, para os músicos de maracatu (rancho carnavalesco que baila ao som de instrumentos de percussão). As queixas auditivas mais freqüentes citadas pelos músicos foram tontura e zumbido. Os hábitos auditivos mais citados pelos músicos foram a freqüência a discotecas e o uso de walkman. Os níveis mínimos de audição dos músicos mostraram alteração de $47,37 \%$ no grupo de frevo e de $16,13 \%$ no grupo de maracatu.

Mori (1985) examinou a audição de 175 estivadores que não apresentaram problemas relacionados ao sistema auditivo ou história de perdas auditivas na 
família. Desse grupo, 69\% eram ouvintes de gravação, e, destes, 43\% utilizavam fones de ouvido. Foi observado que os usuários de fones de ouvido apresentaram mais perdas auditivas permanentes do que os não-usuários nas freqüências de 4 $\mathrm{kHz}$ e $6 \mathrm{kHz}$.

Erkko Airo et al. (2004) apresentaram um estudo para investigar a exposição ao ruído do pessoal de produção de radiodifusão de rádio e TV e para avaliar a eficiência do equipamento de proteção em uso. Foi realizado um total de 182 medições de exposição ao ruído, feitas em concertos, esportes e outros eventos ao vivo. Adicionalmente, 48 medições foram feitas utilizando a técnica do microfone no ouvido real - MIRE. O ruído no interior do receptor do headset de comunicação foi medido com dois diferentes gravadores digitais, com dois microfones miniatura, sendo um da marca Senheiser - KE4-211-2 e o outro foi um sistema de microfone sem fio Tipo MKE2-4. Medições de ruído ambiental também foram feitas utilizando dosímetros. Os cameramen foram os expostos aos maiores níveis, com exposição média de $86 \mathrm{~dB}(\mathrm{~A})$; quanto aos supervisores, técnicos de palco, engenheiros de iluminação e som, a exposição ficou entre $81 \mathrm{~dB}(\mathrm{~A})$ e $82 \mathrm{~dB}(\mathrm{~A})$. O mais alto nível foi tipicamente medido em concertos, mas a exposição mais alta foi também registrada em eventos esportivos. A faixa dos níveis equivalentes (LAeq) medidos no interior do fone de comunicação foi de $62 \mathrm{~dB}(\mathrm{~A})$ a $101 \mathrm{~dB}(\mathrm{~A})$.

Em um estudo conduzido por Ivanovich et al. (1994), foram monitoradas 260 operadoras de telefonia usuárias de fones de ouvido. O ruído captado pelo microfone do ouvido artificial registrou níveis entre 78,4 dB (A) e 86,6 dB (A) e picos de níveis de pressão sonora de $90 \mathrm{~dB}(\mathrm{~A})$ a $96 \mathrm{~dB}(\mathrm{~A})$.

Stephen et al. (1995) realizaram um estudo com 37 operadores de teleatendimento usuários de fones de ouvido, utilizando a técnica do microfone no ouvido real, utilizando um minimicrofone colocado na entrada do canal auditivo de cada um dos indivíduos. Os resultados mostraram níveis sonoros na faixa de 79,9 dB (A) a 103,8 $\mathrm{dB}(\mathrm{A})$, cuja média foi de $87 \mathrm{~dB}(\mathrm{~A})$.

Um mesmo tipo de fone de ouvido usado por diferentes pessoas pode produzir níveis de pressão sonora significativamente diferente em cada um dos ouvintes, 
dependendo da geometria individual da orelha, da impedância acústica do ouvido, do modelo de fone e do posicionamento deste na orelha, de acordo com Gierlich (2002).

Da mesma forma, Darlington (2003) aponta que existem diferenças acústicas entre uma e outra orelha e que as diferenças na suscetibilidade individual ao ruído gerador da perda auditiva, não são levadas em conta na legislação a respeito do ruído ocupacional, pois apenas estabelece limites de nível equivalente de ruído em campo livre.

Gierlich (2002) ainda testou 6 diferentes fones de ouvido em 12 indivíduos distintos. Os níveis de pressão sonora medidos variaram numa faixa de $\pm 10 \mathrm{~dB}(\mathrm{~A})$ em todas as faixas de freqüência, confirmando que o uso da técnica da cabeça artificial com um simulador de ouvido e com molde de orelha externa padrão proporcionou resultados mais realísticos quando comparados com os dados das características das orelhas humanas.

Peretti et al. (2003) ressaltam, em artigo, a escassez de estudos e publicações sobre a avaliação e exposição ocupacional de operadores sujeitos ao ruído produzido por equipamentos de comunicação. Para eles, isso se deve, talvez, à pouca disponibilidade de equipamentos e metodologias de avaliação para medição dos níveis de ruído. Pesquisas nesse campo, segundo eles, têm mostrado dados não uniformes. Estudos empreendidos em operadores de telefonia por Glorig et al. (1969), Alexander et al. (1979) e Juan et al. (1979) tendem a excluir o risco de perda auditiva relativo à exposição ocupacional ao ruído. Ao contrário, em estudos empreendidos por Chiusano et. al (1995), em que pessoas continuamente se utilizam de headsets nas instalações do Departamento de Defesa dos Estados Unidos; por lanniello (1996), com operadores de telefone; e por Dajani et al. (1996), em trabalhadores de manutenção de cabos telefônicos e pessoal de terra de aeroportos, mostraram que esse risco pode realmente existir. Ainda segundo Peretti et. al (2003), ele conduziu, na última década, quatro diferentes estudos experimentais em trabalhadores que utilizam fones de ouvido do tipo headset: o primeiro, na divisão de gravação de fita; o segundo e terceiro em salas de central telefônica; e o quarto em uma central de atendimento de um banco. Em particular, 
para os profissionais de comunicação, os valores dos níveis sonoros têm de ser medidos dentro da área entre a fonte sonora e a orelha, por exemplo, na cavidade da concha ou no canal auditivo. Deve-se, nesse caso, aplicar uma transformação da pressão dependendo da freqüência e dos níveis sonoros registrados no interior da orelha para os níveis de pressão sonora externa a orelha, de forma a recuperar os dados medidos e poder compará-los com os valores limites de tolerância estabelecidos pelas normas aceitáveis para a avaliação da exposição ao ruído. A esse respeito, são citadas as normas internacionais da série ISO 11904, que constam de duas partes. Segundo Kuhn et al. (1983) e Yost et al. (1986), essa transformação dependente da freqüência que é baseada no ganho proporcionado pela orelha para diferentes freqüências - é a resposta em freqüência. $O$ ganho de ressonância no canal auditivo aparece em $2,5 \mathrm{kHz}$, enquanto na concha aparece entre $5 \mathrm{kHz}$ e $6 \mathrm{kHz}$. O nível do ganho é em torno de $10 \mathrm{~dB}$.

Assim, nesses estudos experimentais, foi utilizada a técnica do manequim, composto do conjunto simulador de cabeça e torso da marca Brüel \& Kjaer $^{\circledR}$ modelo 4128, com microfones localizados na referência do tímpano, conectados a um analisador de freqüência de duplo canal, da marca Larson Davis modelo 2900. Os resultados variaram muito, de um valor mínimo de $50 \mathrm{~dB}$ (A) para um valor máximo de $87 \mathrm{~dB}$ (A), e os valores médios, entre 63,3 \pm 5,6 e 84,2 \pm 1,7. Em 16 casos (17\%) o nível de $80 \mathrm{~dB}(\mathrm{~A})$ foi excedido. Nesse artigo, foi feita uma revisão desses estudos a fim de obter dados os mais representativos quanto possível. Também foram apresentados gráficos comparativos relacionados ao efeito da resposta em freqüência e das respostas em freqüência dos campos livre e difuso comparativamente aos valores padrões normalizados com os valores especificados pelo fabricante. 


\subsection{DADOS E RESULTADOS DE ESTUDOS}

\subsubsection{Empresa TELEPAR}

Mendes (1995), estudou, entre agosto de 1992 e agosto de 1994, na Telecomunicações do Paraná S.A. - TELEPAR da cidade de Curitiba - PR, a audição em telefonistas (grupo de estudo com 50 empregadas) com idade entre 35 e 50 anos, com mais de 10 anos de utilização de telefone tipo telefonista headphones e com jornada de trabalho de 6 horas. Rita C. C. G. Mendes (1995), comparou os resultados com um grupo-controle formado por uma população amostral de mulheres (amostra aleatória de 291 empregadas) com a mesma faixa etária e sem história de exposição a ruídos de forte intensidade (cargos administrativos). Com isso, estabeleceu-se a incidência de perda auditiva em ambos os grupos e o risco de surdez ocupacional no grupo de estudo. A incidência de perda auditiva em telefonistas do sexo feminino com idades entre 35 e 50 anos foi de $12,0 \%$.

\subsubsection{Empresa TELEBRASILIA}

No VI Encontro de Segurança e Medicina do Trabalho do Sistema Telebrás, foram apresentados pelo Dr. Paulo César Marinho Faria (1985) os dados mostrados na Tabela 1, referentes a uma avaliação audiométrica de 442 telefonistas acompanhadas de 1976 a 1982 na Telecomunicações de Brasília S.A - Telebrasília. Foram computados 1.287 exames audiométricos. 
Tabela 1 - Dados Estatísticos e Casuística

\begin{tabular}{lcc}
\hline \multicolumn{1}{c}{ Anos de Função } & № de Empregados & Percentual \\
\hline 1 ano & 14 & 3,17 \\
2 anos & 40 & 9,05 \\
3 anos & 55 & 12,44 \\
4 anos & 88 & 19,91 \\
5 anos & 105 & 23,76 \\
$>5$ anos & 140 & 31,67 \\
TOTAL & 442 & 100,00 \\
\hline
\end{tabular}

Fonte: Anais do VI Encontro de Segurança e Medicina do Sistema Telebrás, Recife, 19 a 22/11/1985, p.96

A partir da Tabela 1, pode-se traçar um perfil audiométrico médio, inicial e final, que resulta em:

i) Comparação dos perfis audiométricos inicial e final:

- 81,2\% (359 telefonistas) mantiveram curva audiométrica atual (no período de estudo) semelhante à inicial;

- $12,7 \%$ (56 telefonistas) apresentaram queda qualitativa de audição (10 a $15 \mathrm{~dB}$ em 3 freqüências), porém mantiveram perfil ainda dentro dos limites de normalidade (perdas até $25 \mathrm{~dB}$ em qualquer freqüência do teste audiométrico) e apresentaram boa discriminação vocal;

- 4,5\% (20 telefonistas) tiveram disacusia neurossensorial, em geral bilateral;

- $\quad 0,9 \%$ (4 telefonistas) tiveram disacusia mista;

- $\quad 0,7 \%$ (3 telefonistas) tiveram disacusia de transmissão.

ii) No mesmo período, foram registrados 59 casos de trauma acústico. Desses, 41 sem comprometimento auditivo posterior e 18 (4,07\% do total de telefonistas) com conseqüências auditivas. Os sinais e sintomas mais freqüentes anotados foram:

- Tonturas: 8;

- Disacusia: 7; 
- Disacusia bilateral: 11 ;

- Cefaléia: 6;

- Otalgia: 5;

- Problemas psíquicos: 6.

iii) O exame otoneurológico dos empregados com conseqüências auditivas revelou:

- $61,1 \%$ (11 pessoas) apresentaram audição vestibular normal;

- $33,3 \%$ (6 pessoas) tiveram comprometimento vestibular periférico;

- $5,6 \%$ (1 pessoa) apresentou vestibulopatia central.

\subsubsection{Relatório sobre alteração na audição nos empregados que ocupam cargos de risco auditivo na Telecomunicações do Rio de Janeiro S.A. - TELERJ}

Foram avaliados audiometricamente 6.093 empregados em cargos de risco auditivo no período de março de 1991 a abril de 1994. (TELECOMUNICAÇÕES DO RIO DE JANEIRO, 1994)

Esses empregados estão distribuídos em 11 (onze) cargos, dos quais 10 (dez) utilizam fones de ouvido até 8 horas por dia e 1 (um) cargo com exposição a ruído ambiental de 8 horas diárias.

Os exames constaram inicialmente de triagem anual, quando foram feitas audiometrias por via aérea, testando as freqüências de 250, 500, 1.000, 2.000, 4.000 e $8.000 \mathrm{~Hz}$, com o objetivo de detectar as perdas mais precocemente, a tempo de estabelecer medidas preventivas mais eficazes. 
Foram consideradas normais as perdas de até $25 \mathrm{~dB}$ em qualquer freqüência, tendo como resultados:

i) Dos 6.093 empregados avaliados, 5.688 (93,3\%) tiveram audiometrias normais e 405 (6,7\%) apresentaram algum tipo de perda auditiva, sendo a perda neurossensorial a de maior incidência $(6,1 \%)$;

ii) Em relação ao tempo de exposição diária, observou-se que a maior incidência se deu entre os cargos que usam fones de 1 a 6 horas por dia $(52,6 \%)$. Os que usam fones mais de 6 horas por dia representaram $32,4 \%$ e os que usam eventualmente os fones representaram apenas $2,2 \%$ do total;

iii) Quanto ao tempo de permanência em cargos de risco auditivo, a maior incidência se deu nos empregados que estão expostos ao ruído por um período de entre 10 e 20 anos, que coincide com a média de permanência na empresa, que é de 15 anos;

iv) Na avaliação em relação à idade, a maior incidência se deu entre 40 e 50 anos. Foi encontrada uma incidência alta de disacusia neurossensorial entre os empregados dos cargos de risco auditivo. Os dados obtidos confirmam os seguintes dados da literatura:

- Quanto maior o tempo de exposição, maior a incidência;

- Quanto maiores os níveis de ruído, maior a incidência;

- Os intervalos na jornada de trabalho que favorecem o repouso auditivo diminuem a incidência. 


\subsubsection{Empresa TELEBRÁS}

Tabela 2 - Quantidade de casos de doenças ocupacionais atribuídas ao ruído por cargo/função, nas empresas do Sistema Telebrás. Período de 1982 a 1994

\begin{tabular}{lc}
\hline \multicolumn{1}{c}{ Cargos } & Quantidade \\
\hline Cabista & 40 \\
Telefonista & 24 \\
Instalador Reparador & 18 \\
Técnico de Telecomunicações & 15 \\
Examinador de Cabos e Linhas & 10 \\
Ligador & 08 \\
Supervisor de Redes & 07 \\
Auxiliar Técnico de Telecomunicações & 03 \\
Atendente Comercial & 02 \\
Engenheiro & 02 \\
Operador de Radiofonia & 02 \\
Técnico de Comutação & 02 \\
Técnico de Transmissão & 01 \\
Auxiliar Técnico de Economia e Finanças & 01 \\
Marceneiro & 01 \\
Técnico de Infra Estrutura & 01 \\
Motorista & 01 \\
Reparador Eletromecânico & 01 \\
Não informados & 05 \\
TOTAL & 144 \\
\hline
\end{tabular}

Fonte: RACITRA - Relatório de Acidentes do Trabalho, emitido pela Telebrás. Apud Telecomunicações do Paraná. Exposição Ocupacional ao Ruído em Empresas de Telecomunicações - Parte I: Identificação, Avaliação e Medidas de Controle. Relatório do grupo técnico de assessoria em saúde e segurança do trabalho da Telebrás, 18p, 1996. Acesso Restrito. p.5 


\subsubsection{Empresa TELESP - Telecomunicações de São Paulo S.A.}

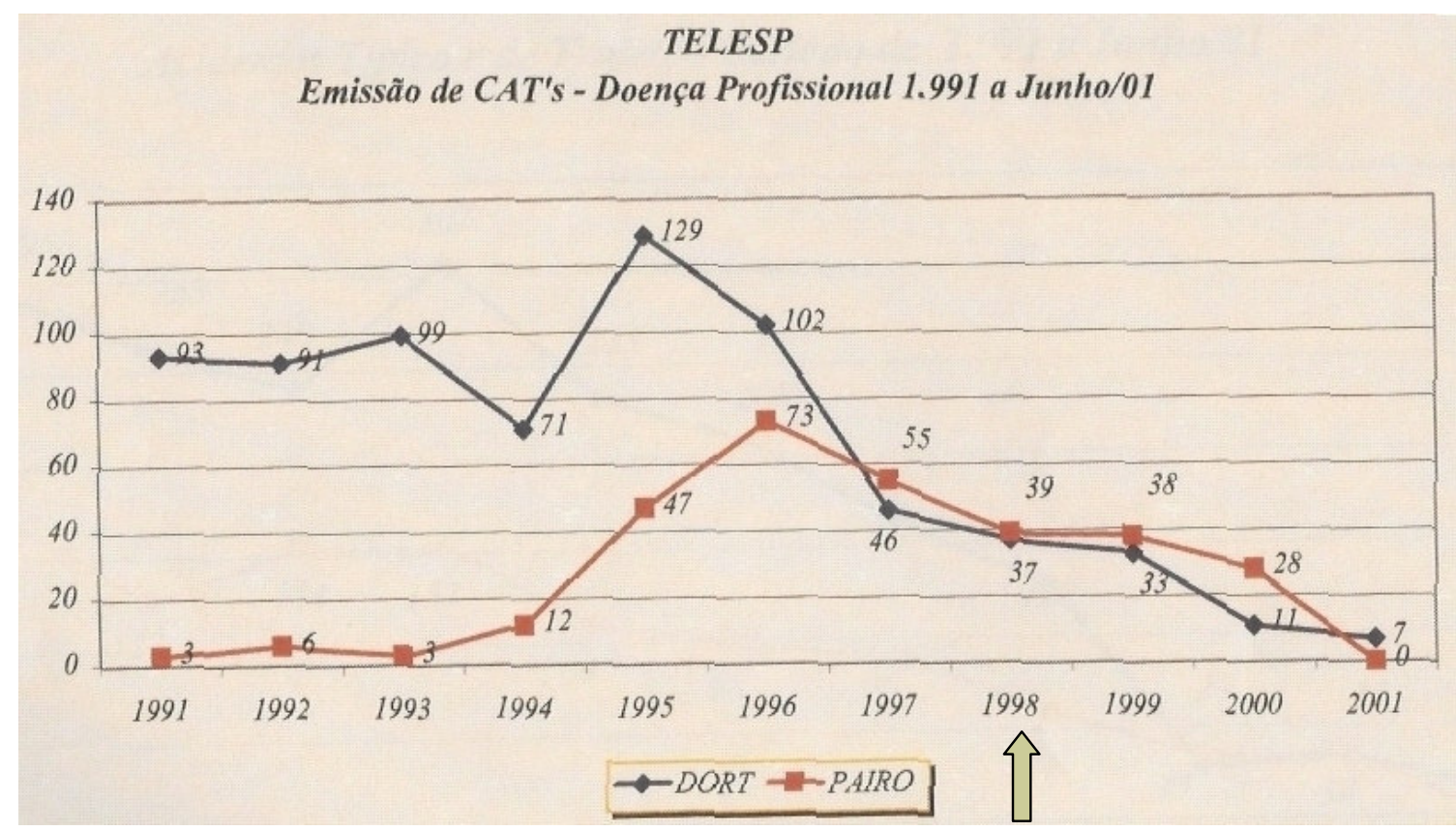

Gráfico 1 - Estatística - Emissão de CATs - Comunicações de Acidente do Trabalho

Fonte: Dados da Divisão de Saúde e Segurança do Trabalho da Telesp, 2001. Acesso Restrito.

PAIRO - Perdas Auditivas Induzidas por Ruído Ocupacional

DORT - Distúrbios Osteomusculares Relacionados ao Trabalho

Observa-se no Gráfico 1 que a seta indica que, no ano de 1998, ocorreram a privatização e a terceirização desses serviços, havendo, coincidentemente, o declínio do número de CATs emitidas.

\subsubsection{Estimativa do número de operadores de telemarketing/teleatendimento}

Segundo dados fornecidos pela Dra. Lys Esther Rocha no Seminário SAÚDE OCUPACIONAL - Operadores de Call Center (2004), nos Estados Unidos, havia 5 milhões de operadores de telemarketing e na Europa, 1,5 milhão. Segundo dados da Associação Brasileira de Telemarketing, também apresentados no Seminário SAÚDE OCUPACIONAL - Operadores de Call Center (2004), no Brasil, havia 400 mil operadores de telemarketing (sendo 120 mil no Estado de São Paulo). 
Acompanhando o crescimento do setor, a Associação Brasileira de Telemarketing passou a se chamar Associação Brasileira de Telesserviços - ABT.

Respondendo a uma consulta, a superintendente da ABT, Sra. Anna Maria Prado, informou (por correio eletrônico) que o setor no Brasil fechou o ano de 2007 com um crescimento dos Call Centers de 10\% em relação ao ano anterior (2006), e espera crescer também 10\% em 2008. O número de empregos diretos fechou o ano de 2007 com 750.000 empregados (PRADO, 2008). Convém destacar a expansão e o ritmo crescente na geração de milhares de novos empregos no setor.

Esta informação vem ao encontro da estimativa do Procurador José Fernando Ruiz Maturana, que, conforme já visto, previu a proteção de aproximadamente 700 mil operadores (de acordo com o item 1.4 - JUSTIFICATIVAS), do presente trabalho de pesquisa. (SÃO PAULO, 2008)

\subsection{PERDA AUDITIVA INDUZIDA POR RUÍDO (PAIR)}

Sabe-se que os critérios vigentes para caracterização de doenças profissionais nas empresas não são uniformes, inclusive no tocante à emissão das Comunicações de Acidente do Trabalho (CATs), que podem ainda ser subnotificadas.

Neste contexto, a Agência Brasil (2007) indica que a subnotificação de doenças e acidentes de trabalho é um problema considerado grave na área de saúde do trabalhador. Nesse mesmo artigo, segundo Pérsio Dutra, diretor do Departamento Intersindical de Estudos e Pesquisas de Saúde e dos Ambientes de Trabalho (Diesat), também reclama da subnotificação dos acidentes de trabalho no país.

Os dados de que se dispõe hoje sobre acidente de trabalho são todos fornecidos pela Previdência Social. E ela só fornece os dados dos benefícios que concedeu. O grande problema é que a Previdência Social só reconhece, segundo estudos que já foram feitos, menos de $15 \%$ daquilo que realmente é acidente ou doença de trabalho, por conta das subnotificações de CAT. 
Outra dificuldade com relação às estatísticas oficiais da Previdência Social do Brasil, é que as perdas auditivas não são segmentadas por tipo e natureza da perda, fornecendo somente números globais.

Com o intuito de atender os trabalhadores com suspeita de agravos à saúde relacionados ao trabalho, incluindo os procedimentos compreendidos entre 0 primeiro atendimento e a notificação, o Ministério da Saúde (BRASIL, 2006) elaborou uma série de publicações de Saúde do Trabalhador, entre elas o Protocolo de Complexidade Diferenciada № 5 de Perda Auditiva Induzida por Ruído (PAIR), com o objetivo de auxiliar os profissionais da rede do Sistema Único de Saúde (SUS) a identificar e notificar os casos de PAIR, conforme determina a Portaria $\mathrm{n}=777$, de 28/4/2004 (BRASIL, 2004), bem como dar subsídios aos órgãos de vigilância para intervenções nos ambientes de trabalho. A partir da notificação da PAIR, será possível conhecer sua prevalência para tornar eficaz qualquer planejamento de ações de capacitação e organização de recursos em função da capacidade instalada necessária para prevenir e diagnosticar PAIR, assim como reabilitar os portadores dessa doença.

A definição de Perda Auditiva Induzida por Ruído (PAIR) é a perda provocada pela exposição por tempo prolongado ao ruído. Configura-se como uma perda auditiva do tipo neurossensorial, geralmente bilateral, que é irreversível e progressiva com o tempo de exposição ao ruído. Consideram-se como sinônimos: perda auditiva por exposição ao ruído no trabalho, perda auditiva ocupacional, surdez profissional, disacusia ocupacional, perda auditiva induzida por níveis elevados de pressão sonora, perda auditiva induzida por ruído ocupacional, perda auditiva neurossensorial por exposição continuada a níveis elevados de pressão sonora de origem ocupacional.

Ainda segundo o Protocolo no 5, também chamado de Cartilha sobre PAIR, os dados epidemiológicos sobre perda auditiva no Brasil são escassos e referem-se a determinados ramos de atividades. Portanto, não há registros epidemiológicos que caracterizem a real situação. Os dados disponíveis sobre as ocorrências dão uma idéia parcial da situação de risco relacionada à perda auditiva. No Protocolo estimase que $25 \%$ da população trabalhadora exposta seja portadora de PAIR em algum 
grau. Apesar de ser o agravo mais freqüente à saúde dos trabalhadores, ainda são pouco conhecidos seus dados de prevalência no Brasil. Isso reforça a importância da notificação, que torna possível o conhecimento da realidade e o dimensionamento das ações de prevenção e assistência necessárias. Todo caso de Perda Auditiva Induzida por Ruído é passível de notificação compulsória pelo SUS, segundo parâmetro da Portaria GM/MS no 777, de 28 de abril de 2004 (BRASIL, 2004). Da mesma forma, todo caso de PAIR deve ser comunicado à Previdência Social, por meio de abertura de Comunicação de Acidente do Trabalho (CAT).

Quando o ruído é intenso e a exposição a ele é continuada, em média $85 \mathrm{~dB}(\mathrm{~A})$ por oito horas por dia, ocorrem alterações estruturais na orelha interna que determinam a ocorrência da PAIR (Código Internacional de Doenças CID 10 - H83.3). O código H90 - Perda da audição por transtorno de condução e/ou neurossensorial - significa que as células ciliares do órgão de Corti foram lesadas. É irreversível e quase sempre bilateral. O Ministério do Trabalho, pela Portaria no 19 GM/SSSTb, de 9 de abril de 1998 (BRASIL, 1998), estabelece as condições para a avaliação audiológica. É importante diferenciar a PAIR de outros agravos auditivos "diagnóstico diferencial", que possuem características diferentes e não são objeto desse Protocolo. É o caso do trauma acústico, também conhecido por choque acústico: é a perda auditiva súbita, decorrente de uma única exposição a ruído intenso, tendo como origem, por exemplo, explosão de fogos de artifícios, disparos de armas de fogo, ruídos de motores a explosão e alguns tipos de máquinas de grande impacto. O elemento causador dessa perda auditiva é, geralmente, muito traumático e a pessoa envolvida não tem dificuldade em especificar o início do problema auditivo.

O diagnóstico deverá, portanto, englobar a avaliação clínica e ocupacional, seguido de avaliação audiológica, podendo ser feito em qualquer dos níveis de atenção à saúde do Sistema Único de Saúde (SUS), do Ministério da Saúde. Considera-se audição normal o limiar de perda da resposta em até $25 \mathrm{~dB}$ em todas as freqüências testadas. As empresas devem manter, de acordo com as Normas Regulamentadoras do Ministério do Trabalho e Emprego, um Programa de Prevenção de Riscos Ambientais (PPRA - NR 9), no qual os diversos riscos existentes no trabalho devem ser identificados e quantificados para, a partir dessa 
informação, direcionar as ações do Programa de Controle Médico de Saúde Ocupacional (PCMSO - NR 7), que procederá às avaliações de saúde dos trabalhadores.

\subsection{LEGISLAÇÃO BRASILEIRA SOBRE RUÍDO OCUPACIONAL}

A Consolidação das Leis do Trabalho - CLT, instituída no Brasil pelo Decreto-Lei no 5.452, de 01/05/1943 (BRASIL, 1943), introduz entre os direitos dos trabalhadores a redução dos riscos inerentes ao trabalho, por meio de normas de saúde, higiene e segurança. Posteriormente, a Lei № 6.514/1977 (BRASIL, 1977) alterou o Capítulo V do Título II da CLT e instituiu em todo o país disposições a respeito da Segurança e Medicina do Trabalho. A Portaria № 3.214 de 08 Junho de 1978 (BRASIL, 1978) aprovou as Normas Regulamentadoras (NRs), responsáveis pelas regras de segurança e medicina nas atividades relativas ao trabalho em nível nacional.

A seguir são apresentadas a legislação atual e as normas em vigor, que tratam ou estão correlacionadas com a questão do ruído, para o propósito da presente pesquisa.

\subsubsection{Legislação Trabalhista}

2.4.1.1 Portaria no. 3.214 de 08 de junho de 1978 do Ministério do Trabalho (BRASIL, 1978)

A Norma Regulamentadora NR 15 estabeleceu no Anexo $n \div$. 1, os limites de tolerância para ruído contínuo ou intermitente e, no Anexo ํo. 2, os limites de tolerância para ruídos de impacto.

A Norma Regulamentadora NR 15 caracteriza-se como critério legal. 
2.4.1.2 NHO 01 - Norma de Higiene Ocupacional da Fundacentro: Procedimento Técnico - Avaliação da Exposição Ocupacional ao Ruído (BRASIL, FUNDACENTRO, 1999)

A FUNDACENTRO - Fundação Jorge Duprat Figueiredo de Segurança e Medicina do Trabalho, órgão ligado ao Ministério do Trabalho e Emprego - MTE estabeleceu, por meio da Norma de Higiene Ocupacional - NHO 01 - Avaliação da Exposição Ocupacional ao Ruído, critérios e procedimentos para a avaliação da exposição ocupacional a ruído contínuo ou intermitente e a ruído de impacto em quaisquer situações de trabalho que implique em risco potencial de surdez ocupacional.

A norma aplica-se à exposição ocupacional a ruído contínuo ou intermitente e a ruído de impacto, em quaisquer situações de trabalho, contudo não está voltada para a caracterização das condições de conforto acústico.

\subsubsection{NR 9 - Programa de Prevenção de Riscos Ambientais - PPRA}

(BRASIL, 1994)

A NR 9 foi regulamentada pela Portaria №. 3.214 de 08 de junho de 1978 do Ministério do Trabalho, e esta foi alterada pela Portaria GM no. 3.214, de 08 de junho de 1978 (DOU 06/07/78, e pela Portaria SSST №. 25, de 29 de dezembro de 1994 (DOU 30/12/94 - republicada em 15/12/1995).

A NR 9 é uma norma regulamentadora que estabelece a obrigatoriedade da elaboração e implementação, por parte de todos os empregadores e instituições que admitam trabalhadores como empregados, do Programa de Prevenção de Riscos Ambientais - PPRA, visando à preservação da saúde e da integridade dos trabalhadores por meio da antecipação, reconhecimento, avaliação e conseqüente controle da ocorrência de riscos ambientais existentes ou que venham a existir no ambiente de trabalho, tendo em consideração a proteção do meio ambiente e dos recursos naturais. 
O PPRA é parte integrante do conjunto mais amplo das iniciativas da empresa no campo da preservação da saúde e da integridade dos trabalhadores, devendo estar articulado com o disposto nas demais NRs, em especial com o Programa de Controle Médico de Saúde Ocupacional - PCMSO, previsto na NR 7.

Para efeito desta NR, consideram-se riscos ambientais os agentes físicos, químicos e biológicos existentes nos ambientes de trabalho que, em função de sua natureza, concentração ou intensidade e tempo de exposição, são capazes de causar danos à saúde do trabalhador.

O ruído é um dos agentes físicos a que podem estar expostos os trabalhadores.

Deverão ser adotadas as medidas necessárias suficientes para a eliminação, a minimização ou o controle dos riscos ambientais sempre, dentre outras situações, que os resultados das avaliações quantitativas da exposição dos trabalhadores excedam os valores dos limites previstos na NR 15 ou, na ausência destes, os valores limites de exposição ocupacional adotados pela American Conference of Governmental Industrial Hygienists - ACGIH® (ACGIH, update annually) ou aqueles que venham a ser estabelecidos em negociação coletiva de trabalho, desde que mais rigorosos do que os critérios técnico-legais estabelecidos; e quando, por meio do controle médico da saúde, ficar caracterizado o nexo causal entre danos observados na saúde dos trabalhadores e a situação de trabalho a que eles ficam expostos.

\subsubsection{NR 7 - Programa de Controle Médico de Saúde Ocupacional - PCMSO} (BRASIL, 1994)

A NR 7 foi regulamentada pela Portaria no 3.214 de 08 de junho de 1978 do Ministério do Trabalho, e esta foi alterada pela Portaria SSST $\mathrm{n} \cong 24$ de 29 dezembro de 1994 (DOU 30/12/1994). 
Essa norma regulamentadora (NR) estabelece a obrigatoriedade de elaboração e implementação, por parte de todos os empregadores e instituições que admitam trabalhadores como empregados, do Programa de Controle Médico de Saúde Ocupacional - PCMSO, com o objetivo de promoção e preservação da saúde do conjunto dos seus trabalhadores.

A NR estabelece os parâmetros mínimos e diretrizes gerais a serem observados na execução do PCMSO, podendo eles ser ampliados mediante negociação coletiva de trabalho.

O PCMSO deverá ser planejado e implantado com base nos riscos à saúde dos trabalhadores, especialmente os identificados nas avaliações previstas no PPRA e nas demais NR.

\subsubsection{NR 17 - Ergonomia}

(BRASIL, 1990)

A NR 17 foi regulamentada pela Portaria №. 3.214 de 08 de junho de 1978 do Ministério do Trabalho, e esta foi alterada pela Portaria no. 3.751, de 23/11/1990.

Essa norma regulamentadora visa a estabelecer parâmetros que permitam a adaptação das condições de trabalho às características psicofisiológicas dos trabalhadores, de modo a proporcionar um máximo de conforto, segurança e desempenho eficiente.

As condições ambientais de trabalho devem estar adequadas às características psicofisiológicas dos trabalhadores e à natureza do trabalho a ser executado.

Nos locais de trabalho onde são executadas atividades que exijam solicitação intelectual e atenção constantes, tais como: salas de controle, laboratórios, escritórios, salas de desenvolvimento ou análise de projetos, dentre outros, são recomendadas as seguintes condições de conforto. Especificamente, com relação 
ao ruído, tem-se que os níveis de ruído devem estar de acordo com o estabelecido na NBR 10152 (1987) - Norma Brasileira Registrada no Instituto Brasileiro de Metrologia, Normalização e Qualidade Industrial - INMETRO, a qual fixa níveis de ruído compatíveis com o conforto acústico em ambientes diversos.

Para as atividades que possuam as características definidas na NR 17, mas não apresentam equivalência ou correlação com aquelas relacionadas na NBR 10152 (1987), o nível de ruído aceitável para efeito de conforto será de até $65 \mathrm{~dB}(\mathrm{~A})$ e a curva de avaliação de ruído (NC), de valor não superior a 60 dB.

Os parâmetros previstos devem ser medidos nos postos de trabalho, sendo os níveis de ruído determinados próximos à zona auditiva, e as demais variáveis, na altura do tórax do trabalhador.

\subsubsection{Portaria no. 08, de 30/03/2007, que aprova o Anexo I da NR 17:}

Trabalho dos Operadores de Checkout (BRASIL, 2007)

Esse anexo da norma objetiva estabelecer parâmetros e diretrizes mínimas para adequação das condições de trabalho dos operadores de checkout, visando à prevenção dos problemas de saúde e segurança relacionados ao trabalho.

Aplica-se aos empregadores que desenvolvem atividade comercial utilizando sistema de auto-serviço e checkout, como supermercados, hipermercados e comércio atacadista. 
2.4.1.7 Portaria no. 09, de 30/03/2007, que aprova o Anexo II da NR 17:

Trabalho em Teleatendimento/Telemarketing

(BRASIL, 2007)

O presente anexo estabelece parâmetros mínimos para o trabalho em atividades de teleatendimento/telemarketing nas diversas modalidades desse serviço, de modo a proporcionar um máximo de conforto, segurança, saúde e desempenho eficiente.

As disposições desse anexo aplicam-se a todas as empresas que mantêm serviço de teleatendimento/telemarketing nas modalidades ativo ou receptivo em centrais de atendimento telefônico e/ou centrais de relacionamento com clientes (call center), para prestação de serviços, informações e comercialização de produtos.

Entende-se como call center o ambiente de trabalho no qual a principal atividade é conduzida via telefone e/ou rádio com utilização simultânea de terminais de computador.

O anexo aplica-se, inclusive, a setores de empresas e postos de trabalho dedicados a essa atividade, além daquelas empresas especificamente voltadas para essa atividade-fim.

Entende-se como trabalho de teleatendimento/telemarketing aquele cuja comunicação com interlocutores clientes e usuários é realizada à distância por intermédio da voz e/ou mensagens eletrônicas, com a utilização simultânea de equipamentos de audição/escuta, fala telefônica e sistemas informatizados ou manuais de processamento de dados.

Com relação ao assunto ruído, foi identificado, no item referente a equipamentos dos postos de trabalho, que devem ser fornecidos gratuitamente conjuntos de microfone e fone de ouvido (headsets) individuais, que permitam ao operador a alternância do uso das orelhas ao longo da jornada de trabalho e que sejam substituídos sempre que apresentarem defeito ou desgaste devido ao uso. 
Os headsets devem:

i) ter garantido pelo empregador a correta higienização e as condições operacionais recomendadas pelos fabricantes;

ii) ser substituídos prontamente quando situações irregulares de funcionamento forem detectadas pelo operador;

iii) ter seus dispositivos de operação e controles de fácil uso e alcance;

iv) permitir ajuste individual da intensidade do nível sonoro e ser providos de sistema de proteção contra choques acústicos e ruídos indesejáveis de alta intensidade, garantindo o entendimento das mensagens.

O empregador deve também garantir o correto funcionamento e a manutenção contínua dos equipamentos de comunicação, incluindo os conjuntos de headsets, utilizando pessoal técnico familiarizado com as recomendações dos fabricantes.

Quanto às condições ambientais de trabalho, os locais devem ser dotados de condições acústicas adequadas à comunicação telefônica, adotando-se medidas tais como o arranjo físico geral e dos postos de trabalho, pisos e paredes, isolamento acústico do ruído externo, tamanho, forma, revestimento e distribuição das divisórias entre os postos, de forma a atender ao disposto na NR 17, conforme já visto.

O Programa de Controle Médico de Saúde Ocupacional (PCMSO), além de atender à norma regulamentadora NR 7, deve necessariamente reconhecer e registrar os riscos identificados na análise ergonômica.

O empregador deverá fornecer ao empregado, cópia dos Atestados de Saúde Ocupacional e cópia dos resultados dos demais exames.

O empregador deve implementar um programa de vigilância epidemiológica para detecção precoce de casos de doenças relacionadas ao trabalho comprovadas ou objeto de suspeita, que inclua procedimentos de vigilância passiva (processando a demanda espontânea de trabalhadores que procurem serviços médicos) e procedimentos de vigilância ativa, por intermédio de exames médicos dirigidos que incluam, além dos exames obrigatórios por norma, a coleta de dados sobre sintomas 
referentes aos aparelhos psíquico, osteomuscular, vocal, visual e auditivo, analisados e apresentados com a utilização de ferramentas estatísticas e epidemiológicas.

\section{4..2 Legislação Previdenciária}

2.4.2.1 Instrução Normativa INSS/PRES no 11 20/09/2006, DOU de 21/09/2006. (BRASIL, 2006)

A Instrução $n \underline{\underline{0}} 11$ e as instruções de alteração, Instrução Normativa INSS/PRES no 15, de 15 de março de 2007, DOU de 16/03/2007 e a Instrução Normativa INSS/PRES № 17, de 9 de abril de 2007, DOU de 16/04/2007, considerando o disposto nas Leis $\mathrm{n}=8.212$ e $\mathrm{n}=8.213$, ambas de 24 de julho de 1991, o estabelecido no Regulamento da Previdência Social - RPS, aprovado pelo Decreto no 3.048 , de 6 de maio de 1999; e considerando a necessidade de estabelecer rotinas para agilizar e uniformizar a análise dos processos de reconhecimento, manutenção e revisão de direitos dos beneficiários da Previdência Social, para a melhor aplicação das normas jurídicas pertinentes, com observância dos princípios estabelecidos no art. 37 da Constituição Federal, é previsto, no tocante à Aposentadoria Especial, no art. 158, que as demonstrações ambientais de que trata o caput, constituem-se, entre outros, nos seguintes documentos: Programa de Prevenção de Riscos Ambientais - PPRA; Programa de Gerenciamento de Riscos - PGR; Programa de Condições e Meio Ambiente de Trabalho na Indústria da Construção - PCMAT; Programa de Controle Médico de Saúde Ocupacional - PCMSO; Laudo Técnico de Condições Ambientais do Trabalho - LTCAT; Perfil Profissiográfico Previdenciário - PPP e Comunicação de Acidente do Trabalho - CAT.

No art. 179, os procedimentos técnicos de levantamento ambiental, ressalvada disposição em contrário, deverão considerar a metodologia e os procedimentos de avaliação dos agentes nocivos estabelecidos pelas Normas de Higiene Ocupacional 
- NHO 01 da Fundacentro, bem como os limites de tolerância estabelecidos pela NR 15 do Ministério do Trabalho e Emprego - MTE.

O art. 180 prevê que a exposição ocupacional a ruído dará ensejo à aposentadoria especial quando os níveis de pressão sonora estiverem acima de oitenta $\mathrm{dB}(\mathrm{A})$ até 5 de março de 1997, noventa dB (A) de 6 de março de 1997 e até 18 de novembro de 2003, e a partir de 19/11/2003, será efetuado o enquadramento quando o Nível de Exposição Normalizado - NEN, definido na NHO 01 da FUNDACENTRO, se situar acima de oitenta e cinco dB (A), ou for ultrapassada a dose unitária, aplicando os limites de tolerância definidos na NHO - 01 da FUNDACENTRO, com as fórmulas ajustadas para incremento de duplicidade da dose igual a cinco.

\subsubsection{Portaria Interministerial MPS/MS/MTE №. 800, 03/05/2005, DOU de 05/05/2005. (BRASIL, 2005)}

Apresenta os fundamentos e diretrizes de uma Política Nacional de Segurança e Saúde do Trabalhador - PNSST, com vistas a garantir que o trabalho seja realizado sem prejuízo para sua saúde, integridade física e mental.

\subsubsection{Lei n‥ 11.430 de 26 de dezembro de 2006, DOU de 24/12/2006.}

(BRASIL, 2006)

Altera a Lei no. 8.213, de 24/07/1991, do Plano de Benefícios da Previdência Social, no art. 21-A, em que a perícia médica do INSS considerará caracterizada a natureza acidentária da incapacidade quando constatar ocorrência de nexo técnico epidemiológico entre o trabalho e o agravo, decorrente da relação entre atividade da empresa e a entidade mórbida motivadora da incapacidade elencada na Classificação Internacional de Doenças - CID. A perícia médica do INSS deixará de aplicar o disposto no artigo quando demonstrada a inexistência do nexo tratado por ele. 
A empresa poderá requerer a não aplicação do nexo técnico epidemiológico.

\subsubsection{Decreto №. 6.042 de 12/02/2007, DOU de 12/02/2007.} (BRASIL, 2007)

Disciplina a aplicação, acompanhamento e avaliação do Fator Acidentário de Prevenção - FAP e do Nexo Técnico Epidemiológico, e dá outras providências.

Importante pelo seu art. 337, segundo o qual o acidente do trabalho será caracterizado tecnicamente pela perícia médica do INSS, mediante a identificação do nexo entre o trabalho e o agravo. A empresa poderá requerer ao INSS a não aplicação do nexo técnico epidemiológico ao caso concreto mediante a demonstração de inexistência de correspondente nexo causal entre o trabalho e o agravo, por meio de evidências técnicas circunstanciadas e tempestivas à exposição de segurado, podendo ser produzidas no âmbito de programas de gestão de risco, a cargo da empresa.

2.4.2.5 Instrução Normativa INSS/PRES no. 16 de 27/03/2007, DOU de 30/03/2007. (BRASIL, 2007)

Dispõe sobre procedimentos e rotinas referentes ao Nexo Técnico Epidemiológico Previdenciário - NTEP, estabelecendo critérios para a aplicação do NTEP pelo INSS como uma das espécies do gênero nexo causal.

Essa instrução cabe atenção especial para esta pesquisa sobre ruídos em fones, pois o nexo técnico epidemiológico entre a entidade mórbida motivadora da incapacidade e o ramo de atividade econômica da empresa pode ou não ser reconhecido ou mesmo estabelecido. Caso isso ocorra, a perícia médica do INSS poderá solicitar as demonstrações ambientais da empresa, efetuar pesquisa, realizar 
vistoria do local de trabalho ou solicitar o Perfil Profissiográfico Previdenciário (PPP) diretamente ao empregador.

De outro lado, a empresa poderá requerer ao INSS a não aplicação do nexo técnico epidemiológico ao caso concreto, quando dispuser de dados e informações que demonstrem que os agravos não possuem nexo causal com o trabalho exercido pelo trabalhador.

\subsection{DISCUSSÃO REFERENTE À LEGISLAÇÃO}

Quanto à Norma de Higiene Ocupacional da Fundacentro NHO 01, depreende-se que há diferenças entre os critérios técnicos da norma NHO 01 e os legais da NR 15 - Anexos nํ.1 e nํ2, existentes sobre a avaliação do ruído ocupacional.

Nesse contexto, também há divergências entre essas normas e os critérios do INSS que são abordados nesta pesquisa.

No Anexo I da NR 17, não foi identificada nenhuma preocupação com relação a aspectos de ruído.

Em reuniões da Comissão que elaborou a Portaria no 09 de 30/03/2007, que aprova - Anexo II da NR 17, das quais o autor deste trabalho teve a oportunidade de participar, foram colocadas as preocupações do pesquisador quanto aos aspectos do nível de ruído nos headsets e sua avaliação. Porém, como não há respaldo técnico-legal quanto à metodologia e procedimentos específicos de avaliação, essa questão deixou de ser contemplada.

No Anexo II da NR 17, paradoxalmente ao objetivo do anexo específico para atividades de teleatendimento/telemarketing quanto a proporcionar o máximo de conforto, segurança, saúde e desempenho eficiente, não foi nem sequer citada qualquer preocupação com a avaliação de ruído em headsets. 
Quanto ao Anexo n‥ 13, Operações Diversas, da NR 15 da Portaria n․ 3.214 do Ministério do Trabalho (BRASIL, 1978), o texto legal refere-se à recepção de sinais em fones, e não à recepção de voz humana em fones. Portanto, sua aplicação se restringe apenas às transmissões de sinais de Código Morse nos antigos aparelhos de radiotelegrafia e radiotelefonia.

IMPORTANTE: Sobre o Anexo n‥ 13 da NR 15, a Telesp, por meio do autor deste texto, fez uma consulta ao Diretor do Departamento de Segurança e Saúde no Trabalho do Ministério do Trabalho e Emprego - MTE, que, em resposta, emitiu a NOTA TÉCNICA № 10/2002, de 18/04/2002: (BRASIL, 2002)

\begin{abstract}
De forma genérica, podemos constatar que a legislação se refere à recepção de sinais em fone. Esses sinais de telegrafia e radiotelegrafia são de alta freqüência e eram comuns nos antigos equipamentos de comunicação. O caso específico de telefonia não envolve, normalmente, recepção de sinais, e sim a fala através de aparelhos telefônicos, muito diferentes dos sinais transmitidos nos sistemas de telegrafia e radiotelegrafia. Portanto, para a caracterização e classificação de atividades como insalubre, no caso de telefonista, é necessário que seja verificado por meio de laudo pericial in loco o nível de ruído a que está sujeito este empregado.
\end{abstract}

Posto isto, fica claro a necessidade da avaliação do nível de ruído em fones, para a perfeita caracterização da exposição. 


\section{METODOLOGIA}

Os materiais e métodos utilizados nesta pesquisa constam de (i) revisão da literatura, (ii) experiência e estudos do autor e (iii) análise dos estudos e trabalhos de outros especialistas, incluindo uma proposta alternativa para avaliação de ruído em fones. Foram feitos também vários contatos pessoais, telefônicos e por correio eletrônico, com vários profissionais da Fundacentro, da Universidade de Santa Catarina, de empresas, consultores especializados, fabricantes de equipamentos de medição, dentre outros.

Assim, de tudo o que foi desenvolvido e mostrado sobre a medição dos níveis de ruído em usuários de fones de ouvido e em face dos resultados das análises comparativas desses trabalhos e estudos, foram abordadas com detalhes as Normas Internacionais da Série ISO 11904, que são divididas em duas partes: a ISO 11904-1 (2002) - Técnica do Minimicrofone em Ouvido Real, conhecida por Técnica MIRE - Microphone in a Real Ear, e a ISO 11904-2 (2004) - Técnica da Cabeça Artificial de Manequim, conhecida como Técnica usando Manequim, que são aplicadas para determinar os níveis de exposição a ruído para fontes sonoras próximas à orelha das pessoas que se utilizam de fones de ouvido de modo geral.

Em princípio, pelo que foi apresentado, sugere-se que os dois métodos podem proporcionar boas estimativas de avaliação, de forma eficiente e efetiva. Para a confirmação disso, será desenvolvida uma análise detalhada sobre as metodologias das normas indicadas.

Exemplos de aplicação dessas normas são para pessoas expostas aos sons de fones de ouvido que transmitem música e conversação, armas e ferramentas de pressão usadas junto à cabeça e situações combinadas de uma fonte junto a orelha e outra no campo sonoro externo. 


\subsection{CONSIDERAÇÕES GERAIS SOBRE NORMAS TÉCNICAS}

\subsubsection{Importância das normas}

Como exemplo da importância de uma norma técnica, pode-se citar, de interesse para o presente trabalho, as normas para medidores de nível sonoro da série IEC 61672. Nota-se que foram definidas algumas novas nomenclaturas e ponderações em freqüência; as ponderações temporais, a matemática de integração, etc. são as mesmas. Sob o ponto de vista do uso, para os laboratórios de calibração e de aprovação de modelos, as mudanças são radicais.

Nesse sentido, seria possível extrair, entre outras conclusões, que as normas da série IEC 61672 vieram para disciplinar e "moralizar" o mercado de medidores de nível sonoro, evitando a concorrência desleal e a frustração dos consumidores. Entretanto, ainda se faz necessário que os Laboratórios da Rede Brasileira de Calibração (RBC) sejam acreditados para calibrar de acordo com a IEC 61672-3 (2006), reduzindo os níveis de incerteza dos instrumentos de medição, parâmetro da maior relevância na aplicação dos métodos da série ISO 11904 na avaliação dos níveis de ruído em fones, cujas incertezas, dependendo do seu grau, poderão anular as medições realizadas.

\subsubsection{Características das normas técnicas}

Como neste trabalho se abordou muito sobre normas técnicas, talvez seja oportuno, a título informativo, fazer algumas considerações sobre as características e quanto à natureza e a abrangência das principais normas técnicas.

Por definição, uma norma técnica é um documento estabelecido por consenso e aprovado por um organismo reconhecido, que fornece, para uso comum e repetitivo, 
regras, diretrizes ou características para atividades ou seus resultados, visando à obtenção de um grau ótimo de ordenação em um dado contexto.

Uma norma nacional é adotada por um organismo nacional de normalização e colocada à disposição do público. Exemplo: NBR - Norma Brasileira Registrada (Brasil), DIN - Deutsches Institut für Normung (Alemanha), ANSI - National Standards Institute (Estados Unidos). Uma norma internacional, por sua vez, é uma norma que é adotada por uma organização internacional com atividades de normalização ou por uma organização internacional de normalização e colocada à disposição do público, como a ISO (International Organization for Standardization), IEC (International Electrotechnical Commission) e ITU (International Telecommunication Union), que foram aqui amplamente discutidas.

A ISO é uma organização voluntária não governamental de padronização fundada em Genebra em 1947 e orientada a todos os tipos de padrões, exceto àqueles relativos à Engenharia Elétrica e Eletrônica, considerados de responsabilidade da IEC.

A IEC é também uma organização não governamental de padronização, fundada em 1906 e muito atuante na área de padrões relativos a Engenharia Elétrica e Eletrônica.

A ITU é uma organização internacional ligada a ONU - Organização das Nações Unidas. Embora criada em 1865, ainda com o nome de International Telegraph Union (ITU), em 1956, após várias fusões, foi formado o CCITT (International Telephone and Telegraph Consultative Committee). Desde o final de 1992, a ITU foi reestruturada em 3 setores, Telecommunications Standardization Sector (ITU-T), Radiocommunication Sector (ITU-R), e Development Sector (ITU-D). O representante brasileiro na ITU é a ANATEL - Agência Nacional de Telecomunicações.

Na América do Norte, tem-se a ANSI - American National Standards Institute, que é uma norma nacional americana. É uma organização privada sem fins lucrativos que administra e coordena a padronização e certificação voluntária. A ANSI é o mais 
antigo organismo regional de coordenação de normas técnicas. Fundado em 1916, a partir de cinco associações de engenharia (Elétrica, Mecânica, Civil, Minas/Metalúrgica e Materiais), reúne as mais diversas entidades de padronização. Entre os organismos creditados pelo ANSI tem-se o Institute of Electrical and Electronics Engineers - IEEE, cujos objetivos vão além da padronização e abrangem o desenvolvimento científico e tecnológico nas áreas de engenharia eletroeletrônica e de tecnologia de informação.

É importante ressaltar que as normas brasileiras são desenvolvidas e utilizadas voluntariamente. Elas tornam-se obrigatórias somente quando explicitadas em um instrumento do Poder Público (lei, decreto, portaria normativa, etc.) ou quando citadas em contratos. Entretanto, mesmo não sendo obrigatórias, as normas são sistematicamente adotadas em questões judiciais por conta do inciso VIII do art. 39 do Código de Defesa do Consumidor. Isso é muito importante no contexto do presente trabalho, quando uma das possíveis alternativas para resolver a questão das medições de ruído em fones de ouvido poderia ser a adoção de uma norma internacional, no presente caso as normas da série ISO 11904; ISO 11904-1 e/ou ISO 11904-2. 


\section{ESTUDOS E EXPERIÊNCIAS}

Como já comentado, no Brasil não há uma metodologia normalizada para medir a exposição ao ruído que permita avaliar os riscos provocados pelo ruído próximo à entrada do sistema auditivo, e que não há muitos trabalhos a esse respeito.

$\mathrm{Na}$ verdade, é muito difícil quantificar o nível de ruído no canal auditivo, porque no pavilhão auditivo o campo sonoro é fechado, comprometendo a resposta da maioria dos microfones de medição comercialmente disponíveis.

A seguir são apresentadas duas experiências do autor (item 4.1 - ESTUDO I e item 4.2 - ESTUDO II) e quatro experiências de outros especialistas (item 4.3 - ESTUDO III; item 4.4 - ESTUDO IV; item 4.5 - ESTUDO V e item 4.6 - ESTUDO VI). No item 4.7 - ESTUDO VII, é apresentada uma proposta alternativa para medição/avaliação de ruído em fones.

\subsection{ESTUDO I - LAUDO TÉCNICO (FELICIO, 1991)}

Levantamento das Condições Ambientais (Nível de Pressão Sonora - "Ruído") e estudos sobre o perfil acústico relacionados às atividades de telefonistas e outras categorias que permanentemente utilizam de telefones nos diversos locais das instalações de salas de PABX da CESP - Companhia Energética de São Paulo.

O referido trabalho foi solicitado à Telecomunicações de São Paulo S.A. - Telesp, em março de 1990 e entregue à CESP, datado e assinado, em 30 de abril de 1991. 


\subsubsection{Objetivos}

Um dos objetivos foi subsidiar conversações sindicais sobre o pedido de Adicional de Insalubridade (Ofício 019/90, de 22/01/1990 do Sindicato dos Trabalhadores nas Indústrias da Energia Elétrica de São Paulo), reivindicado por telefonistas, operadores de telex e radioperadores da CESP.

Outro objetivo foi cumprir exigências da Norma Regulamentadora NR 9, item 9.4, alínea $a$, realizando o empregador controle periódico dos riscos ambientais constantes da Norma Regulamentadora NR 15 - ATIVIDADES E OPERAÇÕES INSALUBRES, aprovada pela Portaria $\mathrm{n} \cong$ 3.214, de 8 de junho de 1978, do Ministério do Trabalho, da Lei 6.514 de 22 de dezembro de 1977.

Esse estudo teve por finalidade estudar o "Perfil Acústico" e avaliar os Níveis de Pressão Sonora - Ruído comparativamente aos limites de tolerância previstos na NR 15, nos Anexos no 1 e no 2, respectivamente, Limites de Tolerância para Ruído Contínuo ou Intermitente e Limites de Tolerância para Ruídos de Impacto.

\subsubsection{Considerações}

O trabalho foi realizado pelo Engo Jair Felicio, na época, empregado da Divisão de Segurança e Medicina do Trabalho da Telesp, que, por ocasião dos levantamentos, contou com a colaboração da Divisão de Desenvolvimento - Seção de Laboratório da Telesp.

Foram realizados 50 (cinqüenta) levantamentos/medições durante os diversos horários da jornada normal de trabalho, em todos os 8 (oito) locais onde havia instalações e atividades das categorias apontadas pela CESP que utilizavam aparelhos telefônicos, compreendendo 20 (vinte) posições e 20 (vinte) operadoras. Os trabalhos em campo foram feitos entre os meses de julho e agosto de 1990. 


\subsubsection{Avaliação}

A avaliação contou com várias etapas:

i) Reconhecimento: Foram feitos reconhecimentos por meio de visitas preliminares, durante as quais se observou principalmente 0 posto de trabalho, a posição, o ciclo de trabalho, os equipamentos de trabalho, a marca, o tipo e o modelo e a quantidade de mesas telefônicas;

ii) Avaliação: Em face das características peculiares das atividades levantadas na etapa de Reconhecimento e da finalidade do trabalho, o estudo sobre a caracterização da exposição foi feito de maneira individual, ou seja, os dados foram coletados de forma a se poder definir situações de exposição de cada um dos operadores de cada local e instalação;

iii) Quanto ao tráfego telefônico: A fim de considerar os diversos fatores sazonais que pudessem alterar o resultado e o perfil das avaliações, foi levantada, em cada posição e local, a quantidade de ligações telefônicas pelo período de uma semana, comparando-se com a quantidade do dia da avaliação;

iv) Ruído de Fundo: Igualmente importante foi a verificação do nível de ruído de fundo, para se saber da contribuição da exposição ao ruído de fundo do ambiente.

\subsubsection{Critérios}

Diferença de Critérios: o estudo considerou os critérios legal e técnico. Assim, tevese que recorrer a outras normas em complementação às Normas Regulamentadoras (NR), já que, no caso em especial, elas, à época e ainda hoje, especificam uma METODOLOGIA para Avaliação nos Ambientes de Trabalho em campo livre, e não em telefones e fones. 
Assim, nesse estudo, para atender o objetivo de realizar as medições nos aparelhos telefônicos e fones, utilizou-se uma metodologia de medição indireta, composta de um conjunto de cabeça, boca e ouvido artificial, em concordância com as recomendações das assembléias plenárias do Comitê Consultivo Internacional de Telegrafia e Telefonia (CCITT), cuja sede fica em Genebra, na Suíça, que atualmente são as recomendações da União Internacional de Telecomunicações ITU.

\subsubsection{Metodologia do trabalho de campo}

Quanto ao posicionamento e montagem no caso da avaliação em questão, não foi possível introduzir o microfone do instrumento de medição de ruído no ouvido do operador em função do uso dos telefones e fones.

Assim, teve-se que instalar e utilizar em paralelo (extensão), aparelhos telefônicos idênticos usados em cada tipo/modelo de mesa telefônica de cada posição e local analisado. As próprias mesas já possuem tomada jack adicional específica para essa conexão paralela (extensão).

Ocorre que, com o acréscimo de mais um aparelho, o fone, introduz-se uma resistência (impedância) adicional ao circuito, provocando uma queda no nível do sinal, atenuando assim o nível acústico.

Para contornar esse problema, foi necessário determinar, para cada tipo/modelo de aparelho telefônico utilizado, um fator de correção, de forma a obter assim os níveis reais de exposição para a situação específica analisada. Para tanto, teve-se que recorrer à utilização do Sistema para Medição Eletroacústica de Transmissão Telefônica Tipo 3352 da BRÜEL \& $\mathrm{KJAER}^{\circledR}$, um dos mais renomados fabricantes mundiais de instrumentos de medição de ruído e vibração, composto de vários equipamentos dispostos em racks, instalados no Laboratório de Ensaios da Telesp (Figura 1). 


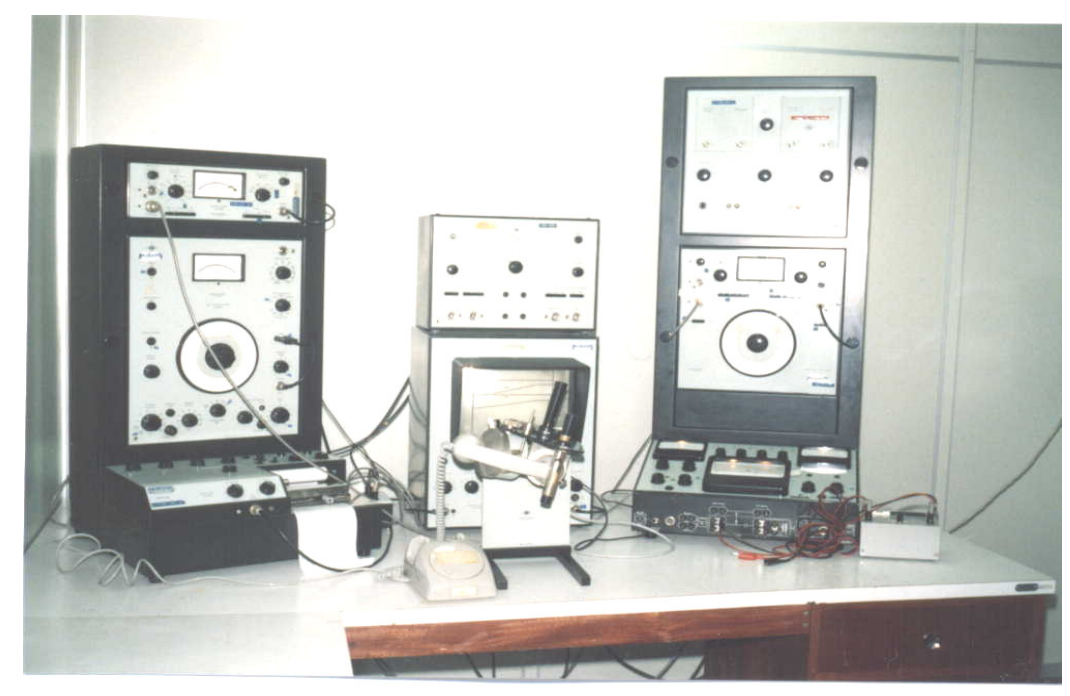

Figura 1 - Vista geral do conjunto gerador do sinal padrão, com o acoplamento via ligação telefônica, do laboratório Telesp à Cesp, 1990. Fonte: Felicio, J. Laudo Técnico da Telesp para a Cesp, 1991.

Acesso Restrito

Este sistema, à época, era uma aparelhagem de última geração, de alta confiabilidade, com características físicas bem definidas, que produzia um resultado tido como padrão.

No caso específico, basicamente, o sistema teve como função gerar um nível objetivo SPL (Sound Pressure Level) de $94 \mathrm{~dB}$ correspondente exatamente a pressão sonora de 1 Pascal (sinal padrão normalizado), que simula a conversação em tom normal de um ser humano a $4 \mathrm{~cm}$ do microfone da cápsula transmissora do aparelho telefônico, com um sinal de varredura constante de uma vez por segundo na freqüência 200-3400-200 Hz, que está na faixa de transmissão telefônica convencional.

O sinal padrão gerado foi então conectado ao microfone, cápsula transmissora, e este, por sua vez, encaixado adequadamente, por meio de acopladores e discos de encosto normalizados, ao dispositivo denominado boca artificial, que guarda as mesmas características da boca humana. Foi então transmitido, pelo estabelecimento de uma ligação telefônica real, com todas as suas características, desde o Laboratório de Eletroacústica da Telesp até as mesas telefônicas dos diversos locais analisados. A Figura 2 permite melhor identificação da boca artificial. 


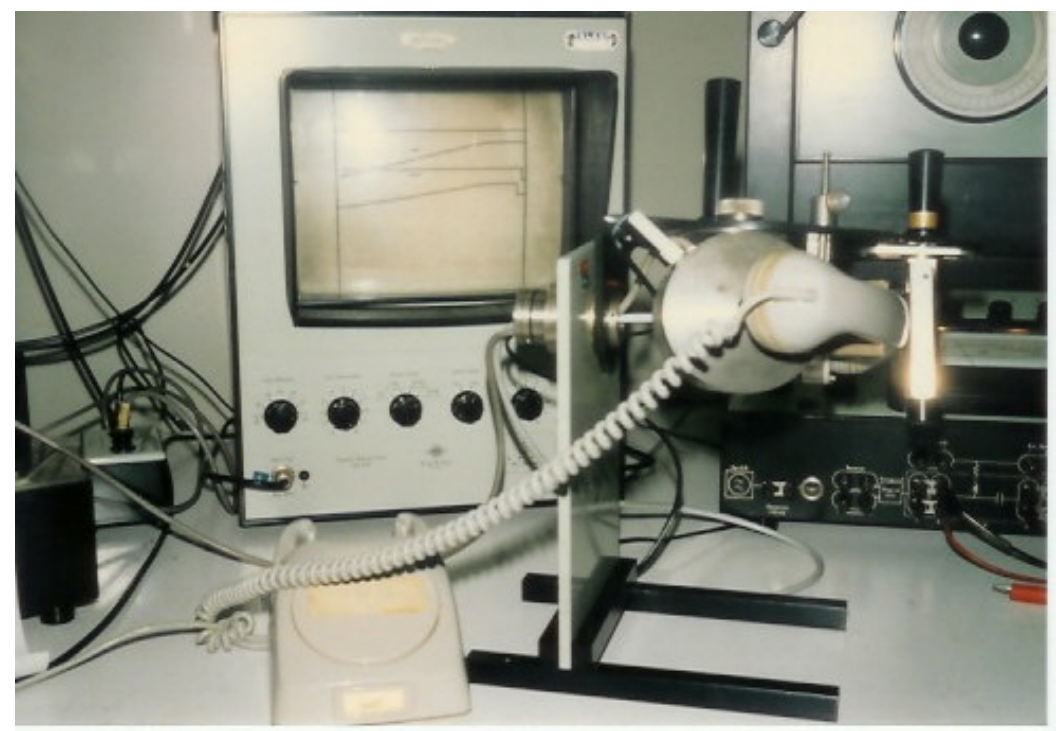

Figura 2 - Em detalhe, conjunto montado na cabeça artificial, com a cápsula transmissora do telefone acoplada junto à boca artificial, para transmitir o sinal padrão via ligação telefônica, 1990.

Fonte: Felicio, J. Laudo Técnico da Telesp para a Cesp, 1991.

Acesso Restrito

A Figura 3 mostra um exemplo de como eram feitos em laboratório os testes de conformidade e aceitação de cápsulas telefônicas receptoras quanto às características padronizadas e normalizadas internacionalmente pelo então Comitê Consultivo Internacional de Telegrafia e Telefonia - CCITT, utilizando-se, neste caso, o ouvido artificial.

Tanto a boca artificial quanto o ouvido artificial são fixados a um dispositivo denominado cabeça artificial, utilizado para o perfeito encaixe dos outros dois dispositivos aos aparelhos telefônicos, acopladores e discos de encosto normalizados para cada tipo de geometria dos aparelhos telefônicos. 


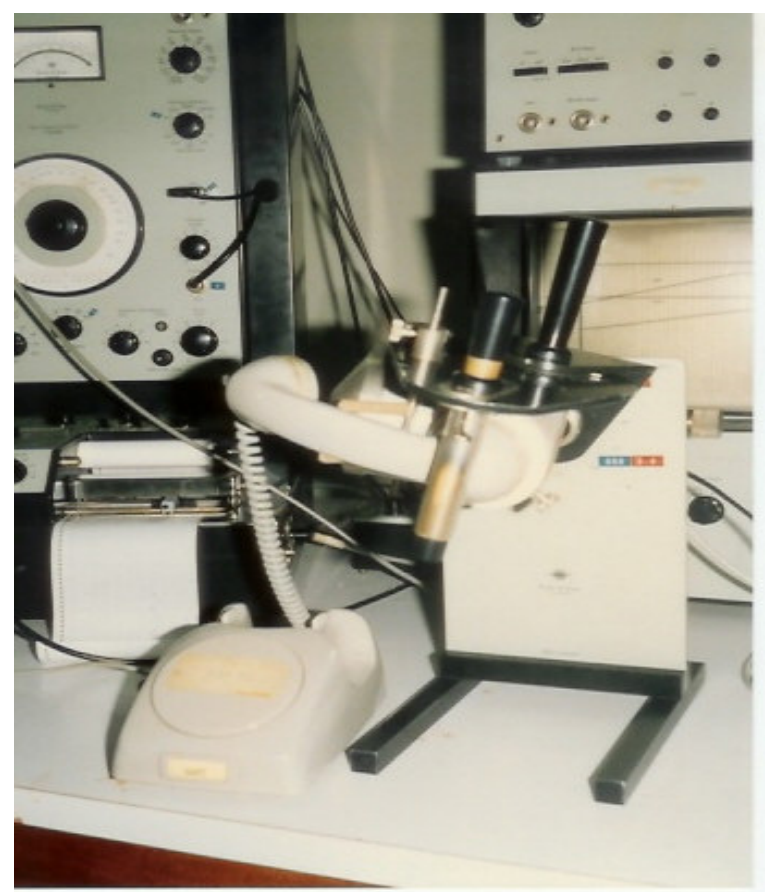

Figura 3 - Em detalhe, conjunto montado na cabeça artificial, com a cápsula receptora do telefone acoplada ao ouvido artificial, 1990. Fonte: Felicio, J. Laudo Técnico da Telesp para a Cesp, 1991.

Acesso Restrito

A Figura 4 mostra os acopladores e discos de encosto/encaixe normalizados

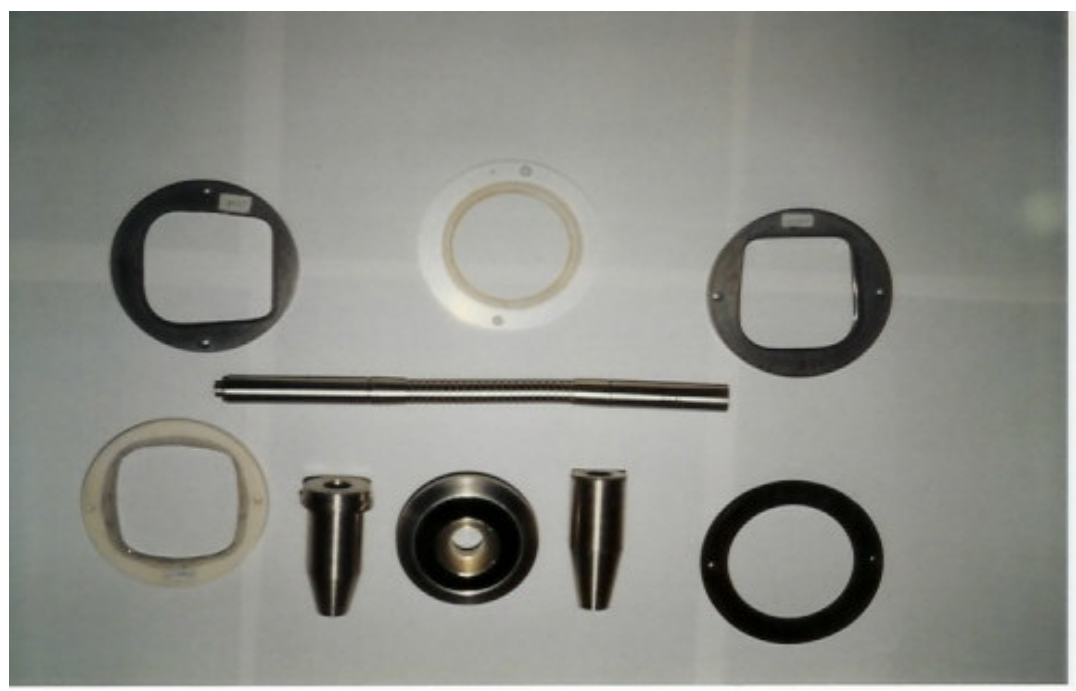

Figura 4 - Acopladores e discos de encosto normalizados, utilizados em função dos diversos tipos/modelos e geometria de aparelhos telefônicos, 1990.

Fonte: Felicio, J. Laudo Técnico da Telesp para a Cesp, 1991. Acesso Restrito 
Em campo, do lado da recepção, os aparelhos telefônicos foram fixados pelo lado da sua cápsula receptora ao dispositivo denominado ouvido artificial, que guarda as mesmas características do ouvido humano, por meio de acopladores e discos de encosto normalizados pelo então CCITT - Comitê Consultivo Internacional de Telegrafia e Telefonia, desenvolvidos em função das características do ouvido e do tipo/modelo e geometria dos fones. No outro lado do ouvido artificial foi instalado o microfone com o Medidor Integrado de Nível Sonoro.

Para melhor identificação, Figura 5.

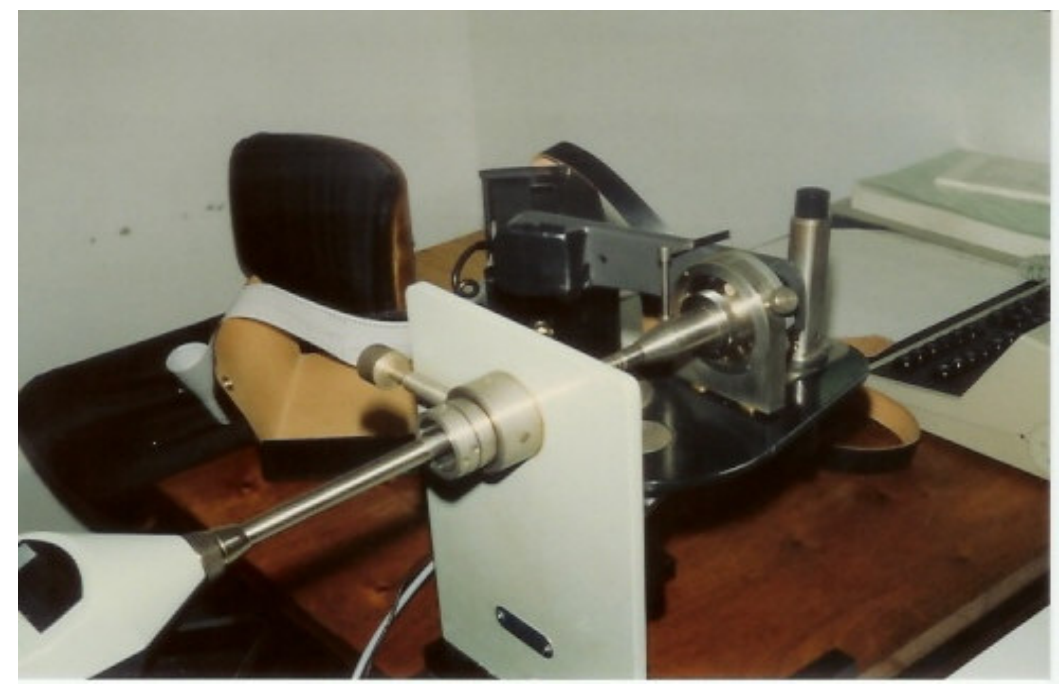

Figura 5 - Em detalhe, conjunto montado na cabeça artificial, com a cápsula receptora do telefone acoplada ao ouvido artificial, para receber o sinal padrão via ligação telefônica, 1990.

Fonte: Felicio, J. Laudo Técnico da Telesp para a Cesp, 1991.

Acesso Restrito

Assim, um a um, foram medidos os aparelhos telefônicos quanto ao Nível do Sinal Padrão na Recepção. Os mesmos fones foram então colocados em paralelo $(1+1)$, medindo-se novamente o Nível do Sinal Padrão na Recepção de cada um deles.

Com esses dados, determinou-se o valor do fator de correção para cada aparelho telefônico, já que esse valor corresponde às características próprias de ganho/atenuação de cada cápsula telefônica, que provocou uma diferença dos Níveis Acústicos expressos em dB $(A)$ e dB (L), sendo essa diferença praticamente 
constante para cada circuito, dentro da faixa de freqüência de transmissão telefônica definida para o canal de voz, entre $300 \mathrm{~Hz}$ e $3.400 \mathrm{~Hz}$.

Para ilustração e melhor identificação dos equipamentos e instrumentos utilizados em campo, de sua montagem e dos locais analisados, são apresentadas as figuras correspondentes (Figuras 6, 7 e 8).

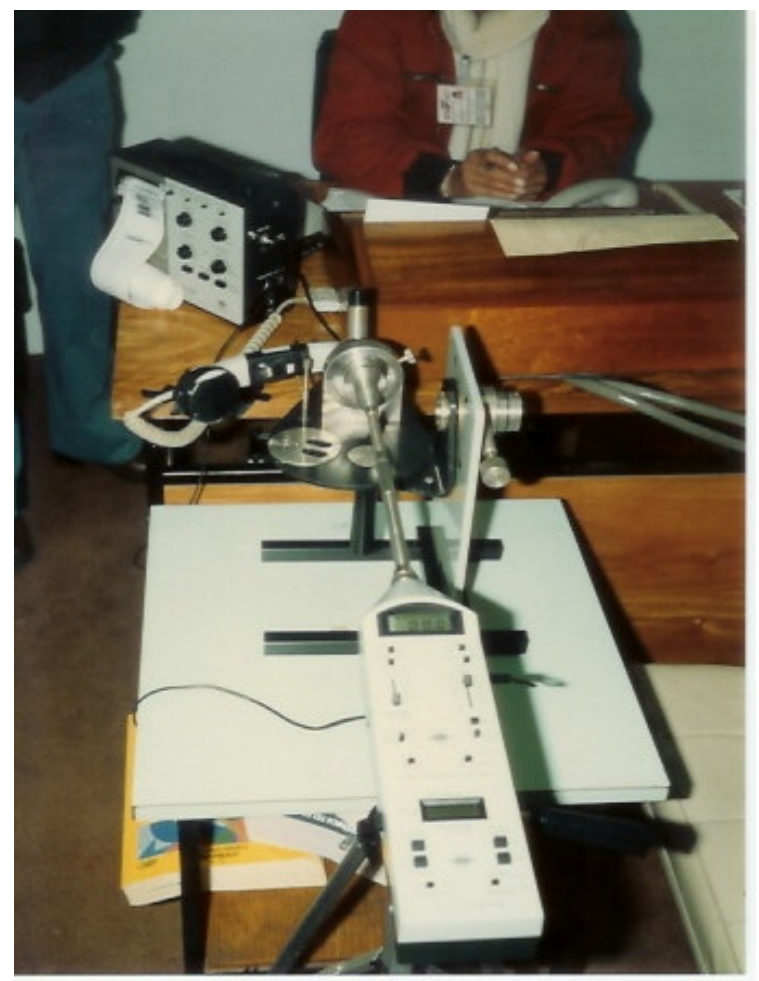

Figura 6 - Vista principal do conjunto de equipamentos utilizados nas avaliações em campo, 1990.

Fonte: Felicio, J. Laudo Técnico da Telesp para a Cesp, 1991.

Acesso Restrito 


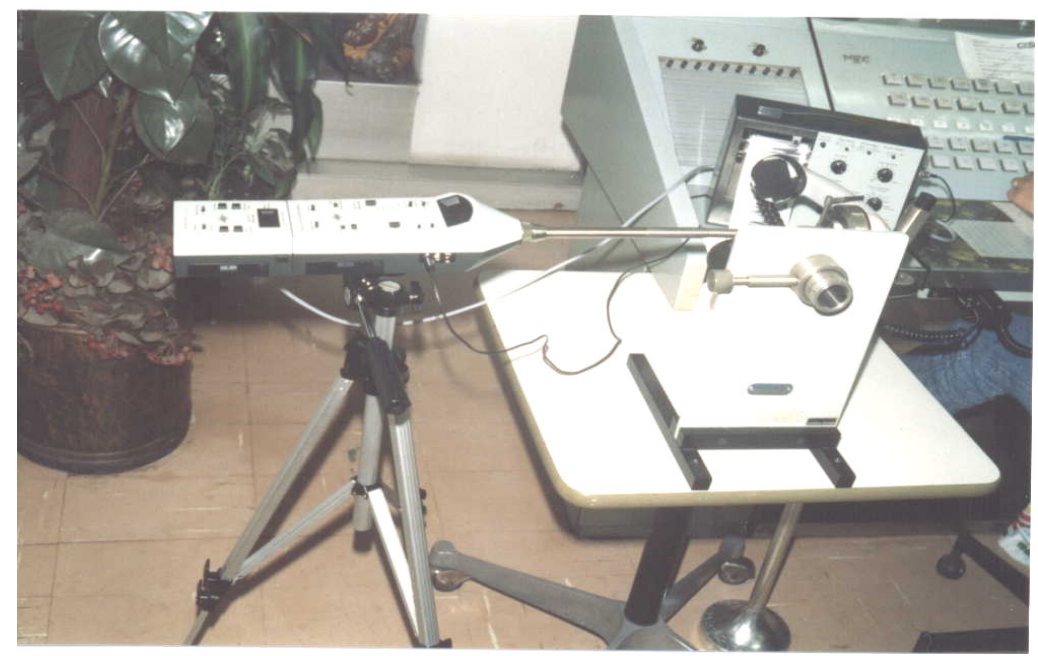

Figura 7 - Vista geral - em outro ângulo - da montagem dos equipamentos e instrumentação de medição utilizada em campo, 1990.

Fonte: Felicio, J. Laudo Técnico da Telesp para a Cesp, 1991. Acesso Restrito

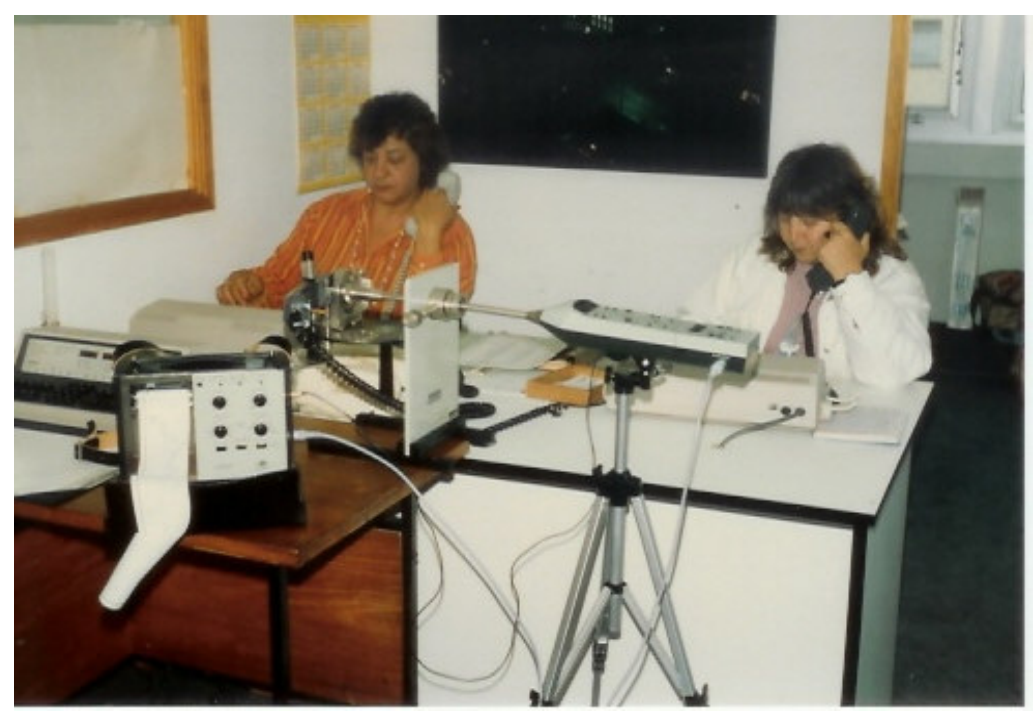

Figura 8 - Vista geral de uma das salas de PABX e da montagem dos equipamentos e instrumentação de medição utilizada em campo, 1990.

Fonte: Felicio, J. Laudo Técnico da Telesp para a Cesp, 1991. Acesso Restrito 


\subsubsection{Aparelhagem}

Em laboratório, foi utilizado o sistema para Medição Eletroacústica de Transmissão Telefônica Tipo 3352, composto de:

- Oscilador de batimento em freqüência Tipo $1022 \mathrm{E}$;

- Amplificador de medição Tipo 2608;

- Pré-amplificador Tipo 2619 para microfones capacitivos de 1/2" e 1";

- Medidor de referência equivalente Tipo 4904 (94 dB SPL);

- Cabeça artificial para teste de telefone Tipo 4905;

- Fonte de energia do telefone tipo simulador de central telefônica;

- Registrador gráfico de nível Tipo 2305 A;

- Traçador de resposta em freqüência Tipo 4712;

- Espectrômetro de audiofreqüência Tipo 2113 A;

- Microfone capacitivo de 1" Tipo 4144;

- Microfone capacitivo de 1/2 " Tipo 4134;

- Boca artificial Tipo 4219;

- Ouvido artificial Tipo 4152;

- Filtro heterodino Tipo 2020;

- Acopladores para BOCA E OUVIDO ARTIFICIAL, com seus respectivos adaptadores, COLAR E DISCOS DE ENCOSTO.

Para melhor visualização, Figuras 1, 2, 3 e 4.

Em campo, foram utilizados:

- Medidor de precisão integrado de nível sonoro Tipo 2230; 
- Filtro de bandas de terço e oitava Tipo 1625;

- Registrador gráfico de nível Tipo 2317;

- Calibrador de nível sonoro Tipo 4230;

- Cabeça artificial para teste de telefone Tipo 4904;

- Ouvido artificial Tipo 4152;

- Acopladores para OUVIDO ARTIFICIAL com seus respectivos adaptadores, COLAR e DISCOS DE ENCOSTO;

- Tripé.

Para melhor visualização, Figuras 4, 5, 6, 7 e 8.

Toda essa aparelhagem, acessórios e componentes são da marca BRÜEL \& $\mathrm{KJAER}^{\circledR}$, de procedência dinamarquesa, e foram devidamente operados, calibrados e aferidos previamente à série de amostragens, conforme especificações do fabricante.

O objetivo de incluir essas fotografias foi dar uma visão geral dos instrumentos e acessórios utilizados à época, mostrando suas características básicas, disposição e montagem.

\subsubsection{Análise}

O medidor utilizado em campo possibilitou realizar quatro medições simultaneamente:

- SPL: SOUND PRESSURE LEVEL - Nível de Pressão Sonora - valor instantâneo;

- MIN: Mínimo valor de SPL que ocorreu desde que o medidor foi acionado ou ressetado; 
- MAX: Máximo valor de SPL que ocorreu desde que o medidor foi acionado ou ressetado;

- Leq: é o nível médio equivalente de pressão sonora sobre o período da medição.

Tendo em vista, a intermitência de exposição dos operadores a diferentes níveis sonoros, a análise considerou os seus efeitos combinados, determinando-se assim a dose equivalente de ruído, obtida por meio dos resultados dos Níveis Equivalentes de Ruído - Leq.

Foram também realizadas as medições de Ruído de Impacto, com o instrumento operando no detector RMS, no circuito LINEAR e no circuito de resposta IMPULSE. Adicionalmente foram feitas medições de Ruído de Impacto, medindo-se o VALOR DE PICO com o instrumento operando no detector PEAK, no circuito LINEAR, atendendo-se assim os critérios da ACGIH - American Conference of Governmental Industrial Hygienists, à época.

O detetor RMS (Root Mean Square) é um tipo especial de valor médio matemático valor eficaz. É de grande importância em medições de som, porque o valor eficaz é diretamente relacionado à quantidade de energia no sinal sonoro.

O detetor PEAK é um recurso para determinação do valor de pico de sinais impulsivos.

Todas as medições foram feitas em cada operador, durante um ciclo completo de trabalho, e, sempre que necessário, durante toda a jornada de trabalho. Foram realizadas também análises dos registros gráficos.

\subsubsection{Resultados}

Os valores encontrados de níveis equivalentes de ruído (Leq) nos aparelhos telefônicos para ruído contínuo ou intermitente estão situados em geral (para todas 
as 8 (oito) localidades/instalações analisadas), numa faixa que variou de $77 \mathrm{~dB}(\mathrm{~A}) \mathrm{a}$ $86 \mathrm{~dB}(\mathrm{~A})$ para jornadas integrais de 6 horas de trabalho. Nesses valores, já estão computados o fator de correção para compensar a queda no nível do sinal, devido ao acréscimo de mais um aparelho telefônico em paralelo.

\subsubsection{Comentários}

Este estudo, inédito até então, teve o mérito de conseguir demonstrar que, mesmo a legislação não prevendo critérios e metodologias para a avaliação (no caso, dos Níveis Sonoros em Aparelhos Telefônicos), sempre é possível estudar, desenvolver e obter um critério técnico que se aplica ao assunto.

Ressalte-se, por oportuno, que esse conjunto de equipamentos do laboratório destina-se a atender às recomendações da CCITT - Comitê Consultivo Internacional de Telegrafia e Telefonia, cuja metodologia e todo o sistema de medição originalmente eram especificados para avaliação da qualidade das partes, do sistema de telecomunicações e de sua conformidade, não tendo, à época, nenhuma referência quanto à indicação de utilização para a avaliação do nível de ruído em fones do ponto de vista de Higiene Ocupacional.

\subsection{ESTUDO II - MEDIÇÕES EM FONES TIPO TELEFONISTA HEADSET (FELICIO, 1990/91)}

A metodologia aplicada é a mesma da apresentada no trabalho anterior - Estudo I, só que agora em atividades com telefones de telefonistas - headsets na Sala de Tráfego Telefônico - Serviços: 101 (Auxílio Interurbano), 102 (Informações - Auxílio à lista), 121 (Informações/Auxílio à Lista - chamadas de outros estados), 107 (Auxílio Interurbano - Telefone Público). 
O estudo foi realizado no seguinte endereço: Rua 7 de Abril, 309 - Centro - São Paulo - SP.

Também aqui, o Sinal Padrão do Laboratório foi enviado por uma ligação telefônica até as mesas das telefonistas.

Para melhor visualização, Figuras 9 e 10.

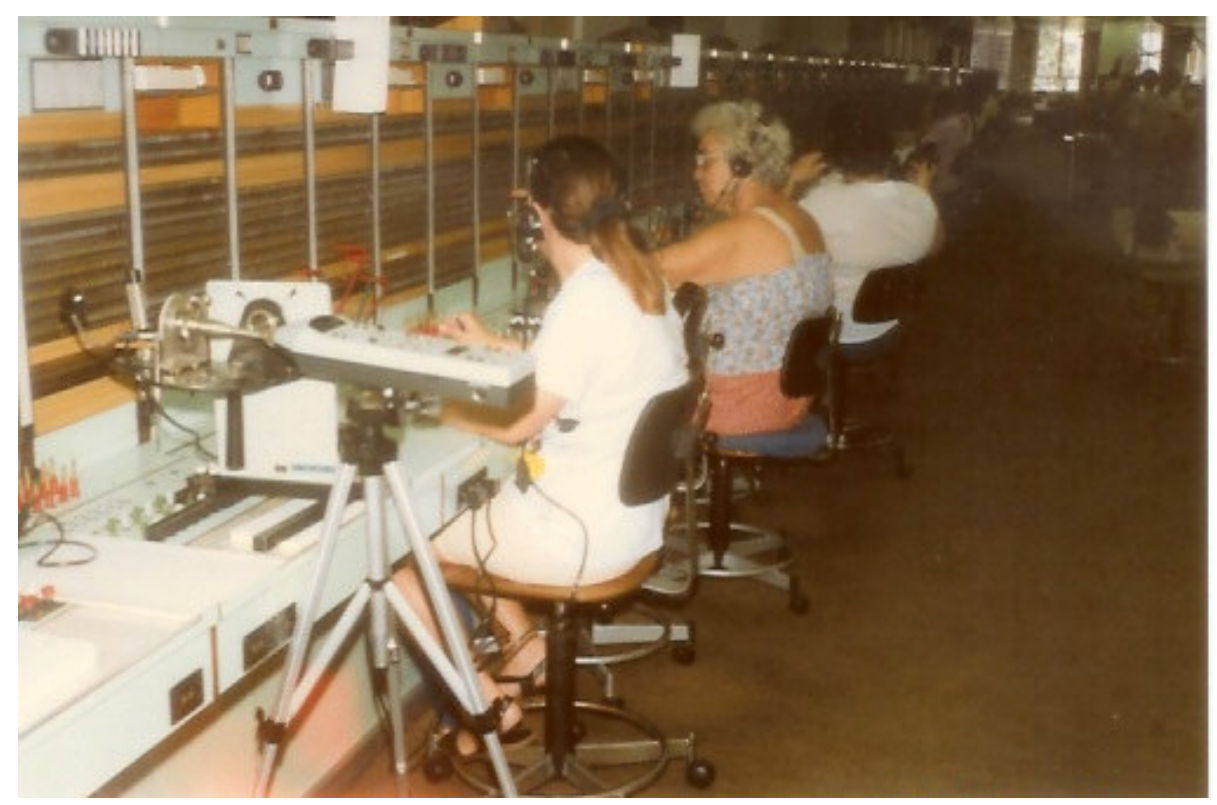

Figura 9 - Posição das telefonistas na antiga sala de tráfego telefônico da rua sete de abril - São Paulo/SP, e a montagem dos equipamentos e instrumentação de medição utilizada em campo (dez. 1990).

Fonte: Felicio, J. Laudos/Relatórios Técnicos da Telesp,1990/91.

Acesso Restrito. 


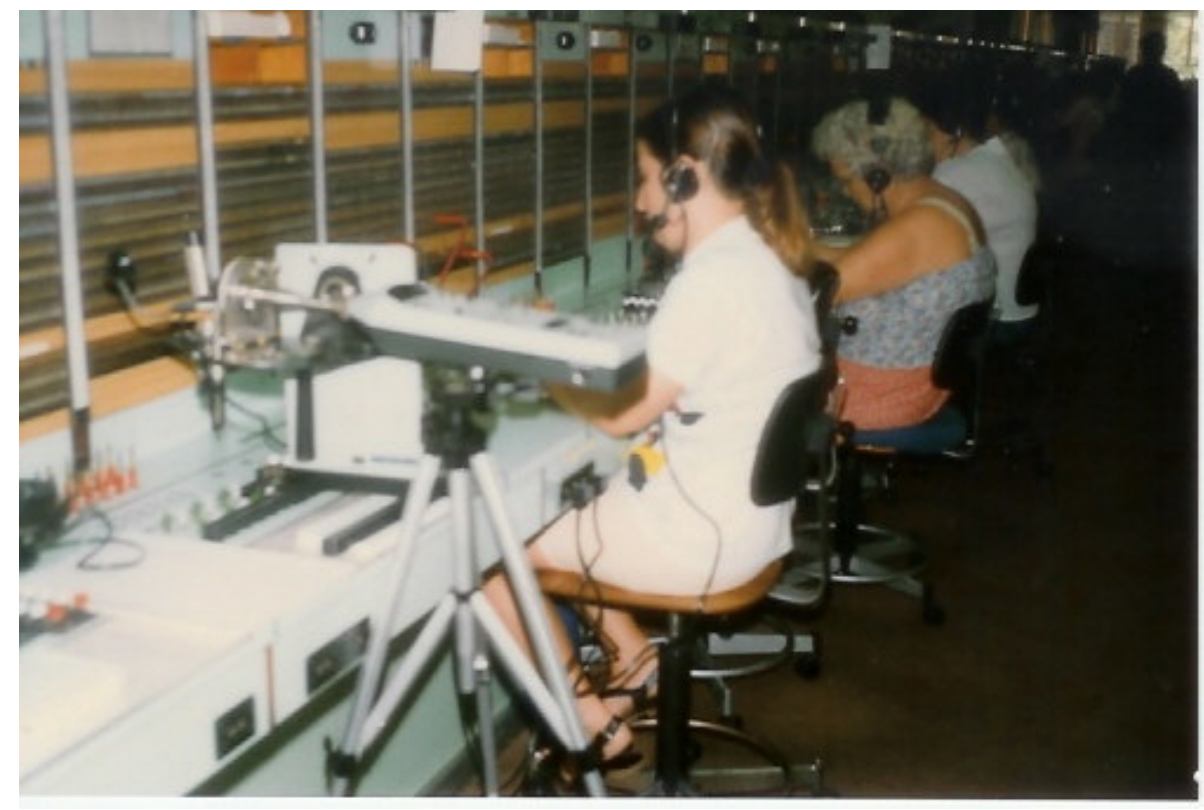

Figura 10 - Atentar para o tipo de fones headsets utilizados à época e observar a proximidade entre as telefonistas. Este salão era dividido em duas alas, com um total de 600 posições (dez. 1990)

Fonte: Felicio, J. Laudos/Relatórios Técnicos da Telesp, 1990/91.

Acesso Restrito

Em primeiro lugar, foram feitas medições e testes de curta duração, com o Sinal Padrão do Laboratório para comparação dos resultados, com o instrumento de medição sendo operado nos circuitos de resposta Lenta (SLOW) e Rápida (FAST) e com dois fones em paralelo (um fone na telefonista e outro fone no ouvido artificial) para determinar a Atenuação do Sinal.

Os dois fones são idênticos, testados previamente no laboratório quanto às suas características operacionais e parâmetros de qualidade e conformidade, tais como de ganho e atenuação das cápsulas transmissoras e receptoras.

É importante observar que o instrumento de medição ficou acoplado ao ouvido artificial. 


\subsubsection{Alguns testes, avaliações e resultados}

i) $\underline{\underline{\underline{a}} \text { Avaliação }}$

Dados referentes à 1 a avaliação:

- Data: $18 / 12 / 1990$

- Mesa $n$ 우 308

- Aparelho telefônico tipo headset - Modelo AW52 fixo (sem ajuste de volume)

- Telefonista: Eliane

Tabela 3 - Avaliação Sinal Padrão com apenas um fone acoplado ao ouvido artificial - amostragem em dB (A)

\begin{tabular}{cccccc}
\hline \multicolumn{3}{c}{ Curta duração $>$ 5minutos } & \multicolumn{3}{c}{ Curta duração $>2$ minutos } \\
Modo & FAST & SLOW & Modo & FAST & SLOW \\
\hline Min. & 64,5 & 84,7 & Min. & 78,3 & 83,4 \\
Max. & 101,0 & 89,4 & Max. & 90,4 & 88,5 \\
Leq & 89,5 & 89,5 & Leq & 88,1 & 86,6 \\
\hline
\end{tabular}

Fonte: Felicio, J. Laudos/Relatórios Técnicos da Telesp, 1990/91. Acesso Restrito

Tabela 4 - Avaliação Sinal Padrão com os dois fones - amostragem em dB (A)

\begin{tabular}{cccccc}
\hline \multicolumn{2}{c}{ Curta duração $>5$} & minutos & \multicolumn{3}{c}{ Curta duração $>2$ minutos } \\
Modo & FAST & SLOW & Modo & FAST & SLOW \\
\hline Min. & 72,1 & 77,1 & Min. & 71,0 & 76,0 \\
Max. & 97,3 & 84,1 & Max. & 85,2 & 83,4 \\
Leq & 82,9 & 82,9 & Leq & 78,4 & 81,2 \\
\hline
\end{tabular}

Fonte: Felicio, J. Laudos/Relatórios Técnicos da Telesp, 1990/91. Acesso Restrito

Tabela 5 - Resultado do Nível Sonoro - Atividade de Telefonista - amostragem em dB (A)

\begin{tabular}{cc}
\hline & Jornada integral de 6 horas \\
Modo & $\mathrm{dB}(\mathrm{A})$ \\
\hline Max. & 105,0 \\
Leq & 83,1 \\
\hline
\end{tabular}

Fonte: Felicio, J. Laudos/Relatórios Técnicos da Telesp, 1990/91.

Acesso Restrito 
Observa-se que, durante a avaliação constante na Tabela 5, foram registrados os números de chamadas constantes na Tabela 6.

Tabela 6 - Números de chamadas no período

\begin{tabular}{lc}
\hline \multicolumn{1}{c}{ Período das chamadas } & № de chamadas no período \\
\hline Das 10h às 11h & 25 \\
Das 11h às 12h & 52 \\
Das 12h às 13h & 34 \\
Das 13h às 14h & 40 \\
Das 14h às 15h & 40 \\
Das 15h às 16h & 43 \\
Total: 6 horas & 234 \\
\hline Fonte: Felicio, J. Laudos/Relatórios Técnicos da Telesp, 1990/91. Acesso Restrito
\end{tabular}

Comentários e discussão sobre a 1ํa avaliação:

- Em relação às Tabelas 3 e 4, quanto à resposta do medidor, rápido (FAST) ou lento (SLOW), o manual do instrumento utilizado nas medições em campo, o Tipo 2230 da Brüel \& Kjaer®, indica que, ao se medir o Leq, este deve estar operando no circuito de resposta FAST, caso contrário, aparece no visor um símbolo indicativo de erro operacional. Por isso, como se tinha à mão a disponibilidade de utilizar o sinal padrão normalizado, foi feita a comparação, que apresentou, num primeiro momento, uma diferença de sensibilidade significativa de 3 a $4 \mathrm{~dB}$, conforme medida em SLOW ou FAST (modo para amostragem de curta duração, para um tempo superior a 2 min. e igual ou inferior a 5 min.), sendo maior na FAST, demonstrando que, provavelmente, na resposta em FAST, se incorpore mais apropriadamente os picos e valores máximos em períodos mais curtos. Entretanto, para um período de amostragem superior a 5 min., há uma estabilidade nos resultados, notadamente dos valores de Leq, talvez, devido ao maior tempo de integração de resposta do medidor, desaparecendo, assim, as diferenças apontadas entre SLOW e FAST. Essa verificação precisava ser feita a priori, para determinar o fator de correção correspondente à real atenuação do sinal, em virtude do acréscimo de mais um fone em paralelo.

- Em relação à Tabela 5 , os resultados obtidos de $\mathrm{Leq}=83,1 \mathrm{~dB}(\mathrm{~A})$, foram compatíveis a este tipo de aparelho telefônico e coerentes com os levantamentos anteriores, realizados nas mesmas instalações. 
ii) $\underline{\underline{\underline{\underline{a}}} \text { Avaliação }}$

Dados referentes à $2 \underline{\underline{\underline{a}}}$ avaliação:

- Data:19/12/1990

- Mesa ㄲo 415

- Aparelho telefônico tipo telefonista headset - Modelo AW52 ( $\underline{\mathrm{com}}$ ajuste de volume)

- Telefonista: Eunice

Tabela 7 - Avaliação Sinal Padrão com apenas um fone acoplado ao ouvido artificial - amostragem em dB (A)

\begin{tabular}{cccccc}
\hline \multicolumn{2}{c}{ Curta duração $>5$ minutos } & \multicolumn{3}{c}{ Curta duração $>2$ minutos } \\
Modo & FAST & SLOW & Modo & FAST & SLOW \\
\hline Min. & 86,2 & 91,9 & Min. & 79,4 & 79,4 \\
Max. & 94,4 & 93,1 & Max. & 95,8 & 95,8 \\
Leq & 92,5 & 92,5 & Leq & 91,4 & 91,3 \\
\hline
\end{tabular}

Fonte: Felicio, J. Laudos/Relatórios Técnicos da Telesp, 1990/91. Acesso Restrito

Tabela 8 - Avaliação Sinal Padrão com os dois fones - amostragem em dB (A)

\begin{tabular}{cccccc}
\hline \multicolumn{2}{c}{ Curta duração $>$} & 5 minutos & \multicolumn{3}{c}{ Curta duração $>2$ minutos } \\
Modo & FAST & SLOW & Modo & FAST & SLOW \\
\hline Min. & 58,7 & 89,2 & Min. & 78,8 & 78,8 \\
Max. & 91,6 & 90,3 & Max. & 116,0 & 87,6 \\
Leq & 89,6 & 89,8 & Leq & 93,4 & 85,3 \\
\hline
\end{tabular}

Fonte: Felicio, J. Laudos/Relatórios Técnicos da Telesp, 1990/91. Acesso Restrito

Tabela 9 - Resultado da Avaliação da Atividade - Amostragem da jornada integral de 6 horas com os dois fones - amostragem em dB (A)

\begin{tabular}{cc}
\hline \multicolumn{2}{c}{ Jornada integral de 6 horas } \\
Modo & $\mathrm{dB}(\mathrm{A})$ \\
\hline Max. & 109,4 \\
Leq & 88,9 \\
\hline
\end{tabular}

Fonte: Felicio, J. Laudos/Relatórios Técnicos da Telesp, 1990/91.

Acesso Restrito

Observa-se que, nesta avaliação, a telefonista ficou à vontade para ajustar, a seu critério e necessidade, o volume de recepção de seu fone. Durante a avaliação 
constante na Tabela 9, foram registrados os números de chamadas constantes na Tabela 10.

Tabela 10 - Números de chamadas no período

\begin{tabular}{lc}
\hline \multicolumn{1}{c}{ Período das chamadas } & № de chamadas no período \\
Das 10h às 11h & 52 \\
\hline Das 11h às 12h & 25 \\
Das 12h às 13h & 24 \\
Das 13h às 14h & 42 \\
Das 14h às 15h & 27 \\
Das 15h às 16h & 30 \\
Total: 6 horas & 200 \\
\hline Fonte: Felicio, J. Laudos/Relatórios Técnicos da Telesp, 1990/91. Acesso Restrito
\end{tabular}

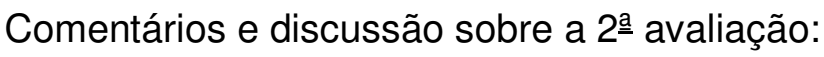

- Em relação à Tabela 9 , os resultados obtidos de $\mathrm{Leq}=88,9 \mathrm{~dB}(\mathrm{~A})$ foram significativamente mais elevados do que em outras situações, como aqueles da Tabela 5 , em que obteve $\mathrm{Leq}=83,1 \mathrm{~dB}(\mathrm{~A})$. Isto se deveu à utilização de um dispositivo amplificador com ajuste de volume conectado aos headsets, permitindo ao usuário regulá-los à sua vontade.

iii) $\underline{3 \underline{\underline{a}} \text { Avaliação }}$

Em face dos resultados encontrados nas duas avaliações anteriores, resolveu-se realizar testes adicionais específicos no laboratório para avaliar o dispositivo de ajuste do volume dos fones headsets, utilizando o Sistema para Medição Eletroacústica de Transmissão Telefônica Tipo 3352 da BRÜEL \& KJAER ${ }^{\circledR}$, gerando um Sinal Padrão de 94 dB (LINEAR), instalado no Laboratório de Ensaios da Telesp.

Para melhor identificação, Figuras 1, 2 e 3.

Dados referentes à $3 \underline{\underline{a}}$ avaliação:

- Data: 05/04/1991 
- Aparelhos telefônicos tipo telefonista headsets - Modelo AW52, com dispositivo para ajuste do volume amplificador de sinais marca Plantronics.

Tabela 11 - Avaliação com Sinal Padrão - referência 0 km* - ajuste de volume do headset no mínimo (sem amplificação) - Amostragem em dB (A) e em dB (LINEAR)

\begin{tabular}{cccccc}
\hline \multicolumn{2}{c}{ Com apenas um fone acoplado } & \multicolumn{3}{c}{ Com os dois fones } \\
Modo & $\mathrm{dB}(\mathrm{A})$ & LINEAR & Modo & $\mathrm{dB}(\mathrm{A})$ & LINEAR \\
\hline Min. & 76,3 & 76,9 & Min. & 71,4 & 72,1 \\
Max. & 84,1 & 87,6 & Max. & 80,8 & 82,9 \\
Leq & 81,6 & 82,3 & Leq & 76,3 & 77,3 \\
\hline
\end{tabular}

* Referência 0 km: é uma simulação feita com o "padrão normalizado do sistema", equivalente a uma ligação de assinante $A$ para assinante $B$, no mesmo local.

Fonte: Felicio, J. Laudos/Relatórios Técnicos da Telesp, 1990/91. Acesso Restrito

Tabela 12 - Avaliação com Sinal Padrão - referência 0 km - ajuste de volume do headset no máximo

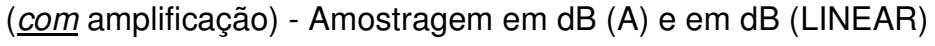

\begin{tabular}{ccccrc}
\hline \multicolumn{2}{c}{ Com apenas um fone acoplado } & \multicolumn{3}{c}{ Com os dois fones } \\
Modo & $\mathrm{dB}(\mathrm{A})$ & LINEAR & Modo & $\mathrm{dB}(\mathrm{A})$ & LINEAR \\
\hline Min. & 99,2 & 100,6 & Min. & 96,3 & 97,7 \\
Max. & 108,7 & 108,3 & Max. & 106,1 & 105,7 \\
Leq & 106,2 & 106,0 & Leq & 103,5 & 103,3 \\
\hline
\end{tabular}

* Referência $0 \mathrm{~km}$ : é uma simulação feita com o "padrão normalizado do sistema", equivalente a uma ligação de assinante $A$ para assinante $B$, no mesmo local.

Fonte: Felicio, J. Laudos/Relatórios Técnicos da Telesp, 1990/91. Acesso Restrito

Tabela 13 - Avaliação com Sinal Padrão - referência $7 \mathrm{~km}$ - ajuste de volume do headset no mínimo

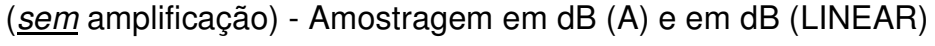

\begin{tabular}{cccccc}
\hline \multicolumn{2}{c}{ Com apenas um fone acoplado } & \multicolumn{3}{c}{ Com os dois fones } \\
Modo & dB $(\mathrm{A})$ & LINEAR & Modo & dB $(\mathrm{A})$ & LINEAR \\
\hline Min. & 62,0 & 64,8 & Min. & 57,2 & 61,8 \\
Max. & 72,2 & 75,4 & Max. & 71,9 & 72,1 \\
Leq & 68,9 & 71,4 & Leq & 64,1 & 68,2 \\
\hline
\end{tabular}

* Referência 7 km: é uma simulação feita com o "padrão normalizado do sistema", equivalente a uma ligação de assinante A para assinante $B$, a uma distância de $7 \mathrm{~km}$.

Fonte: Felicio, J. Laudos/Relatórios Técnicos da Telesp, 1990/91. Acesso Restrito 
Tabela 14 - Avaliação com Sinal Padrão - referência 7 km - ajuste de volume do headset no máximo

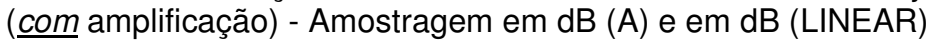

\begin{tabular}{cccccc}
\hline \multicolumn{2}{c}{ Com apenas um fone acoplado } & \multicolumn{3}{c}{ Com os dois fones } \\
Modo & dB $(\mathrm{A})$ & LINEAR & Modo & dB $(\mathrm{A})$ & LINEAR \\
\hline Min. & 89,2 & 90,3 & Min. & 79,7 & 85,9 \\
Max & 99,8 & 98,4 & Max & 95,3 & 94,8 \\
Leq & 96,8 & 95,7 & Leq & 90,1 & 91,8 \\
\hline
\end{tabular}

* Referência $7 \mathrm{~km}$ : é uma simulação feita com o "padrão normalizado do sistema", equivalente a uma ligação de assinante A para assinante $B$, a uma distância de $7 \mathrm{~km}$.

Fonte: Felicio, J. Laudos/Relatórios Técnicos da Telesp, 1990/91. Acesso Restrito

Comentários e discussão sobre a 3 르 avaliação:

- Os ensaios feitos no laboratório aplicando Sinal Padrão Normalizado de $94 \mathrm{~dB}$ (LINEAR) no dispositivo amplificador de ajuste de nível "volume" da Plantronics mostraram uma sensibilidade de resposta na faixa de $84 \mathrm{~dB}$ a $108 \mathrm{~dB}$, isto é, uma variação de $24 \mathrm{~dB}$, sendo $10 \mathrm{~dB}$ de atenuação e $14 \mathrm{~dB}$ de ganho, tendo como referencial o sinal padrão aplicado de $94 \mathrm{~dB}$.

\subsection{ESTUDO III - ESTUDO PILOTO DA AVALIAÇÃO DE RUÍDO (IN SITU) EM FONES DE OUVIDO DOS OPERADORES DE TELEFONIA (SILVA, 1994)}

\subsubsection{Objetivos}

Desenvolver um método mais simples e mais barato para avaliar, in situ, os níveis de ruído dos operadores de telefonia que usam fones de ouvido.

Segundo Marcos Domingos da Silva (1994), as considerações apresentadas são preliminares, uma vez que essa questão é complexa. 


\subsubsection{Perfil da exposição ao ruído estudada}

O estudo piloto apresentado é fruto de um trabalho de consultoria e pesquisa, desenvolvido em um período de um ano e meio em duas importantes companhias brasileiras, chamadas por Silva (1994), de Empresa A e Empresa B.

$\mathrm{Na}$ empresa A havia um elevado índice de perda auditiva entre os trabalhadores da área de manutenção de linhas telefônicas. Também foi avaliada a exposição ao ruído das telefonistas que atendem as chamadas públicas.

$\mathrm{Na}$ Tabela 15 está indicada a população estimada de trabalhadores que usavam fones de ouvido, incluindo o pessoal de empreiteira - Empresa A.

Tabela 15 - População estimada de trabalhadores que usam fones de ouvido

\begin{tabular}{cc}
\hline Função Exercida & Número de Expostos \\
\hline Cabistas & 384 \\
Examinadores & 77 \\
Instaladores & 565 \\
Telefonistas & 381 \\
Ajudantes & 168 \\
\hline
\end{tabular}

Fonte: Silva, M.D. Revista Proteção, v.6, n. 36, dez. 1994

Na Tabela 16 é apresentada uma estimativa do número de perdas auditivas em trabalhadores com exposição ao ruído.

Tabela 16 - Estimativa dos operadores com perda auditiva

\begin{tabular}{cccc}
\hline Função & População & $\begin{array}{c}\text { Perda Auditiva } \\
\text { Por Ruído }\end{array}$ & Não por Ruído \\
\hline Cabistas & & $29(20 \%)^{*}$ & 13 \\
Examinadores & 150 & $8(22 \%)^{*}$ & 3 \\
Total & 35 & 37 & 16 \\
\hline
\end{tabular}

* As perdas auditivas assinaladas entre parênteses foram observadas em trabalhadores entre 10 e 15 anos de exposição ao ruído, que utilizavam fones.

Fonte: Silva, M.D. Revista Proteção, v.6, n. 36, dez. 1994 


\subsubsection{Bibliografia e fundamentos técnicos}

Silva (1994) relatou, já na época, que havia pouca literatura a respeito. O levantamento bibliográfico feito na biblioteca da FUNDACENTRO reuniu cerca de 50 (cinqüenta) trabalhos sobre operadores de telefonia, mas somente quatro deles tratavam especificamente de ruído. Três deles apresentavam uma metodologia de avaliação bastante complicada e obsoleta.

O único trabalho aproveitável foi o da Health Hazard Evaluation Report no $\mathrm{HHE}-81$ 086-837, J. Erdreich e J. P. Flesh, publicado pelo National Institute for Occupational Safety and Health - NIOSH, 1981 apud Silva (1994), realizado com operadores de telefonia de atendimento ao público, com um ouvido artificial, cujo resultado foi de no máximo $85 \mathrm{~dB}(\mathrm{~A})$.

\subsubsection{Metodologia adotada no estudo piloto}

A primeira idéia para se medir níveis de ruído em operadores de telefonia que usam fones de ouvido seria posicionar um microfone dentro da orelha do trabalhador.

Então, para atender o objetivo desse estudo piloto foram utilizados dosímetros, do fabricante Quest, de origem norte-americana, modelos M15, M28 e Q400, em razão de possuírem microfones pequenos e compactos, possíveis de serem ajustados entre o fone de ouvido e a orelha dos trabalhadores.

Em todos esses modelos Quest, o microfone é omnidirecional, $8 \mathrm{~mm}$, PZT, de cerâmica, projetados para ter a melhor resposta dentro de um ângulo de $50^{\circ}$ a $70^{\circ}$ do eixo da fonte.

Embora os microfones Quest pudessem ser razoavelmente ajustados na orelha dos operadores, ficava a dúvida do ponto de vista de resposta acústica, uma vez que os dados disponíveis são válidos para campo livre. (SILVA, 1994). 


\subsubsection{Metodologia Padrão}

Para dirimir essa questão, foi feita uma série de testes comparativos, utilizando o Sistema do fabricante Brüel \& $\mathrm{Kjaer}^{\circledR}$, de procedência dinamarquesa, composto pelo Head and Torso Simulator Tipo 4128 (B\&K, 1991), os Simuladores de Ouvido Esquerdo e Direito Tipo 4158 e 4159 e o Analisador Dual Channel Real Time Frequency Analyser Tipo 2144 (B\&K, 1991), como mostram as Figuras 11 e 12.

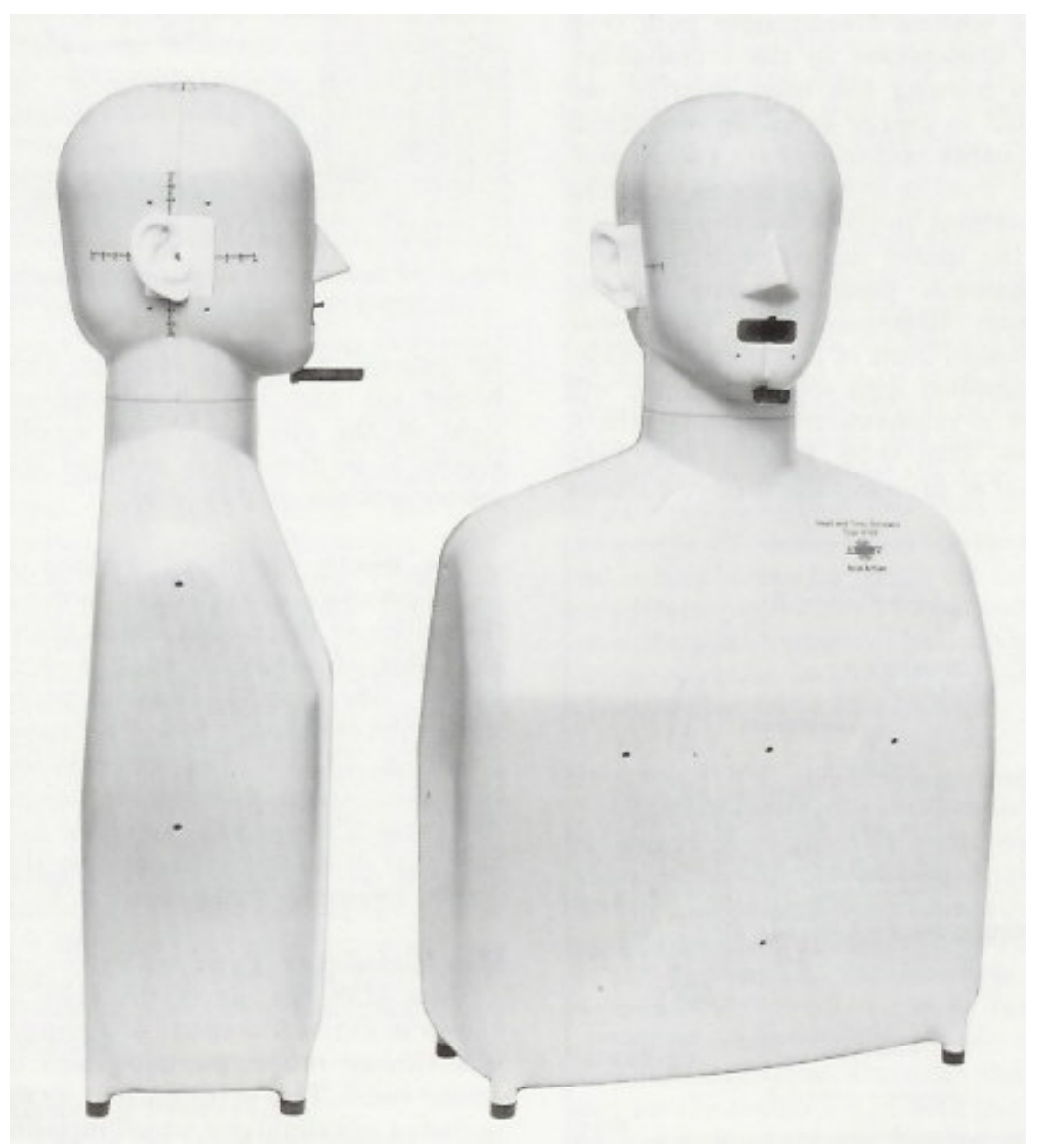

Figura 11 - "Head and Torso Simulator" (HATS) - Cabeça/Torso Artificial Fonte: Catálogo do fabricante - Brüel \& Kjaer ${ }^{\circledR}$, (B\&K, 1991) 


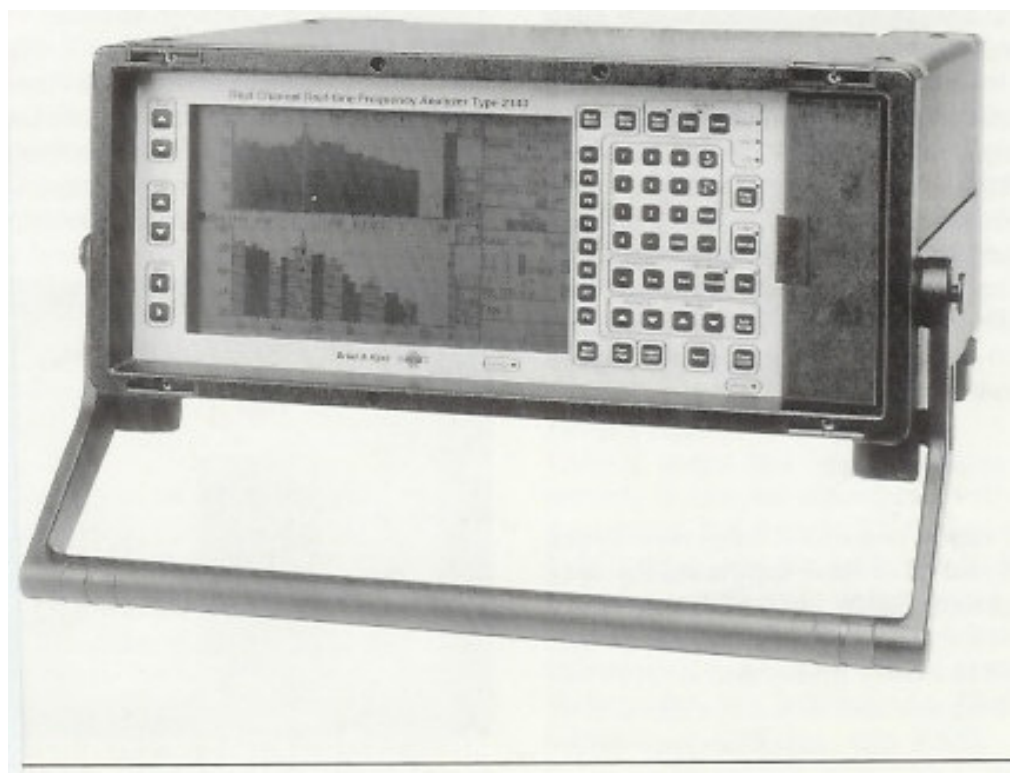

Figura 12 - Analisador de Espectro de Freqüência de Duplo Canal em Tempo Real Fonte: Catálogo do fabricante - Brüel \& Kjaer $^{\circledR}$, (B\&K, 1991)

Embora esse sistema da Brüel \& $\mathrm{Kjaer}^{\circledR}$ atenda a várias normas internacionais de telecomunicações, as medições não são feitas IN SITU, mas sim em um manequim com características geométricas semelhantes à de uma pessoa adulta, tendo, no interior de sua cabeça, um simulador de ouvido Tipo 4128 que inclui um microfone de $1 / 2$ " do tipo pressão.

No Sistema Brüel \& $\mathrm{Kjaer}^{\circledR}$ (B\&K), as medições de ruído foram feitas em um fone de ouvido ligado paralelamente ao utilizado pelo operador de telefonia. De qualquer forma nesse ESTUDO PILOTO foi chamado de PADRÃO PRIMÁRIO.

\subsubsection{Testes comparativos com o Padrão Primário BRÜEL \& KJAER® $(B \& K)$}

Os testes comparativos foram feitos em uma grande empresa de telefonia Empresa B. Nesse estudo, o autor do presente texto, participou como colaborador. 
As medições foram feitas simultaneamente com o Sistema Padrão B\&K, conectado com uma saída paralela da mesa de operação, com o microfone do dosímetro Quest instalado a maior parte do tempo na orelha do manequim e uma vez na telefonista, que atendia em média 50 chamadas telefônicas por hora.

Ambos os fones de ouvido foram ajustados para as condições normais de audição. Os testes realizados são apresentados na Tabela 17

Tabela 17 - Testes Realizados ${ }^{2}$

\begin{tabular}{ccc}
\hline Testes & Tempo de Leitura (min.) & Observação \\
\hline A & 10 & Leq de 10 min. \\
B & 15 & Leq de 15 min. - Microfone na \\
C & 10 & Orelha da telefonista \\
D & 15 & 10 Leituras com Leq de 1 min \\
E & 30 & Leq de 15 min. \\
F & 5 & Leq de 30 min. \\
G & 10 & Leq. de 5 min. \\
H & 15 & Leq de 10 min. \\
I & 10 & Leq de 15 min. \\
\hline
\end{tabular}

Fonte: Silva, M.D.. Revista Proteção, v.6, n. 36, dez. 1994

Foram feitos vários testes comparativos entre o Sistema B\&K e os dosímetros Quest. São apresentados, na Tabela 18, os resultados de 9 (nove) deles.

Tabela 18 - Testes Comparativos - Leituras Obtidas de Leq em dB (A)

\begin{tabular}{cccc}
\hline Teste & $\begin{array}{c}\text { Sistema B\&K } \\
(4128 \text { e 2144) } \\
\text { Leq }\end{array}$ & $\begin{array}{c}\text { Dosímetros Quest } \\
\text { (M15, M28 e Q400) }\end{array}$ & $\begin{array}{c}\text { Diferença } \\
\text { (B\&K - Quest) } \\
\text { dB }\end{array}$ \\
\hline A & 91 & 82,8 & 8,2 \\
B $^{*}$ & 88,5 & 82,2 & 6,3 \\
D & $84-92,5$ & $70-78,9$ & $12,5-14,0$ \\
E & 86,3 & 74,7 & 11,6 \\
F & 83,2 & 71,6 & 11,6 \\
G & 84,5 & 75,6 & 8,9 \\
H & 83,2 & 73,4 & 9,8 \\
I & 78,8 & 69,8 & 9,0 \\
\hline
\end{tabular}

* Microfone colocado na orelha da telefonista

Fonte: Silva, M.D.. Revista Proteção, v.6, n. 36, dez. 1994

\footnotetext{
${ }^{2}$ Todos os testes foram feitos com o microfone original da Quest, retirando-se somente o prendedor ("jacaré")
} 
A Tabela 18 mostra que as leituras obtidas com os dosímetros Quest foram todas inferiores às do Sistema $B \& K$. A diferença, ora maior ora menor, é conseqüência direta da posição do microfone Quest no pavilhão auricular.

Nos testes, houve mais dificuldade de ajustar o microfone Quest na orelha artificial do manequim do que na das telefonistas. É por isso que, segundo Silva, a menor diferença entre as leituras foi a do teste $B$.

\subsubsection{Testes de Campo}

O instrumental para as medições em campo constou dos dosímetros Quest, modelos M15 e M28, colocando-se sempre o microfone no pavilhão auricular, junto à cápsula do fone de ouvido do operador. As medições foram feitas somente na Empresa A.

Quanto à estratégia de medição, a Tabela 19 resume toda a abordagem feita com os trabalhadores que usaram os fones de ouvido.

Tabela 19 - Trabalhadores que utilizaram fones de ouvido ${ }^{3}$

\begin{tabular}{cccc}
\hline Função/Jornada Diária & № de Operadores & $\begin{array}{c}\text { Dosimetrias } \\
\text { Feitas }\end{array}$ & $\begin{array}{c}\text { Tempo da } \\
\text { Dosimetria }\end{array}$ \\
\hline Cabistas/8h & 5 & 6 & 30 min. \\
Examinadores/7h e 12min. & 6 & 10 & 1 a 2 horas \\
Telefonistas/6h & 60 & 8 & 1 a 1,5 horas \\
\hline
\end{tabular}

Fonte: Silva, M.D.. Revista Proteção, v.6, n. 36, dez. 1994

A Tabela 20 apresenta os resultados obtidos a partir dessas medições:

\footnotetext{
${ }^{3}$ Os operadores utilizaram dois tipos de fones de ouvido: Miguelão e IBCT (moderno)
} 
Tabela 20 - Resultados das Medições de Campo - Empresa A

\begin{tabular}{|c|c|c|c|}
\hline Função & Fone de Ouvido & Projeção da Dose (\%) & $\begin{array}{c}\text { Leq } \\
\mathrm{dB}(\mathrm{A}) \\
\end{array}$ \\
\hline $\begin{array}{c}\text { Cabistas } \\
\text { (Galeria de Cabos) }\end{array}$ & Miguelão & $316,00(8 h)$ & 93,30 \\
\hline $\begin{array}{c}\text { Cabistas } \\
\text { (Armário de rua) }\end{array}$ & Miguelão & $2.476,00$ (8h) & 108,10 \\
\hline Examinador \# 1 & IBCT & 51,44 (7h 12min.) & 81,03 \\
\hline Examinador \# 2 & IBCT & $50,20$ (7h $12 \mathrm{~min})$. & 80,80 \\
\hline Examinador \# 3 & IBCT & 42,26 (7h 12min.) & 79,50 \\
\hline Examinador \# 4 & IBCT & $248,30$ (7h $12 \mathrm{~min})$. & 92,34 \\
\hline Examinador \# 5 & IBCT & $376,00$ (7h $12 \mathrm{~min})$. & 94,50 \\
\hline Examinador \# 6 & IBCT & $238,97$ (7h $12 \mathrm{~min})$. & 92,00 \\
\hline Examinador \# 7 & IBCT & $91,80$ (7h $12 \mathrm{~min})$. & 85,10 \\
\hline Examinador \# 8 & IBCT & 79,50 (7h 12min.) & 84,10 \\
\hline Examinador \# 9 & IBCT & $109,26$ (7h $12 \mathrm{~min})$. & 86,42 \\
\hline Examinador \#10 & IBCT & $190,10$ (7h $12 \mathrm{~min})$. & 90,31 \\
\hline Examinador \# 1 & IBCT & 212,85 (7h 12 min.) & 91,20 \\
\hline $\begin{array}{l}\text { Telefonista \# } 1 \\
\text { (Interurbanos) }\end{array}$ & Miguelão & $30,65(6 h)$ & 78,50 \\
\hline $\begin{array}{l}\text { Telefonista \# } 2 \\
\text { (Interurbanos) }\end{array}$ & IBCT & $30,16(6 h)$ & 80,00 \\
\hline $\begin{array}{l}\text { Telefonista \# } 3 \\
\text { (Interurbanos) }\end{array}$ & IBCT & 7,88 (6h) & 68,71 \\
\hline $\begin{array}{c}\text { Telefonista \# } 1 \\
\text { (Chamadas Locais) }\end{array}$ & Miguelão & $109,77(6 h)$ & 87,75 \\
\hline $\begin{array}{c}\text { Telefonista \# } 2 \\
\text { (Chamadas Locais) }\end{array}$ & IBCT & $60,60(6 h)$ & 83,45 \\
\hline $\begin{array}{c}\text { Telefonista \# } 3 \\
\text { (Chamadas Locais) }\end{array}$ & IBCT & $45,43(6 h)$ & 81,30 \\
\hline $\begin{array}{c}\text { Telefonista \# } 3 \\
\text { (Chamadas Locais) }\end{array}$ & Miguelão & $63,40(6 h)$ & 83,70 \\
\hline
\end{tabular}

Fonte: Silva, M.D.. Revista Proteção, v.6, n. 36, dez. 1994

Silva (1994) ressalta que alguns resultados foram influenciados pelos ajustes individuais de volume dos fones de ouvido, elevando ou reduzindo os níveis de ruído de acordo com a sensibilidade auditiva da cada operador, o que, em alguns casos, pode sinalizar uma acentuada perda auditiva.

\subsection{ESTUDO IV - PERÍCIA E AVALIAÇÃO DE RUÍDO EM SISTEMA DE TELEFONIA (RIBEIRO,A, et al, Acesso 2008)}

Alexandre Santana Ribeiro (pesquisador do Laboratório de Transdutores da Pontifícia Universidade Católica do Rio de Janeiro - PUC - Rio) et al., disponibilizaram na Internet um estudo que realizou auxiliado por outros 
pesquisadores, sobre a utilização de uma cabeça artificial que simula aproximadamente as dimensões anatômicas de uma pessoa adulta, incluindo uma modelagem do seu trato auditivo (pavilhão auricular e canais auditivos). Comenta que algumas situações podem ainda requerer, além da cabeça artificial, a utilização de um torso que compõe uma modelagem mais adequada do ser humano. Nas medições realizadas pelo Laboratório de Transdutores da PUC-Rio, foi utilizada uma cabeça artificial de Neumann, que possui internamente microfones, préamplificadores e fonte de alimentação. O sinal de medição é acoplado por meio de dispositivo específico de casamento de impedância ao audiodosímetro 706 da Larson Davis. As medições consistem, como pode ser visto no desenho esquemático da Figura 13, na substituição do microfone e do pré-amplificador do equipamento de medição pela cabeça artificial que simula as características do ouvido humano. Utilizando um adaptador específico, conecta-se o sinal de saída da cabeça com o medidor a ser utilizado. Para isso, deve-se optar por equipamentos de medição que permitam a conexão de sinais diretos. A verificação do sistema é feita com um calibrador específico com certificado de calibração reconhecido. Tal calibração é necessária antes e após as medições.

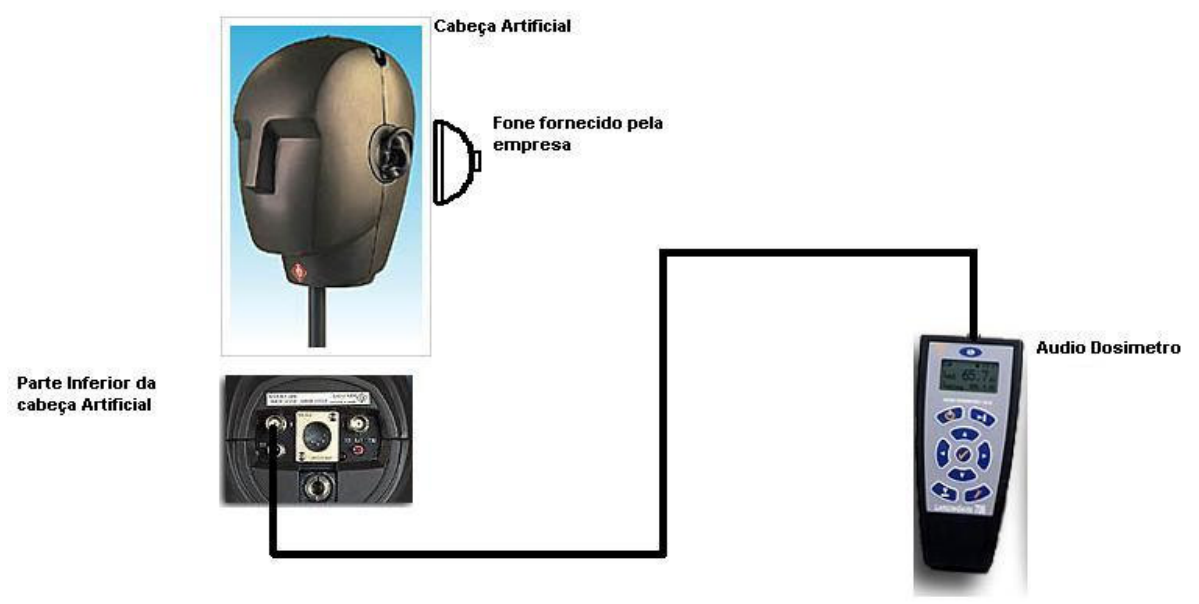

Figura 13 - Desenho esquemático do sistema de medição com Cabeça Artificial. Fonte: llustração extraída do site: www.isegnet.com/br/arquivosartigo_cabecadoc. (RIBEIRO, et al, 2008)

Continuando sua descrição, o sistema de medição composto por calibrador/cabeça artificial e audiodosímetro fornece os resultados dos níveis de pressão sonora em intervalos de 15 segundos em dB (A) na detecção SLOW; os níveis de pico nesses mesmos intervalos em $d B(C)$ na detecção FAST e fornece o nível global em $d B(A)$ 
de toda a jornada com os respectivos valores da dose e do tempo de exposição conforme os parâmetros da Norma Regulamentadora do Ministério do Trabalho e Emprego - NR 15, anexo 1; e também em qual porcentagem de tempo eles ocorreram. Foram feitas algumas medições em laboratório e analisados os dados tendo como referência os parâmetros da Norma NR 15 e os procedimentos de medição da Norma de Higiene Ocupacional - Procedimento Técnico - NHO 01 da Fundacentro. Segundo os autores deste estudo, os níveis limite são os mesmos da NR 15; a incerteza de medição do sistema de medição é de $\pm 2,5 \mathrm{~dB}$; o nível de pressão sonora obtido com a cabeça artificial no ambiente é o mesmo do medido na altura do ombro do usuário do audiodosímetro, posição recomendada pela norma da Fundacentro NHO 01.

\subsection{ESTUDO V - AVALIAÇÃO DOS NÍVEIS DE RUÍDO DA TRIPULAÇÃO DE HELICÓPTERO (RIFFEL e MACHADO, Acesso, 2007)}

Riffel e Machado (2002) realizaram medições para analisar os níveis de ruído aos quais se encontrava exposta a tripulação de helicópteros do GRAER da Polícia Militar de Santa Catarina, sediado no aeroporto internacional da cidade de Florianópolis - SC. São utilizados equipamentos de proteção, tais como capacetes especiais para a aviação, com sistema de comunicação acoplado (fone de ouvido e microfone), além de um aparelho de proteção auditiva tipo concha, com sistema de comunicação (fone de ouvido e microfone). Também são utilizados plugues de inserção tipo espuma expansiva, marca 3M, modelo 1100 ou similar.

O procedimento incluiu medições dos níveis de ruído no interior da aeronave e dentro e fora tanto do protetor auditivo quanto do capacete durante as operações de decolagem, vôo, manobras e pouso, visando à avaliação da exposição ao ruído.

Nas avaliações individuais, foram utilizados dois dosímetros de ruído (marca Quest, modelo M28). O microfone de um deles foi instalado dentro da concha e o do outro, instalado fora, durante os procedimentos das operações em solo e em vôo. Num dos 
eventos, os aparelhos foram instalados num tripulante e, no outro evento, num piloto (Figuras 14, 15 e 16).

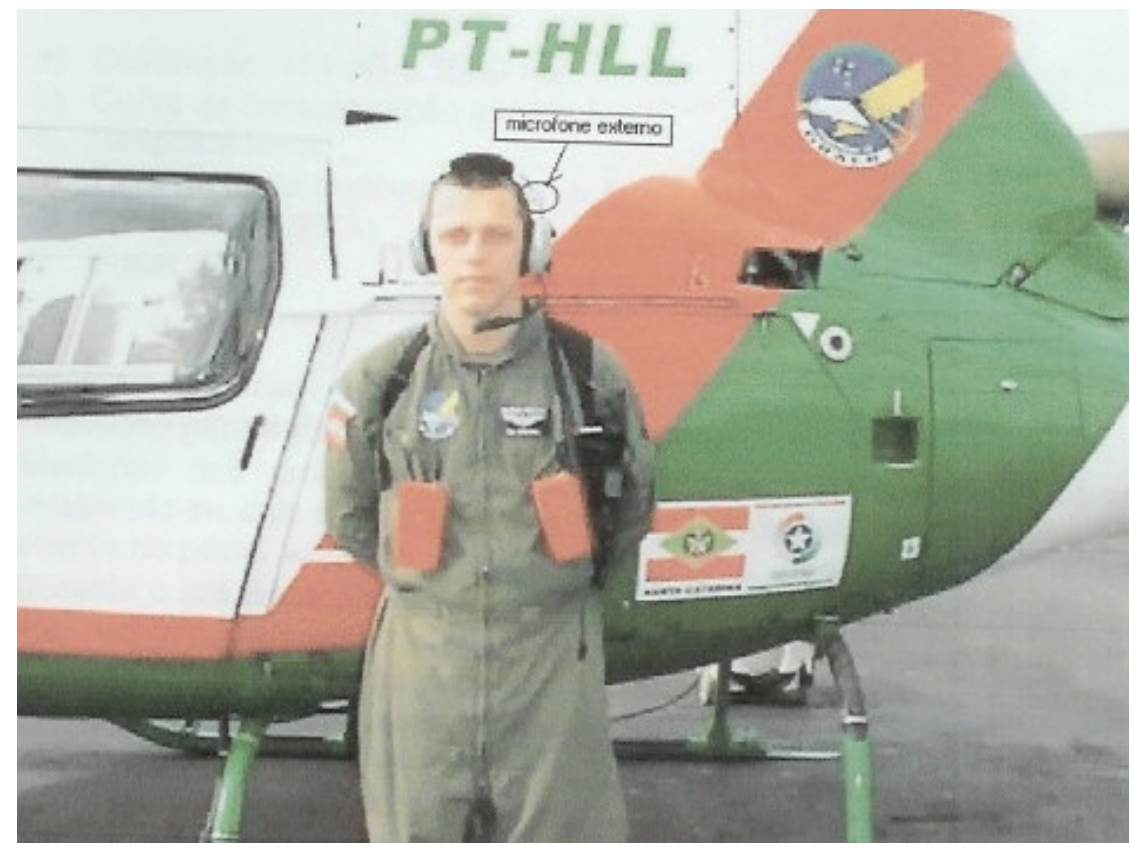

Figura 14 - Indica a posição do microfone externo. O tripulante porta dois dosímetros Fonte: Extraído do Laudo Técnico no 01/GSHST/02 de 20/09/2002 da Universidade Federal de Santa Catarina. (RIFFEL, G; MACHADO, R.L., 2002)

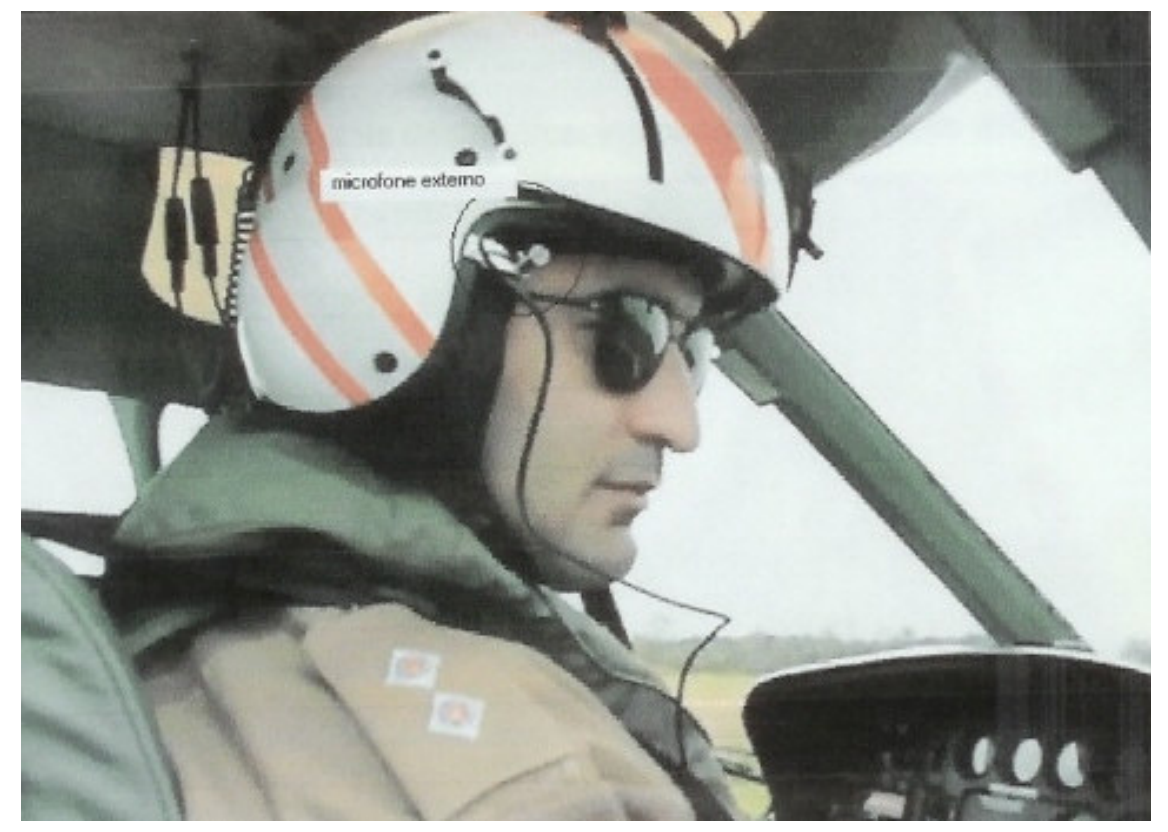

Figura 15 - Indica a posição do microfone externo. O piloto porta dois dosímetros Fonte: Extraído do Laudo Técnico ㄲo 01/GSHST/02 de 20/09/2002 da Universidade Federal de Santa Catarina. (RIFFEL, G; MACHADO, R.L., 2002) 


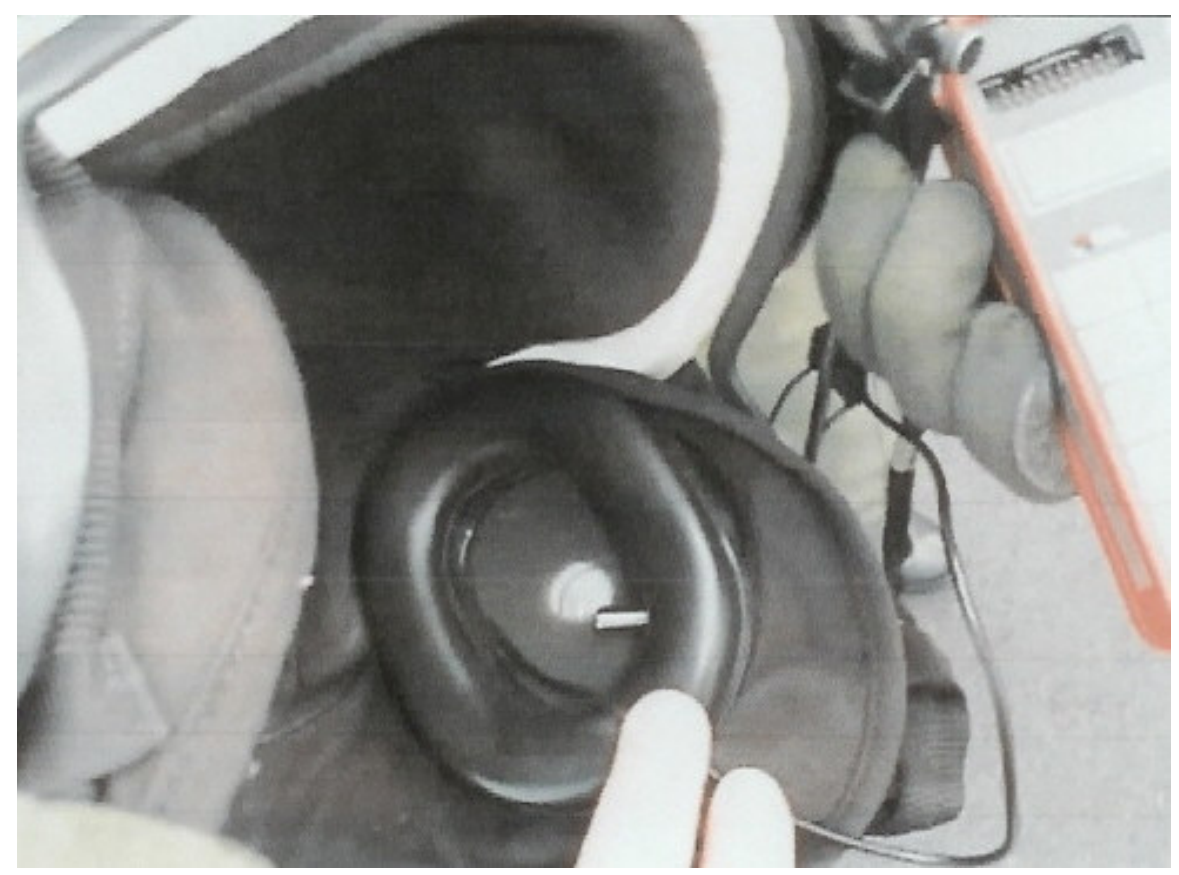

Figura 16 - Indica o microfone do dosímetro instalado dentro da concha do capacete Fonte: Extraído do Laudo Técnico noo 01/GSHST/02 de 20/09/2002 da Universidade Federal de Santa Catarina. (RIFFEL, G; MACHADO, R.L., 2002)

Os valores médios medidos no tripulante (evento 1) e no piloto (evento 2) e o percentual estatístico por nível de exposição dos valores medidos dentro e fora da concha mostraram que praticamente $52 \%$ do ruído externo está entre os níveis de 95 e $100 \mathrm{~dB}(\mathrm{~A})$ e que os níveis dentro da concha estão em sua maioria próximos a $85 \mathrm{~dB}(\mathrm{~A})$, mostrando haver atenuação pelo uso do protetor auditivo. Ao final, tem-se os Leq (valores equivalentes) registrados pelos dosímetros e a atenuação apresentada em cada ocorrência, além da atenuação apresentada pela média aritmética durante o uso pelo tripulante e pelo piloto.

(Valor com Dosímetro Externo - Valor com Dosímetro Interno) = Atenuação

Segundo Riffel e Machado (2002), avaliando a atenuação média, a do tripulante com o valor de 14,4 dB representa o valor que o protetor utilizado pelo seu usuário atenua em condições reais de uso (no evento medido). Para o piloto, o valor médio de 5,8 dB sugere que ocorrem vazamentos de ruído durante o uso do protetor auditivo, vindo a expor seu usuário a níveis mais elevados, o que demonstra que há a necessidade de reavaliar esse caso. O protetor usado pelo tripulante possui uma 
pressão constante no arco que suporta as conchas, enquanto no capacete do piloto as conchas são pressionadas sobre as orelhas pela fixação jugular do capacete. Se este não for devidamente apertado, ocorrem vazamentos, expondo seu usuário a níveis elevados de ruído e com possibilidade de danos ao seu aparelho auditivo.

\subsection{ESTUDO VI - AVALIAÇÃO DA EXPOSIÇÃO AO RUÍDO DE OPERADORES DE TELEATENDIMENTO (VERGARA et al., 2006)}

Vergara et al. (2006) apresentaram um trabalho desenvolvido no setor de teleatendimento de uma empresa de telefonia do Estado de Santa Catarina com 1.200 pessoas numa área de $2.000 \mathrm{~m}^{2}$. O grupo de avaliação foi constituído de 32 operadores de atendimento (usuários de fones de ouvido) escolhidos aleatoriamente, de ambos os sexos, cuja idade variava de 18 a 43 anos. Subgrupos de oito operadores foram distribuídos em cada um dos quatro turnos de trabalho estabelecidos, nos setores denominados receptivo e vendas (ativo). Para a obtenção dos resultados, foram utilizadas as duas técnicas de medição para avaliação dos níveis sonoros em fones de ouvido descritas nas normas internacionais da série ISO 11904, divididas em duas partes, a ISO 11904-1 - Técnica do Minimicrofone em Ouvido Real (conhecida por Técnica MIRE - Microphone in a Real Ear) e a ISO 11904-2 - Técnica da Cabeça Artificial de Manequim (conhecida como Técnica Usando Manequim).

O estudo teve por objetivo comparar os resultados da aplicação simultânea de ambas as técnicas em campo. Também foi adicionado um microfone fixado a um tripé para medição simultânea do ruído do ambiente, em atendimento à Norma Regulamentadora NR 17 do Ministério do Trabalho, que trata da Ergonomia, segundo a qual os níveis de ruído do ambiente de trabalho devem estar de acordo com o estabelecido na NBR 10152 (1987), que determina um nível de pressão sonora de até $65 \mathrm{~dB}(\mathrm{~A})$ e uma curva de avaliação de ruído (NC) de valor não superior a $60 \mathrm{~dB}$ para as atividades de operadores de teleatendimento. 
Na Figura 17, é apresentado o esquema do sistema de medição para avaliação da exposição de usuários de fones de ouvido proveniente das atividades desempenhadas nos postos de trabalho da central de atendimento (call center). $\mathrm{O}$ agente ruído sob teste é o próprio sinal que chega à central de atendimento, entra no sistema de telefonia (aparelho telefônico) e passa pelo regulador de volume do fone de ouvido. O aparelho telefônico apresenta duas saídas, para dois fones simultaneamente, sendo um deles acoplado a um manequim e o outro ajustado a um operador de teleatendimento, que está portando um minimicrofone. O operador utiliza o fone acoplado à sua orelha externa junto ao minimicrofone. O manequim, que recebeu um fone de ouvido da mesma marca e modelo do utilizado pelo operador de teleatendimento, é instalado no posto de trabalho próximo a ele, de modo que o mesmo sinal seja captado tanto pelo minimicrofone de um quanto pelo simulador de ouvido do outro, podendo assim

ser registrado o nível de pressão sonora em bandas de freqüência de terço de oitava pelo analisador de sinais.

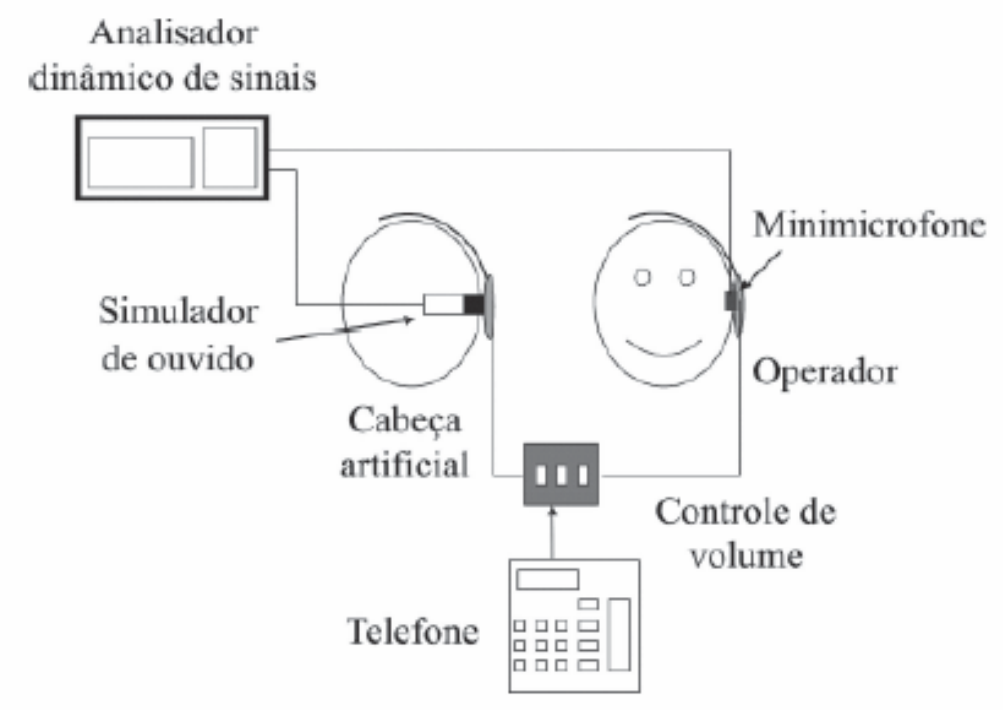

Figura 17 - Diagrama do sistema de medição para avaliar a exposição de operadores de teleatendimento a ruído: técnica em ouvido real e manequim.

Fonte: Vergara et al (2006). Revista Brasileira de Saúde Ocupacional, Figura 1, v.31, n. 114, 2006. p.168 
A aplicação da Técnica do Minimicrofone em Ouvido Real - MIRE consistiu na colocação de um minimicrofone no meato/conduto auditivo externo do operador, usuário de fones de ouvido, realizada por um fonoaudiólogo de acordo com os cuidados especializados requeridos pela técnica. Foram utilizados um minimicrofone de 1/8" do tipo pressão da marca DPA, modelo H 17546, e um amplificador MPS 6010, que foram calibrados, juntamente com os equipamentos de conexão, conforme os requisitos das normas da série IEC 61672. O minimicrofone e o seu respectivo amplificador foram conectados a um computador portátil equipado com um software analisador dinâmico de sinais, que realizou a medição em bandas de terço de oitava dos níveis de pressão sonora produzidos pelo fone de ouvido durante a situação normal de trabalho.

Os operadores selecionados aleatoriamente para participarem da aplicação dessa técnica passaram por uma avaliação audiológica e clínica por meio de anamnese clínica dirigida a todos os aspectos de saúde geral do indivíduo, como também da saúde auditiva, seguida de otoscopia e audiometria tonal limiar, para permitir que se realizassem todos os procedimentos requeridos para as medições necessárias com o máximo de segurança, além de garantir que problemas de saúde não interferissem nos resultados. Assim, colocado adequadamente o minimicrofone na posição escolhida para os testes (no exterior da entrada do canal auditivo), com o(s) operador (es) em seu posto real de trabalho, foi requisitado a ele(s) regular os controles de volume dos fones de ouvido de acordo com sua conveniência e predileção e, a partir de então, executar suas funções normalmente.

Na aplicação da Técnica da Cabeça Artificial de Manequim (maniquim technique), foi utilizado um simulador de cabeça, sem tronco, para medições telefonométricas, equipado com um molde de orelha externa adulta feito em silicone para se assemelhar às características da orelha humana e com um simulador de ouvido modelo 4157, acoplado a um simulador de conduto auditivo externo, modelo DB 2012, com amplificador para microfone modelo 2804, todos da marca Brüel \& $\mathrm{Kjaer}^{\circledR}$, fabricados de acordo com as normas IEC 60711 (1981) e ANSI S3.25,1989 (R2003).

A partir de então, foram realizadas as medições do ruído proveniente dos fones de ouvido utilizando-se as duas técnicas referidas. 
O tempo de medição foi determinado de modo a ser realmente representativo da exposição. A avaliação da exposição a ruído foi determinada para cinco medições de 60 segundos cada, realizadas no momento de maior atividade de trabalho, a fim de garantir o tempo mínimo exigido pela norma ISO 11904.

Para obter os níveis de pressão sonora em bandas de terço de oitava relacionados em campo difuso LDF,f , é necessário subtrair do nível de pressão sonora do canal auditivo (Lear,exp, $f$ para a técnica de ouvido real e $L M, \exp , f$ para a técnica do manequim) a resposta em freqüência de campo difuso, obtidos das Tabelas específicas das normas ISO 11904 ( $\Delta L D F, H, f$ para a técnica em ouvido real, na posição de colocação do minimicrofone no canal auditivo aberto e $\Delta L D F, M, f$ para a técnica utilizando o

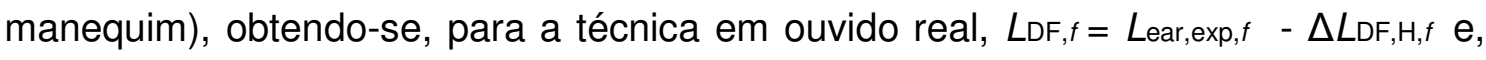
para a técnica com manequim, $L D F, f=L M, \exp , f-\Delta L D F, M, f$.

Assim, após a realização das medições dos níveis de pressão sonora, com as duas técnicas, cada um dos níveis das bandas de terço de oitava foi ajustado com a resposta em freqüência para campo difuso. Esses níveis em bandas de terço de oitava foram ainda ajustados usando a curva de ponderação $A$ e subseqüentemente foram combinados para obter o nível de pressão sonora contínuo equivalente ponderado A relacionado ao campo difuso $L_{D F}$,Aeq, que representa a exposição global ao ruído.

Os resultados das avaliações realizadas utilizando as duas técnicas apresentaram uma média da exposição ao ruído de 76,2 dB (A) e um desvio-padrão de 4,1 dB (A) para as medições utilizando a técnica do ouvido real e, para a técnica do manequim, de 78,5 dB (A) e 4,8 dB (A) de desvio-padrão, como é mostrado na Tabela 21. 
Tabela 21 - Valores médios e os desvios padrão das medições da exposição sonora LDF,Aeq das técnicas com minimicrofone e manequim para os 32 operadores de teleatendimento

\begin{tabular}{|c|c|c|c|c|}
\hline \multirow{3}{*}{ Operador } & \multicolumn{4}{|c|}{ Exposição a ruído dB $(A)$} \\
\hline & \multicolumn{2}{|c|}{ Minimicrofone no ouvido real } & \multicolumn{2}{|c|}{ Manequim com simulador } \\
\hline & Média & Desvio & Média & Desvio \\
\hline 1 & 71,4 & 4,5 & 78,6 & 3,9 \\
\hline 2 & 72,1 & 3,7 & 81,4 & 2,7 \\
\hline 3 & 65,4 & 4,2 & 74,5 & 2,7 \\
\hline 4 & 73,3 & 3,3 & 78,8 & 4,4 \\
\hline 5 & 75,2 & 3,1 & 82,6 & 2,6 \\
\hline 6 & 71,2 & 4,7 & 67,3 & 0,9 \\
\hline 7 & 74,4 & 4,5 & 76,2 & 3,8 \\
\hline 8 & 76,1 & 7,2 & 69,3 & 2,0 \\
\hline 9 & 83,2 & 6,2 & 89,5 & 6,5 \\
\hline 10 & 73,2 & 2,1 & 81,6 & 2,7 \\
\hline 11 & 80,1 & 5,2 & 86,4 & 6,6 \\
\hline 12 & 86,4 & 2,3 & 79,8 & 2,1 \\
\hline 13 & 76,8 & 0,5 & 79,0 & 1,8 \\
\hline 14 & 74,0 & 1,1 & 80,8 & 1,0 \\
\hline 15 & 78,4 & 2,8 & 80,2 & 2,9 \\
\hline 16 & 71,3 & 6,8 & 73,5 & 4,5 \\
\hline 17 & 80,1 & 4,7 & 85,2 & 3,8 \\
\hline 18 & 81,3 & 6,5 & 82,3 & 5,0 \\
\hline 19 & 79,7 & 1,2 & 80,8 & 1,5 \\
\hline 20 & 78,3 & 5,3 & 81,6 & 6,2 \\
\hline 21 & 79,5 & 2,7 & 78,7 & 2,6 \\
\hline 22 & 74,5 & 5,1 & 74,3 & 2,8 \\
\hline 23 & 77,0 & 5,6 & 76,8 & 3,9 \\
\hline 24 & 75,9 & 3,9 & 77,9 & 3,5 \\
\hline 25 & 75,1 & 3,4 & 74,5 & 3,0 \\
\hline 26 & 75,4 & 2,4 & 82,5 & 1,9 \\
\hline 27 & 76,2 & 1,9 & 73,9 & 2,6 \\
\hline 28 & 73,7 & 3,1 & 74,1 & 1,3 \\
\hline 29 & 73,3 & 3,8 & 74,6 & 2,9 \\
\hline 30 & 80,0 & 1,2 & 82,7 & 1,7 \\
\hline 31 & 76,5 & 1,6 & 79,5 & 1,1 \\
\hline 32 & 79,3 & 2,3 & 74,1 & 1,5 \\
\hline Valor Global & 76,2 & 4,1 & 78,5 & 4,8 \\
\hline
\end{tabular}

Fonte: Vergara et al (2006). Revista Brasileira de Saúde Ocupacional, Tabela 3, v.31, n.114, 2006. p. 170

\subsection{ESTUDO VII - SISTEMA PROPOSTO PELA EMPRESA ETYMOTIC RESEARCH PARA AVALIAÇÃO DE DOSIMETRIA EM FONES DE CALL CENTER - PROPOSTA TÉCNICA - COMERCIAL. (ETYMOTIC, 2006)}

A proposta datada de 23 de maio de 2006 foi recebida por meio eletrônico, pela Associação Brasileira de Higienistas Ocupacionais - ABHO. Apresenta características de baixo custo e de utilizar uma sonda/tubo de $1 \mathrm{~mm}$ de diâmetro, de 
forma a inseri-la aproximadamente $15 \mathrm{~mm}$ dentro do canal auditivo, conectar a outra ponta ao microfone e este ao sistema, que se liga ao dosímetro.

Para melhor identificação do sistema, Figuras 18, 19 e 20.

A empresa Etymotic Research - Research and Product Development For The Ear, da cidade de Chicago, EUA, apresentou um Sistema utilizando os equipamentos e a metodologia indicados, para realizar as medições de dosimetria de ruído nos aparelhos headsets de telefonistas de call centers.(ETYMOTIC, 2006)

O sistema proposto apresenta as seguintes características:

i) O sistema microfone/sonda ER-7C é conectado à pessoa, por meio de um tubo de $1 \mathrm{~mm}$ de diâmetro, inserido aproximadamente $15 \mathrm{~mm}$ dentro do canal auditivo e fixado no local com uma fita. O corpo do microfone é fixado no local (pendurado/suspenso) na parte exterior da orelha da pessoa a ser avaliada;

ii) O sinal do microfone/sonda ER-7C é amplificado para produzir $50 \mathrm{mV}$ a $94 \mathrm{~dB}$ SPL de estímulo;

iii) O sistema microfone/sonda ER-7C fornece um tom de calibração de $94 \mathrm{~dB}$ SPL (Nível de Pressão Sonora) a $1 \mathrm{kHz}$ onde o tubo de $1 \mathrm{~mm}$ pode ser inserido para verificação do sistema;

iv) Como o sinal medido na saída do ouvido não tem o mesmo valor daquele medido no canal auditivo, em razão da ressonância deste (15 dB de pico a 2,7 kHz), um Filtro Inversor de Campo Difuso (DFI) é aplicado à saída do sistema ER-7C para reverter esse efeito. Isso, segundo a empresa Etymotic Research, deverá produzir uma dose real comparada à leitura feita no ombro em campo livre;

v) O Filtro Inversor de Campo Difuso - DFI (Difuse Filter Inverse) deverá ter pelo menos na saída $10 \mathrm{~dB}$ para $15,8 \mathrm{mV}$, equivalente a um estímulo de $94 \mathrm{~dB}$ SPL;

vi) O dosímetro da Etymotic Research aceita um microfone externo ou um sinal proveniente do microfone quando conectado. Essa entrada auxiliar espera ter 
$10 \mathrm{mV}$ a $94 \mathrm{~dB}$ SPL, embora a saída do filtro DFI seja atenuada $4 \mathrm{~dB}$ pelo divisor de tensão;

vii) O dosímetro de entrada está internamente programado pelo fornecedor para ponderação A e três amostragens, e pode ser programado para cinco requisitos de medição;

viii)O dosímetro tem uma porta de comunicação por meio da qual internamente são armazenados dados que podem ser baixados num computador para análises posteriores.

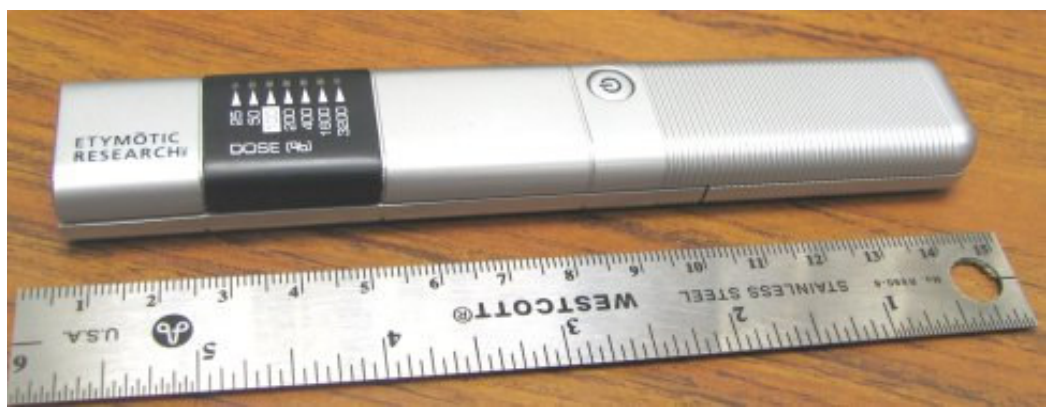

Figura 18 - Dosímetro de ruído Fonte: Proposta Técnica da Empresa Etymotic, 2006. Recebida pela $\mathrm{ABHO}$.

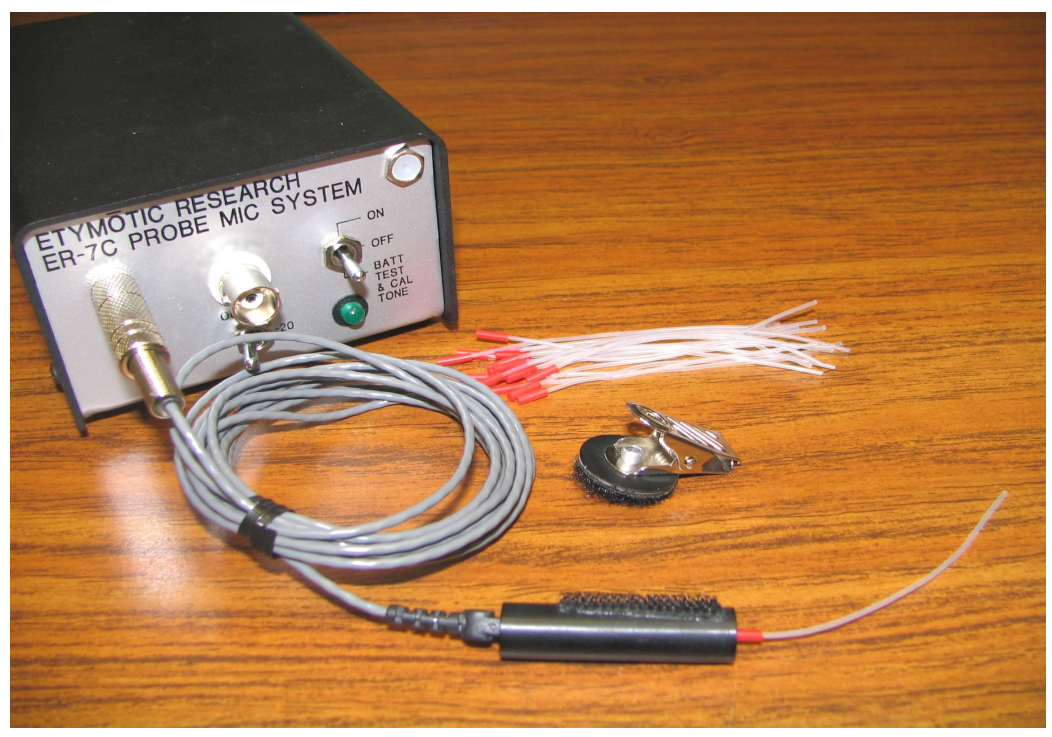

Figura 19 - Sistema Microfone e Sonda

Fonte: Proposta Técnica da Empresa Etymotic, 2006. Recebida pela $\mathrm{ABHO}$. 


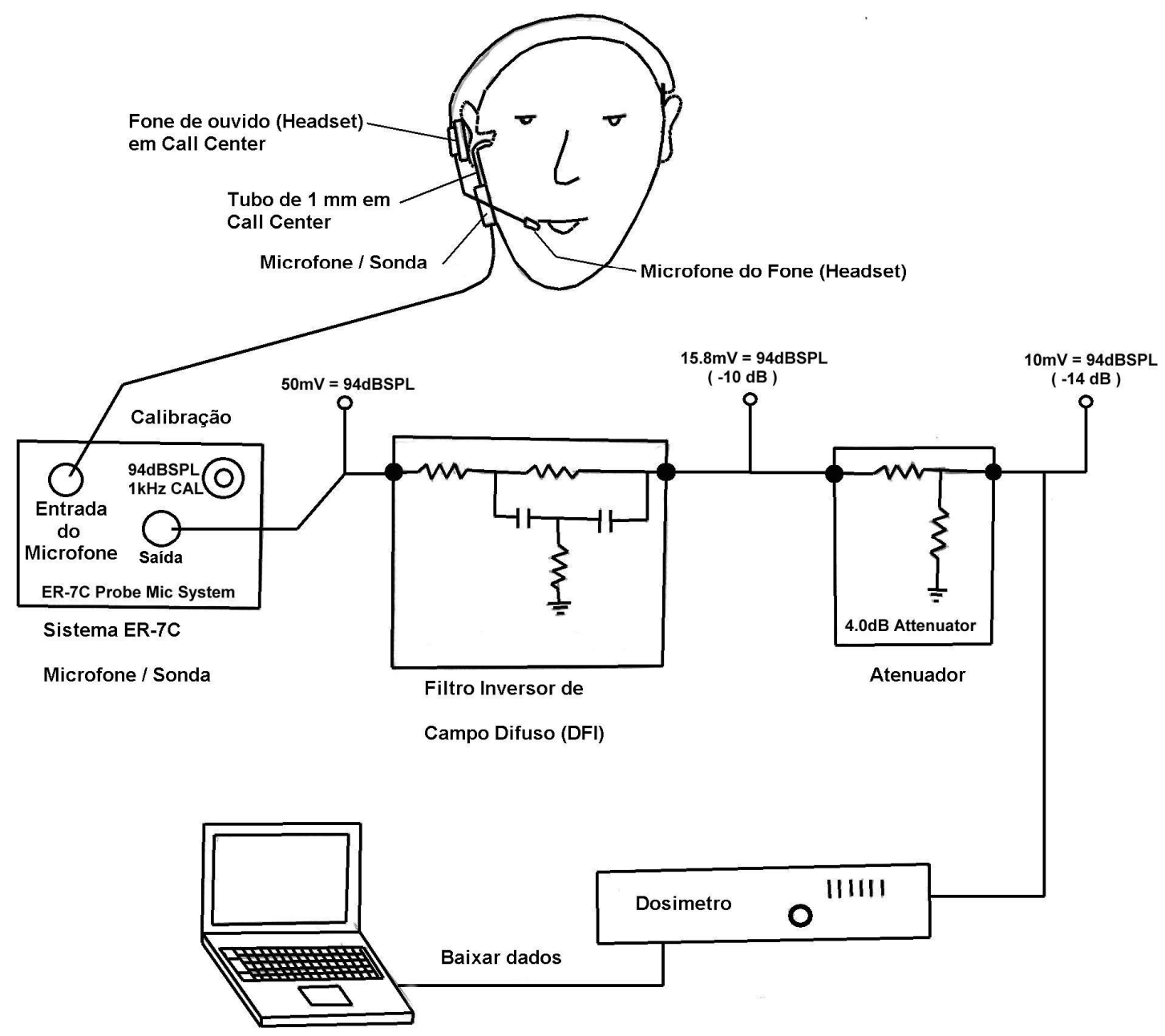

Figura 20 - Diagrama para dosimetria de ruído em headsets medido dentro do canal auditivo Fonte: Proposta Técnica da Empresa Etymotic, 2006. Recebida pela ABHO. 


\subsection{DISCUSSÃO REFERENTE AOS ESTUDOS E EXPERIÊNCIAS}

\subsubsection{Quanto ao Estudo I}

Foram feitas medições em praticamente todos os locais onde tais atividades eram exercidas e nos equipamentos. Calculou-se em cada caso a DOSE EQUIVALENTE DE RUÍDO durante um período de 6 horas para cada medição, em função do ciclo de trabalho e das características de repetitividade das medições.

Os valores encontrados para Ruído Contínuo ou Intermitente estão situados em geral numa faixa que vai de $77 \mathrm{~dB}(\mathrm{~A})$ a $86 \mathrm{~dB}(\mathrm{~A})$, o que caracteriza uma situação aceitável, de não insalubridade do ponto de vista acústico tendo em vista que os limites de tolerância são de $87 \mathrm{~dB}(\mathrm{~A})$ para jornadas de 6 horas de trabalho e de 85 $\mathrm{dB}(\mathrm{A})$ para as jornadas de 8 horas de trabalho, nos exatos termos do Anexo $\mathrm{n}$ ㅇ 1 da NR 15 da Portaria no 3.214 do Ministério do Trabalho.

Igualmente, os valores encontrados para Ruído de Impacto também estão situados numa faixa considerada aceitável de não insalubridade, tendo em vista que o limite de tolerância de $130 \mathrm{~dB}(\mathrm{~L})$, nos termos do Anexo $\mathrm{n}=2$ da NR 15, jamais foi ultrapassado em qualquer situação, seja em valores de dB (L), SPL, dB(L) max. e mesmo em valores de pico, conforme os critérios limite da American Conference of Governmental Industrial Hygienists (ACGIH).

Nas atividades de telefonistas de um dos edifícios, foram encontrados alguns valores um pouco acima de $\mathrm{Leq}_{e}=87 \mathrm{~dB}(\mathrm{~A})$, tendo-se constatado, em tempo, que tais alterações eram acidentais, pelo fato de estarem sendo utilizados, até então, aparelhos de telefonistas (handsets) não originais, não apropriados ao respectivo tipo de equipamento de mesa telefônica. Prova disso é que testes realizados com fones originais revelaram valores abaixo de $\mathrm{Leq}_{\mathrm{i}}=87 \mathrm{~dB}(\mathrm{~A})$, idênticos e similares ao padrão geral dos demais locais analisados. 
Assim, concluiu-se à época que o Perfil Acústico das atividades estudadas não se enquadra como insalubre nos exatos termos dos Anexos $n=1$ e $n^{0} 2$ da Norma Regulamentadora NR 15 da Portaria no 3.214 do Ministério do Trabalho.

\subsubsection{Quanto ao Estudo II}

Ficou mais uma vez demonstrado que, ao introduzir o referido dispositivo de amplificação para ajuste do nível "volume" na cápsula receptora do headset, aumentou-se em até $14 \mathrm{~dB}$ o nível sonoro, passando-se, assim, de uma situação aceitável, dentro dos limites de tolerância, para uma situação inaceitável.

\subsubsection{Quanto ao Estudo III}

\section{Estudo Piloto}

Embora as diferenças de leitura entre os dosímetros Quest e o sistema B\&K sejam ligeiramente acentuadas, esse Estudo Piloto demonstra que é possível desenvolver um método mais simples e barato de se caracterizar o risco potencial de surdez ocupacional entre os operadores de telefonia.

Segundo Silva (1994), autor deste estudo, as diferenças encontradas decorrem principalmente da posição do microfone no interior do pavilhão auricular, sendo menores à medida que o eixo do microfone coincide com o da fonte. Melhores resultados serão conseguidos com um microfone de menor tamanho.

\section{Quanto à exposição dos operadores de telefonia na Empresa $\mathrm{A}$}

Considerando que os dosímetros apresentaram leituras inferiores aos obtidos pela metodologia padrão, pode-se inferir que os dados de campo estão sub- 
dimensionados, o que exige uma interpretação de resultados mais rigorosa. (SILVA, 1994).

\subsubsection{Quanto ao Estudo IV}

Nas medições realizadas em laboratório mencionadas no estudo, os resultados apresentaram diferenças entre as medições de nível de pressão sonora com dois dosímetros similares (Larson Davis ${ }^{\circledR} 706$ ) verificados com o mesmo calibrador, neste caso, foi de 1,8 dB a mais para o audiodosímetro da cabeça quando comparado com um outro audiodosímetro posicionado a menos de $15 \mathrm{~cm}$ do ouvido do operador. Segundo o autor, essa diferença é compatível com a incerteza de medição estimada, e pode ser relacionada a diversos fatores como a posição em relação à fonte e reverberação da sala, entre outros. A apresentação dos níveis de pressão sonora estatísticos permite avaliar o tempo de permanência em determinados níveis de ruído, inclusive se ocorreram níveis acima de $115 \mathrm{~dB}(\mathrm{~A})$ e em qual percentagem de tempo eles ocorreram. (RIBEIRO, et al, 2008)

\subsubsection{Quanto ao Estudo V}

Nesse estudo, foi adotado um procedimento particular de avaliação de níveis de ruído em fones por meio da verificação da atenuação dos equipamentos de proteção individual auditiva utilizados pelo piloto e pela tripulação do helicóptero.

\subsubsection{Quanto ao Estudo VI}

Pode-se notar que se trata de um trabalho com respaldo técnico científico em que foram aplicados na prática todos os conceitos e procedimentos constantes das Normas ISO 11904-1 e 11904-2. É um estudo que sem dúvida deva servir como 
referência para pesquisas posteriores sobre a questão da avaliação de ruído em fones.

\subsubsection{Quanto ao Estudo VII}

A Associação Brasileira de Higienistas Ocupacionais - ABHO, em contato com representante da Empresa Etymotic Research - Research and Product Development For The Ear, da cidade de Chicago, EUA, foi informada que utilizando os equipamentos e a metodologia indicados, podem ser feitas com exatidão as medições de dosimetria de ruído nos aparelhos headsets de telefonistas de call centers.

Considerando as suas especificações e características de custo e praticidade, é uma alternativa que merece ser mais bem estudada e desenvolvida para verificar a sua conformidade às normas ISO 11904. 


\section{ANÁLISE DA NORMA INTERNACIONAL ISO 11904}

Neste capítulo, será abordada detalhadamente as normas internacionais da Série ISO 11904.

A ISO 11904, sob o título geral de "Acústica - Determinação da emissão sonora de fontes sonoras colocadas junto à orelha", conforme já visto, consiste de duas partes que apresentam uma série de normas que especificam métodos para medição e avaliação desses tipos de emissões sonoras, cuja exposição sonora não é adequadamente representada, na posição do ouvinte, quando o indivíduo está ausente.

Visando, então, a adequar essas medições por meio de critérios bem estabelecidos, a exposição a ruído proveniente de fones de ouvido é medida e subseqüentemente convertida para níveis correspondentes aos de campo livre ou campo difuso. O resultado é apresentado em termos de "nível contínuo equivalente de pressão sonora, na ponderação A, relacionado ao campo livre ou difuso". Os níveis medidos são expressos da seguinte maneira: $L F F, H, A e q$ ou $L D F, H, A e q$, quando a ISO 11904-1 é usada, ou LFF,M,Aeq ou LDF,M,Aeq, se aplicada a ISO 11904-2.

A ISO 11904-1 descreve medições por meio de minúsculos microfones, ou microfone, ligados a microssondas e colocados dentro do canal auditivo da pessoa exposta, conhecida como Técnica MIRE (Microphone In a Real Ear). A ISO 11904-2, por sua vez, descreve medições por meio de um manequim, e a técnica de que ela trata, portanto, ficou conhecida como "Técnica do Manequim", em que microfones são incluídos dentro de simuladores de ouvido.

As duas normas da ISO 11904 devem oferecer resultados semelhantes. A ISO 11904-1 fornece as especificações para medições em pessoas, enquanto a ISO 11904-2 se utiliza de um manequim que pretende reproduzir os efeitos acústicos de um humano médio adulto. Entretanto, os dois métodos ainda apresentam diferentes incertezas nas medições, as quais podem influenciar na escolha do método. 
Somente o método descrito na ISO 11904-1 fornece resultados indicando a variância da população humana.

Informações sobre as incertezas das medições que serão abordadas neste trabalho de pesquisa, são apresentadas nos anexos $A$ e $B$ do texto original das normas da série ISO 11904.

Quando a técnica MIRE é utilizada, problemas operacionais podem ocorrer se os microfones ou sondas estiverem mal posicionados no canal auditivo. Por isso, devese analisar bem o modelo de fone, principalmente se for do tipo de inserção ou estetoscópio, além de cuidar da calibração do sistema de medição.

Quando a técnica do manequim é utilizada, a cabeça ou o fone de ouvido tem de ser acoplado adequadamente a uma orelha artificial externa (molde) e ao canal auditivo. Qualquer desvio na flexibilidade ou tamanho do molde da orelha artificial em relação à orelha humana tem um significativo impacto nos resultados, podendo invalidar os resultados obtidos.

\subsection{ISO 11904-1 PARTE 1: TÉCNICA DO MINIMICROFONE EM OUVIDO REAL, CONHECIDA POR TÉCNICA MIRE - MICROPHONE IN A REAL EAR}

Essa parte da ISO 11904 é aplicada para a avaliação da exposição de fontes sonoras junto às orelhas, por exemplo, durante testes de equipamentos, em locais de trabalho que utilizam fones de ouvido ou protetores auriculares com facilidades de comunicação. É aplicada para a faixa de freqüência de $20 \mathrm{~Hz}$ a $16 \mathrm{kHz}$. 


\subsubsection{Termos e definições}

Para os propósitos desta parte da ISO 11904, são aplicados os seguintes termos e definições:

- Posição de medição do canal auditivo - posição correta de colocação do minimicrofone no canal auditivo, onde é feita a medição da pressão sonora;

- Nível de pressão sonora (NPS) do canal auditivo Lear - nível contínuo equivalente de pressão sonora medido na posição do canal auditivo ${ }^{4}$;

- Resposta humana em freqüência relacionada a campo livre $\Delta L F F, H f$ - é a diferença, como uma função das bandas de freqüência em terço de oitava $f$, entre o nível da pressão sonora medido na posição de teste no canal auditivo com a pessoa exposta frontalmente a uma onda plana sonora incidente e o nível de pressão sonora do mesmo campo sonoro com a pessoa ausente;

- Resposta humana em freqüência relacionada a campo difuso $\Delta L \mathrm{DF}, \mathrm{Hf}$ - é a diferença, como uma função das bandas de freqüência em terço de oitava $f$, entre o nível de pressão sonora medido na posição de teste do canal auditivo com a pessoa exposta a um campo sonoro difuso e o nível de pressão sonora do mesmo campo sonoro com a pessoa ausente ${ }^{6}$;

- Nível de pressão sonora (NPS) relacionado a campo livre LFF,H - nível de pressão sonora de uma onda sonora plana no qual deverá ser adicionada a medição do

\footnotetext{
${ }^{4}$ Quando as medições são feitas durante a exposição sonora sob teste, é denominada Lear,exp. Quando opcionalmente medições são feitas durante exposição referente a campo sonoro na determinação das respostas em freqüência de campo livre ou campo difuso, é denominado Lear,FF ou Lear,DF, respectivamente. Quando as medições forem feitas em bandas de freqüência em terço de oitava com freqüência central nominal $f$, adiciona-se o símbolo $f$, sendo denominadas Lear,expf, Lear,FF $f$ e Lear,DFf.

${ }^{5}$ A resposta em freqüência de campo livre é idêntica à amplitude da função de transferência relativa à cabeça - Head - Related Transfer Function (HRTF) para incidência sonora frontal. Essa definição é aplicada para pessoas individualmente e em grupos.

${ }^{6}$ Essa definição é aplicada para pessoas individualmente e em grupos.
} 
nível de pressão sonora do canal auditivo Lear,exp, quando a pessoa sob teste estiver exposta frontalmente a onda plana sonora incidente ${ }^{7}$;

- Nível de pressão sonora (NPS) relacionado a campo difuso LDF,H - nível de pressão sonora de um campo sonoro difuso ao qual deverá ser adicionada a medição do nível de pressão sonora do canal auditivo Lear,exp quando a pessoa sob teste estiver exposta a um campo difuso ${ }^{8}$;

- Canal auditivo aberto - essa expressão é utilizada quando for possível colocar objetos estranhos (tais como microfones, elementos de suporte e de fios de conexão) ocupando menos que $5 \mathrm{~mm}^{2}$ da área de seção transversal, em qualquer ponto/posição ao longo do canal auditivo;

- Canal auditivo obstruído ou bloqueado - essa expressão é utilizada quando for possível colocar um corpo estranho (por exemplo, um protetor de ouvido tipo plugue) ocupando totalmente a área de seção transversal em qualquer ponto/posição ao longo do canal auditivo;

- Canal auditivo parcialmente obstruído ou bloqueado - essa expressão é utilizada quando forem colocados objetos estranhos no canal auditivo externo, ocupando mais de $5 \mathrm{~mm}^{2}$ da área de seção transversal, em ponto/posição ao longo do canal auditivo que não está nem totalmente aberto nem fechado.

\footnotetext{
7 A definição pode ser aplicada a freqüências específicas ou bandas de freqüência, a níveis ponderados/compensados ou não, tempos específicos de resposta, etc., por exemplo, nível contínuo equivalente de pressão sonora, curva de ponderação $A$, relacionado a campo livre (referência a campo livre $L$ H,Aeq, também abreviado por $L F F, H, A e q)$.

${ }^{8}$ A definição pode ser aplicada a freqüências específicas ou bandas de freqüência, a níveis com ponderação ou não, tempos específicos de resposta, etc., por exemplo, "nível contínuo equivalente de pressão sonora, curva de ponderação A, relacionado a campo difuso" (referência a campo difuso LH,Aeq, também abreviado por LDF,H,Aeq).
} 


\subsubsection{Princípios de medição}

Microfones de tamanho bem reduzido, tipo miniatura, ou sondas (tubos) acopladas aos microfones são instalados dentro do canal auditivo. A pessoa testada fica exposta à fonte sonora em questão, e o nível contínuo equivalente de pressão sonora é medido em bandas de terço de oitavas, identificado como Lear,exp,f.

De acordo com a norma ISO, a faixa de freqüência de maior significância para os objetivos do teste é uma relação sinal-ruído de pelo menos $10 \mathrm{~dB}$ que deve ser garantida em cada faixa de freqüência em bandas de terço de oitava.

O tempo de medição $t$ varia em cada faixa de freqüência em bandas de terço de oitava, e deve ser representativo da exposição, sendo especificado na norma: $t \geq 5000 / f$ para $f \leq 2000 \mathrm{~Hz}$ e $t \geq 2,5 \mathrm{~s}$; para $f>2000 \mathrm{~Hz}$, especificações dadas referidas a ruído randômico; para outros tipos de testes, outros períodos podem ser usados contanto que incertezas nas medidas não sejam incrementadas.

O método recomenda que cada nível das bandas de terço de oitava seja ajustado conforme a Tabela 22, mostrada adiante, de acordo com a resposta em freqüência para campo livre $\Delta L F F, H f$ ou campo difuso $\Delta L D F, H f$, para obter os correspondentes níveis de pressão sonora com referência a campo livre ou com referência a campo difuso. Esses níveis de terço de oitava são corrigidos pela curva de ponderação $A$ [dB (A)] e subseqüentemente ajustados para obter o nível contínuo equivalente de pressão sonora com ponderação $A$, referente ao campo livre $L F F, H, A e q$ ou difuso LDF,H,Aeq.

As medições ${ }^{9}$ podem ser feitas para um ou dois ouvidos, conforme o caso.

\footnotetext{
${ }^{9} \mathrm{~A}$ exatidão do resultado final depende de vários parâmetros (por exemplo, da posição de medição no canal auditivo, do número de pessoas expostas aos testes, etc.).
} 


\subsubsection{Instrumentação}

- Microfone no canal auditivo:

A pressão sonora no canal auditivo deverá ser medida por um microfone de qualquer um dos tipos: microfone miniatura colocado no canal auditivo ou um microfone com sonda acoplada consistindo de um microfone colocado fora da orelha e equipado com uma sonda/tubo instalada no canal auditivo. Para prevenir danos ao tímpano e à pele do canal auditivo, o tubo deverá ser feito de um material flexível e macio.

O microfone utilizado deverá ter sua resposta de pressão comparada a leituras obtidas com outro microfone de pressão, calibrado de acordo com a IEC 61094-1 - Specifications for laboratory standard microphones. (IEC 61094-1, 2000)

- Microfone relacionado ao campo:

Quando particulares respostas em freqüência de campo livre $\Delta L F F, H$ ou de campo difuso $\Delta L D F, H$, são determinadas, um microfone relacionado ao campo é utilizado para determinar o nível de pressão sonora no campo sonoro relacionado com a ausência da pessoa. Esse microfone e os equipamentos conectados utilizados devem atender totalmente aos requisitos da norma IEC 61672-1 - Sound level meters para instrumento de classe 1, e deverão ser conhecidas as respostas em campo livre ou em campo difuso. (IEC 61672-1, 2002-05)

- Verificação da Calibração:

A calibração dos microfones e dos equipamentos de medição deverá ser apropriadamente verificada. Para microfones utilizados em campo, isso deverá ser feito utilizando um calibrador acústico, que deve cumprir com os requisitos para classe 1 da IEC 60942 - Electroacustics - Sound calibrators. (IEC 60942, 2003). 
- Filtros:

Os sinais deverão ser analisados com filtros de freqüência em bandas de freqüência de terço de oitava, devendo atender aos requisitos para classe 1 da IEC 61260 (1995) - Electroacustics - Octave band and fractional octave band filters. (IEC 61260, 1995).

- Utilização do microfone no canal auditivo:

O ajuste do microfone deve proporcionar uma posição estável, livre de ressonâncias pronunciadas, e isso pode requerer o uso de suportes especiais. A idéia é evitar "distúrbios" no campo sonoro ou vazamentos entre o fone de ouvido e a orelha. A máxima área ocupada pelo minúsculo microfone na concha auditiva da orelha (incluindo elementos de suporte e fios de conexão) não poderá exceder $10 \mathrm{~mm}^{2}$ em qualquer plano.

- Escolha das pessoas a serem testadas:

Somente pessoas livres de inflamação e qualquer outra doença ou enfermidade da orelha externa e da orelha média são adequadas para participar das avaliações. Para medições em canal auditivo aberto, somente pessoas com canais não tão estreitos, retos ou severamente inclinados, e que não revelaram defeitos ou problemas no tímpano, deverão ser escolhidas. Se houver cerume obstruindo o canal auditivo, ele deverá ser removido a priori. A instalação de dispositivos no canal auditivo deve ser feita ou acompanhada por pessoas qualificadas, como profissionais da área médica, familiarizadas e com especialização no assunto.

- Escolha da posição de medição no canal auditivo

O ponto de medição no canal auditivo deverá estar entre a entrada do canal auditivo e o tímpano, ou, no caso de canal auditivo obstruído, entre a entrada e a obstrução, em cada caso, de preferência próximo do centro do eixo do canal.

O posicionamento do microfone ou da sonda dentro do canal auditivo é extremamente importante, devendo-se escolher uma das três situações adiante (Figura 21): 
i) Membrana timpânica com o canal auditivo aberto.

ii) Entrada do canal auditivo aberto.

iii) Entrada de um canal auditivo bloqueado, tendo um plugue tampão na entrada.

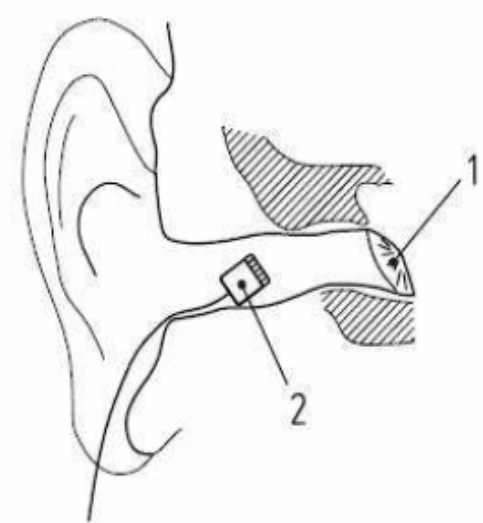

i) Microfone miniatura no canal auditivo aberto

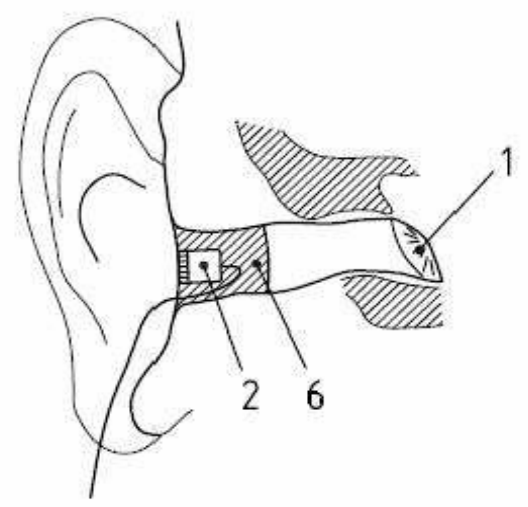

iii) microfone miniatura no canal auditivo bloqueado

Legenda:

1 Tímpano

2 Microfone miniatura

3 Sonda tubo

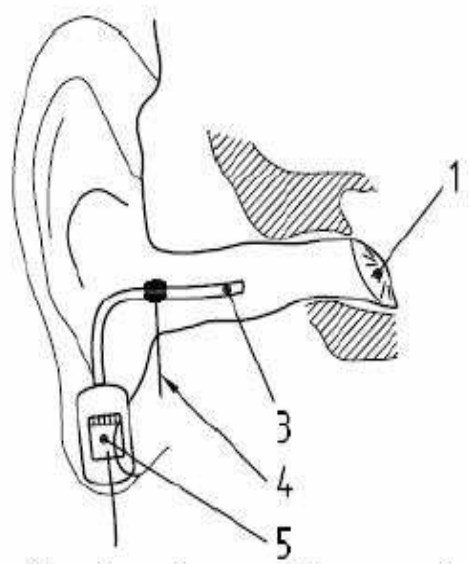

ii) Microfone de sonda com o tubo no canal auditivo aberto 


\subsubsection{Determinação das respostas em freqüência de campo livre ou campo difuso - Correções}

Se forem adotadas as posições de medição mencionadas anteriormente, os níveis medidos deverão ser ajustados conforme a Tabela 22, extraída do texto original da norma.

Medições diferenciadas devem ser feitas (de acordo com o item 10 do texto apresentado na norma original).

Tabela 22 - Correção dos níveis de pressão sonora para obtenção da resposta em freqüência no campo livre e no campo difuso em função das posições de medições selecionadas no canal auditivo

\begin{tabular}{|c|c|c|c|c|c|c|}
\hline \multirow{2}{*}{$\begin{array}{c}\text { Freqüência } \\
\text { da banda } \\
\text { central em } \\
\text { terço de } \\
\text { oitava }\end{array}$} & \multicolumn{3}{|c|}{$\begin{array}{l}\text { Resposta em freqüência } \\
\text { de campo livre } \Delta L F F, H, f\end{array}$} & \multicolumn{3}{|c|}{$\begin{array}{l}\text { Resposta em freqüência } \\
\text { de campo difuso } \Delta L D F, H, f\end{array}$} \\
\hline & Tímpano & $\begin{array}{l}\text { Entrada } \\
\text { aberta }\end{array}$ & $\begin{array}{l}\text { Entrada } \\
\text { bloqueada }\end{array}$ & Tímpano & $\begin{array}{l}\text { Entrada } \\
\text { aberta }\end{array}$ & $\begin{array}{l}\text { Entrada } \\
\text { obstruída }\end{array}$ \\
\hline $\mathrm{Hz}$ & $d B$ & $\mathrm{~dB}$ & $\mathrm{~dB}$ & $d B$ & $d B$ & $d B$ \\
\hline$\leq 100$ & 0,0 & $\overline{0,0}$ & 0,0 & $\overline{0,0}$ & 0,0 & $\overline{0,0}$ \\
\hline 125 & 0,2 & 0,2 & 0,2 & 0,2 & 0,2 & 0,2 \\
\hline 160 & 0,4 & 0,4 & 0,4 & 0,4 & 0,4 & 0,4 \\
\hline 200 & 0,6 & 0,6 & 0,6 & 0,6 & 0,6 & 0,6 \\
\hline 250 & 0,8 & 0,8 & 0,8 & 0,8 & 0,8 & 0,8 \\
\hline 315 & 1,1 & 1,1 & 1,1 & 1,1 & 1,1 & 1,1 \\
\hline 400 & 1,5 & 1,5 & 1,5 & 1,5 & 1,5 & 1,5 \\
\hline 500 & 2,0 & 1,6 & 1,7 & 2,1 & 1,7 & 1,7 \\
\hline 630 & 2,3 & 1,8 & 1,8 & 2,8 & 2,1 & 2,2 \\
\hline 800 & 3,1 & 1,3 & 1,4 & 3,3 & 2,5 & 2,3 \\
\hline 1000 & 2,7 & 0,6 & $-0,4$ & 4,1 & 2,9 & 2,3 \\
\hline 1250 & 2,9 & 1,5 & 1,3 & 5,5 & 3,6 & 3,1 \\
\hline 1600 & 5,8 & 5,2 & 4,1 & 7,7 & 4,7 & 3,8 \\
\hline 2000 & 12,4 & 8,6 & 6,6 & 11,0 & 6,4 & 4,4 \\
\hline 2500 & 15,7 & 9,5 & 7,1 & 15,3 & 8,2 & 5,9 \\
\hline 3150 & 14,9 & 7,8 & 10,1 & 15,7 & 5,8 & 8,1 \\
\hline 4000 & 13,2 & 5,7 & 12,8 & 12,9 & 3,0 & 10,3 \\
\hline 5000 & 8,9 & 5,6 & 10,5 & 10,6 & 5,1 & 10,0 \\
\hline 6300 & 3,1 & 2,9 & 2,8 & 9,4 & 6,9 & 7,3 \\
\hline 8000 & $-1,4$ & $-2,0$ & $-1,2$ & 9,5 & 5,6 & 6,0 \\
\hline 10000 & $-3,8$ & $-5,0$ & 0,2 & 6,8 & $-0,9$ & 3,8 \\
\hline 12500 & $-0,1$ & 5,1 & 6,1 & 3,8 & 1,0 & 2,0 \\
\hline 16000 & $-0,4$ & 2,2 & 2,4 & 0,7 & $-0,9$ & $-0,2$ \\
\hline
\end{tabular}

Fonte: Norma ISO 11904-1, 2002. Tabela 1, p.8 


\subsubsection{Tratamento dos dados}

As medições obtidas dentro do canal auditivo, Lear,exp, $f$, não podem ser comparadas diretamente com os níveis estabelecidos na Norma Regulamentadora NR 15 Anexos 1 e 2 do Ministério do Trabalho ou com a Norma de Higiene Ocupacional NHO 01 da Fundacentro. As leituras devem ser corrigidas conforme a posição de medição e a freqüência dos sons, observando as seguintes equações:

$L \mathrm{FF}, \mathrm{H}, f=L$ ear,exp, $f-\Delta L \mathrm{FF}, \mathrm{H}, f$

$L D F, H, f=L$ ear,exp,f $-\Delta L D F, H, f$

Onde: $L_{F F}, H, f$ ou $L D F, H, f$ - nível contínuo equivalente de pressão sonora relacionado ao campo livre ou difuso;

Lear,exp,f - medições obtidas dentro do canal auditivo;

$\Delta L F F, H, f$ ou $\Delta L D F, H, f-$ correções dadas na Tabela 1 do texto original da norma, que corresponde a Tabela 22 do presente trabalho de pesquisa.

Os dados corrigidos em cada banda de freqüência são somados e em seguida devem ser calculados, observando a curva de ponderação $A[\mathrm{~dB}(\mathrm{~A})]$, utilizando as constantes Af calculadas ou especificadas na norma IEC 61672-1 (2002) de acordo com a Tabela 23. 
Tabela 23 - Ponderações em freqüência e limites de tolerância incluindo os valores máximos das incertezas das medições

\begin{tabular}{|c|c|c|c|c|c|}
\hline \multirow{2}{*}{$\begin{array}{c}\text { Freqüência } \\
\text { nominal } \\
\mathrm{Hz}\end{array}$} & \multicolumn{3}{|c|}{$\begin{array}{l}\text { Ponderação em freqüência } \\
\qquad \mathrm{dB}\end{array}$} & \multicolumn{2}{|c|}{$\begin{array}{l}\text { Limites de tolerância }(\mathrm{dB}) \\
\text { Classe }\end{array}$} \\
\hline & $A(A f)$ & C & Z & 1 & 2 \\
\hline 10 & $-70,4$ & $-14,3$ & 0,0 & $+3,5 ;-\infty$ & $+5,5 ;-\infty$ \\
\hline 12,5 & $-63,4$ & $-11,2$ & 0,0 & $+3,0 ;-\infty$ & $+5,5 ;-\infty$ \\
\hline 16 & $-56,7$ & $-8,5$ & 0,0 & $+2,5 ;-4,5$ & $+5,5 ;-\infty$ \\
\hline 20 & $-50,5$ & $-6,2$ & 0,0 & $\pm 2,5$ & $\pm 3,5$ \\
\hline 25 & $-44,7$ & $-4,4$ & 0,0 & $+2,5 ;-2,0$ & $\pm 3,5$ \\
\hline 31,5 & $-39,4$ & $-3,0$ & 0,0 & $\pm 2,0$ & $\pm 3,5$ \\
\hline 40 & $-34,6$ & $-2,0$ & 0,0 & $\pm 1,5$ & $\pm 2,5$ \\
\hline 50 & $-30,2$ & $-1,3$ & 0,0 & $\pm 1,5$ & $\pm 2,5$ \\
\hline 63 & $-26,2$ & $-0,8$ & 0,0 & $\pm 1,5$ & $\pm 2,5$ \\
\hline 80 & $-22,5$ & $-0,5$ & 0,0 & $\pm 1,5$ & $\pm 2,5$ \\
\hline 100 & $-19,1$ & $-0,3$ & 0,0 & $\pm 1,5$ & $\pm 2,0$ \\
\hline 125 & $-16,1$ & $-0,2$ & 0,0 & $\pm 1,5$ & $\pm 2,0$ \\
\hline 160 & $-13,4$ & $-0,1$ & 0,0 & $\pm 1,5$ & $\pm 2,0$ \\
\hline 200 & $-10,9$ & 0,0 & 0,0 & $\pm 1,5$ & $\pm 2,0$ \\
\hline 250 & $-8,6$ & 0,0 & 0,0 & $\pm 1,4$ & $\pm 1,9$ \\
\hline 315 & $-6,6$ & 0,0 & 0,0 & $\pm 1,4$ & $\pm 1,9$ \\
\hline 400 & $-4,8$ & 0,0 & 0,0 & $\pm 1,4$ & $\pm 1,9$ \\
\hline 500 & $-3,2$ & 0,0 & 0,0 & $\pm 1,4$ & $\pm 1,9$ \\
\hline 630 & $-1,9$ & 0,0 & 0,0 & $\pm 1,4$ & $\pm 1,9$ \\
\hline 800 & $-0,8$ & 0,0 & 0,0 & $\pm 1,4$ & $\pm 1,9$ \\
\hline 1000 & 0 & 0 & 0 & $\pm 1,1$ & $\pm 1,4$ \\
\hline 1250 & $+0,6$ & 0,0 & 0,0 & $\pm 1,4$ & $\pm 1,9$ \\
\hline 1600 & $+1,0$ & $-0,1$ & 0,0 & $\pm 1,6$ & $\pm 2,6$ \\
\hline 2000 & $+1,2$ & $-0,2$ & 0,0 & $\pm 1,6$ & $\pm 2,6$ \\
\hline 2500 & $+1,3$ & $-0,3$ & 0,0 & $\pm 1,6$ & $\pm 3,1$ \\
\hline 3150 & $+1,2$ & $-0,5$ & 0,0 & $\pm 1,6$ & $\pm 3,1$ \\
\hline 4000 & $+1,0$ & $-0,8$ & 0,0 & $\pm 1,6$ & $\pm 3,6$ \\
\hline 5000 & $+0,5$ & $-1,3$ & 0,0 & $\pm 2,1$ & $\pm 4,1$ \\
\hline 6300 & $-0,1$ & $-2,0$ & 0,0 & $+2,1 ;-2,6$ & $\pm 5,1$ \\
\hline 8000 & $-1,1$ & $-3,0$ & 0,0 & $+2,1 ;-3,1$ & $\pm 5,6$ \\
\hline 10000 & $-2,5$ & $-4,4$ & 0,0 & $+2,6 ;-3,6$ & $+5,6 ;-\infty$ \\
\hline 12500 & $-4,3$ & $-6,2$ & 0,0 & $+3,0 ;-6,0$ & $\pm 6,0 ;-\infty$ \\
\hline 16000 & $-6,6$ & $-8,5$ & 0,0 & $+3,5 ;-17,0$ & $+6,0 ;-\infty$ \\
\hline 20000 & $-9,3$ & $-11,2$ & 0,0 & $+4,0 ;-\infty$ & $+6,0 ;-\infty$ \\
\hline
\end{tabular}

Fonte: Norma IEC 61672-1, 2002. Tabela 2, p.33 
Para se obter o nível contínuo equivalente de pressão sonora com ponderação $A$, relacionado ao campo livre LFF,H,Aeq ou difuso LDF,H,Aeq, deve-se calculá-lo conforme as correspondentes fórmulas:

$$
L_{F F, H, A e q}=10 \log \left[\Sigma_{f} 10^{\mathrm{a}}\right] \quad \mathrm{dB}(\mathrm{A})
$$

Onde $\mathrm{a}=\left(L \mathrm{FF}, \mathrm{H}, f+\mathrm{A}_{f}\right) / 10$

$$
L \mathrm{DF}, \mathrm{H}, \mathrm{Aeq}=10 \log \left[\Sigma_{f} 10^{\mathrm{a}}\right] \quad \mathrm{dB}(\mathrm{A})
$$

Onde $\mathrm{a}=\left(\mathrm{LDF}, \mathrm{H}, f+\mathrm{A}_{f}\right) / 10$

Os níveis de pressão sonora contínua equivalente relacionados ao campo difuso que representam a exposição global ao ruído devem ser calculados usando a ponderação $A$, definido como $A$, por meio da seguinte expressão:

$$
L_{\mathrm{DF}, \text { Aeq }}=10 \log \left\{\Sigma_{f} 10^{\mathrm{a}}\right\} \mathrm{dB}(\mathrm{A})
$$

Onde $\mathrm{a}=\left(\mathrm{LDF}_{\mathrm{f}, f}+\mathrm{A}_{f}\right) / 10$

No anexo A (apresentado nos originais das normas da série ISO 11904), são dados exemplos de incertezas de medição, devidas a: posição inadequada do microfone no canal auditivo; número limitado de pessoas participantes dos testes; utilização de dados tabulados de resposta em freqüência de campo livre ou difuso; respostas em freqüência determinadas individualmente para campo livre ou campo difuso. Também são apresentados exemplos comparativos de situações similares de medição realizadas por meio da técnica MIRE e técnica do manequim, que resultaram em desvios nos respectivos resultados. 
A ISO 11904 -1 (no seu anexo A.3 apresentado na norma original), considerando o fato de que somente um número limitado de pessoas pode ser utilizado nas medições o que resulta numa incerteza estatística dos resultados, mostra como devem ser calculadas as médias aritméticas dos $L_{F F}, \mathrm{H}, f$ ou $L_{\mathrm{DF}, \mathrm{H}, f}$ e os respectivos desvios-padrão $\sigma$ das leituras obtidas em cada ouvido testado, utilizando dados tabulados ou respostas em freqüência determinadas individualmente.

O erro ou o desvio-padrão da média (dentre os indivíduos) para o campo livre relacionado com o nível de pressão sonora, $\sigma\left(\bar{L}_{F F, f}\right)$, ou o erro-padrão da média (dentre os indivíduos) para o campo difuso relacionado com o nível de pressão sonora, $\sigma\left(\bar{L}_{D F, f}\right)$, pode ser calculado a partir de:

i) Desvio-padrão (entre indivíduos) do nível de pressão sonora no canal auditivo:

$$
\sigma\left(\bar{L}_{\text {ear,exp, }, \mathrm{f}}\right)
$$

ii) do número de indivíduos $n$ :

$$
\sigma\left(\bar{L}_{F F, f}\right) \approx \sigma\left(\bar{L}_{D F, f}\right) \approx \sqrt{\frac{\sigma^{2}\left(L_{e a r, e x p, f}\right)}{n}}
$$

De acordo com a norma ISO 11904-1 (em seu anexo B apresentado na norma original) o que segue é um exemplo de como as incertezas podem ser estimadas para uma determinação hipotética de $L_{F F}$,Aeq ou $L D F$,Aeq de um fone de ouvido supraaural tipo aberto. Isso não deve ser assumido como uma lista (exaustiva) de todas as possíveis incertezas nem como um guia para valores típicos, mas apenas um exemplo de uma análise de incerteza para uma situação específica.

Além disso, deve-se estimar a incerteza das medições pelo método ISO/IEC Guide 98 (1995) - Guide to the expression of uncertainty in measurement (GUM). Um 
exemplo da aplicação do GUM é dado no anexo B (apresentado no texto original da norma ISO 11904-1 como Tabela B.1), como mostra a Tabela 27.

$\mathrm{Na}$ estimativa das incertezas das medições com a técnica MIRE (orelha real), são consideradas as seguintes condições: utilização de minimicrofones; respostas em freqüência de pessoas sob teste em campo livre ou campo difuso; ruído branco ou ruído rosa que simulam a fala e a música como sinal de teste de entrada no fone de ouvido; resultado médio das medições em ambas as orelhas de oito pessoas sob teste; seis medições na orelha de cada uma das oito pessoas sob teste; utilização de fone de ouvido supra-aural tipo aberto, sempre utilizando a cápsula esquerda na orelha esquerda e a cápsula direita na orelha direita. As medições referentes a resposta em freqüência devem ser repetidas imediatamente após as medições sonoras sob teste e devem ser cuidadosamente verificadas por comparação com a primeira medição, de forma que, se ocorrerem desvios não esperados, o procedimento completo de medição deve ser repetido.

As análises das incertezas são então transportadas para o resultado final de $L F F, H, A e q$ ou LDF,H,Aeq. As incertezas são obtidas pela multiplicação do padrão combinado de incertezas pelo fator de correção k=2, que cobre a probabilidade de 95\%.

As incertezas resultam de 6 (seis) diferentes fontes. As correspondentes componentes são avaliadas como incertezas do Tipo B.

$\mathrm{Na}$ Tabela 27 deste trabalho de pesquisa (Tabela B.1 do texto original da norma ISO 11904-1) são apresentados os resultados dessas análises das incertezas.

\subsubsection{Interpretação de resultados}

No item 11 (do texto original da norma ISO 11904 -1) são elencadas basicamente 11 (onze) informações [de a) até $k$ )] que devem ser incluídas no relatório de testes das avaliações, consideradas como a quantidade mínima. (Tabela 26). 
No item 5.3 deste trabalho de pesquisa, é abordado o assunto referente ao relatório de testes das avaliações e à análise de incerteza das medições.

O resultado final deve ser usado para comparação com os limites de tolerância e critérios estabelecidos na legislação brasileira do Ministério do Trabalho, Norma Regulamentadora NR-15 - Anexos 1 e 2 ou com a norma NHO 01 da Fundacentro.

\subsection{ISO 11904-2 PARTE 2 - TÉCNICA DA CABEÇA ARTIFICIAL DE MANEQUIM, CONHECIDA COMO TÉCNICA USANDO MANEQUIM}

Essa parte da ISO 11904 também é aplicada para avaliação da exposição de fontes sonoras junto às orelhas, por exemplo, durante testes de equipamentos, em locais de trabalho que utilizem fones de ouvido ou para protetores auriculares com facilidades de comunicação. É aplicada para a faixa de freqüência de $20 \mathrm{~Hz}$ a 10 $\mathrm{kHz}$.

\subsubsection{Termos e Definições}

Para os propósitos dessa parte da ISO 11904, são aplicados os seguintes termos e definições:

- Nível de pressão sonora no manequim LM,exp,f - nível contínuo equivalente de pressão sonora em bandas de freqüência de terço de oitava com freqüência central nominal $f$, medidas com o microfone no simulador de ouvido integrado ao manequim, quando o manequim está exposto a fonte sonora sob teste.

- Resposta em freqüência relacionada a campo livre utilizando manequins $\Delta L_{\mathrm{FF}, \mathrm{M}, f}$ - resposta em freqüência do ouvido médio humano relacionado a campo livre para utilização com manequins corrigida pela diferença entre a transmissão sonora (nível de pressão sonora) no canal auditivo humano médio e a 
correspondente transmissão sonora (nível de pressão sonora medido pelo microfone) do simulador de ouvido do manequim. ${ }^{10} 1112$

- Resposta em freqüência relacionada a campo difuso utilizando manequins $\Delta L D F, M, f$ - resposta em freqüência do ouvido médio humano relacionado a campo difuso para utilização com manequins corrigida pela diferença entre a transmissão sonora (nível de pressão sonora) no canal auditivo humano médio e a correspondente transmissão sonora (nível de pressão sonora medido pelo microfone) do simulador de ouvido do manequim. ${ }^{13} 14$

- Nível de pressão sonora relacionado a campo livre determinado com um manequim LFF,M - nível de pressão sonora em campo livre determinado com o método da parte 2 da norma ISO $11904 .^{15} 1617$

- Nível de pressão sonora relacionado a campo difuso determinado com um manequim LDF,M - nível de pressão sonora em campo difuso determinado com o método da parte 2 da norma ISO $11904 .^{18} 1920$

\footnotetext{
${ }^{10}$ Para aplicabilidade com manequins, a referência no tímpano é substituída pela saída do simulador do ouvido do manequim em valores tabulados de $\Delta L F F, M, f$.

${ }^{11}$ Para resposta em freqüência de campo livre para utilização com manequins, é idêntica a amplitude da função de transferência relativa a cabeça - Head -Related Transfer Function (HRTF) para incidência sonora frontal.

${ }^{12}$ A resposta humana em freqüência de campo livre é definida na norma ISO 11904-1, reproduzida no subitem 5.1.1 deste trabalho.

${ }^{13}$ Para aplicabilidade com manequins, a referência no tímpano é substituída pela saída do simulador do ouvido do manequim em valores tabulados de $\Delta L D F, M, f$.

${ }^{14}$ A resposta humana em freqüência de campo difuso é definida na norma ISO 11904-1, reproduzida no subitem 5.1.1 deste trabalho.

15 A definição pode ser aplicada a freqüências específicas ou bandas de freqüência, a níveis ponderados/compensados ou não, tempos específicos de resposta, etc., por exemplo, nível contínuo equivalente de pressão sonora, curva de ponderação A, relacionado a campo livre (referência a campo livre LM,Aeq, também denominada $L F F, M, A e q)$.

${ }^{16} \mathrm{O}$ método destinado a obter a média dos níveis de pressão sonora relacionados a campo livre pretende que os resultados encontrados sejam representativos da maioria da população humana.

${ }_{17}$ A resposta humana em freqüência de campo livre é definida na norma ISO 11904-1, reproduzida no subitem 5.1.1 deste trabalho.

${ }^{18}$ A definição pode ser aplicada a freqüências específicas ou bandas de freqüência, a níveis ponderados/compensados ou não, tempos específicos de resposta, etc., por exemplo, nível contínuo equivalente de pressão sonora, curva de ponderação/compensação $A$, relacionado a campo difuso (referência a campo difuso $L \mathrm{M}, A$ eq, também denominada $L \mathrm{DF}, \mathrm{M}, \mathrm{Aeq}$ ).

${ }^{19} \mathrm{O}$ método destinado a obter a média dos níveis de pressão sonora relacionados a campo difuso pretende que os resultados encontrados sejam representativos da maioria da população humana.

${ }^{20}$ A resposta humana em freqüência relacionada de campo difuso $\Delta L D F, H, f$ é definida na norma ISO 11904-1, reproduzida no subitem 5.1.1 deste trabalho.
} 


\subsubsection{Princípios de medição}

Os níveis de ruído $\left(L_{M}, \exp , f\right)$ são medidos em bandas de freqüência de terço de oitava por meio de um manequim padronizado, constituído basicamente por uma cabeça e um torso, que fica exposto às fontes sonoras, tendo dois ouvidos artificiais instalados de forma similar ao corpo humano.

Com o manequim exposto à fonte sonora em questão, o nível contínuo equivalente de pressão sonora é medido para cada banda de terço de oitava, identificado como LM,exp,f, devendo ser medido com cada simulador de ouvido. A faixa de freqüência deverá cobrir todas as freqüências de maior significância para os objetivos do teste e uma relação sinal-ruído de pelo menos $10 \mathrm{~dB}$ que deve ser garantida em cada faixa de freqüência em bandas de terço de oitava. Se somente um simulador de ouvido for utilizado, isso deverá ser informado.

O tempo de medição $t$ varia em cada faixa de freqüência em bandas de terço de oitava, e deve ser representativo da exposição, sendo especificado na norma: $t \geq 5000 / f$ para $f \leq 2000 \mathrm{~Hz}$ e $t \geq 2,5 \mathrm{~s}$; para $f>2000 \mathrm{~Hz}$, especificações dadas referidas a ruído randômico; para outros tipos de testes, outros períodos podem ser usados contanto que incertezas nas medidas não sejam incrementadas.

\subsubsection{Instrumentação}

- Manequim

O simulador pode ser composto por um conjunto de cabeça e torso ou somente pela cabeça artificial e devem atender as especificações da União Internacional de Telecomunicações ITU (International Telecommunication Union), sediada em Genebra (Suíça), definidas na recomendação ITU-T P.58 (1996), itens 4.3, primeiro parágrafo, 5.1 e 6.1 para o simulador de ouvido e demais características acústicas desse conjunto, respectivamente. 
Nos casos em que as fontes sonoras (tais como fones de ouvido, protetores auriculares com facilidades de comunicação) tocarem a orelha, elas deverão ser acopladas a um simulador de orelha (molde de uma orelha artificial de um humano adulto médio) tão fechada quanto possível para evitar vazamentos. ${ }^{21}$

- Verificação da Calibração

A calibração dos microfones e do sistema de medição devem ser feita em conjunto com o simulador de ouvido artificial obstruído, de acordo com a norma IEC 60942 (2003) classe 1, devendo ser acoplado ao simulador de ouvido obstruído. O nível de pressão sonora, nesse caso, deverá ser medido, no circuito ou resposta, sem ponderação em qualquer freqüência.

Essa medição é geralmente conduzida com a ajuda de um adaptador na extensão do canal auditivo. Deverá ser conhecido e considerado que o adaptador poderá alterar os valores nominais dos níveis de pressão sonora do calibrador.

A resposta em freqüência do sistema de medição sem o simulador de ouvido obstruído/bloqueado pode ser medida utilizando na entrada um apropriado sinal elétrico.

- Filtros

Os sinais deverão ser analisados com filtros de freqüência em bandas de freqüência de terços de oitava, devendo atender aos requisitos para classe 1 da IEC 61260 (1995).

\footnotetext{
${ }^{21}$ Nos casos em que os fones de ouvido ou outros objetos toquem a orelha, há os desvios devidos à rigidez ou molde da orelha artificial em relação à orelha humana. Isso tem um significativo impacto no resultado e pode até mesmo invalidar os resultados.
} 


\subsubsection{Determinação das respostas em freqüência de campo livre ou campo difuso - Correções}

O método recomenda que cada um dos níveis de ruído obtidos no manequim, nas bandas de terço de oitava, seja ajustado para uma resposta de freqüência em campo livre $(\Delta L F F, M, f)$ ou difuso $(\Delta L D F, M, f)$.

A resposta em freqüência para campo livre ou difuso é obtida com base na Tabela 24 integrante da norma, com a qual os níveis medidos deverão ser ajustados.

É importante informar que, no rodapé da Tabela constante na versão original da norma ISO 11904-2 (que corresponde à Tabela 24 do presente trabalho de pesquisa), em nota, é indicado que os dados na entrada obstruída/bloqueada do ouvido humano médio são transferidos para a entrada obstruída/bloqueada do "tímpano do manequim" utilizando a função de transferência dos simuladores de ouvido de acordo com a norma IEC 60711 (1981). 
Tabela 24 - Resposta em freqüência de campo livre e do campo difuso para uso com manequins

\begin{tabular}{|c|c|c|}
\hline $\begin{array}{c}\text { Freqüência da banda central, } \\
\text { em terço de oitava } \\
\mathrm{Hz}\end{array}$ & $\begin{array}{c}\text { Resposta em freqüência de } \\
\text { campo livre } \\
\Delta L_{\mathrm{FF}, \mathrm{M}, f} \\
\mathrm{~dB}\end{array}$ & $\begin{array}{c}\text { Resposta em freqüência de } \\
\text { campo difuso } \\
\Delta L D F, M, f \\
d B\end{array}$ \\
\hline$\leq 100$ & 0 & 0 \\
\hline 125 & 0,4 & 0,3 \\
\hline 160 & 0,8 & 0,6 \\
\hline 200 & 1,2 & 0,9 \\
\hline 250 & 1,5 & 1,2 \\
\hline 315 & 1,5 & 1,4 \\
\hline 400 & 1,7 & 1,8 \\
\hline 500 & 2,1 & 2,3 \\
\hline 630 & 2,5 & 3,2 \\
\hline 800 & 2,2 & 4,0 \\
\hline 1000 & 1,7 & 4,6 \\
\hline 1250 & 3,8 & 6,0 \\
\hline 1600 & 8,4 & 8,1 \\
\hline 2000 & 12,9 & 11,4 \\
\hline 2500 & 15,6 & 15,0 \\
\hline 3150 & 15,6 & 14,2 \\
\hline 4000 & 14,2 & 11,9 \\
\hline 5000 & 10,6 & 9,8 \\
\hline 6300 & 4,0 & 8,5 \\
\hline 8000 & 2,0 & 11,0 \\
\hline 10000 & $-0,3$ & 7,1 \\
\hline
\end{tabular}

Fonte: Norma ISO 11904-2, 2004. Tabela 1, p.5

A nota informa também que foram encontrados desvios sistemáticos nos valores de exposição a fontes sonoras colocadas na orelha fechada, medidos com manequins, comparados às medições utilizando a técnica MIRE, utilizando seres humanos. Para compensação, a resposta em freqüência listada na Tabela 24 difere da resposta em freqüência dos manequins especificados na ITU-T P.58 (1996) ou na IEC 60959 (1990). Assim, a resposta em freqüência relacionada ao campo difuso em orelha fechada na técnica utilizando o manequim $(\Delta L D F, M, f)$ pode ser obtida utilizando a Recomendação ITU-T P.58 (1996), que corresponde à Tabela 25 do presente trabalho de pesquisa.

Obs.: Se for necessário utilizar um manequim de cabeça sem torso, devido à variação do método, torna-se necessário utilizar outra Tabela de correção ajustada às características do manequim de cabeça utilizado. 
Tabela 25 - Correção dos níveis de pressão sonora para obtenção da resposta em freqüência de campo difuso na técnica utilizando manequim com cabeça artificial e torso

\begin{tabular}{|c|c|c|c|}
\hline $\begin{array}{c}\text { Freqüência } \\
(\mathrm{Hz})\end{array}$ & $\begin{array}{l}\text { Resposta em freqüência de } \\
\text { campo difuso } \Delta L D F, M, f \\
(\mathrm{~dB})\end{array}$ & \multicolumn{2}{|c|}{$(\mathrm{dB})$} \\
\hline 100 & 0,0 & \multicolumn{2}{|c|}{ $\pm 1,0$} \\
\hline 125 & 0,0 & \multicolumn{2}{|c|}{ \pm 10} \\
\hline 160 & 0,0 & \multicolumn{2}{|c|}{ $\pm 1,0$} \\
\hline 200 & 0,0 & \multicolumn{2}{|c|}{ $\pm 1,0$} \\
\hline 250 & 0,5 & \multicolumn{2}{|c|}{ $\pm 1,0$} \\
\hline 315 & 0,5 & \multicolumn{2}{|c|}{ $\pm 1,0$} \\
\hline 400 & 1,0 & \multicolumn{2}{|c|}{ $\pm 1,0$} \\
\hline 500 & 1,5 & \multicolumn{2}{|c|}{$\begin{array}{l} \pm 1,0 \\
\pm 1,5\end{array}$} \\
\hline 630 & 2.0 & \multicolumn{2}{|c|}{ $\pm 1,5$} \\
\hline 800 & 4,0 & \multicolumn{2}{|c|}{ $\pm 2,0$} \\
\hline 1000 & 5,0 & \multicolumn{2}{|c|}{ $\pm 2,0$} \\
\hline 1250 & 6,5 & \multicolumn{2}{|c|}{ $\pm 1,5$} \\
\hline 1600 & 8,0 & \multicolumn{2}{|c|}{$\begin{array}{l} \pm 1.5 \\
\pm\end{array}$} \\
\hline 2000 & 10,5 & +2.0 & -1.0 \\
\hline 2500 & 14,0 & $+2,0$ & $-3,0$ \\
\hline 3150 & 12,0 & $+6,0$ & $-1,0$ \\
\hline 4000 & 11,5 & $+5,0$ & $-2,0$ \\
\hline 5000 & 11,0 & $+5,5$ & $-2,0$ \\
\hline 6300 & 8.0 & +2.0 & -3.0 \\
\hline 8000 & 6,5 & $+5,0$ & $-4,0$ \\
\hline 10000 & 10,5 & 0,0 & $-10,0$ \\
\hline
\end{tabular}

Fonte: Recomendação ITU-T P.58, 1996. Quadro 3/p.58, p.15

Depois, os níveis das bandas de terço de oitava são ajustados ou corrigidos de acordo com a curva de ponderação $A[\mathrm{~dB}(\mathrm{~A})]$ e subseqüentemente combinados para obter o nível contínuo equivalente de pressão sonora Leq em $d B(A)$, referente ao campo livre $L F F, M, A e q$ ou difuso $L D F, M, A e q$.

As medições podem ser feitas em um ou nos dois ouvidos, conforme a necessidade.

\subsubsection{Tratamento dos dados}

Igualmente ao já comentado em relação ao método MIRE, as medições obtidas por meio do manequim ( $L \mathrm{M}, \mathrm{exp}, f)$ também não podem ser comparadas diretamente com os níveis estabelecidos na legislação brasileira, nos Anexos ㄲo. 1 e №. 2 da Norma Regulamentadora NR 15 do Ministério do Trabalho ou com a Norma de Higiene Ocupacional NHO 01 da Fundacentro. 
As leituras devem ser corrigidas conforme a posição de medição e a freqüência dos sons, observando as seguintes equações:

$$
\begin{aligned}
& L_{\mathrm{FF}, \mathrm{M}, f}=L_{\mathrm{M}, \mathrm{exp}, f-\Delta L \mathrm{FF}, \mathrm{M}, f} \\
& L_{\mathrm{DF}, \mathrm{M}, f}=L_{\mathrm{M}, \exp , f-\Delta L \mathrm{DF}, \mathrm{M}, f}
\end{aligned}
$$

Onde: $L F F, M, f$ ou $L D F, M, f$ - nível contínuo equivalente de pressão sonora relacionado ao campo livre ou difuso obtido com o manequim;

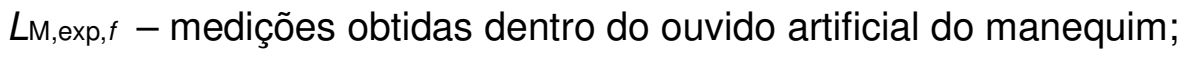

$\Delta L \mathrm{FF}, \mathrm{M}, f$ - correções dadas pela Tabela 24 - da norma ISO 11904-2;

$\Delta L D F, M, f$ - correções dadas pela Tabela 24 - da norma ISO 11904-2 - ou pela Tabela 25 - da recomendação ITU-T P.58 (1996).

As Tabelas deverão sempre ser analisadas quanto a sua aplicação e selecionadas para cada caso.

Os dados corrigidos em cada banda de freqüência são somados e em seguida devem ser calculados, observando a curva de ponderação $A[\mathrm{~dB}(\mathrm{~A})]$, utilizando as constantes Af especificadas, conforme já visto, na norma IEC 61672-1 (2002), para obter o nível contínuo equivalente de pressão sonora com ponderação A relacionado ao campo livre ( $L F F, M, A e q)$ ou difuso (LDF,M,Aeq). Os cálculos obedecem às seguintes fórmulas:

$$
L F F, M, A e q=10 \log \left[\Sigma_{f} 10^{\mathrm{a}}\right] \quad \mathrm{dB}(\mathrm{A})
$$

Onde $\mathrm{a}=\left(L F F, M, f+A_{f}\right) / 10$

$$
L_{D F, M, A e q}=10 \log \left[\Sigma_{f} 10^{\mathrm{a}}\right] \quad \mathrm{dB}(\mathrm{A})
$$

Onde $\mathrm{a}=\left(L D F, M, f+A_{f}\right) / 10$ 
Os níveis de pressão sonora contínua equivalente relacionados ao campo difuso que representa a exposição global ao ruído devem ser calculados usando a ponderação $A$, definido como $A f$, utilizando-se a expressão (5).

A ISO 11904 -2 mostra como devem ser calculadas as médias aritméticas dos LFF,M,f ou $L D F, M, f$ e os respectivos desvios-padrão $\sigma$ das leituras obtidas em cada ouvido testado.

Conforme já visto, (no anexo A apresentado nos originais das normas da série ISO 11904), são dados exemplos de incertezas de medição, devidas a: posição inadequada do microfone no canal auditivo; número limitado de pessoas participantes dos testes; utilização de dados tabulados de resposta em freqüência de campo livre ou difuso; respostas em freqüência determinadas individualmente para campo livre ou campo difuso. Também são apresentados exemplos comparativos de situações similares de medição, realizadas por meio da técnica MIRE e da técnica de manequim, que resultaram em desvios nos respectivos resultados.

A ISO 11904 -2 (em seu anexo A.4 apresentado na norma original), considera a possibilidade de desvio entre os resultados obtidos com o manequim e os obtidos com a população humana, resultando em incertezas.

Dois termos podem contribuir para isso: o desvio em $L M, \exp , f$ e o desvio em $\Delta L F F, M, f$ ou $\Delta L D F, M, f$. Para freqüências de até e incluindo $5 \mathrm{kHz}$ nas bandas de freqüência de terço de oitava, desvios são tipicamente abaixo de $2,5 \mathrm{~dB}$ para $L F F, f$ e abaixo de $2 \mathrm{~dB}$ para LDF,f. Entretanto, algumas combinações de fones de ouvido e manequins apresentam desvios consideravelmente maiores, em particular para certas bandas de freqüências.

Além disso, deve-se estimar a incerteza das medições pelo método ISO/IEC Guide 98 (1995) - Guide to the expression of uncertainty in measurement (GUM). Um exemplo da aplicação do GUM é dado no anexo B (apresentado no texto original da norma ISO 11904-2 como Tabela B.1), como mostra a Tabela 28. 
$\mathrm{Na}$ estimativa das incertezas das medições com manequins, são consideradas as seguintes condições: escolha de um adequado manequim para medição de um específico fone de ouvido; ruído branco ou ruído rosa que simulam a fala e a música como sinal de teste de entrada no fone de ouvido; valores padronizados da resposta em freqüência do manequim em conformidade com a Recomendação ITU-T P.58 (1996) para campo livre ou campo difuso; o resultado médio de três experimentos e medições. As análises das incertezas são então transportadas para o resultado final de $L F F, M, A e q$ Ou $L D F, M$, Aeq.

As incertezas resultam de 8 (oito) diferentes fontes. A componente devida à repetitividade é avaliada como incerteza do Tipo $A$, e as componentes restantes são avaliadas como incertezas do Tipo $B$.

$\mathrm{Na}$ tabela 28 deste trabalho de pesquisa (Tabela B.1 do texto original da norma ISO 11904-2) são apresentados os resultados dessas análises das incertezas.

\subsubsection{Interpretação de resultados}

No item 7 (do texto original da norma ISO 11904-2), são elencadas basicamente 8 (oito) informações [de a) até h)] que devem ser incluídas no relatório de testes das avaliações, consideradas como a quantidade mínima (Tabela 26).

No item 5.3 deste trabalho de pesquisa, é abordado o assunto referente ao relatório de testes das avaliações e à análise de incerteza das medições.

O resultado final deve ser usado para a comparação com os limites de tolerância e os critérios estabelecidos na legislação brasileira nos Anexos №. 1 e №. 2 da Norma Regulamentadora NR 15 do Ministério do Trabalho ou com a Norma de Higiene Ocupacional NHO 01 da Fundacentro. 


\subsection{AVALIAÇÕES (RELATÓRIO E INCERTEZA DAS MEDIÇÕES)}

\subsubsection{Relatório dos testes}

Tabela 26 - Informações mínimas que um relatório de teste deve conter, segundo a Norma ISO 11904, para cada uma das técnicas

\begin{abstract}
Técnica do Microfone em Ouvido Real - MIRE ISO 11904-1 da pessoa responsável pelas medições. sonora, condições de operação, faixa de freqüência, etc. data e local da calibração.

e) descrição das pessoas sob teste (nome, número, sexo, idade) e da posição escolhida.

f) descrição do campo sonoro de referência, se for usado;
\end{abstract}

\author{
Técnica com Manequim
} ISO 11904-2

a) data e local das medições, indicando qual das partes da norma ISO 11904 foi utilizada (ISO 119041 ou ISO 11904-2) e os itens usados nas medições, juntamente com o nome da instituição/empresa e

b) descrição de todas as informações relevantes a respeito do ruído sob teste, das fontes de emissão

c) descrição do local das medições com especial consideração às propriedades acústicas.

d) descrição dos instrumentos utilizados, incluindo informações a respeito dos períodos de medição,

g) para cada pessoa sob teste e respectivo ouvido, os dados de Lear,FF,f ou Lear,DF, $f$, Lref,FF,f ou Lref,DF, fe $\Delta L F F, H, f$ ou $\Delta L D F, H, f$ podem ser apresentados em gráficos.

h) para cada pessoa sob teste e respectivo ouvido, os dados de Lear,exp,f, LFF,H,fou LDF,H,fe LFF,H,Aeq ou LDF,H,Aeq podem ser apresentados graficamente.

i) apresentar média aritmética e desvio-padrão para $L F F, H, A e q$ ou $L D F, H, A e q$ dos ouvidos testados.

j)Avaliação de incertezas da medição. k)Outras informações relevantes que influenciaram nos resultados das medições. e) descrição do manequim utilizado, incluindo a escolha do simulador de ouvido (lado esquerdo ou direito, ou ambos).

f) para cada simulador de ouvido do manequim, devem ser informados os valores das respostas em freqüência de campo livre ou difuso ( $L F F, M, f$ Ou $L D F, M, f)$, os níveis contínuos equivalentes de pressão sonora ponderados em $A$ relacionados em campo livre ou difuso ( $L F F, M, A$ eq ou $L D F, M, A e q)$ e todos os demais resultados como $L M$,exp, $f$, etc., podendo os dados ser apresentados graficamente.

Fonte: Norma ISO 11904-1, 2002. Item 11, p.10 e Norma ISO 11904-2, 2004. Item 7, p.6 


\title{
5.3.2 Análise de incertezas
}

\author{
Nas Tabelas 27 e 28 a seguir, extraídas do texto original das normas ISO 11904-1 \\ (2002) e ISO 11904-2 (2004), são apresentados os respectivos resultados dessas \\ análises das incertezas.
}

Tabela 27 - Análise das Incertezas

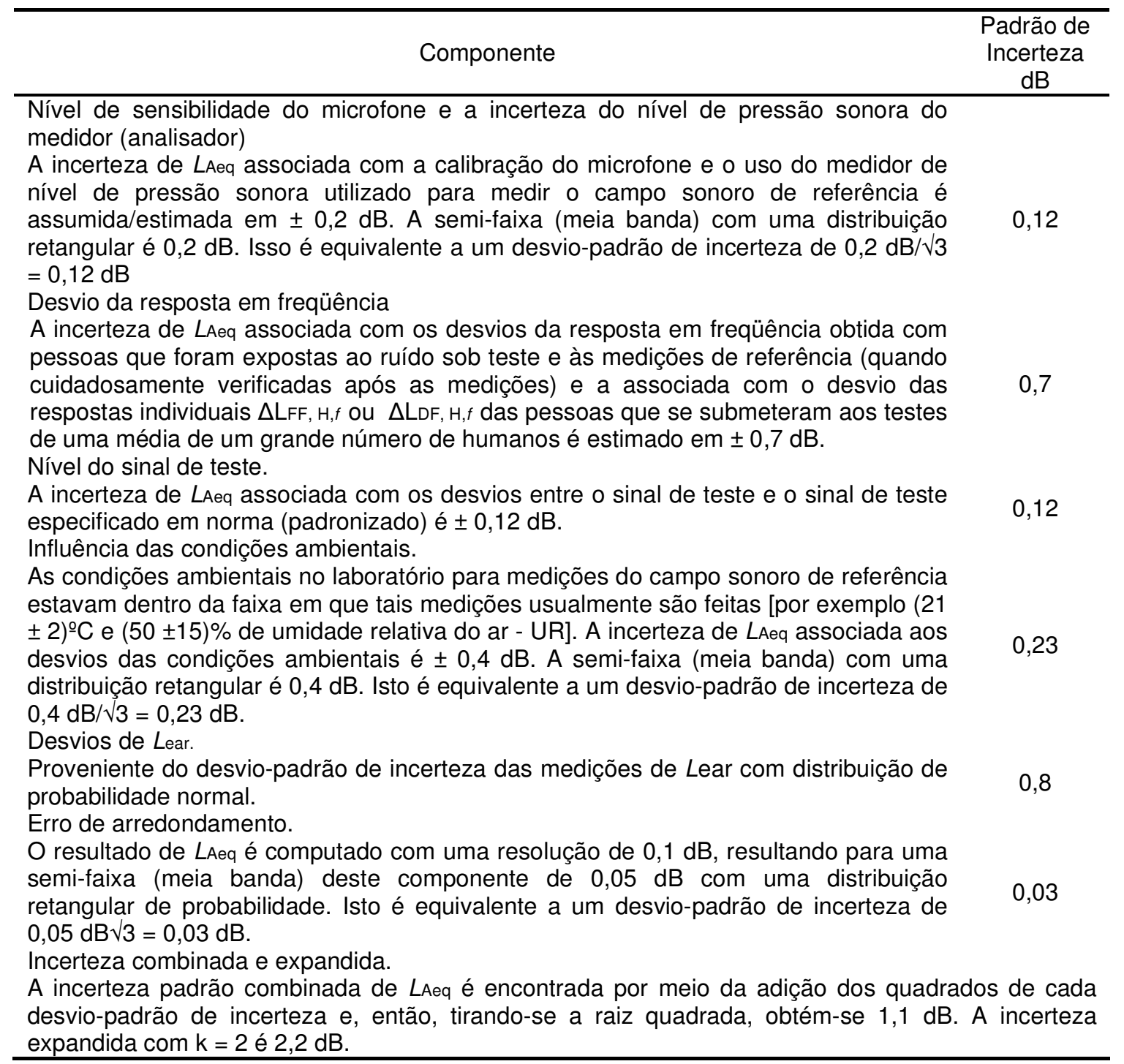

Fonte: Norma ISO 11904-1, 2002. Tabela B.1, p.18 
Tabela 28 - Análise das Incertezas

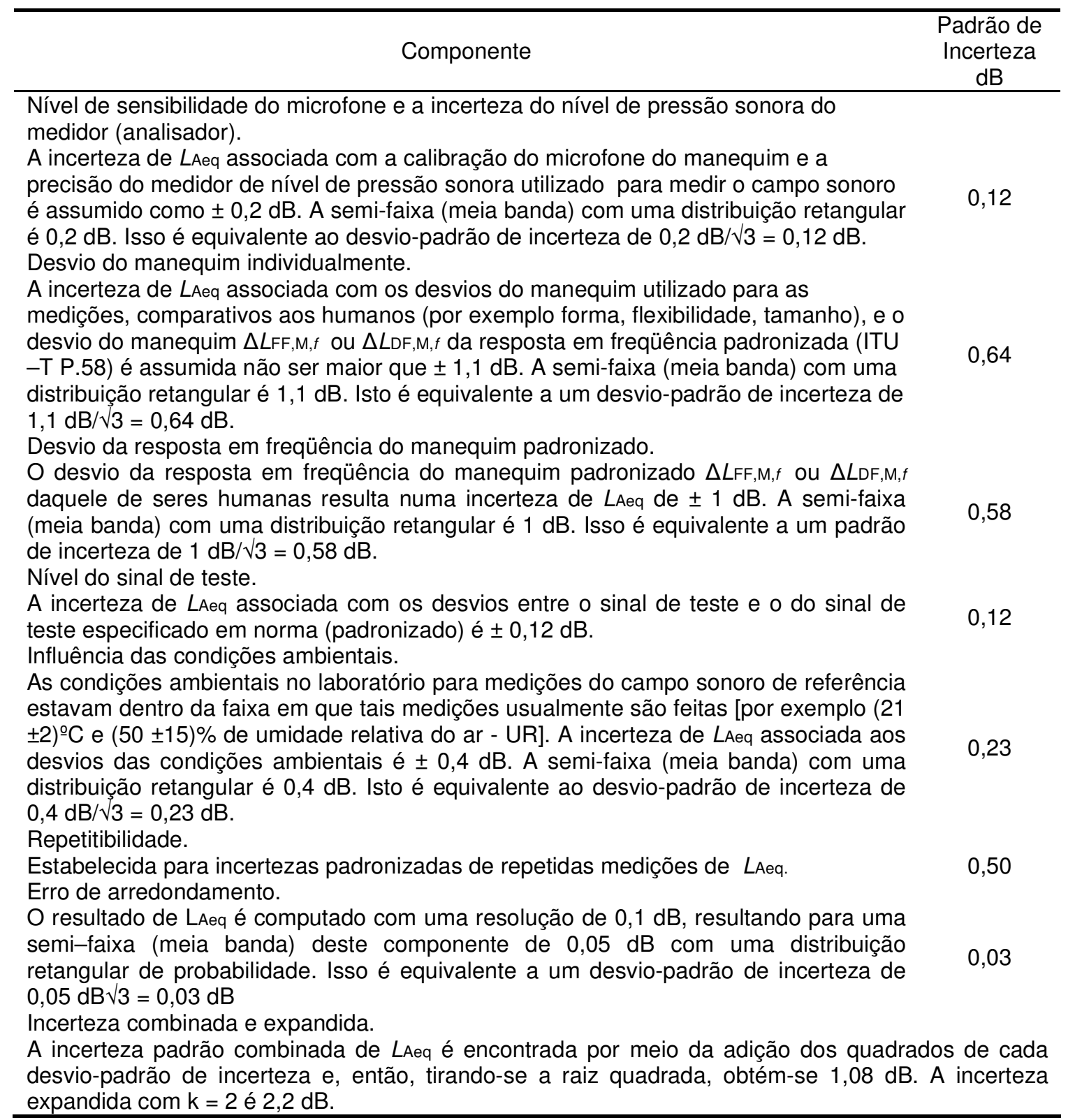

Fonte: Norma ISO 11904-2, 2004. Tabela B.1, p.15

\subsubsection{Considerações sobre os relatórios dos testes e a incerteza das medições}

Steffani (2005), em sua tese de doutorado, estudou detalhadamente a análise de incertezas da exposição ao ruído dos usuários de fone de ouvido. Discorre que, é possível observar que as normas ISO 11904, ao fornecer as informações mínimas 
que um relatório de testes deve conter, faz referência à avaliação de incertezas da medição, apontada nas Tabelas anteriores. Quando se relata o resultado de medição de uma grandeza física, é obrigatório que seja dada alguma indicação quantitativa da qualidade do resultado, de forma tal que aqueles que o utilizam possam avaliar sua confiabilidade. Sem essa indicação, resultados de medição não podem ser comparados, seja entre eles mesmos seja com valores de referência fornecidos numa especificação ou numa norma. É, portanto, necessário que haja um procedimento implementado, um "protocolo" facilmente compreendido e de aceitação geral, para caracterizar a qualidade de um resultado de uma medição, isto é, para avaliar e expressar sua incerteza (ABNT, INMETRO, 2003).

Por oportuno, pode-se definir como medição o conjunto de operações que têm por objetivo determinar o valor de uma grandeza; e mensurado, como o objeto de medição (grandeza específica submetida à medição).

Na prática, existem muitas fontes possíveis de incerteza em uma medição. A própria ISO 11904 aponta em seu conteúdo, conforme já visto, algumas fontes de incerteza nos métodos de avaliação descritos tanto na parte 1 (técnica usando microfone em ouvido real), quanto na parte 2 (técnica usando manequim). Segundo a norma, algumas fontes de incerteza das medições são: calibração incorreta do campo de referência do microfone; calibração incorreta do simulador de ouvido; posicionamento inadequado do minimicrofone no canal auditivo; as variações do sinal sonoro sob teste, dentre outras. Steffani (2005) comenta que, segundo o método ISO GUM (Guide to the expression of uncertainty in measurement), também chamado de GEIM (Guia para a Expressão da Incerteza de Medição), todas as medições são afetadas por erros que podem ser provenientes do mensurado, do instrumento de medição e de grandezas de influência externa, e que, ainda de acordo com o GEIM, a incerteza padrão $(\boldsymbol{u})$, é a incerteza do resultado de uma medição expressa como um desvio-padrão. A incerteza expandida $(\boldsymbol{U})$, por sua vez, é uma grandeza que define um intervalo em torno do resultado de uma medição, com o qual se espera abranger uma grande fração da distribuição dos valores que possam ser razoavelmente atribuídos ao mensurado. A incerteza expandida geralmente corresponde a um intervalo de confiança de $95 \%$ de probabilidade, 
enquanto o fator de abrangência ( $\boldsymbol{k}$ ) é um fator numérico usado como multiplicador da incerteza padrão combinada de modo a obter uma incerteza expandida.

$$
\boldsymbol{U}(x)=\boldsymbol{k} x \cdot \boldsymbol{u}(x)
$$

Onde: $\boldsymbol{u}$ : incerteza padrão;

$U$ : incerteza expandida;

$\boldsymbol{k}$ : fator de abrangência;

$x$ : grandeza pesquisada.

O objetivo principal do estudo quantitativo de cada fonte de incerteza é a aplicação no balanço de incertezas. Steffani (2005) informa ainda que há duas formas de se avaliar as incertezas que, por sua vez, são denominadas de avaliação Tipo $A$ e avaliação Tipo $B$.

A avaliação da incerteza Tipo $A$ é um método de avaliação da incerteza pela análise estatística de séries de observações. Na maioria dos casos, a melhor estimativa disponível do valor esperado $\mu q$ de uma grandeza $q$ que varia aleatoriamente e para a qual $n$ observações independentes $q k$ foram obtidas sob as mesmas condições de medição é a média aritmética ou média $q$ das $n$ observações:

$$
\bar{q}=\frac{1}{n} \sum_{k=1}^{n} q_{k}
$$

A avaliação da incerteza Tipo $B$ é um método de avaliação da incerteza por outros métodos que não a análise estatística da série de observações. Aqui, a avaliação Tipo $B$ baseia-se em todas as informações disponíveis sobre a possível variabilidade, podendo incluir um conjunto de informações disponíveis sobre a variabilidade de $x_{i}$, tais como: dados de medições prévias; a experiência ou 0 conhecimento geral do comportamento e propriedades de materiais e instrumentos; especificações de fabricante; dados fornecidos em certificados de calibração e 
outros documentos; incertezas atribuídas a dados de referência extraídos de manuais, dentre outros.

Ao se verificar a abordagem das normas da série ISO 11904, pode-se identificar que nelas há informações relativas à análise de incertezas. Por isso, é importante lembrar que os anexos das referidas normas são informativos, conforme indicados no seu texto original, e propõem apenas exemplos de análises de incertezas para esses tipos de medições específicas, não se constituindo, portanto nem uma análise de incertezas, nem uma recomendação rígida para esta. Assim, não é necessário seguir rigorosamente todo seu conteúdo. Dessa forma, no presente estudo, o cálculo da incerteza do resultado final da medição depende de qual técnica foi utilizada. Para a Técnica em Ouvido Real, uma questão-chave é o grau de representação de um número limitado de indivíduos em relação a uma população. Para a Técnica Usando Manequim, a questão correspondente é o grau de representação do modelo em relação a um ser humano médio. Para cada uma das técnicas, a incerteza também depende se os dados (correções) para a resposta em freqüência do campo livre ou do campo difuso foram obtidos das Tabelas das respectivas normas ou se foram determinados individualmente para os seres humanos (participantes) ou para o tipo de manequim utilizado.

A Tabela 29 a seguir dá uma visão geral do impacto no resultado final de algumas fontes de erro típicas quando se usa cada uma das duas partes da ISO 11904. 
Tabela 29 - Visão Geral das fontes típicas de incerteza das medições e de seus impactos nas várias situações

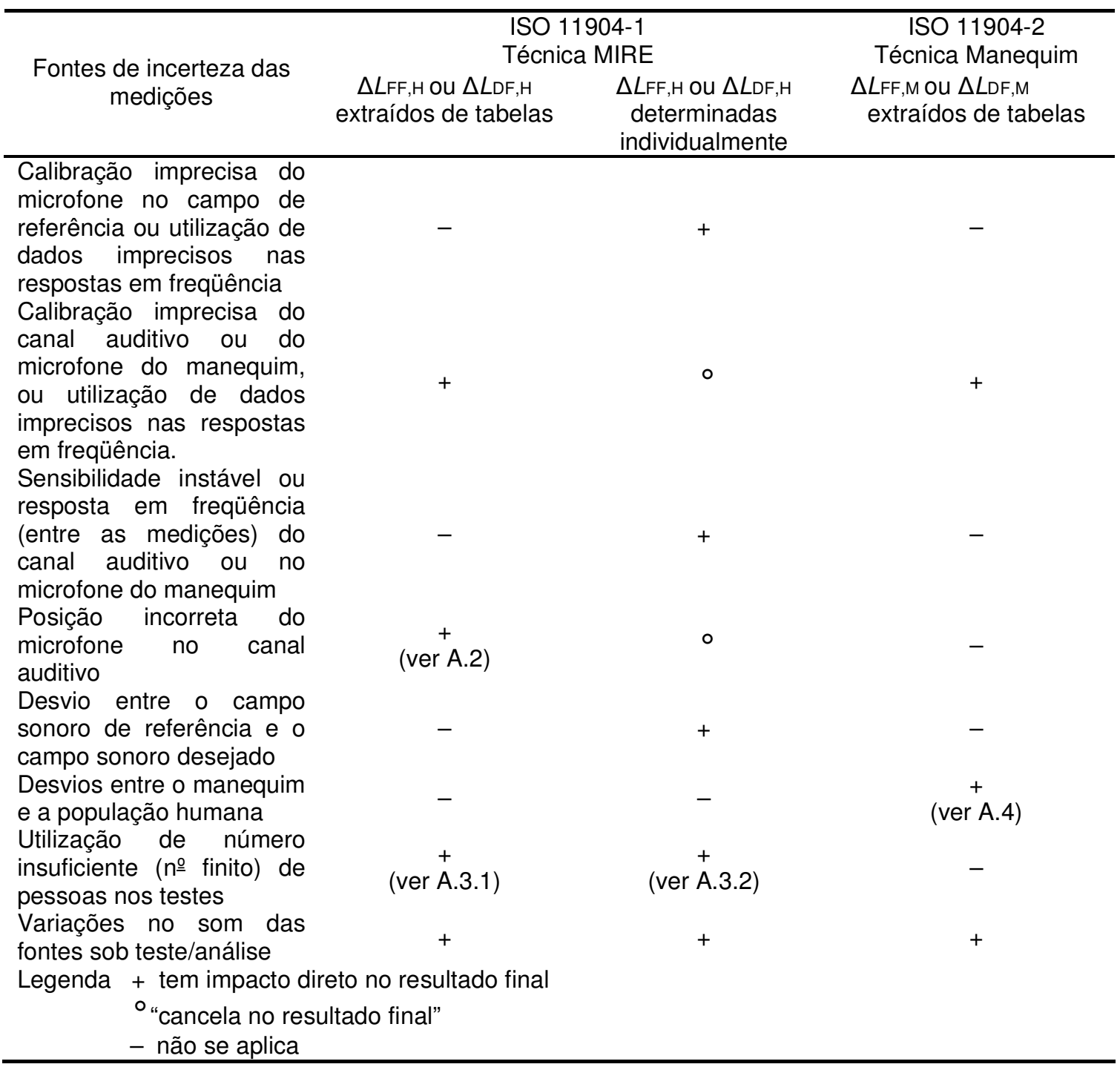

Fonte: Norma ISO 11904-1, 2002. Tabela A.1 p.12 e Norma ISO 11904-2, 2004. Tabela A.1, p.8

As referências sobre A.3.1 e A.3.2 apontadas na Tabela 29, que são subseções do Anexo A da norma original ISO 11904-1, dizem respeito às explicações sobre cálculos de desvios-padrão de valores de níveis de pressão sonora medidos no canal auditivo dos indivíduos. A referência sobre A.4, que é subseção do anexo $A$ da norma ISO 11904-2, considera a possibilidade de desvios dos resultados obtidos com o manequim e os obtidos da população humana, resultando em incertezas.

Steffani (2005) menciona também no seu trabalho que foi feita uma avaliação de incerteza segundo a norma ISO 11904-1 e o Guia para a Expressão da Incerteza de 
Medição (GEIM). Porém, apenas para a técnica de medição em ouvido real. Foram buscadas diversas fontes de incertezas, mas não é um estudo exaustivo no qual se garante que todas as grandezas de influências foram consideradas. A avaliação de incertezas das medições em simulador de ouvido não pôde ser concluída devido à falta de informações adequadas sobre a incerteza associada ao simulador de ouvido utilizado. Principalmente sobre as incertezas relacionadas à cavidade acústica do simulador de ouvido, cujas informações não foram encontradas na literatura e nem fornecidas por parte dos fabricantes, pois as características e/ou valores de incertezas não são fornecidos.

\subsubsection{Quanto ao balanço de incertezas}

Fontes de incertezas Tipo $A$ e Tipo $B$ podem ser combinadas no cálculo de incertezas com objetivo de obter uma estimativa do valor global da incerteza de medição, conhecida como abordagem mista. Porém, isso nem sempre é possível de realizar. É o caso do trabalho de Steffani, visto anteriormente, que fez a avaliação da incerteza de medição segundo a norma ISO 11904-1 e o GEIM, apenas para a técnica de medição em ouvido real, pela falta de informações adequadas de incertezas das medições com o simulador de ouvido, o que ele definiu como balanço de incertezas dos equipamentos do sistema (cadeia de medição) utilizados nas avaliações com a técnica do minimicrofone em ouvido real. Enfim, não pôde incluir as variações do sinal de conversação em razão da presença de variações de níveis de pressão sonora, que foram denominados como parâmetro variável, e não como uma fonte de incerteza, a qual seria denominada de incerteza Tipo A. Portanto, foram contemplados na forma de desvios-padrão sem serem multiplicados por nenhum fator de abrangência.

O mesmo autor, referente a esse mesmo estudo, apresenta uma análise das incertezas do resultado final das medições. Ele calculou-as considerando a norma ISO 11904-1 para a técnica do microfone em ouvido real - MIRE. Os dados mostram as incertezas geradas de diferentes fontes no sistema de medição utilizando a técnica MIRE, reproduzidos na Tabela 30. 
As incertezas expandidas são baseadas no desvio-padrão multiplicado por $k=2$, provendo um intervalo de confiança de aproximadamente 95\%.

Tabela 30 - Balanço das Incertezas previstas do sistema de medição utilizando a técnica MIRE.

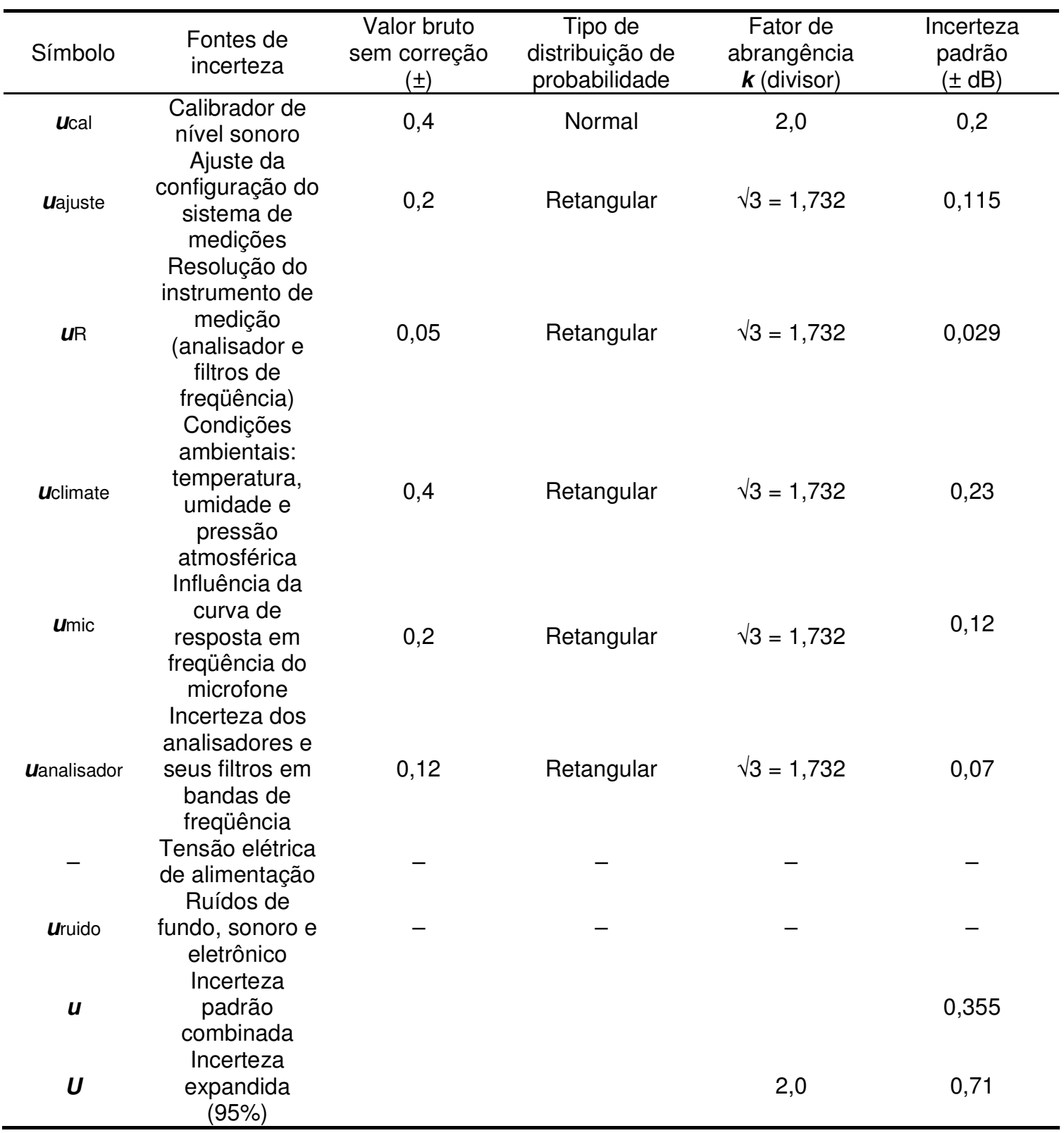

Fonte: Tese de doutorado de J. A. Steffani. Comparação das técnicas de medição e análise de incertezas da exposição ao ruído dos usuários de fone de ouvido, 2005. p.145 Legenda:

u: incerteza padrão

U: incerteza expandida

k: fator de abrangência 
As fontes de incerteza relativas ao calibrador de nível sonoro e as influências atmosféricas ambientais nas medições dão valores grandes na elaboração da incerteza, 0,2 dB e 0,23 dB de incerteza padrão, respectivamente. O valor global do balanço da incerteza, as incertezas expandidas $U$, são aproximadamente 0,7 dB. Se um ruído branco ou rosa foi usado, de acordo com as características padronizadas, com adequada estabilidade, os valores esperados dos desvios deverão estar entre $0,7 \mathrm{~dB}$ e 2,2 dB, ou seja, ao redor do valor calculado da incerteza da configuração das medições e dos valores calculados no exemplo da norma ISO 11904-1.

\subsection{VISÃO GERAL DAS DIFERENÇAS DAS DUAS PARTES DA ISO 11904}

Tabela 31 - Visão geral das diferenças entre as técnicas MIRE e Manequim

\begin{tabular}{|c|c|c|}
\hline Parâmetro & ISO 11904-1 & ISO 11904-2 \\
\hline \multirow{4}{*}{$\begin{array}{l}\text { Tipo de Método } \\
\text { Limitação do } \\
\text { Método }\end{array}$} & Técnica do Microfone em Ouvido Real & Técnica Manequim \\
\hline & $\begin{array}{l}\text { Com fones de ouvido do tipo inserção } \\
\text { e estetoscópio, problemas práticos } \\
\text { podem ocorrer em razão do } \\
\text { posicionamento dos microfones no } \\
\text { canal auditivo. }\end{array}$ & $\begin{array}{l}\text { Um adequado acoplamento nem } \\
\text { sempre pode ser obtido se a orelha } \\
\text { artificial difere da orelha humana em } \\
\text { rigidez ou formato. }\end{array}$ \\
\hline & & $\begin{array}{l}\text { Em alguns casos, a exposição pessoal } \\
\text { não pode ser substituída pelo } \\
\text { manequim; por exemplo, se a pessoa }\end{array}$ \\
\hline & & $\begin{array}{l}\text { opera um equipamento ou se } \\
\text { movimenta. }\end{array}$ \\
\hline \multirow{4}{*}{$\begin{array}{l}\text { Principais } \\
\text { questões que } \\
\text { afetam a } \\
\text { precisão }\end{array}$} & $\begin{array}{l}\text { Número de pessoas submetidas aos } \\
\text { testes }\end{array}$ & $\begin{array}{l}\text { Similar do manequim para as pessoas } \\
\text { sob teste }\end{array}$ \\
\hline & $\begin{array}{l}\text { Quando são utilizados os valores } \\
\text { tabulados de } \Delta L F F, H \text { ou } \Delta L D F, H \text { : } \\
\text { - calibração do microfone no canal } \\
\text { auditivo } \\
\text { - precisão na posição do microfone no } \\
\text { canal auditivo }\end{array}$ & Calibração do manequim \\
\hline & $\begin{array}{l}\text { Quando são utilizados os valores } \\
\text { individuais de } \Delta L F F, H \text { ou } \Delta L D F, H \text { : } \\
\text { - qualidade do campo sonoro de } \\
\text { referência }\end{array}$ & \\
\hline & $\begin{array}{l}\text { - estabilidade da sensibilidade e } \\
\text { resposta em freqüência, bem como da } \\
\text { posição do microfone no canal } \\
\text { auditivo. }\end{array}$ & \\
\hline $\begin{array}{l}\text { Faixa de } \\
\text { Freqüência }\end{array}$ & $20 \mathrm{~Hz}$ a $16 \mathrm{kHz}$ & $20 \mathrm{~Hz}$ a $10 \mathrm{kHz}$ \\
\hline
\end{tabular}

Fonte: Norma ISO 11904-1, 2002. Tabela 01, p.vi e Norma ISO 11904-2, 2004. Tabela 01, p.vi 


\subsection{DISCUSSÃO REFERENTE À NORMA INTERNACIONAL ISO 11904}

Pode-se inferir que a preocupação com a surdez ocupacional dos usuários de fones de ouvido não despertou, no passado, interesse nos pesquisadores por se tratar de uma parcela pequena de trabalhadores. Atualmente, com 0 aparecimento de aparelhos sofisticados de comunicação e de recreação (tocadores digitais de musicais), mais acessível ao público em geral, o contingente de usuários cresceu exponencialmente, elevando consideravelmente o potencial de danos auditivos.

O surgimento, portanto, em 2002 e 2004, das normas da INTERNATIONAL ORGANIZATION FOR STANDARDIZATION - ISO Série 11904, respectivamente, Parte 1 e Parte 2, é de certa forma uma resposta a essa problemática. Esses documentos representam uma série de normas que especificam métodos para determinar emissões sonoras de fontes colocadas junto ao ouvido, cuja exposição sonora é adequadamente representada na posição do ouvinte.

Utilizando os métodos das normas ISO da série 11904, há a possibilidade de se atuar com valores compreendidos nos intervalos de confiança obtidos através dos graus de incerteza, uma vez que esta norma é a única que traz os conceitos de tratamento de dados e de análise de incertezas das medições. Então, ao considerar os erros, pode-se afirmar que é possível obter informações confiáveis, desde que os resultados das medições venham acompanhados da respectiva incerteza. Os métodos propostos examinam os elementos de cada situação, permitindo um melhor conhecimento dos diversos aspectos e fatores determinantes das medições, nos quais são identificados, entre outros, o tamanho da amostra, o tratamento estatístico dos dados, os procedimentos e o posicionamento de medição, as vantagens e as limitações de cada método.

A presente pesquisa revela que as normas da série ISO 11904 - ISO 11904-1 e/ou ISO 11904-2 são as mais adequadas e específicas para avaliação dos níveis de ruído em fones de ouvido, sendo assim a principal referência. Porém, não são de fácil aplicação, como também não são auto-suficientes, pois várias outras normas tratam de aspectos relacionados e devem ser analisadas e utilizadas conjuntamente, 
se pertinente, conforme o caso. As normas da série ISO 11904 não especificam, por exemplo: tipo de microfone de medição, tipo de simulador de ouvido, tipo de orelha e boca artificial, tipos de acopladores relacionados aos modelos de fones, etc. As demais normas e recomendações definem aspectos relevantes, que originalmente foram concebidos para especificações gerais, técnicas, operacionais e construtivas, além de fornecerem diretrizes sobre conformidade de fabricação (forma, dimensões, tipo de materiais), características de desempenho, qualidade, testes e métodos de ensaio e de calibração, dispositivos e arranjos de acoplamentos, controle da manutenção e procedimentos de montagem, e também, condições climáticas ambientais, sendo a maioria desses itens voltados para medições telefonométricas.

Além disso, há a necessidade de se empregar, nas medições e avaliações, pessoal altamente especializado e com expertise e experiência na área de telecomunicações e higiene ocupacional. Também o conjunto de equipamentos e acessórios necessários para a realização de tais medições é bastante dispendioso e requer complexos softwares para a coleta e tratamento de dados. Isto é, a adoção legal direta das normas da série ISO 11904 seria inviável do ponto de vista de seu cumprimento por parte da maioria das empresas, e do número limitadíssimo de entidades e prestadores aptos a realizar estas medições, isso sem contar os custos para a sua realização, a par da demanda reprimida por esses serviços.

Não resta dúvidas de que as normas internacionais da série ISO 11904 trazem parâmetros de grande importância para a adequada avaliação dos níveis de ruído em fones e podem ser adotadas como normas oficiais no Brasil, entretanto, face ao exposto neste trabalho, devido à complexidade de sua aplicação, teria de ser implementado um estudo para elaboração de uma instrução técnica ou norma de higiene ocupacional nos moldes da NHO 01 - Norma de Higiene Ocupacional da Fundacentro sobre Procedimento Técnico de Avaliação da Exposição Ocupacional ao Ruído, que trouxesse um Protocolo com procedimentos bem definidos, passo a passo, de como aplicar cada uma das normas da série ISO 11904, incluindo as demais normas relacionadas, contendo as especificações de microfones, fatores de conversão e de correção, graus de incerteza, tratamento de dados, etc. 
$\mathrm{Na}$ realidade essas demais normas e recomendações complementam ou suplementam a ISO 11904, e por isso não podem deixar de ser estudadas, considerando-se sua aplicação caso a caso.

Ressalte-se por oportuno, que a maioria dessas normas e recomendações, originalmente, não foram destinadas a avaliar ruído ocupacional em fones de ouvido, estando elas voltadas às medições telefonométricas de concepção, de conformidade, de testes de aceitação de aparelhos de telecomunicações, incluindo fones de ouvido. Então há a necessidade da junção de várias normas, relacionandoas aos parâmetros de importância para a Higiene Ocupacional.

Algumas normas relacionadas à série ISO 11904:

- IEC 61672-1 (2002) - Eletroacústica - Medidores de Nível Sonoro - Parte 1: Especificações;

- IEC 61672-2 (2003) - Eletroacústica - Medidores de Nível Sonoro - Parte 2: Padrões de Ensaios/Testes para Avaliação de Modelos;

- IEC 61672-3 (2006) - Eletroacústica - Medidores de Nível Sonoro - Parte 3: Calibração e testes periódicos;

- IEC 61260 (1995) - Eletroacústica - Filtros de bandas de oitava e frações de oitava;

- IEC 60065 (2005) - Aparelhos de áudio, vídeo e aparelhos eletrônicos análogos - Exigências de segurança;

- IEC 60601-1 (2005) - Aparelhos eletromédicos - Parte 1: Exigências gerais para segurança básica e desempenho essencial;

- IEC 60268-1 (1985) - Equipamentos para Sistemas Eletroacústicos - Parte 1: Características gerais;

- IEC 60268-4 (2004) - Equipamentos para Sistemas Eletroacústicos - Parte 4: Microfones; 
- IEC 60268-7 (1996) - Equipamentos para Sistemas Eletroacústicos - Parte 7: Fones de ouvido e fones de cabeça;

- IEC 60942 (2003) - Eletroacústica - calibradores sonoros;

- IEC 61094-1 (2000) - Microfones de medição - Parte 1: Especificações de microfones padrão de laboratório;

- IEC 61094-4 (1995) - Microfones de medição - Parte 4: Especificações de microfones padrão de trabalho usados para determinados sistemas de medição;

- IEC 61842 (2002) - Microfones e fones de ouvido para comunicações de fala;

- IEC 60711 (1981) - Simulador de ouvido ocluso/fechado para medições de fones de ouvido tipo plugue acoplados à orelha por fones de inserção;

- IEC/TR 60959 (1990) - Simulador provisório de cabeça e torso para medições acústicas e condução aérea de aparelhos de correção auditiva;

- IEC 60118-8 (2005) - Aparelhos de correção auditiva - Parte 8: Métodos de medição das características de performance dos aparelhos de correção auditiva sob condições simuladas de funcionamento in situ,

- IEC 60318-1 (1998) - Eletroacústica - Simuladores de cabeça e orelha humana - Parte 1: Simulador de orelha para calibração de fones de ouvido supra-aural;

- IEC 60318-2 (1998) - Eletroacústica - Simuladores de cabeça e orelha humana - Parte 2: Acoplador acústico de calibração de fones de ouvido para audiometrias;

- IEC 60318-3 (1998) - Eletroacústica - Simuladores de cabeça e orelha humana - Parte 3: Acoplador acústico para calibração de fones de ouvido supra-aural utilizados em audiometria;

- IEC 60318-5 (2006) - Eletroacústica - Simuladores de cabeça e orelha humana - Parte 5: Acoplador para medição de aparelhos de correção auditiva e de acopladores de fones de ouvido por meio de inserção (moldados ou similares). 
Demais normas e recomendações correlatas:

- ITU-T P.57 (2005) - Série P: Qualidade de transmissão telefônica, instalações telefônicas e redes locais - Aparelhos para medições objetivas: Ouvidos artificiais;

- ITU-T P.58 (1996) - Série P: Qualidade de transmissão telefônica - Aparelhos para medições objetivas: Simulador de cabeça e torso para medições telefonométricas;

- ANSI S 3.36 (1985) - R 2006 - Especificação de um manequim simulado in situ para medições de ruídos aéreos. Essa norma complementa a ANSI S 3.35 (2004);

- ANSI S 3.35 (2004) - Método de medição das características de eficiência das próteses auditivas sob condições de trabalho simuladas em orelha real;

- ANSI S 12.42 (1995) - R 2004 - Métodos do teste acústico e microfone em ouvido real, para medição da perda de inserção de equipamentos de proteção auditiva do Tipo Circum-aural;

- ANSI S 12.57 - 2002/ISO 3747-2000: Acústica padrão - Determinação dos níveis de potência sonora de fontes de ruído usando a pressão sonora - Comparação com o método in situ.

Destas normas, são apresentadas e destacadas algumas, a saber:

\subsection{IEC 60711 (1981) - SIMULADOR DE OUVIDO OCLUSO/FECHADO PARA MEDIÇÕES DE FONES DE OUVIDO TIPO PLUGUE ACOPLADOS À ORELHA POR INSERÇÃO}

Essa norma especifica um simulador destinado à calibração de fones de ouvido na faixa de freqüência de $100 \mathrm{~Hz}$ a $10.000 \mathrm{~Hz}$ em termos de pressão sonora no tímpano. O simulador de orelha oclusa, além disso, é utilizado para servir de base a 
um aparelho destinado a simular o canal auditivo completo, para calibração de fones de ouvido acoplados à orelha por meio de molde aberto fixado por dispositivos simuladores.

O simulador de orelha oclusa simula os valores médios de relevantes características acústicas apropriadas às orelhas normais de adultos. O simulador de orelha oclusa não simula vazamentos entre um molde de orelha e um canal de orelha humana; entretanto, os resultados obtidos com o simulador podem desviar dos resultados de desempenho do fone de inserção acoplado a orelha real, especialmente às baixas freqüências. Adicionalmente, as grandes variações dos resultados de desempenho existentes entre diferentes orelhas podem ocorrer, e isso deve ser avaliado e levado em conta nos resultados obtidos com os simuladores.

Quanto ao microfone, este deverá ser do tipo especificado pelo fabricante para ser utilizado em simulador de ouvido ocluso/fechado. O nível de sensibilidade do microfone de pressão deverá ser conhecido dentro de uma precisão de $\pm 0,3 \mathrm{~dB}$ ou para $250 \mathrm{~Hz}$. Relativo a esse valor para $250 \mathrm{~Hz}$, esse nível não deverá variar mais do que $\pm 0,5 \mathrm{~dB}$ na faixa de freqüência de $100 \mathrm{~Hz}$ a $5 \mathrm{kHz}$ e +1,5 dB, - 0,5 dB na faixa de freqüência de $5 \mathrm{kHz}$ a $10 \mathrm{kHz}$.

\subsection{RECOMENDAÇÃO ITU - T P.57 (2005)}

Faz parte da série $P$ que cuida da qualidade de transmissão telefônica, instalações e aparelhos para medições objetivas, os ouvidos artificiais. Especifica as características eletroacústicas dos ouvidos artificiais utilizados em telefonometria. São especificados três dispositivos, que contemplam os diferentes tipos, tamanhos e tecnologias de transdutores: um tipo de banda telefônica para aparelhos telefônicos tradicionais, um do tipo de inserção e um tipo que reproduz fielmente as características do ouvido humano.

No texto dessa recomendação, são referenciadas outras recomendações e disposições, tais como IEC 60318-1 - Eletroacústica - Simuladores de cabeça e 
ouvido humano - Parte 1: Simulador de ouvido para calibração de fones de ouvido do tipo supra-aural (1998); IEC 60711 - Simulador de orelha fechada para medições de fones de ouvido acoplados a orelha por inserção (1981); ITU - T P.58 (1996); ITU - T P.79 - Cálculo de índices de segurança dos aparelhos telefônicos (1999); ITU -T P.380 - Medidas eletroacústicas em fones de ouvidos (2003); IEC 61260 Eletroacústica - Filtros de bandas de oitava e frações de bandas de oitava (1995); IEC/TR 60959 - Simulador provisório de cabeça e torso, para medições acústicas da condução aérea em aparelhos de correção auditiva (1990).

Houve um aperfeiçoamento do desempenho de aparelhos telefônicos na utilização de simuladores de ouvido ITU-T P.57 (2005) para medições telefonométricas.

As medições em aparelhos telefônicos tradicionalmente feitas utilizando o simulador de ouvido Tipo 1 inclui um acoplador especificado na IEC 60318-1 (1998), o qual foi introduzido no mercado há mais de três décadas atrás. Trata-se de um simulador bem grosseiro do ouvido humano, e as condições sob as quais ele é destinado para utilização não apresentam uma boa precisão do uso normal dos aparelhos telefônicos. Entretanto, alguns novos simuladores de ouvido têm sido especificados pela ITU (International Telecommunication Union), os quais simulam melhor a carga acústica do ouvido humano quando utilizados em modernos aparelhos telefônicos.

A introdução desses novos tipos de simuladores em norma de telefonia durante os recentes anos tem levado a algumas confusões entre projetistas de aparelhos telefônicos. A primeira delas é que a utilização de novos acopladores levam a resultados de medições diferentes daqueles obtidos com o usual simulador Tipo 1. Além disso, questiona-se se as tolerâncias das normas de telefonia até aqui especificadas são aplicáveis aos novos tipos de simuladores. O objetivo dessas observações é descrever quanto à utilização de diferentes simuladores de ouvido para medições em vários tipos de aparelhos telefônicos, e em particular selecionar o mais adequado simulador para um determinado tipo de aparelho/fone de ouvido, cuja geometria também pode influenciar nas medições. Do mesmo modo, medições realizadas com diferentes simuladores levam a diferentes resultados para alguns tipos de fones de ouvido. 
Quando se discute medições de níveis sonoros em orelha humana, vários termos são utilizados para descrever as condições de medição. Uma visão geral desses termos é apresentada na Figura 22 a seguir, que mostra um desenho esquemático da anatomia de uma orelha humana.

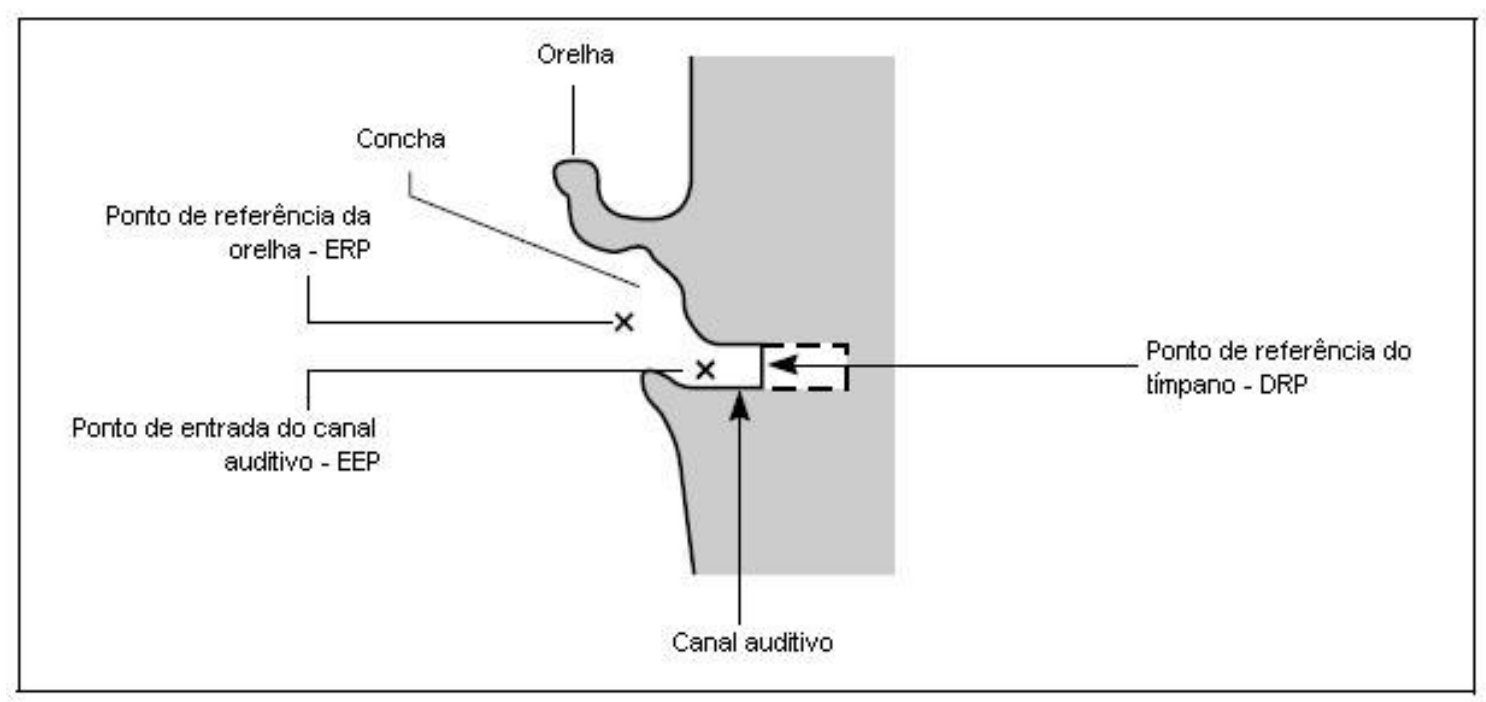

Figura 22 - Desenho esquemático da anatomia da orelha e definições dos pontos de referência Fonte: Application note improving telephone handset performance - Brüel \& Kjaer ${ }^{\circledR}$ (B\&K), 2005

Quando o nível de pressão sonora é referido à orelha, três relevantes pontos de medição são definidos. A exata localização desses pontos de medição é mostrada na Figura 22.

- Ponto de referência da orelha ERP - Ear Reference Point: é o ponto virtual de referência geométrica situado na entrada da orelha do ouvinte e tradicionalmente utilizado para o cálculo dos índices de audibilidade telefonométricos;

- Ponto de entrada do canal auditivo EEP - Ear Canal Entrance Point: é o ponto situado no centro da abertura do canal auditivo;

- Ponto de referência do tímpano DRP - Ear Drum Reference Point: é o ponto situado no final do canal auditivo, correspondente à posição do tímpano.

Na Recomendação ITU - T P.57 (2005) se definem outros importantes termos: 
- Ouvido artificial: Dispositivo para a calibração de fones de ouvido que incorporam um acoplador acústico e um microfone calibrado para medir a pressão acústica e que tem uma impedância acústica total similar à do ouvido humano médio numa determinada banda de freqüência;

- Extensão do canal auditivo: Cavidade cilíndrica que estende a simulação do canal auditivo proporcionado pelo simulador de ouvido obstruído fora da cavidade da concha;

- Simulador de ouvido: Dispositivo para medir a pressão sonora de saída de um fone de ouvido em condições de exposição bem definidas em uma faixa de freqüência especificada. Consiste essencialmente em uma cavidade principal, uma carga acústica e um microfone calibrado. A posição do microfone é escolhida de modo que a pressão sonora no microfone corresponda aproximadamente à pressão sonora existente no tímpano humano;

- Simulador de ouvido obstruído: Simulador de ouvido que simula a parte interior do canal auditivo, desde a ponta de um fone de ouvido de inserção até o tímpano;

- Simulador de orelha: Dispositivo que tem forma e dimensões aproximadas da orelha e do pavilhão auditivo de um adulto médio. Molde de orelha externo adulto feito em silicone para se assemelhar às características da orelha humana (Figura 23). 


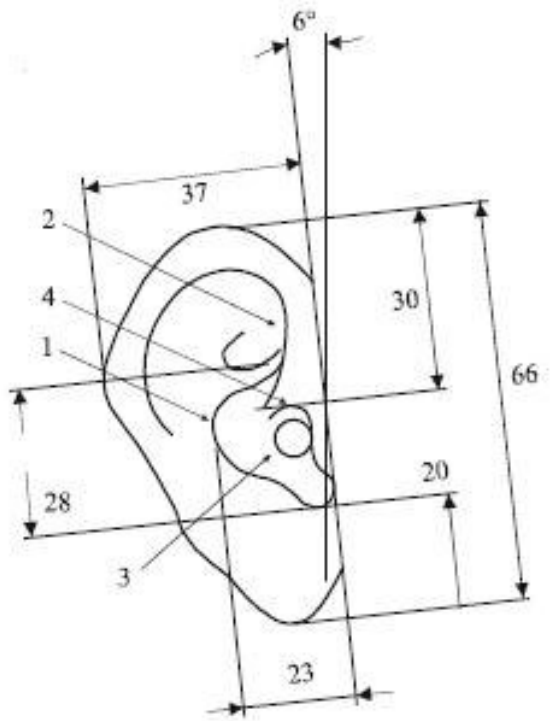

a) Vista lateral

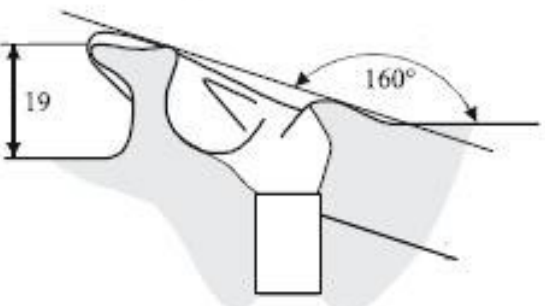

b) Seção transuersal

1 Antihélice 2 Pêndulo de Hélice 3 Concha 4 Trago

Figura 23 - Simulador de orelha moldado anatomicamente (sem escala, unidades em $\mathrm{mm}$ ) Fonte: Recomendação ITU-T P.57, 2005. Figura 7a/p.57, p.14

- Fones de ouvido circum-auricular: São fones que cobrem o pavilhão auditivo e se apóiam na superfície circundante da cabeça. $O$ contato com a cabeça se mantém normalmente mediante almofadas macias. Os fones de ouvido circum-auriculares podem tocar a orelha, porém sem comprimi-las significativamente, conforme Figura 24.

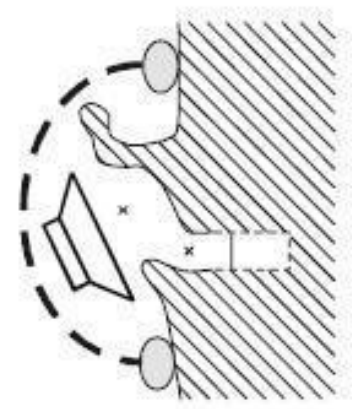

a) Fone circum-auricular (aberto)

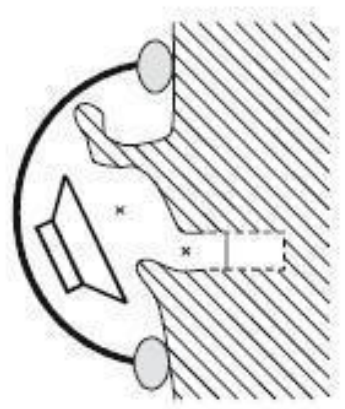

b) Fone circum-auricular (fechado) 
- Fones de ouvido supra-auricular ou supra-aural: São fones de ouvido que descansam sobre a orelha e têm um diâmetro externo (ou dimensão máxima) de pelo menos $45 \mathrm{~mm}$ (Figura 25).

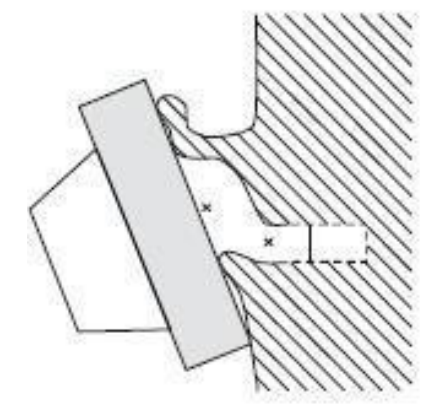

a) Fone supra-auricular (aberto)

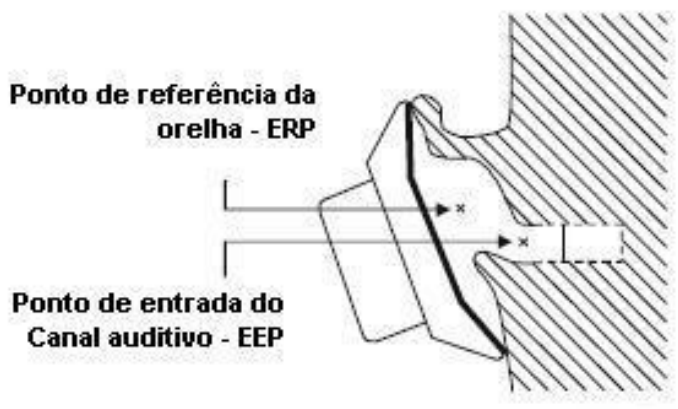

b) Fone supra-auricular (fechado)

Figura 25 - Fones de ouvido supra-auricular Fonte: Recomendação ITU-T P.57, 2005. Figura 2/p.57, p.3

- Fones de ouvido supraconcha: São fones de ouvido destinados a descansar sobre as bordas da cavidade da concha e que têm um diâmetro externo (ou dimensão máxima) superior a $25 \mathrm{~mm}$ e inferior a $45 \mathrm{~mm}$ (Figura 26).

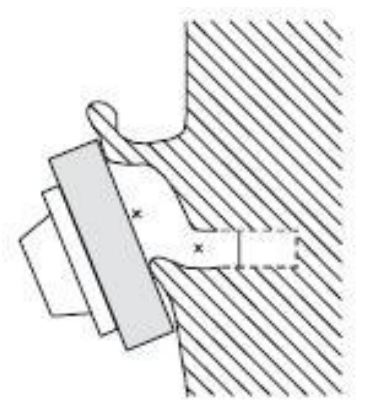

Figura 26 - Fone de ouvido supraconcha (aberto)

Fonte: Recomendação ITU-T P.57, 2005. Figura 3/p.57, p.3

- Fones de ouvido intraconcha: Fones de ouvido destinados a apoiarem-se no interior da concha. Têm um diâmetro externo (ou dimensão máxima) inferior a 25 mm, mas não estão previstos para entrar em contato com o canal auditivo (Figura 27). 


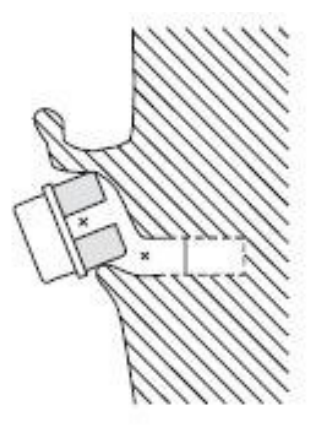

a) Fone intra-concha (aberto)

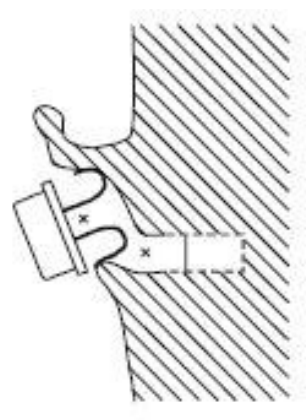

b) Fone intra-concha (fechado)

Figura 27 - Fones de ouvido intraconcha

Fonte: Recomendação ITU-T P.57, 2005. Figura 4/p.57, p.3

- Fones de ouvido de inserção: fones de ouvido destinados a entrar/penetrar parcial ou completamente no canal auditivo (Figura 28).

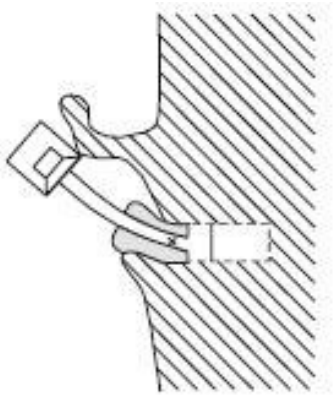

a) Fone de inserção (aberto)

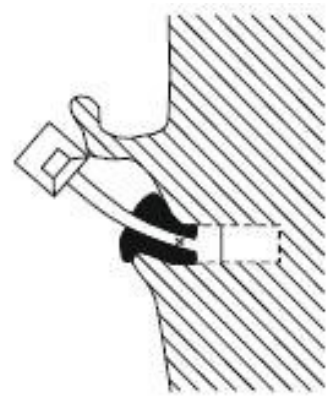

b) Fone de inserção (fechado)

Figura 28 - Fones de ouvido de inserção

Fonte: Recomendação ITU-T P.57, 2005. Figura 5/p.57, p.4

- Fones de ouvido acusticamente abertos (nominalmente não herméticos): São fones de ouvido que intencionalmente proporcionam um trajeto acústico entre o entorno externo e o canal auditivo;

- Fones de ouvido acusticamente fechados (nominalmente herméticos): São destinados a impedir todo acoplamento acústico entre o entorno externo e o canal auditivo. 
Um simulador de ouvido, conforme já visto, é um dispositivo incorporado a um acoplador acústico e a um microfone de medição. O acoplador simula as propriedades do ouvido, enquanto o microfone representa o tímpano humano, captando a pressão sonora. Para uma dada faixa de freqüência, o ouvido artificial deverá simular a impedância acústica média do ouvido humano.

Assim, o principal objetivo de um simulador de ouvido é a comprovação de ter um receptor nas condições que mais se aproximem do uso real em seres humanos. Não se devem modificar os ouvidos artificiais ou os procedimentos dos testes. Não se deve utilizar material flexível hermético, como massa de vidro ou similar, com a finalidade de evitar alterações no volume da concha especificada e/ou fugas.

Quanto aos tipos de simuladores de ouvido, a Recomendação ITU -T P.57 (2005) especifica diversos tipos de simuladores de ouvido. A seguir, é apresentada numa tabela uma visão geral dos vários tipos de simuladores de ouvido (Figura 32).

Tabela 32 - Visão geral dos tipos de simuladores de ouvido

\begin{tabular}{|c|c|c|c|c|}
\hline $\begin{array}{c}\text { ITU-T P.57 } \\
\text { Tipo de ouvido } \\
\text { artificial }\end{array}$ & $\begin{array}{c}\text { Tipos de } \\
\text { fones de ouvido }\end{array}$ & $\begin{array}{c}\text { Ponto } \\
\text { de } \\
\text { Medição }\end{array}$ & $\begin{array}{c}\text { Função de } \\
\text { correção } \\
\text { ERP-DRP }\end{array}$ & $\begin{array}{c}\text { Brüel \& Kjaer }^{(\mathbb{}}{ }^{2} \\
\text { Modelo } \mathrm{n} \underline{0} \\
\left(^{\star}\right)\end{array}$ \\
\hline 1 & $\begin{array}{l}\text { Supra-aural, } \\
\text { supraconcha }\end{array}$ & $\begin{array}{c}\text { ERP } \\
\text { Fechado }\end{array}$ & $\begin{array}{c}\text { Calibrado } \\
\text { individualmente }\end{array}$ & $4158 / 4153$ \\
\hline 2 & $\begin{array}{c}\text { Fones de ouvido } \\
\text { de inserção }\end{array}$ & DRP & $\begin{array}{c}\text { ITU-T P.57 } \\
\text { Tabelas 2a/b }\end{array}$ & 4157 \\
\hline 3.1 & $\begin{array}{c}\text { Fones de ouvido } \\
\text { intraconcha }\end{array}$ & DRP & $\begin{array}{l}\text { ITU-T P.57 } \\
\text { Tabelas } 2 \mathrm{a} / \mathrm{b}\end{array}$ & - \\
\hline 3.2 & $\begin{array}{l}\text { Supra-aural, } \\
\text { Supraconcha }\end{array}$ & DRP & $\begin{array}{c}\text { Calibrado } \\
\text { individualmente }\end{array}$ & 4195 \\
\hline 3.3 & Supraconcha & DRP & $\begin{array}{l}\text { ITU-T P.57 } \\
\text { Tabelas 2a/b }\end{array}$ & $\begin{array}{c}4128 \\
\text { (com } 4158 / 4159)\end{array}$ \\
\hline 3.4 & Supraconcha & DRP & $\begin{array}{l}\text { ITU-T P.57 } \\
\text { Tabelas } 2 \mathrm{a} / \mathrm{b}\end{array}$ & - \\
\hline
\end{tabular}

Fonte: Application note improving telephone handset performance - Brüel \& $\operatorname{Kjaer}^{\circledR}(B \& K), 2005$ $\left(^{*}\right)$ Obs.: Estão indicados os modelos de ouvido artificial do fabricante Brüel \& $\mathrm{Kjaer}^{\circledR}$, que atendem os requisitos específicos em função do tipo de ouvido artificial correspondente ao tipo de fone de ouvido.

Informações sobre cada tipo de ouvido artificial são especificadas por diferentes normas, conforme detalhado a seguir. 
i) Tipo 1 - Especificado na norma IEC 60318-1 (1998) - Simulador de ouvido para calibração de fones de ouvido supra-aural

Recomenda-se utilizá-lo como simulador de ouvido tradicional para medições em fones supra-aural e supraconcha, selados, que se acoplam hermeticamente de maneira natural à borda do simulador, destinado a aplicações de telefonia de banda estreita (100 Hz a $4 \mathrm{kHz}$ ). A impedância acústica de entrada e a resposta em freqüência da sensibilidade do ouvido artificial Tipo 1 se determinam com referência diretamente ao Ponto de Referência da Orelha (ERP).

O ouvido artificial do Tipo 1 não é adequado para medir em fones de ouvido de baixa impedância acústica.

O ouvido artificial do Tipo 1 é definido para simular uma carga acústica do ouvido humano sem vazamentos.

É recomendado aplicar uma força de $5 \mathrm{~N}$ a $10 \mathrm{~N}$ para fixar os fones de ouvido ao ouvido artificial Tipo 1. Sempre se deve indicar a força aplicada nas medições.

ii) Tipo 2 - Especificado na norma IEC 60711 (1981) - Simulador de ouvido para fones de ouvido de inserção

Recomenda-se utilizá-lo para medições em fones de inserção, herméticos e não herméticos.

A medição sonora medida pelo ouvido artificial Tipo 2 se determina com referência ao Ponto de Referencia do Tímpano (DRP).

Para converter os dados obtidos na posição do Ponto de Referência do Tímpano (DRP) para a posição do Ponto de Referência da Orelha (ERP) deve-se utilizar, conforme necessário, as correções indicadas em quadros de normas específicas.

Para se obter a Função de Transferência (SDE) de DRP para ERP, veja exemplo no quadro a seguir: 
Tabela 33 - Função de Transferência SDE - Medições em terço de oitava

\begin{tabular}{cccc}
\hline $\begin{array}{c}\text { Freqüência } \\
(\mathrm{Hz})\end{array}$ & $\begin{array}{c}\text { SDE } \\
(\mathrm{dB})\end{array}$ & $\begin{array}{c}\text { Freqüência } \\
(\mathrm{Hz})\end{array}$ & $\begin{array}{c}\text { SDE } \\
(\mathrm{dB})\end{array}$ \\
\hline 100 & 0,0 & 1000 & $-1,7$ \\
125 & 0,0 & 1250 & $-2,6$ \\
160 & 0,0 & 1600 & $-4,2$ \\
200 & 0,0 & 2000 & $-6,5$ \\
250 & $-0,3$ & 2500 & $-9,4$ \\
315 & $-0,2$ & 3150 & $-10,3$ \\
400 & $-0,5$ & 4000 & $-6,6$ \\
500 & $-0,6$ & 5000 & $-3,2$ \\
630 & 0,7 & 6300 & $-3,3$ \\
800 & $-1,1$ & 8000 & $-16,0$ \\
& & 10000 & $-14,4$ \\
\hline
\end{tabular}

SDE Função de transferência de DRP para ERP

$\mathrm{SDE}=20 \log 10(\mathrm{PE} / \mathrm{PD})$

Onde: PE: Pressão sonora em ERP

$P_{D}$ : Pressão sonora em DRP

Os valores deste quadro se aplicam unicamente às medições realizadas em bandas terço de oitava.

Fonte: Recomendação ITU -T P.57, 2005. Quadro 2a/p.57, p.6

iii) $\underline{\text { Tipo } 3}$ - Especificado na norma IEC 60711 (1981)

Todos os ouvidos artificiais do Tipo 3 consistem de um simulador de ouvido obstruído/fechado Tipo 2, ao qual se une a extensão do canal auditivo, terminando com um dispositivo de simulação do pavilhão auditivo "simulador de orelha" também conhecido por "pinna", que proporciona as configurações de acoplamento adequadas para realizar diferentes tipos de medições. Para tanto, as configurações do ouvido artificial Tipo 3 se classificam em quatro tipos: 3.1; 3.2; 3.3 e 3.4.

Os fones de ouvido abertos acusticamente, equipados com almofadas macias, devem fixar-se ao ouvido artificial Tipo $3 \mathrm{com}$ a mesma força que se aplica na utilização normal, devendo sempre indicar-se a força aplicada durante as medições.

iv) Tipo 3.1 - Simulador de concha inferior

A simulação realiza-se por meio de uma terminação da extensão do canal auditivo de 10,0 mm, simulando a parte inferior da concha. 
Recomenda-se utilizá-lo para medições de fones intraconcha desenhados para colocá-los na parte inferior da cavidade da concha.

A medição da pressão sonora é realizada no Ponto de Referência do Tímpano (DRP).

v) Tipo 3.2 - Simulador de orelha simplificado

A simulação da orelha se realiza mediante uma cavidade que termina na extensão do canal auditivo de 10,0 mm. Nesse simulador, são bem definidos os graus de vazamento, da cavidade ao exterior, simulando o valor médio das perdas de acoplamento do ouvido real para os fones handsets, sustentados firmemente (versão baixo vazamento) ou com pouca força (versão alto vazamento) contra o ouvido humano. O simulador de ouvido Tipo 3.2 é recomendado para medições em fones de ouvido destinados para funcionar em estreito contato com o pavilhão auditivo real,

como o supra-aural e o supraconcha, selados e não selados, de alta e baixa impedância, destinados a aplicações de telefonia tanto de banda larga como de banda estreita ( $100 \mathrm{~Hz}$ a $8 \mathrm{kHz}$ ), cobrindo praticamente todos os modelos de fones. Também se recomenda aplicar uma força entre $5 \mathrm{~N}$ a $10 \mathrm{~N}$ para fixar os fones ao ouvido artificial Tipo 3.2.

A medição da pressão sonora é realizada no Ponto de Referência do Tímpano (DRP), devendo-se, se necessário for, utilizar para correção a Função de Transferência (SDE) de DRP para ERP.

vi) Tipo 3.3 - Simulador de pavilhão auditivo (orelha)

A simulação realiza-se por meio de uma terminação da extensão do canal auditivo real com um simulador de orelha descrito na norma IEC/TR 60959 (1990). 
O simulador de orelha, conforme já visto, deverá ser fabricado com um elastômero de alta qualidade, cuja dureza medida na superfície de $15 \mathrm{~mm}$ adiante da abertura do canal auditivo deverá ser de $35 \pm 6$ Shore-00.

Recomenda-se utilizá-lo para medições de fones supraconcha, selados e não selados, os quais, em razão da sua particular forma, não assentam adequadamente nas bordas circulares dos simuladores do Tipo 1 ou do Tipo 3.2.

A medição da pressão sonora é realizada no Ponto de Referência do Tímpano (DRP).

vii) Tipo 3.4 - Simulador de orelha (simplificado)

A simulação da orelha se realiza pela terminação do plano de referência do tímpano do ouvido artificial do Tipo 2 com uma extensão do canal auditivo e uma orelha simplificada, que deverá ser fabricada com elastômero de alta qualidade, com dureza de $25 \pm 2$ Shore- 00 a $20^{\circ} \mathrm{C} \pm 2^{\circ} \mathrm{C}$.

Recomenda-se utilizar o ouvido artificial Tipo 3.4 como alternativa do Tipo 3.3 para medições em todos os tipos de dispositivos, principalmente nos fones supraconcha e supra-aural. O ouvido artificial Tipo 3.4 se destina a reproduzir os vazamentos típicos que aparecem na utilização real para forças de pressão compreendidas entre $1 \mathrm{~N} \mathrm{e}$ $13 \mathrm{~N}$.

A medição da pressão sonora é realizada no Ponto de Referência do Tímpano (DRP).

$\mathrm{Obs}_{1}$ : Para a calibração dos vários tipos de ouvido artificial, devem ser seguidos os procedimentos específicos, nas respectivas normas e recomendações aqui citadas.

$\mathrm{Obs}_{2}$ : É importante notar a quantidade de outras normas e recomendações que estão correlacionadas com a Recomendação ITU - T P.57 (2005), a qual, por sua vez, é referida nas normas da série ISO 11904, e essas a outras mais, que nem sempre são mencionadas. Por exemplo: 
- ITU - T Recommendation P.51 (1996): Artificial mouths;

- ITU - T Recommendation P.581 (2000): Use of head and torso simulator (HATS) for hands-free terminal testing;

- ITU - T Recommendation P.832 (2000): Subjective performance evaluation of Hand-free Terminals;

- ITU - T Recommendation P.380 (2003): Electro-acoustic measurements on headsets;

- ITU - T Recomendation P.360 (2006): Efficiency of devices for preventing the occurrence of excessive acoustic pressure by telephone receivers and assessment of daily noise exposure of telephone users.

\subsection{DEMAIS NORMAS E RECOMENDAÇÕES RELEVANTES}

Neste contexto, chamou a atenção a Recomendação ITU -T P.360 (2006), que trata sobre a eficiência dos dispositivos destinados a evitar a geração de pressões acústicas excessivas nos receptores telefônicos.

A citada recomendação propõe a aplicação de limites para a pressão acústica gerada em fones pelos aparelhos telefônicos, assim como fornece algumas orientações de como medir esses níveis. $\mathrm{Na}$ realidade, após leitura e análise preliminar, essa recomendação basicamente "remete" à norma ISO 11904, no que se refere ao Método da ISO 11904-2 - Parte 2 - Técnica da Cabeça Artificial de Manequim, recomendando, a utilização do conjunto completo Simulador de Cabeça e Torso - "Head and Torso Simulator" (HATS). De qualquer forma, é uma Recomendação que merece ser mais bem estudada, pois apresenta um método de avaliação de níveis de ruído em fones com procedimentos mais simplificados. 


\subsection{CONSIDERAÇÕES FINAIS}

Como visto, não há no Brasil e em muitos outros países, metodologias nacionais padronizadas e normalizadas para avaliação dos níveis sonoros em fones de ouvido. Os critérios tradicionais de medição de ruído estabelecidos em procedimentos do Ministério de Trabalho e Emprego - MTE, da FUNDACENTRO, de Notas Técnicas ou de Instruções Normativas do INSS, não contemplam essa situação acústica. Igualmente não foi encontrada Norma específica da Associação Brasileira de Normas Técnicas (ABNT) que trate do assunto.

Quantificar adequadamente o ruído junto aos usuários de fones de ouvido é indispensável para o planejamento, controle e diminuição dos riscos de perdas auditivas por exposição prolongada a níveis elevados.

Hoje esse problema está sendo mascarado ou mesmo subnotificado, devido a falta de metodologia adequada e de fácil aplicação em campo, nos diversos tipos de ambientes.

A medição do nível do som em fones de ouvido envolve variáveis que, se não levadas em consideração, podem distorcer os resultados.

O importante é que se consiga ter Reprodutibilidade das medições, isto é, concordância dentro de estreitos limites, entre os resultados de avaliações individuais que: são executadas por diferentes métodos de medição, por instrumentos de medição diferentes, por observadores diferentes, em laboratórios diferentes, após intervalos de tempo longos em comparação com a duração de uma única medição, e sob diferentes condições usuais de utilização dos instrumentos. Também se faz necessário que haja Rastreabilidade dos dados e serviços, dentro de limites pré-estabelecidos, por meio de sua identificação e seus registros. 


\section{CONCLUSÕES}

De uma forma geral, os trabalhos publicados sobre o assunto desta dissertação não apresentam metodologias nem padrões similares. Vale também acrescentar que na área acústica, pródiga por oferecer milhares de referências bibliográficas, o número de artigos técnicos encontrado sobre o tema em questão é bastante reduzido. Esse cenário de falta de dados e de ausência de uniformidade nas metodologias adotadas forma um quadro muito atraente para pesquisas futuras.

Nota-se que a maioria dos trabalhos realizados até o momento sobre o assunto foi dedicada à necessidade da avaliação (medição propriamente dita), não havendo em princípio, uma preocupação em padronizar os procedimentos de medição e especificação de Equipamentos. Metodologias, Instrumentos, Critérios, Estratégias de Amostragem e Procedimentos diferentes, gerando diferentes resultados. A chance de subestimar ou superestimar a avaliação das medições é grande.

Importante atentar que, mais do que verificar a conformidade de um valor limite, os métodos propostos têm suas limitações de funcionalidade e praticidade; por exemplo, na avaliação de ruídos em fones de ouvido nas atividades da indústria da mineração, notadamente nas instalações subterrâneas com as suas peculiaridades.

Ficaria a dúvida de como monitorar as medições, como instalar o microfone em ouvido real, como instalar o manequim ao lado do empregado, etc. Na realidade, para a aplicação dos métodos há necessidade de uma complexa logística.

Neste contexto, esta pesquisa trouxe um estudo contendo uma proposta prática e de baixo custo da Empresa Etymotic Research, sediada em Chicago, nos Estados Unidos, de um sistema de medição de nível de ruído diretamente em fones, que utiliza microfone/sonda conectado à pessoa, por meio de um tubo de $1 \mathrm{~mm}$ de diâmetro inserido em seu canal auditivo. Neste particular, este sistema atenderia à Norma ISO 11904-1, uma vez que, na técnica do minimicrofone em ouvido real, essa norma prevê a possibilidade de utilização de um microfone com sonda acoplada. 
Esta técnica proposta é de custo bem inferior às que estão em uso no momento, sinalizando que esse tipo de avaliação poderá ser realizado no futuro, com muito mais facilidade econômica e praticidade.

No entanto, a proposta precisa ser mais bem estudada para verificar a sua conformidade com as normas da Série ISO 11904. O importante é avançar com a idéia da concepção e aplicabilidade do produto.

Portanto, considerando o surgimento das Normas da ISO, o aparecimento de novas técnicas e o desenvolvimento de aparelhos mais baratos, existem agora indicativos mais favoráveis, do ponto de vista técnico - econômico, de se avaliar a exposição ao ruído gerado pelos fones de ouvido, trazendo uma luz à Higiene Ocupacional, que requer avaliações práticas, com resultados reproduzíveis e confiáveis.

Desta forma, convém ressaltar a importância da atuação do avaliador na área de Higiene Ocupacional, mesmo na hipótese de que seja desenvolvido no Brasil todo o aparato legal cabível à medição de ruídos, pois o julgamento profissional do avaliador é imprescindível em todas as etapas das avaliações, incluindo o tratamento de dados e de análise de incertezas das medições.

Espera-se que os dados deste trabalho possam servir de subsídios para a elaboração de normas técnicas e legais, de normas de higiene ocupacional, de procedimentos de medição, de metodologias e critérios de avaliação e de instruções técnicas sobre o assunto, ou mesmo, para a adoção de uma norma internacional, de forma a cobrir a lacuna existente nesse segmento.

Enquanto isso, esta pesquisa contempla os parâmetros necessários para o desenvolvimento de instrumentos normativos que dêem respaldo técnico legal para a realização de avaliações confiáveis dos níveis de ruído, específica para fones de ouvido. 


\subsection{PROPOSTAS PARA FUTUROS TRABALHOS}

Entende-se que o trabalho deva continuar para avançar na aplicabilidade das técnicas de avaliação dos níveis de ruído em fones de ouvido.

O objetivo é desenvolver um sistema composto de instrumentos portáteis, tipo dosímetros comerciais, em bandas de terço de oitava, preferencialmente de duplo canal, com microfone/sonda adequado, que atenda às especificações da Norma ISO 11904-1 e à maioria das demandas.

Sistemas compostos de equipamentos de geração de sinal padrão de laboratório também são necessários para que se possa realizar uma comparação com o sistema proposto. Para tanto, a participação da Universidade é imprescindível, por meio de intercâmbio e obtenção de financiamento para as pesquisas.

Com isso, espera-se a possibilidade de continuidade deste trabalho de pesquisa em nível de doutorado, para que se possa contribuir no desenvolvimento de uma Metodologia e Procedimento Normalizado do Instituto Nacional de Metrologia, Normalização e Qualidade Industrial (INMETRO), que dê respaldo técnico e legal a este tipo de avaliação sobre ruído em fones de ouvido. 


\section{REFERÊNCIAS}

AIRO, E. et al. Noise exposure of broadcast production personnel. Mariehamn, Åland, 8-10 jun. 2004, Joint Baltic-Nordic Acoustics Meeting. Disponível em: $<$ http://www.acoustics.hut.fi/ast/bnam04/webprosari/papers/o42.pdf >. Acesso em 20 jan. 2008.

ALEXANDER, R.W. et al. The effects of noise on telephone operators. Journal of Occupational Medicine, v. 21, n. 1, p.21-25, 1979.

AMERICAN CONFERENCE OF GOVERNMENTAL INDUSTRIAL HYGIENISTS. ACGIH® - Threshold Limit Values for Chemical Substances and Physical Agents and Biological Exposure Indices. Cincinnati, 2007 (update annually).

AMERICAN NATIONAL STANDARDS INSTITUTE. ANSI S3.25 Occluded Ear. New York, 1989 (R2003).

ANSI S 3.35: Method of Measurement of Performance Characteristics of Hearing Aids Under Simulated Real-Ear Working Conditions. New York, 2004.

ANSI S 3.36: Specification for a Manikin for simulatated in-situ airborne Acoustic Measurements. New York, 1985 (R 2006).

ANSI S12.42: Microphone-in-Real-Ear and Acoustic Test Fixture Methods for the Measurement of Insertion Loss of Circumaural Hearing Protection Devices. New York, 1995 (R 2004).

ANSI S12.57 - 2002/ISO 3747-2000: Standard Acoustics - Determination

of sound power levels of noise sources using sound pressure - Comparison method in situ. New York, 2002.

ANDRADE, A. I. A.; LIMA, M. L. L. T.; OLIVEIRA L. C. S.. Avaliação auditiva em músicos de frevo e maracatu. Revista Brasileira de Otorrinolaringologia, v. 68, n. 5, p. 714-720, set./out. 2002. Disponível em: <http://www.sborl.org.br>. Acesso em 25 jan. 2008.

ASSOCIAÇÃO BRASILEIRA DE NORMAS TÉCNICAS. Comitê Brasileiro de Eletricidade. Dicionário brasileiro de eletricidade. Rio de Janeiro: 1986. 437 p. 
ASSOCIAÇÃO BRASILEIRA DE NORMAS TÉCNICAS. NBR 10152: níveis de ruído para conforto acústico. Rio de Janeiro, 1987.

ABNT, INMETRO: Guia para a expressão da incerteza de medição. 3 ed. Rio de Janeiro, 2003.

BRASIL. Fundacentro. Norma de Higiene Ocupacional NHO 01: Procedimento Técnico - Avaliação da Exposição Ocupacional ao Ruído, São Paulo, 1999.

BRASIL. Governo Federal. Decreto-Lei n. 5452, de 01 de maio de 1943. Instituiu a Consolidação das Leis do Trabalho - CLT, introduzindo os direitos dos trabalhadores à redução dos riscos inerentes ao trabalho, por meio de normas. Diário Oficial da União, Rio de Janeiro, DF, 09 ago. 1943. Em vigor: 10 de nov.de 1943.

. Governo Federal. Decreto n. 6.042, de 12 de fevereiro de 2007. Disciplina a aplicação, acompanhamento e avaliação do Fator Acidentário de Prevenção - FAP e do Nexo Técnico Epidemiológico, e dá outras providências. Diário Oficial da União, Brasília, DF, fev. 2007.

Governo Federal. Lei n. 6.367, de 19 de outubro de 1976. Lei de Acidentes do Trabalho, art. $2^{\circ}$ item I $\S 1^{\circ}$, que dispõe sobre o seguro de acidentes do trabalho a cargo do INPS, e dá outras providências. Diário Oficial da União, Brasília, DF, 21 out.1976.

. Governo Federal. Lei n. 6.514, de 22 de dezembro de 1977. Altera o Capítulo V do Título II da Consolidação das Leis do Trabalho, relativo à Segurança e Medicina do Trabalho. Diário Oficial da União, Brasília, DF, 23 dez.1977.

. Governo Federal. Lei n. 11.430, de 26 de dezembro de 2006. Altera a Lei $\mathrm{n}$. 8.213 , de 24 de julho de 1991 do Plano de Benefícios da Previdência Social no art. 21-A, em que a perícia do INSS considerará a natureza acidentária da incapacidade quando constatar ocorrência de nexo técnico epidemiológico entre o trabalho e o agravo, decorrente da relação da atividade da empresa e a doença motivadora da incapacidade elencada na classificação internacional de doenças - CID. Diário Oficial da União, Brasília, DF, dez. 2006.

Ministério da Previdência Social, Ministério da Saúde, Ministério do Trabalho e Emprego. Apresenta os fundamentos e diretrizes de uma Política Nacional de Segurança e Saúde do Trabalhador - PNSST. Portaria Interministerial MPS/MS/MTE n. 800, de 3 de maio de 2005. Diário Oficial da União, Brasília, DF, maio 2005. 
BRASIL. Ministério da Previdência Social. Estabelece os procedimentos técnicos de levantamento ambiental, e os limites de tolerância quanto ao ensejo da aposentadoria especial. Instrução Normativa INSS/PRES n. 11, de 20 de setembro de 2006. Diário Oficial da União, Brasília, DF, set. 2006.

Ministério da Previdência Social. Dispõe sobre os procedimentos e rotinas referentes ao Nexo Técnico Epidemiológico Previdenciário - NTEP, estabelecendo critérios para aplicação do NTEP pelo INSS como uma das espécies do gênero nexo causal. Instrução Normativa INSS/PRES n. 16, de 27 de março de 2007. Diário Oficial da União, Brasília, DF, mar. 2007.

- Ministério da Saúde. Dispõe sobre os procedimentos técnicos para a notificação compulsória de agravos à saúde do trabalhador em rede de serviços sentinela específica, no Sistema Único de Saúde (SUS). Portaria n. 777/MS,GM, de 28 de abril de 2004. Diário Oficial da União, Brasília, DF, n. 81, 29 abr. 2004. Seção 1, p. 37-8.

- Ministério da Saúde. Secretaria de Atenção à Saúde. Departamento de Ações Programáticas Estratégicas. Perda auditiva induzida por ruído (Pair). Brasília: Editora do Ministério da Saúde, 2006. 40 p.

. Ministério do Trabalho. Aprova as Normas Regulamentadoras - NR - do Capítulo V, da Consolidação das Leis do Trabalho, relativas a Segurança e Medicina do Trabalho. Portaria n. 3.214, de 08 de junho de 1978. Diário Oficial da União, Poder Executivo, Brasília, DF, jun. 1978.

. Ministério do Trabalho. Norma Regulamentadora n. 15: Atividades e operações insalubres. Brasília, DF, jun. 1978.

- Ministério do Trabalho. Norma Regulamentadora n. 15: Anexo 13-A Operações diversas. Brasília, DF, jun. 1978.

. Ministério do Trabalho e Emprego. Norma Regulamentadora n. 9: Programa de Prevenção de Riscos Ambientais - PPRA. Portaria de alteração SSST n. 25. Brasília, DF, dez. 1994.

Ministério do Trabalho e Emprego. Norma Regulamentadora n. 7: Programa de Controle Médico de Saúde Ocupacional Prevenção de Riscos Ambientais - PCMSO. Portaria de alteração SSST n. 24, Brasília, DF, dez. 1994. 
BRASIL. Ministério do Trabalho e Emprego. Norma Regulamentadora n. 17: Ergonomia. Portaria de alteração no 3.751, Brasília, DF, nov. 1990.

Ministério do Trabalho e Emprego. Norma Regulamentadora n. 17: Ergonomia. Portaria n. 08, que aprova o Anexo I da NR 17, sobre o Trabalho dos Operadores de Checkout, Brasília, DF, mar. 2007.

Ministério do Trabalho e Emprego. Norma Regulamentadora n. 17: Ergonomia. Portaria n. 09, que aprova o Anexo II da NR 17, sobre o Trabalho em Teleatendimento/Telemarketing, Brasília, DF, mar. 2007.

- Ministério do Trabalho e Emprego. Estabelece diretrizes e parâmetros mínimos para avaliação e acompanhamento da audição em trabalhadores expostos a níveis de pressão sonora elevados. Portaria n. $19 \mathrm{GM} / \mathrm{SSSTb}$, de 9 de abril de 1998. Diário Oficial da União, Brasília, 22 abr. 1998.

- Ministério do Trabalho e Emprego. Secretaria de Inspeção do Trabalho. Departamento de Segurança e Saúde no Trabalho. Operações diversas constantes no Anexo 13-A, da NR 15. Nota Técnica emitida à empresa Telecomunicações de São Paulo, n. 10/2002. Brasília, 18 abr. 2002. 1 p.

BRASIL não notifica adequadamente acidentes de trabalho. Agência Brasil. Disponível em: <http://www.agenciabrasil.gov.br/noticias/2007/07/27/materia.2007-

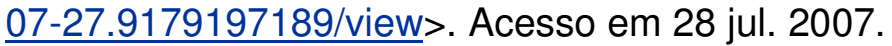

BRÜEL \& KJAER® (B\&K). Chapter 2 - Microphone Theory Sound Level and Sound Fields; Application Note - Improving Telephone Handset Performance. Master Catalogue. Dinamarca: Edition 2005. 1 CD - ROM.

BRÜEL \& KJAER® (B\&K). Short Form Catalogue. Dinamarca: Edition 1991.

CHIUSANO S. V., LEES P. S. J. BREYSSE P. N.. An occupational noise exposure assessment for headset-wearing communications workes. Appl. Occup. Environ. Hyg., v. 10, n. 5, p. 476-481, 1995.

DAJANI, H., KUNOV, H., SESHAGIRI, B.. Real-time method for the measurement of noise exposure from communication headsets. Applied Acoustics, v. 49, n. 3, p. $209-224,1996$. 
DARLINGTON, P.. Practical measurement of telecommunication receiver electroacoustics for the computation of acoustic dose. IOA. Proceedings of the Institute of Acoustics. St. Albans: Institute of Acoustics, 2003, v. 25, part 4, p.234 242.

EARSET. Práticas bem-sucedidas: serviços e equipamentos. In: Seminário Saúde Ocupacional - Operadores de Call Center, São Paulo, 2004. Resumo das apresentações. São Paulo: CBSS, 2004. p. 81-86.

ETYMOTIC RESEARCH. Research and Product Development For The Ear. Proposta de Sistema para realizar medições de dosimetria de ruído em fones de call center (headsets). Chicago, maio 2006.

FARIA, P. C. M. Avaliação audiométrica e otoneurológica de 442 telefonistas durante 5 anos. Encontro de Segurança e Medicina do Trabalho do Sistema Telebrás - STB, 6., Recife, 1985. Anais. Recife: CRTr, 1985. p. $94-102$.

FELICIO, J. Levantamento das condições ambientais (nível de pressão sonora - "ruído") e estudos sobre o perfil acústico relacionados às atividades de telefonistas, operadores de TELEX e radioperadores nas instalações da CESP. Laudo Técnico da empresa Telecomunicações de São Paulo para a Companhia Energética de São Paulo. São Paulo: 1991. 183 p. Acesso Restrito.

FELICIO, J. Medições em fone de telefonista headset. Laudos/Relatórios Técnicos da empresa Telecomunicações de São Paulo (Telesp), 1990/91, São Paulo. Acesso Restrito.

GIERLICH, H. W. Artificial head technology - applications for head measurements in call centres. IOA. Proceedings of the Institute of Acoustics. St. Albans: Institute of Acoustics, 2002, v. 24, part 4, p. 228-233.

GLORIG, A. et. al. Hearing studies of telephone operating personnel. J. Speech Hear. Res., v. 12, n. 1, p. 169-178, 1969.

HUGHES, E. et.al. Damage to hearing aristing from leisure noise. Br. J. Audiol., v. 20, n. 2, p. 157-164, 1986.

IANNIELLO, C.. Valutazione dei livelli di esposizione al rumore di operatori telefonici con un microfono nella conca del padiglione auricolare. Revista Italiana de Acústica, v. 20, n. 1-2, p. 37-46, 1996. 
INTERNATIONAL ELECTROTECHNICAL COMISSION. IEC 60065.ed. 7.1: Group Safety Publication - Audio, video and similar electronic apparatus - Safety requirements, [S.I], 2005.

. IEC 60118-8.ed. 2.0: Electroacoustics - Hearing aids - Part 8: Methods of measurement of performance characteristics of hearing aids under simulated in situ working conditions, [S.I.], 2005. [S.I.], 2004.

IEC 60268-4. ed. 3.0: Sound System equipments. Part 4: Microphones, . IEC 60268-7.ed. 2.0: Sound System equipments. Part 7: Headphones and earphones, [S.I.], 1996-2.

. IEC 60318-1.ed. 1.0: Simulators of human head and ear. Part 1: Ear simulator for the calibration of supra-aural earphones, [S.I.], 1998 - 07.

IEC 60318-2.ed. 1.0: Simulators of human head and ear. Part 2: An interim acoustic coupler for the calibration of audiometric earphones in the extendend highfrequency range, [S.I.], 1998 - 08.

IEC 60318-3.ed. 1.0: Simulators of human head and ear. Part 3: Acoustic coupler for the calibration of supra-aural earphones used in audiometry, [S.I.], 1998 08.

. IEC 60318-5.ed. 1.0: Simulators of human head and ear. Part 5: $2 \mathrm{~cm}^{3}$ $\overline{\text { coupler }}$ for the measurement of hearing aids and earphones coupled to the ear by means of ear inserts, [S.I.], $2006-08$.

. IEC 60601.ed. 3.0: Medical electrical equipment - Part 1: General requirements for basic safety and essential performance, [S.I.], 2005.

. IEC 60711 ed. 1.0: Occluded-ear simulator for the measurement of earphones coupled to the ear inserts, [S.I.], 1981.

. IEC 60942.ed. 3.0: Electroacoustics - Sound calibrators, [S.I.], 2003.

IEC 61094-1.ed. 2.0: Measurement microphones - Part 1: Specifications for laboratory standard microphones, [S.I.], 2000. 
INTERNATIONAL ELECTROTECHNICAL COMISSION. IEC 61094-4.ed. 1.0: Measurement microphones - Part 4: Specifications for working standard microphones, [S.I.], 1995.

IEC 61260.ed. 1.0: Electroacoustics - Octave-band and fractional-octaveband filters, [S.I.], 1995.

$-05$.

IEC 61672-1.ed. 1.0: Sound level meters. Part 1: Specifications, [S.I.], 2002

IEC 61672-2.ed. 1.0: Sound level meters. Part 2: Pattern evaluation tests, [S.I.], $2003-04$.

. IEC 61672-3.ed. 1.0: Sound level meters. Part 3: Periodic tests, [S.I.] 2006 10.

. IEC 61842-1.ed.1.0: Microphones

and earphones for

speech

. IEC/TR 60959.ed. 1.0: Provisional head and torso simulator for acoustic measurements and air conduction hearing aids. Technical Report, [S.I.], 1990 - 04.

INTERNATIONAL ORGANIZATION FOR STANDARDIZATION. ISO 11904-1 ed. 01: Acoustics - Determination of sound immission from sound sources placed close to the ear. Part 1: technique using a microphone in a real ear (MIRE technique). Geneva, 2002-10-01.

ISO 11904-2 ed. 01: Acoustics - Determination of sound immission from sound sources placed close to the ear. Part 2: technique using a manikin. Geneva, 2004-11-01. (GUM), [S.I.], 1995.

ISO/IEC Guide 98: Guide to the expression of uncertainty in measurement . ITU.T. Recommendation P.51 (08/1996): Artificial mouth. Disponível em: $\overline{<h t t p / / w w w . i t u . i n t / r e c / t-r e c-p .51>. ~ A c e s s o ~ e m: ~} 10$ jul. 2007. 
INTERNATIONAL TELECOMMUNICATION UNION. ITU.T. Recommendation P. 57 (11/2005): Artificial ears. Disponível em: <http//www.itu.int/rec/t-rec-p.57>. Acesso em: 04 jul. 2007.

ITU.T. Recommendation P. 57 Corrigendum 1 (01/2005): Artificial ears. Disponível em: <http//www.itu.int/rec/t-rec-p.57>. Acesso em: 04 jul. 2007.

ITU T. Recommendation P. 58 (08/1996): Head and torso simulator for telephonometry. Disponível em: <http//www.itu.int/rec/t-rec-p.58>. Acesso em: 04 jul. 2007.

ITU.T. Recommendation P. 58 Erratum 1 (31/03/2003): Head and torso simulator for telephonometry. Disponível em: <http//www.itu.int/rec/t-rec-p.58>. Acesso em: 04 jul. 2007.

ITU.T. Recommendation P.79 (09/1999): Calculation of loudness rating for telephone sets. <Disponível em: http//www.itu.int/rec/t-rec-p.79>. Acesso em: 28 jun. 2007.

ITU.T. Recommendation P.79 Erratum 1 (05/2000): Calculation of loudness rating for telephone sets. Disponível em: <http//www.itu.int/rec/t-rec-p.79>. Acesso em: 28 jun. 2007.

. ITU.T. Recommendation P.79 Annex G (11/2001): Annex G: Wideband loudness rating algorithm. <Disponível em: http//www.itu.int/rec/t-rec-p.79>. Acesso em: 28 jun. 2007.

ITU.T. Recommendation P.79 Corrigendum 1 (10/2000): Calculation of loudness rating for telephone sets. Disponível em: <http//www.itu.int/rec/t-rec-p.79>. Acesso em: 28 jun. 2007.

ITU.T. Recommendation P.79 Corrigendum 2 (05/2001): Calculation of loudness rating for telephone sets. Disponível em: <http//www.itu.int/rec/t-rec-p.79>. Acesso em: 28 jun. 2007.

ITU.T. Recommendation P.79 Corrigendum 3 (01/2005): Calculation of loudness rating for telephone sets. Disponível em: <http//www.itu.int/rec/t-rec-p.79>. Acesso em: 28 jun. 2007. 
INTERNATIONAL TELECOMMUNICATION UNION. ITU.T. Recommendation P.360 (07/2006): Efficiency of devices for preventing the occurrence of excessive acoustic pressure by telephone receivers. Disponível em: $<\mathrm{http} / \mathrm{www}$.itu.int/rec/t-recp.360>. Acesso em: 29 jun. 2007.

ITU.T. Recommendation P.380 (11/2003): Electro-acoustic measurements on headsets. Disponível em: <http//www.itu.int/rec/t-rec-p.380>. Acesso em: 29 jun. 2007.

ITU.T. Recommendation P. 581 (05/2000): Use of head and torso simulator

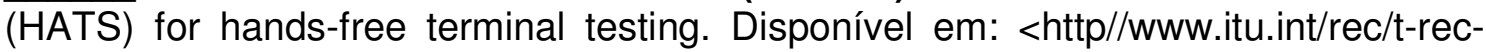
p.581 >. Acesso em: 04 jul. 2007.

ITU.T. Recommendation P.832 (05/2000): Subjective performance evaluation of hands-free terminals. Disponível em: <http//www.itu.int/rec/t-rec-p.832>. Acesso em: 11 jul. 2007.

IVANOVICH, E. et. al. Noise evaluation and estimation of some specific and nonspecific health indicators in telephone operators. Rev. Environ. Health, v. 10, n. 1, p. 39-46, 1994.

JUAN P. A.; CANO-CORTES J. R.. Medida del ruido impulsivo en el auricolar de operador. Medicina Seguridad Trabajo, v. 27, n. 107, p. 14-27, 1979.

KUHN G. F.; GUERNSEY R. M.. Sound pressure distribution about human head and torso. Journal of the Acoustical Society of America, v. 73, n.1, p. 95-105, 1983.

MENDES, R. C. C. G.. Estudo da audição em telefonistas com mais de dez anos de utilização de monofone, comparação com grupo-controle e avaliação do risco de surdez ocupacional. 1995. 61 p. Dissertação (Mestrado) - Setor de Ciências da Saúde, Universidade Federal do Paraná, Curitiba, 1995.

MORI, T. Effects of record music on hearing loss among young workers in a shipyard. Int. Arch. Occup. Environ. Health, v. 56, n.2, p. 91-97, 1985.

PATEL, J. A.; BROUGHTON K. Assessment of the noise exposure of call centrer operators. Ann. Occup. Hyg., v. 46, n. 8, p. 653-661, 2002. 
PERETTI, A. et. al. Headphone noise: occupational noise exposure assessment for communication personnel, Naples, 2003, European Week for Safety and Health at work (Euronoise). Paper ID: 365-IP. Naples, 2003.

PLANEAU, V. Noise hazards associated with the call centre industry. [S. I.]: Institut National de Recherche et de Sécurité, 2005. 9 p. Disponível em: $<$ http://ew2005.osha.eu.int/europeannoisesummit/speeches/ew05 planeau.doc>. Acesso em 22 jan. 2008.

PRADO, A. M. Dados de call center. [informação pessoal]. Mensagem recebida por correio eletrônico em 22 fev. 2008.

RACITRA - Relatório de Acidentes do Trabalho, emitido pela Telebrás. Apud Telecomunicações do Paraná. Exposição Ocupacional ao Ruído em Empresas de Telecomunicações - Parte I: Identificação, Avaliação e Medidas de Controle. Relatório do grupo técnico de assessoria em saúde e segurança do trabalho da Telebrás, 18p, 1996, p.5. Acesso Restrito.

RIBEIRO, A. et. al. Perícia e avaliação de ruído em sistema de telefonia. Disponível em: <http://www.isegnet.com.br/arquivosartigos/artigo cabeca.doc>. Acesso em 21 fev. 2008.

RIFFEL, G.; MACHADO, R. L. Medições dos níveis de ruído: avaliação da exposição ao ruído da tripulação de helicóptero. Laudo Técnico da Universidade Federal de Santa Catarina no 01/GSHST/02. [informação pessoal]. Mensagem recebida por correio eletrônico (via e-group) em 27 jul. 2007.

ROCHA, L. E.; ABT. Pesquisa das condições de trabalho - saúde mental e Dort, São Paulo, 2004. In: Seminário Saúde Ocupacional - Operadores de Call Center. Resumo das apresentações. São Paulo: CBSS, 2004. p. 27-37.

SÃO PAULO. Procuradoria Regional do Trabalho da 15 Paulo. Ofício referente à Peça de Informação n. 014567/2002, Procurador José Fernando Ruiz Maturana, Bauru, 18 de fev. de 2008. Disponível em: $<$ http://www.prt15.gov.br/site/institucional/oficio bauru.php $>$. Acesso em $18 \mathrm{fev}$. 2008.

SILVA, M. D. Estudo piloto avalia ruído em fones de ouvido de operadores de telefonia. Revista Proteção, Novo Hamburgo, v. 6, n. 36, p. 24-27, dez. 1994. 
STEFFANI, J. A. Comparação das técnicas de medição e análise de incertezas da exposição ao ruído dos usuários de fone de ouvido. 2005. 235 p. Tese (Doutorado) - Centro Tecnológico - Área de Concentração em Ergonomia. Universidade Federal de Santa Catarina, Florianópolis, 2005. Disponível em: <http://teses.eps.ufsc.br>. Acesso em 15 fev. 2008.

STEPHEN, V. et. al. An occupational noise exposure assessment for headsetwearing communications workers. Appl. Occup. Environ. Hyg., v. 10, n. 5, p. 476 481, 1995.

TELECOMUNICAÇÕES DO RIO DE JANEIRO. Alteração da audição nos empregados que ocupam cargos de risco auditivo. Relatório do Departamento de Administração de Benefícios da TELERJ, 1994, Rio de Janeiro. Acesso Restrito.

TELECOMUNICAÇÕES DE SÃO PAULO. Informações sobre emissões de CATs referentes a Dort/Pairo. Relatório que informa ao Ministério Público dados por este solicitados, 2001, São Paulo. Acesso Restrito.

UNITED KINGDOM. Health and Safety Comission - Consultation Document 196 Proposal for new Control of Noise at Work Regulations implementing the Physical Agents (Noise). Directive (2003/10/EC), 2004. Disponível em: $<$ http://www.hse.gov.uk/consult/condocs/cd 196.htm>. Acesso em 22 jan. 2008.

. Health and Safety Enforcing Authorities. Advice regarding call centre working practices. Circular LAC 94/12 ( $n=$ 22), 2006. Disponível em: <http://www.hse.gov.uk/lau/lacs/94-2.pdf>. Acesso em 25 jan. 2008.

Health and Safety Enforcing Authorities. Measurement of noise levels that staff are exposed to at live music events. RR 517 Research Report, 2006. Disponível em: <http://www.hse.gov.uk/research/rrpdf/rr517.pdf>. Acesso em 22 jan. 2008.

UNITED STATES. United States Department of the Interior. Bureau of Mines. Underground mine communications (in four parts): 4. Section-to-place communications. Information Circular 8745, 1977. Disponível em: <http://www.cdc.gov/niosh/mining/topics/topicpage6.htm>. Acesso em 08 jul. 2007.

VERGARA, E. F. et. al. Avaliação da exposição de operadores de teleatendimento a ruído. Revista Brasileira de Saúde Ocupacional, São Paulo, v. 31, n. 114, p. 161 172, 2006.

YOST W. A.; NIELSEN D. W. Le basi della funzione uditiva. Padova: Piccin Nuova Libraria, 1986. 


\section{REFERÊNCIAS CONSULTADAS}

GERGES, S. N. Y. Ruído - Fundamentos e controle. Florianópolis: Universidade Federal de Santa Catarina, 1992. 600 p.

$696 \mathrm{p}$. 2 ed. Florianópolis: Universidade Federal de Santa Catarina, 2000.

INTERNATIONAL ELECTROTECHNICAL COMISSION. IEC 60268-1 ed. 2.0: Sound System equipments. Part 1: General, [S.I.], 1985.

IEC 60268-1. Amendent 1: Sound System equipments. Part 1: General, [S.I.], 1988-01.

. IEC 60268-1. Amendent 2: Sound System equipments. Part 1: General, [S.I.], 1988-06.

INTERNATIONAL TELECOMMUNICATION UNION. ITU.T. Recommendation K. 7 (11/1988) Extract from the Blue Book: Protection against acoustic shock. Disponível em: <http//www.itu.int/rec/t-rec-k7>. Acesso em: 02 jul. 2007.

ITU.T. Recommendation 0.6 (11/1988): $1020 \mathrm{~Hz}$ reference test frequency. Disponível em: <http//www.itu.int/rec/t-rec-o6>. Acesso em: 02 jul. 2007.

. ITU.T. Recommendation P. 10/G.100 (07/2006): Vocabulary for performance and quality of service. Disponível em: <http//www.itu.int/rec/t-rec-p.10>. Acesso em: 29 jun. 2007.

ITU.T. Recommendation P. 10/G.100 Amendment 1(01/2007): Vocabulary for performance and quality of service. Amendment 1: New Appendix I - Definition of Quality of Experience (QoE). Disponível em: <http//www.itu.int/rec/t-rec-p.10>. Acesso em: 29 jun. 2007.

ITU.T. Recommendation P.50 (09/1999): Artificial voices. Disponível em: <http//www.itu.int/rec/t-rec-p.50>. Acesso em: 10 jul. 2007. 
INTERNATIONAL TELECOMMUNICATION UNION ITU.T. Recommendation P.50 Appendix 1 (02/1998): Test signals. Disponível em: <http//www.itu.int/rec/t-recp.50>. Acesso em: 10 jul. 2007.

ITU.T. Recommendation P.50 Erratum 1 (05/2000): Artificial voices. Disponível em: <http//www.itu.int/rec/t-rec-p.50>. Acesso em: 10 jul. 2007.

ITU.T. Recommendation 0.41- Formerly P.53 (10/1994): Psophometer for use on telephone-type circuits. Disponível em: <http//www.itu.int/rec/t-rec-0.41>. Acesso em: 10 jul. 2007.

ITU.T. Recommendation P. 54 (11/1988): Sound level meters (apparatus for the objective measurement of room noise). Disponível em: <http//www.itu.int/rec/trec-p.54>. Acesso em: 10 jul. 2007.

ITU.T. Recommendation P. 59 (03/1993): Artificial conversational speech. Disponível em: <http//www.itu.int/rec/t-rec-p.59>. Acesso em: 11 jul. 2007.

ITU.T. Recommendation P. 64 (09/1999): Determination of sensitivity/frequency characteristics of local telephone systems. Disponível em: $<$ http//www.itu.int/rec/t-rec-p.64>. Acesso em: 11 jul. 2007.

. ITU.T. Recommendation P. 64 Amendment 1 (03/2007): Annex D Definition of handset positions for measuring loudness ratings and frequency responses using the P.57 type 3.4 artificial ear on HATS. Disponível em: <http//www.itu.int/rec/t-rec-p.64>. Acesso em: 02 jul. 2007.

ITU.T. Recommendation P. 64 Erratum (05/2000): Determination of sensitivity/frequency characteristics of local telephone systems. Disponível em: $<$ http//www.itu.int/rec/t-rec-p.64>. Acesso em: 28 jun. 2007.

ITU.T. Recommendation P. 300 - Formerly P.30 (11/2001): Transmission Performance of group audio terminals (GATs). Disponível em: $<$ http//www.itu.int/rec/t-rec-p.300>. Acesso em: 10 jul. 2007.

ITU.T. Recommendation P. $\mathbf{3 1 0}$ (03/2003): Transmission characteristics for telephone band $(300-3400 \mathrm{~Hz})$ digital telephones. Disponível em: $<$ http//www.itu.int/rec/t-rec-p.310>. Acesso em: 10 jul. 2007. 
INTERNATIONAL TELECOMMUNICATION UNION. ITU.T. Recommendation P. 311 (06/2005): Transmission characteristics for wideband $(150-7000 \mathrm{~Hz})$ digital handset telephones. Disponível em: <http//www.itu.int/rec/t-rec-p.311> . Acesso em: 10 jul. 2007.

ITU.T. Recommendation P.340 (05/2000): Transmission characteristics and speech quality parameters of hands-free terminals. Disponível em: <http//www.itu.int/rec/t-rec-p.340>. Acesso em: 10 jul. 2007.

ITU.T. Recommendation P. 340 Corrigendum 1 (03/2004): Transmission characteristics and speech quality parameters of hands-free terminals. Disponível em: <http//www.itu.int/rec/t-rec-p.340>. Acesso em: 10 jul. 2007.

ITU.T. Recommendation P.341 (06/2005): Transmission characteristics for wideband $(150-7000 \mathrm{~Hz})$ digital hands-free telephony terminals. Disponível em: <http//www.itu.int/rec/t-rec-p.341>. Acesso em: 10 jul. 2007.

ITU.T. Recommendation P.342 (05/2000): Transmission characteristics for telephone band (300-3400 Hz) digital loudspeaking and hands-free telephony terminals. Disponível em: <http//www.itu.int/rec/t-rec-p.342>. Acesso em: 10 jul. 2007.

. ITU.T. Recommendation P.370 (08/1996): Coupling Hearing Aids to Telephone sets. Disponível em: <http//www.itu.int/rec/t-rec-p.370>. Acesso em: 10 jul. 2007.

. ITU.T. Recommendation P.501 (05/2000): Test signals for use in telephonometry. Disponível em: <http//www.itu.int/rec/t-rec-p.501>. Acesso em: 10 jul. 2007.

ITU.T. Recommendation P.501 Erratum 1 (09/2001): Test signals for use in telephonometry. Disponível em: <http//www.itu.int/rec/t-rec-p.501>. Acesso em: 11 jul. 2007.

ITU.T. Recommendation P.501 Amendment 1 (05/2004) New annexes A and B. Disponível em: <http//www.itu.int/rec/t-rec-p.501>. Acesso em: 11 jul. 2007.

ITU.T. Recommendation P.501 Amendment 2 (06/2007): Revised Annex B. Disponível em: <http//www.itu.int/rec/t-rec-p.501>. Acesso em: 11 jul. 2007. 
INTERNATIONAL TELECOMMUNICATION UNION. ITU.T. Recommendation P. 502 (05/2000): Objective test methods for speech communication systems using complex test signals. Disponível em: <http//www.itu.int/rec/t-rec-p.502>. Acesso em: 11 jul. 2007.

. ITU.T. Recommendation P. 502 Erratum (07/2001): Objective test methods for speech communication systems using complex test signals. Disponível em: <http//www.itu.int/rec/t-rec-p.502>. Acesso em: 11 jul. 2007.

ITU.T. Recommendation P. 505 (11/2005): One-view visualization of speech quality measurement results. Disponível em: <http//www.itu.int/rec/t-recp.505>. Acesso em: 11 jul. 2007.

ITU.T. Recommendation P.800 (08/1996): Methods for subjective determination of transmission quality. Disponível em: <http//www.itu.int/rec/t-recp.800>. Acesso em: 11 jul. 2007.

ITU.T. Recommendation P. 805 (04/2007): Subjective evaluation of conversational quality. Disponível em: <http//www.itu.int/rec/t-rec-p.805>. Acesso em: 02 jul. 2007. 


\section{GLOSSÁRIO}

As definições a seguir foram extraídas do dicionário brasileiro de eletricidade COBEI (1986); da Norma IEC 60268-4 (2004) sobre microfones de aplicação geral; do Catálogo Máster do fabricante Brüel \& Kjaerß (2005), Capítulo 2 - teoria do microfone; da empresa EARSET - Práticas bem-sucedidas: serviços e equipamentos, apresentado no Seminário Saúde Ocupacional - Operadores de Call Center, São Paulo, 2004; e da Norma IEC 60268-7 (1996) sobre fones de cabeça e ouvido. Os assuntos relacionados à Perda Auditiva, foram extraídos do site: http://www.audioclinicalondrina.com.br/surdez.htm. Acesso em 17/03/2008.

Avaliação Otoneurológica: Consiste num conjunto de procedimentos que levam ao diagnóstico mais preciso das localizações e causas das afecções do aparelho vestibular.

Campo: é uma grandeza física definida em todos os pontos de uma região do espaço.

Campo acústico: é a região de um meio elástico no qual existem ondas acústicas.

Campo acústico difuso: é o campo acústico tal que, numa dada região do espaço, a densidade de energia acústica é estatisticamente uniforme, e as direções de propagação, em cada ponto, têm uma distribuição aleatória.

Campo acústico distante: é o campo acústico afastado de uma fonte acústica, no qual a pressão acústica instantânea e a velocidade acústica instantânea estão em fase.

Campo acústico livre: é o campo acústico em um meio homogêneo e isótropo, cujos limites exercem uma influência insignificante sobre as ondas acústicas nesse meio. 
Campo acústico próximo: é o campo acústico perto de uma fonte acústica, no qual a pressão acústica instantânea e a velocidade acústica instantânea estão substancialmente fora de fase.

Campo acústico reverberante: é o campo acústico no qual todas as ondas acústicas são substancialmente refletidas mais de uma vez pelos limites do meio de propagação, de tal modo que as ondas recebidas diretamente da fonte são praticamente insignificantes.

Campo de pressão: é caracterizado por uma pressão sonora que tem a mesma intensidade e fase para qualquer posição dentro do campo. Microfones de Sensibilidade a Pressão, referem-se a este tipo de campo.

Os campos de pressão podem ser encontrados em ambientes enclausurados ou em cavidades, nas quais são pequenos quando comparados ao comprimento de onda. Tais campos ocorrem em acopladores utilizados em testes de fones de ouvido ou calibração de microfones. Eles também ocorrem na maioria dos tipos de calibradores de nível sonoro.

Campo difuso: um campo sonoro difuso aparece num dado local se o campo é criado por ondas sonoras que chegam mais ou menos simultaneamente de todas as direções com igual probabilidade e nível. $O$ microfone de sensibilidade a campo difuso ou de "Incidência Randômica", refere-se a este tipo de campo, mesmo se, na maioria dos casos, a sensibilidade é calculada para medições sob condições de campo livre.

Campo eletromagnético: é o campo físico determinado pelo conjunto de quatro grandezas vetoriais, que caracterizam os estados elétrico e magnético de um meio material ou do vácuo. Essas quatro grandezas são: o campo elétrico, a indução elétrica, o campo magnético e a indução magnética.

Campo livre: um campo sonoro livre, ou somente um campo livre pode ser criado onde as ondas sonoras podem se propagar livremente, por exemplo, em um meio contínuo sem qualquer objeto interferindo. Microfones de Sensibilidade a Campo Livre, referem-se a este tipo de campo. 
Campos livres reais são difíceis de obter, se não impossíveis. Entretanto, na prática, campos livres são, criados em câmaras anecóicas, aplicáveis na verificação e calibração de instrumentos.

Campo uniforme: é o campo de uma grandeza que é constante em todos os pontos da região do espaço considerada.

Disacusia: Surdez, perda auditiva.

Earphone - fone de ouvido: transdutor eletroacústico pelo qual oscilações acústicas são obtidas de sinais elétricos, e destinado para serem rigorosamente acoplados acusticamente à orelha.

Fonte acústica pontual: é a fonte de vibrações acústicas cujas dimensões geométricas são insignificantes.

Fonte acústica simples: é a fonte de vibrações acústicas que irradia uniformemente em todas as direções de um campo livre.

Função Vestibular: Função do labirinto e suas correlações.

Headphone - fone de cabeça: Montagem de um fone de ouvido (mono-aural) ou dois fones de ouvido (bi-aural) instalados num dispositivo em forma de arco ou numa lâmina curvada, para que seja fixado sobre a cabeça sob uma determinada pressão do arco, para que os fones de ouvido fiquem confortavelmente posicionados e seguros dentro ou próximo da (s) orelha(s) dos usuários, permitindo que os mesmos fiquem com as mãos livres.

Headset - fone de telefonista: é um conjunto "aparelho telefônico" composto de fone de cabeça (mono-aural ou bi-aural), equipado com um microfone (conforme Norma IEC 60268-7).

Headset: aparelho profissional que traz conforto, ergonomia e funcionalidade aos seus usuários. O headset é um conjunto sempre composto de microfone e fone de 
ouvido (conforme EARSET). Nomenclatura de mercado: Headset, aparelho de telefonista, fone do tipo telefonista, telefone de telemarketing, fone de cabeça, fone de operador, dentre outras denominações regionais.

Microfone: é um transdutor eletroacústico que responde a ondas acústicas fornecendo ondas ou sinais elétricos.

Monofone: Dispositivo para manter as cápsulas transmissoras e receptoras associadas em forma rígida, numa só peça, e conveniente para segurá-las simultânea e respectivamente junto à boca e à orelha.

Monofone é o telefone de punho comum, também conhecido como handphone.

Perda Auditiva: É definida como um desvio ou piora na estrutura ou na função auditiva, geralmente fora dos limites da normalidade.

Perda Condutiva: Ocorre quando o som não é transmitido adequadamente a orelha interna.

Perda Mista: Ocorre uma combinação entre perda auditiva Neurossensorial e condutiva.

Perda Neurossensorial: Ocorre quando a cóclea ou o nervo auditivo, na orelha interna, perdem a capacidade de transmitir os sons adequadamente.

Perda de Transmissão: Surdez, com afecção do aparelho de transmissão sonoro (do pavilhão até a cóclea)

Trauma Acústico = Choque Acústico: é a perda auditiva súbita, decorrente de uma única exposição a ruído intenso, tendo como origem ruídos impulsivos de impacto. 